\title{
Endometrial maturation: the role of oestradiol and progesterone
}

Citation for published version (APA):

Dassen, H. H. N. M. (2011). Endometrial maturation: the role of oestradiol and progesterone. [Doctoral Thesis, Maastricht University]. SND Uitgeverij. https://doi.org/10.26481/dis.20111104hd

Document status and date:

Published: 01/01/2011

DOI:

10.26481/dis.20111104hd

Document Version:

Publisher's PDF, also known as Version of record

\section{Please check the document version of this publication:}

- A submitted manuscript is the version of the article upon submission and before peer-review. There can be important differences between the submitted version and the official published version of record.

People interested in the research are advised to contact the author for the final version of the publication, or visit the DOI to the publisher's website.

- The final author version and the galley proof are versions of the publication after peer review.

- The final published version features the final layout of the paper including the volume, issue and page numbers.

Link to publication

\footnotetext{
General rights rights.

- You may freely distribute the URL identifying the publication in the public portal. please follow below link for the End User Agreement:

www.umlib.nl/taverne-license

Take down policy

If you believe that this document breaches copyright please contact us at:

repository@maastrichtuniversity.nl

providing details and we will investigate your claim.
}

Copyright and moral rights for the publications made accessible in the public portal are retained by the authors and/or other copyright owners and it is a condition of accessing publications that users recognise and abide by the legal requirements associated with these

- Users may download and print one copy of any publication from the public portal for the purpose of private study or research.

- You may not further distribute the material or use it for any profit-making activity or commercial gain

If the publication is distributed under the terms of Article $25 \mathrm{fa}$ of the Dutch Copyright Act, indicated by the "Taverne" license above, 


\section{Endometrial maturation: the role of oestradiol and}

progesterone 
Copyright @ 2011 H.H.N.M. Dassen, Maasmechelen, 2011

ISBN: 978-90-809175-0-7

\section{Uitgever: SND Uitgeverij Kerkrade}

Niets uit deze uitgave mag worden verveelvoudigd, opgeslagen in een geautomatiseerd gegevensbestand of openbaar gemaakt worden in enige vorm of op enige wijze, hetzij electronisch, mechanisch of door fotokopieën, opname, of op enige andere manier, zonder voorafgaande schriftelijke toestemming van de auteur.

Cover illustration designed by Irene Keularts

The studies presented in this thesis were financially supported byOrganon (Oss) and Solvay(Hanover) 


\section{Endometrial maturation: the role of oestradiol and progesterone}

\section{Proefschrift}

Ter verkrijging van de graad van doctor aan de Universiteit Maastricht, op gezag van de Rector Magnificus, Prof. Mr. G.P.M.F. Mols, volgens het besluit van het College van Decanen, in het openbaar te verdedigen op vrijdag 4 november 2011 om 14:00 uur

door

Helen Hubertina Nicole Magdalena Dassen

Geboren 30 augustus 1976 te Sittard 


\section{Promotor}

Prof. Dr. J.L.H. Evers

\section{Copromotores}

Dr. G.A.J. Dunselman

Dr. P.G. Groothuis

\section{Beoordelingscommissie}

Prof. Dr. F.C.S. Ramaekers (voorzitter)

Prof. Dr. M. Dhont (Universiteit ziekenhuis Gent, België)

Prof. Dr. A. Zur Hausen

Prof. Dr. R.F.P.M. Kruitwagen

Prof. Dr. V.C.G. Tjan-Heijnen 


\section{Inhoudsopgave}

$\begin{array}{lr}\text { Chapter } 1 \text { General introduction } & 7\end{array}$

Chapter 2 Oestrogen regulation of endometrium in rodents and human 13

Chapter 3 Oestrogen-modulated gene expression in the human endometrium 35

Chapter 4 Olfactomedin-4 regulation by estrogen in the human endometrium requires epidermal growth factor signalling

Chapter 5 Oestrogen metabolizing enzymes in endometrium and endometriosis

Chapter 6 Progesterone regulation of implantation related genes: New insights into the role of oestrogen

Chapter 7 Haemoglobin expression in human endometrium

Chapter 8 General Discussion

Summary

Samenvatting

References

Curriculum Vitae

Dankwoord 



\section{Chapter 1}

\section{General introduction}

\section{Human endometrium}

The endometrium lines the uterine cavity and is the mucosa, which allows embryo implantation and supports its growth and development. The endometrium consists of an epithelial compartment composed of surface and glandular epithelium, and a stromal compartment filled abundantly with stromal fibroblasts, endothelial cells, macrophages, peri-vascular, T-lymphocytes and large granular lymphocytes $[2,3]$. The human endometrium is a dynamic tissue. It undergoes monthly cycles of proliferation, differentiation and degeneration under influence of steroid hormones [6]. The hormonal receptivity of the different cell compartments vary throughout the menstrual cycle, mostly due to changes in the distribution of receptors and cyclic changes in oestrogen and progesterone concentrations.

Oestradiol and progesterone are responsible for the preparation of the endometrium in order to establish successful blastocyst implantation. The oestradiol is responsible for rebuilding the endometrium after menstruation, and preparing the endometrium to respond to the luteal progesterone after ovulation [7-9]. Progesterone is responsible for proper secretory transformation of the glands and stromal decidualization in order to facilitate embryo implantation.

The human endometrium is composed of two different layers, the functional and basal layer. The upper layer, the functional layer is shed during menstruation. After shedding, the functional layer is rebuild from the basal layer under influence of oestrogens in the early and late proliferative phase. Various processes are initiated including epithelial repair, proliferation, angiogenesis, vasculogenesis, cell differentiation and extracellular matrix remodelling. Repair of the endometrial surface already starts during the menstruation process and before the oestrogen concentrations are elevated and as so is oestrogen-independent [10]. About five to six days after the onset of menstruation, the growing follicles in the ovary start producing estrogens and the human endometrium is exposed to oestrogens. Oestrogens are supposed to modulate the growth of the human endometrium by inducing proliferation. Proliferative activity in the developing functional layer peaks between cycle days (CDs) 8 and 10, whereas the proliferative activity in the basal layer remains constantly low [10, 11]. Interestingly, the endometrial cells in the basal layer continue to proliferate during menstruation and the repair of the endometrium is initiated prior to the rise in peripheral oestradiol concentrations [11]. 
After ovulation, the regenerated endometrium is exposed to the increasing levels of progesterone, which prepares the mucosa for blastocyst implantation. Implantation is a complex process which involves attachment of the embryo to the endometrial surface (luminal epithelium), breaching of the epithelial lining and invasion into the underlying endometrial stroma [12]. The human endometrium allows this process only for a brief period of time, starting approximately 5 days after the LH surge [7, 8, 13-16]. Even though the timing of this implantation window is determined by the sequence of events orchestrated by follicular oestrogens and luteal progesterone, the endometrium is susceptible to a wide range of exposure times and blood concentrations in order to establish pregnancy. [7-9]. This is illustrated by the fact that only extremely high oestrogen levels and/or prolonged oestrogen exposure accelerates endometrial maturation thus disturbing the synchrony of embryo and endometrium development and subsequent implantation [17-19]. The optimal length of oestrogen exposure during artificial endometrium preparation is 12-19 days [18], yet a minimum of five days of oestrogen exposure is sufficient to build an appropriately thick $(>6 \mathrm{~mm}$ ) endometrium for the embryo to be able to implant [20-22].

Our understanding of the mechanisms of the actions of oestrogens and progestins have evolved from the simple concept that the effects of these hormones are directly mediated via oestrogen (ER) and progesterone receptors (PR) located in the epithelial and stromal compartments [23], to that of a finely tuned interplay between the steroid receptors and a multitude of other signals in the cell. The actions of oestrogens and progestins are determined by the ratio and distribution of receptor isoforms, the availability of co-activators and/or co-repressors, cross-talk with secondary signal transduction pathways, local steroid metabolism, and paracrine interactions between epithelial cells, extracellular matrix components and cells in the connective tissue.

Two types of oestrogen receptors have been identified, $\operatorname{ER} \alpha$ and $\operatorname{ER} \beta$. The $\mathrm{ER} \alpha$ and $\mathrm{ER} \beta$ are described from two different genes [24, 25]. Studies with knockout mice demonstrated that $\mathrm{ER} \alpha$ rather than $\mathrm{ER} \beta$ is essential for normal uterine function $[26,27]$.

Human progesterone receptor (hPR) has two functionally distinctive isoforms, PR-A and PR-B [28]. The isoforms arise from the same gene by using different promoters [28]. PR-B contains 164 amino acids more at the N-terminus, compared to PR-A [28]. Both PR isoforms display indistinguishable hormone and DNA binding [28]. However depending on the cell type and promoter, it was shown that PR-A and PR-B have different transcription activities [29-31]. PR-A knockout (PRAKO) mice show an inhibited decidualisation process [32], whereas PR-B knockout (PRBKO) mice show a normal uterine response to progesterone. The knockout studies suggest, that PR-B is a strong regulator of proliferation, whereas $\mathrm{PR}-\mathrm{A}$ opposes the oestrogen-regulated and PR-B mediated increase in proliferation [28].

Oestrogen and progesterone receptors are present in the nuclei of both stromal and epithelial endometrial cells $[33,34]$. The expression of the oestrogen 
receptor (ER) and progesterone receptor (PR) increases during the proliferative phase and decreases during the secretory phase of the menstrual cycle [34-39]. ER $\alpha$ is the dominant ER isoform in human endometrium in both the functional and basal layer [28]. In stroma PR-A is the dominant PR isoform in human endometrium [28]. It was previously found, that both steroid receptors are highest expressed in stromal cells at the end of the menstrual cycle and in both stromal and epithelial cells during the proliferative and early secretory phase [34]. The importance of this observation is illustrated by the fact that the effects of oestrogen and progesterone on the endometrial epithelial cells are in part mediated through the stromal compartment [40-42]. Both receptors are induced by oestrogens [33, 34, 38, 39], and only ER is suppressed by progesterone during the secretory phase [38]. Whereas the expression of PR is induced by progesterone in stromal cells [43].

The activation of ER and PR is controlled by transactivating domains which are responsible for modulating ligand-dependent (AF-2 at the $\mathrm{C}$-terminal end) and ligand-independent (AF-1 at the N-terminal end) actions [28]. The AF-2 transactivation domain is located in the ligand-binding domain and is dependent on the binding of an agonist/antagonist [44]. The AF-1 domain varies in both size and primary acid sequence in different steroid hormone and nuclear receptors [28] and can be modulated through phosphorylation by mitogen (EGF or IGF-1) activated kinases [45, 46]. Besides the AF1 and AF2, PR-B also contains a third transactivation domain AF3 in the N-terminal region [28] and an inhibitory domain (ID) [47]. Through this ID hPR-A has a higher affinity for the corepressor identified as silencing mediator of retinoic acid receptors and thyroid receptors (SMRT), compared to PR-B [48].

After binding of a ligand to steroid receptors, coregulators mediate the transcription control. Coregulators possess chromatin-remodelling enzyme activities which accommodate transcription of target genes by allowing the transcriptional complex to bind to the promoter region of these genes [28]. Coactivators (i.e. SRC1, AIB1) mediate the functions of activated receptors, whereas corepressors (i.e. NCoR1, SMRT) mediate inhibitory effect of active receptors [28].

\section{Oestrogen and progesterone metabolism}

In normal target tissues the exposure to steroid hormones is controlled by the presence of steroid metabolizing enzymes. Oestrogens are inactivated by steroid sulfotransferases and glucuronidases [49-51], uridine diphosphoglucuronosyltransferases, oxidizing 17 $\beta$-hydroxysteroid dehydrogenases (HSDs) [40, 52-55], enzymes that convert $17 \beta$-oestradiol into the catecholestrogens 2 - and 4hydroxyestradiol [56], CYP3A4 which converts estrone into $16 \alpha$-hydroxyestrone and $17 \beta$-oestradiol into 2-hydroxyestradiol [57], CYP1B1 known to convert 17 $\beta$ - 
oestradiol into 4-hydroxyestradiol [58], and catechol-O-methyltransferase which subsequently convert 2- and 4-hydroxyestradiol into 2- and 4-methoxyestradiol [59]. Progesterone is inactivated by $20 \alpha-\mathrm{HSD}$ and $5 \alpha$ - and $5 \beta$-reductases [60]. The highest level of $5 \alpha$-reductase activity was found in the early proliferative phase, whereas $20 \alpha$-HSD activity was higher in the middle of the secretory phase.

Even though oestrogens and progestins are mainly produced by the ovaries of women, steroid synthesizing enzymes can also be found in adrenals, adipocytes, liver, intestine, brain and endometrium [61]. Tsai et al. [62] demonstrated the expression of steroidogenic acute regulatory protein (StAR) mRNA and protein as well as transcripts for P450 side-chain cleavage enzyme and $3 \beta$-hydroxysteroid dehydrogenase (HSD) to be expressed in endometrium. The StAR protein is responsible for the transfer of cholesterol from the outer mitochondrial membrane to the inner membrane where the cytochrome P450 side-chain cleavage enzyme is located, to split off the cholesterol side chain resulting in pregnenolone. This is the first, and rate limiting, enzymatic step in all steroid synthesis. The $3 \beta-\mathrm{HSD}$ can subsequently convert the pregnenolone into progesterone. $17 \alpha$-Hydroxylase also known as 17,20-lyase, 17,20-desmolase or CYP17A1, is an important enzyme because it converts the pregnenolone into DHEA and progesterone into androstenedione which are precursors for the synthesis of testosterone and oestrogens. $17 \alpha$-Hydroxylase activity has been reported in the human endometrium [63].

Androstenedione and testosterone can then be converted into oestrone and oestradiol respectively by aromatase. Aromatase activity is present in normal endometrium and its expression is highest in the stromal compartment during the proliferative phase of the menstrual cycle [64]. The relatively weak oestrogen, oestrone, can be converted into the active oestradiol through $17 \beta$-hydroxysteroid dehydrogenases (17 $\beta$-HSDs). Until now, fifteen $17 \beta$-HSDs have been identified. The $17 \beta$-HSD types 1 and 7 are responsible for the reduction of oestrone to $17 \beta$ oestradiol. Both are expressed in human endometrium [65-67]. Recently a novel $17 \beta$-HSD has been identified, type $1217 \beta$-HSD. This enzyme can selectively and efficiently transform oestrone into $17 \beta$-oestradiol and is expressed in human endometrium at similar levels as the type 1 [68].

Another source of oestrogens is the pool of sulphated oestrogen in the circulation. The human endometrium expresses steroid sulfatase (STS) which converts sulfated oestrogens, such as oestrone-3-sulfate which is the most abundant circulating oestrogen metabolite with a long half-life [69], into hormonally active oestrogens [70]. The uptake and conversion of oestrogen sulfates by human endometrial tissue is rapid [70]. Similarly, the DHEA sulfate which also has a very slow metabolic clearance rate [71], can be converted into androgestendiol and testosterone which can subsequently be converted into oestradiol.

In the normal endometrium an important route of $17 \beta$-oestradiol inactivation is via $17 \beta$-HSDs types 2,4 and 8 , which form by an oxidative reaction androstenedione (A) and oestrone $\left(\mathrm{E}_{1}\right)$ [54, 65, 66, 72], and by oestrogen sulfotransferase (EST) which conjugates sulfate groups to the 3-hydroxyl position 
[73]. 17 $\beta$-HSD type 2 expression is regulated by progesterone and its mRNA and protein expression and activity are up-regulated in the secretory phase of the menstrual cycle, whereas the $17 \beta$-HSDs types 4 and 8 are constitutively expressed in normal human endometrium [66]. An additional important route of $17 \beta$-oestradiol (and oestrone) inactivation is through conjugation with a sulfate group by oestrogen sulfotransferase (EST), which is also expressed in the human endometrium.

In some oestrogen-dependent diseases, like endometriosis, the balance between oestrogen activating and inactivating enzymes appears to be disturbed, either by the upregulation of oestrogen synthesizing enzymes and/or a reduction of oestrogen-inactivating enzymes. Nobel and co-workers [74] were the first to demonstrate that for instance aromatase mRNA and activity levels are increased in pelvic endometriotic implants, and this has been confirmed by others [75-77]. The clinical relevance of local aromatase activity in endometriosis has been demonstrated by some reports describing the successful treatment of endometriosis using aromatase inhibitors [65, 78]. In addition, expression of 17 $\beta$-HSD types 1 and 7 was reported to be elevated in endometriosis lesions when compared with paired eutopic endometrial samples $[65,66,79]$. High STS mRNA and protein expression and STS activity has also been reported in ectopic lesions $[66,78]$, suggesting that the ectopic endometrium can make use of the pool of sulfated oestrogens available in the circulation.

With regard to the expression of oestrogen inactivating enzymes like $17 \beta$ HSD types 2, 4 and 8 and EST not much information is available in endometriosis. Some reports showed that the expression of $17 \beta-H S D$ type 2 is decreased in endometriotic tissue but this could not be confirmed by others [66, 80, 81].

\section{Objectives of this thesis}

The aim of this thesis is to gain better insights in the regulation of endometrium growth and maturation under the influences of oestradiol and progesterone. To this end we developed an endometrium tissue explant culture system and performed global gene expression profiling on human endometrium tissue and tissue explants cultured in the presence of oestradiol and progesterone. Even though it is evident that oestrogens stimulate endometrial growth, there is little information about the mechanisms that control endometrial cell proliferation.

Endometrial growth has been studied most intensively in rodents and human. Chapter 2 presents a review in which data from microarray studies in human, rat and mouse studies were compared in order to extract information pertaining to oestrogen regulated genes that are known to control the cell cycle and cell division. These comparisons are complemented with findings from the few 
studies that have employed a hypothesis-driven approach to study oestrogenregulation of endometrial cell growth.

In order to be able to investigate the effects of oestrogens on human endometrium, a tissue explant culture model was developed in our lab [33]. To validate the culture system the effects of oestrogen on proliferation and gene expression were studied in explant cultures prepared from various stages of the menstrual and proliferative phase of the menstrual cycle. Global gene expression profiling was used to identify which genes involved in cell cycle control and cell division are modulated after oestrogen exposure. This was done by comparing gene expression profiles prepared from menstrual and late proliferative phase endometrium, and by comparing gene expression profiles prepared from cultured human endometrium tissue exposed to oestradiol or vehicle. The results are presented in Chapter 3.

These studies revealed the identity of a gene, olfactomedin-4, which appeared to be highly sensitive to oestrogen. The regulation of the transcription of this gene and its role in endometrium function was investigated in more detail (Chapter 4).

An important aspect of proper endometrium function is the ability of the tissue to control oestrogen exposure. To this end multiple steroid synthesizing and metabolizing enzymes are present in the human endometrium. Dysbalance in oestrogen metabolism is known to be an etiological factor in various endometriumrelated disorders including endometriosis and endometrial cancer. Chapter 5 evaluates the expression and steroid-regulation of a selection of these enzymes both in normal human endometrium and endometriosis.

Next to promoting growth, oestradiol is important for the preparation of the endometrium to be able to respond properly to the increasing concentrations of progesterone after ovulation. We have referred to this process as maturation. To study this process in more detail, we applied global gene expression analysis on menstrual phase and late proliferative phase endometrial explants after 24 hours exposure to progesterone (Chapter 6).

An unexpected finding was the expression of various members of the haemoglobin family in the human endometrium. Haemoglobin expression was investigated in more detail (Chapter 7), in light of the fact that haemoglobin expression was previously reported in the implantation window [82, 83], and the potential damaging influences of excess levels of haeme and iron in cells. 


\section{Chapter 2}

\section{Oestrogen regulation of endometrium in Rodents and human}

P.G. Groothuis ${ }^{1,3}$, H.H.N.M. Dassen ${ }^{1,2}$, A. Romano ${ }^{1,3}$ and C. Punyadeera ${ }^{4}$

${ }^{1}$ Research Institute GROW, Departments of ${ }^{2}$ Pathology and ${ }^{3}$ Obstetrics and Gynaecology, University Hospital Maastricht/University Maastricht, Maastricht, The Netherlands, ${ }^{4}$ Department of Molecular Diagnostics, Philips Research, High Tech Campus 11, 5656AE, Eindhoven, The Netherlands.

Published in: Human reproduction update 2007; 13: 405-17. 


\section{Abstract}

In this review we discuss our current understanding of the actions of oestrogen on both human and rodent endometrium from the perspective of large scale gene expression profiling, with special emphasis on the regulation of proliferation.

The present review addresses the following topics: a) physiological responses to oestrogen in the rodent uterus (uterine growth) and in the human endometrium (cell proliferation); b) regulation of gene expression by oestrogen in rodent uterus and human endometrium; c) regulation of cell cycle regulators by oestrogens in rodent uteri and human endometrium.

\section{Introduction}

The human endometrium is an amazingly plastic tissue. Throughout the adult reproductive life, monthly steroid hormone controlled cycles of proliferation, differentiation and degeneration occur continuously. Even after menopause, the tissue retains its responsiveness to steroid hormones and endometrial cycles can also be induced. In each menstrual cycle, if no embryo implantation occurs, the functional layer of the endometrium is shed and within two weeks the complete functional layer is restored. The events underlying this phenomenon are highly complex and include repair of the endometrium surface, proliferation, angiogenesis, vasculogenesis, cell differentiation, and extracellular matrix remodelling. Once the functional layer has successfully been rebuild, the actions of progesterone change the oestrogen primed endometrium into a receptive state [7-9].

During the menstrual cycle two phases of elevated oestrogen concentrations can be distinguished. During the proliferative phase the growing follicles produce increasing amounts of oestradiol which peak at ovulation. After ovulation the corpus luteum continues to produce significant amounts of oestrogens, in addition to progesterone. However, it was shown that this mid-luteal rise in oestrogen is not essential for successful implantation in the human [84, 85].

Prior to ovulation, the role of oestrogen is considered to be important in the regeneration and growth of the endometrium and to prepare the tissue to respond to progesterone post-ovulation. Until the advent of microarray technology the study of complex biological mechanisms was hindered by the fact that only the expression of individual genes could be investigated. Genome wide gene expression analysis has proven to be a powerful approach to reveal individual genes and signalling cascades which are directly or indirectly affected by the steroid hormones. Thus far, 
understanding the biological processes and molecular mechanisms associated with endometrium receptivity and embryo implantation has been the centre of attention, whereas the complex events that occur in the human endometrium during the menstrual and proliferative phase under the influence of oestrogen have received little attention. The objective of this review is to provide an update of our current understanding of the actions of oestrogen on both human and rodent endometrium, with special emphasis on the regulation of proliferation, and the value of global gene expression analysis.

\section{Oestrogen regulation of uterine and endometrial growth}

\section{Oestrogen regulation of uterine growth in rodents}

The uterus in rodents and the human undergoes cyclical changes of growth and degeneration. In both species, oestrogens produced by the developing follicles stimulate endometrial growth, and progesterone is responsible for converting the oestrogen-primed endometrium into a receptive state. In rodents, if pregnancy does not occur, diestrous (secretory phase in humans, cycle days 15-28) terminates with regression of the corpus luteum, and the endometrium is resorbed (menstruation in humans, cycle days 1-5). During proestrous (proliferative phase in humans, cycle days 6-14) follicles develop and start to produce oestrogens which stimulate endometrial growth. During oestrous (peri-ovulatory period in humans, cycle days 13-15) ovarian follicles mature.

Rodents are versatile animal models which allow precise hormonal manipulation of the endometrium, usually after ovariectomy. In the classical sense, the uterine growth responses in rodents are grouped as early and late responses in relationship to a single dose of oestradiol (reviewed by Barton et al. [86]). The early responses which usually occur during the first six hours after administration of oestrogen include increases in RNA and protein synthesis as well as water imbibition. Late oestrogen responses include cycles of DNA synthesis and epithelial cell mitosis which begins 10 to 16 hours after oestradiol administration. Two waves of mitotic activity are generally seen. One wave approximately after 16 hours, and one approximately after 24 hours.

The magnitude of uterine growth stimulation is largely dependent upon the duration of bioavailable oestradiol and receptor interaction [87]. Oestriol, which is a short-acting oestrogen agonist, stimulates the early events following a single aqueous dose, but not cell proliferation. The inability of oestriol to stimulate cell proliferation could be due to a rapid clearance of this steroid and low affinity to oestrogen receptors. Similarly, administration of single doses of both oestradiol and 
oestriol immediately activate early genes such as c-myc and c-fos, but additional oestrogen is required for a cell to complete G1 and enter the S-phase [88, 89].

Administration of a low dose of oestradiol (0.25 or $2.5 \mu \mathrm{g} / \mathrm{animal}$ ) to immature rats caused nuclear translocation after 1-3 $\mathrm{hr}$ and maintenance of uterine growth occurred after $24 \mathrm{hr}$. At a higher dose $(10.0 \mu \mathrm{g} / \mathrm{rat})$, circulatory oestradiol levels were maintained longer and a biphasic nuclear translocation occurred. The uterus continued to grow until $72 \mathrm{hr}$, reaching five times its original wet weight. Administration of one dose of oestriol, a short-acting oestrogen, induces the same early responses as oestradiol, however, no uterine proliferative response is induced [90]. These studies show that a single injection of sufficient amounts of oestradiol induces endometrial growth and maturation in rats, provided oestrogen levels remain elevated in the circulation for a long period of time. This is supported by reports which show that administration of increasing doses of oestradiol are required to sustain a full uterine response. Treating immature rats with a single bolus of a longacting oestrogen (17alpha-ethinyl oestriol-3-cyclopentyl ether) did not result in further increases in uterine weight beyond 24-48 h. In contrast, multiple injections of $\mathrm{EE} 3 \mathrm{CPE}$ for 72 hours produced a progressive increase in tissue and uterine weight markedly above the $24 \mathrm{~h}$ level, and responsiveness to oestradiol is maintained [91]. Medlock observed that rats receiving silastic implants with a pharmacological dose of oestradiol $(5.0 \mathrm{mg} / \mathrm{ml})$ did maintain the maximal uterine weight gain through 24 hours, whereas subcutaneous injections of a single dose $(1.0$ and $10.0 \mu \mathrm{g})$ caused only a significant and equivalent increase in uterine weight at six hours, but the weight gain could not be maintained for long [92]. Treating adult mice and immature female rats for several consecutive days with the same dose, also renders the uterine epithelial cells 'refractory' [93, 94], and only when challenged with a higher dose this 'refractory' state could be overcome [93].

The minimal dose of oestradiol that is required to induce uterine sensitivity for implantation was determined to be in the range of 1.5-3 ng [19, 95]. Ma and coworkers showed that the concentration of oestradiol also controls the length of the window of uterine receptivity [19]. At different physiological concentrations implantation can be initiated, however, high doses shorten this period. This is associated with aberrant expression of implantation-related genes including LIF, PTGS1 (cyclooxygenase 1), and AREG (amphiregulin). Finn et al. showed that administration of high doses of oestradiol stimulated cell division, but no decidualization occurred [96].

Collectively, these findings suggest that uterine levels of oestradiol must exceed a certain level to initiate the early events associated with the induction of uterine growth. However, sustained bioavailability of oestrogens as well as the receptors are required to induce a full uterine proliferative response, and excessive levels of oestrogen may have adverse effects on implantation. 


\section{Oestrogen regulation of endometrial growth in the human}

The role of oestrogen in the regulation of human endometrium is still elusive. In contrast to the rodent uterus, endometrial growth in humans is not a result of water imbibition, but mostly a result of cellular amplification. Repair of the endometrial surface is already initiated during the menstruation process in the remaining basal layer, prior to any increase in oestrogen concentrations [10].A process which was also shown to involve recruitment of bone marrow derived cells [97]. Proliferative activity in the basal layer remains constantly low, and once oestrogen concentrations increase, proliferative activity in the developing functional layer of the human endometrium is induced. Proliferative activity peaks between cycle days 8 and 10 [11].

In humans a minimum of five days of oestrogen exposure is required to build a sufficiently thick endometrium to allow implantation of the embryo [20,21]. In this regard, it is worth to mention the recent study from Kurita et al. [98]. They made tissue recombinants from uterine stroma of newborn mice and epithelial cells from newborn murine uteri or epithelial cells from adult human endometrium. These were placed under kidney capsules of female nude mice, which were ovariectomized four weeks later. After two additional weeks the animals were treated with oestradiol. Similar to what is observed in vivo in the mouse and human, the proliferative response in the mouse epithelium was visible after one day, whereas the human epithelium required five days of oestradiol exposure to show a maximum response. In addition, the human uterine epithelial cells responded to oestradiol by up-regulation of progesterone receptor (PR), whereas in the mouse epithelium PR expression was down-regulated.

Previous studies from the same group have shown that the proliferative response in endometrial epithelium is regulated by the stromal compartment. The fact that uterine stroma from a mouse shows the same response as adult endometrial stroma from the human, indicates that these stroma-mediated effects are not species specific. The distinct responses in the mouse and human uterine epithelial cells suggest that the epithelial cells respond differently to the cues from the stromal compartment. This means that it is likely that the early responses of the stromal compartments of mouse and human endometrium show similarities, maybe allowing careful extrapolation of findings in mouse studies to the human, whereas the late responses in the epithelial compartments show more disparities.

Studying the effect of oestrogens on human endometrium is complicated. Most information about the role of oestrogen in the regulation of endometrial development has been obtained in IVF patients in either natural or artificially induced cycles. During IVF, high oestrogen concentrations as a result of the hyperstimulation of the ovaries are thought to result in a disparity in maturation between the epithelium and the stroma, which is more advanced in its development [99], possibly as a result of premature steroid receptor down-regulation [15, 99]. When oestradiol concentrations were $>2500 \mathrm{pg} / \mathrm{ml}$ on the day of human chorionic gonadotropin (HCG) injection, significant decreases in pregnancy and implantation rates were observed compared with patients having low oestradiol concentrations, without affecting embryo quality [100, 101]. Reducing the oestradiol levels using a step-down protocol significantly improved implantation and pregnancy rates compared to the patients that received the standard protocol, without affecting 
fertilization rate and the number of good-quality embryos [102]. In addition, optimal pregnancy rates were achieved when oestrogen was administered for six to eleven days [20, 21] or twelve to nineteen days [18] before progesterone administration.

Others however, did not find abnormal endometrial morphology or reduced implantation and pregnancy rates at high hormone levels [103-107]. Increased implantation and pregnancy rates per embryo transfer were found in cycles with high oestradiol levels $(>5000 \mathrm{pg} / \mathrm{ml})$ compared to controls [108]. The length of oestrogen exposure was also shown to be flexible, ranging from as short as six days to as long as 60 days without affecting receptivity or pregnancy rates [103, 109111]. In line with these findings Remohi and coworkers observed that implantation and pregnancy rates were also normal at very low concentrations $(<50 \mathrm{pg} / \mathrm{ml})$ [22].

Obviously our knowledge about the regulation of endometrial growth and differentiation by oestrogen shows dramatic lacunas. Studying oestrogen regulation from a genomics perspective may provide new insights into the cellular regulatory mechanisms involved.

\section{Global gene expression profiling}

\section{Gene expression studies in rodent uterus}

The outcome and interpretation of global gene expression profiling studies is influenced by the use of different array platforms, the use of different protocols for sample and probe preparation, differences between mouse strains, the manner of application of the steroids, and differences in data processing and analysis. (Table 2.1 presents a summary of gene expression studies aimed at evaluating the effects of oestrogen). For human endometrium this was first demonstrated by Horcajadas et al. [112]. The authors compared the results of four studies on gene expression in human endometrium collected during the implantation window and reported only three genes that were up-regulated in all four studies (osteopontin, apolipoprotein D, Dickkopf) and one down-regulated gene (olfactomedin-1) [112].

Similar disagreements among array studies are also present among rodent studies. Hong et al. [113] and Watanabe et al. [114, 115] treated ovariectomized (ovex) mice for six hours with oestradiol and of the reported genes that were most affected, only seven were commonly regulated (Table 2.2). When including the findings of the study from Hewitt et al. [116], only MAD2 and Small proline-rich protein $2 \mathrm{~A}$ were upregulated by oestradiol in wild type mice in all three studies. 
Table 2.1. Summary of gene profiling studies in rodents and humans to study oestrogen regulation of gene expression in uterus and endometrium

\section{A. Changes in menstrual and oestrous cycles}

Human endometrium

Menstrual (CD3-4) versus late proliferative (CD12-13) phase endometrium [1]

Proliferative phase endometrium, laser capture microdissection (LCM) of epithelium and stroma [117]

Menstrual and proliferative phase endometrium chemokine array [118]

Mouse endometrium

Various stages of the proliferative and secretory phase [82]

Oestrous versus diestrous [119]

Wild-type (Wt) ovariectomized (ovex) mice, oestradiol (E2) $100 \mu \mathrm{g} /$ animal for 6 and 24

hours, followed by LCM epithelial glands and stroma [113]

\section{B. Ovariectomised rodent models}

Wt mice sacrificed 2, 8, 12, 24 hours after one dose of EE (100 $\mu \mathrm{g} / \mathrm{kg})$, or 72 hours (dosed 3x, every 24 hours) [5]

Wt mice sacrificed $0,1,2,6,12,24,48$ hours after one injection of oestradiol $(5 \mu \mathrm{g} / \mathrm{kg})$

Extra control, $\alpha$ ERKO mice treated with oestradiol for 6 hours [114]

Wt and $\alpha$ ERKO mice sacrificed 6 hours after treatment with oestradiol, dose range 0.5-50 $\mu \mathrm{g} / \mathrm{kg}[120]$

Wt, $\alpha$ ERKO, $\beta$ ERKO mice sacrificed 0.5 and 2 hours after $1 \mu \mathrm{g} / \mathrm{kg}$ oestradiol ip in saline, or $6,12,24$ hours after $1 \mu \mathrm{g} / \mathrm{kg}$ oestradiol sc in oil; additional groups received $45 \mu \mathrm{g} / \mathrm{kg}$ ICI in DMSO ip, 30 min prior to oestradiol [116]

Wt and $\alpha$ ERKO mice sacrificed 2 and 24 hours after administration of $1 \mu \mathrm{g} / \mathrm{kg}$ oestradiol, or sacrificed 2 hours after ip injection with $200 \mu \mathrm{g}$ EGF or IGF-1 analogue 2 hours after ip injection, or 24 hours after administration by osmotic pumps [121]

Rats sacrificed after 3 days after receiving $1 \mu \mathrm{g} /$ animal/day oestradiol (Rochett et al., 2002)

Rats sacrificed after 1, 4, and 7days after receiving $2.5 \mathrm{mg} / \mathrm{animal} /$ day oestradiol [122]

\section{Immature rodent models}

Wt mice, 20-21 days old, sacrificed 1, 2, 4, 8, 24, 72 hours after administration of a high dose oestradiol $400 \mu \mathrm{g} / \mathrm{kg}$ [4]

Wt mice treated with $50 \mu \mathrm{g} / \mathrm{kg}$ oestradiol for 3 consecutive days (Waters et al., 2001)

Wt rats treated sc with $0.001-10 \mu \mathrm{g} / \mathrm{kg}$ EE for 4 consecutive days [123]

\section{In vitro models}

Primary cultures epithelium and stroma treated with oestradiol, tamoxifen and raloxifene [124]

Table 2.2. Genes regulated by oestradiol in endometrium of ovariectomized mice after six hours [113115]

Thioether-S-methyltransferase

Serum-inducible kinase

Mitotic checkpoint component Mad2

Small proline-rich protein $2 \mathrm{~A}$

Chemokine orphan receptor 1

GTPase (RAN)

Kruppel-like factor 4 (gut) 
Choosing the animal model system will also have an impact on the outcome. For the study of the effects of steroid hormones on steroid-responsive tissues ovariectomized animals receiving hormone replacement is an established animal model. Alternatively, researchers have employed immature animals. Immature animals were shown to be more sensitive with regard to the detection of oestrogenic effects than the ovariectomized adult animals [125]. In the study of Naciff et al. [123] prepubertal rats received increasing doses of ethynyl oestradiol (EE, 0.001-10 $\mathrm{g} / \mathrm{kg}$ ) and the changes in gene expression were monitored using the Affymetrix Rat Genome U34A high-density oligonucleotide array. In this study, 24 hours exposure to a high dose $(10 \mathrm{~g} / \mathrm{kg})$ of EE induced a 5-fold increase in uterine wet weight and a two-fold increase in uterine height. In contrast, treating adult ovariectomized rats with $500 \mathrm{~g} / \mathrm{kg}$ of EE did not even increase uterine wet weight [122]. Moreover, the magnitude of gene expression induced by oestradiol was higher in the immature rats than the adult ovariectomized rats, i.e. complement component 3 and CD24 were induced 300- and 7.5-fold in the study of Naciff et al. versus only 3.6- and 2.8-fold in the study of Wu et al. [122]. Whether the immature rat model or the ovariectomized/oestradiol supplemented adult rat model is the most reliable model for studying the role of oestradiol in the endometrium and to extrapolate findings to the human situation has yet to be proven.

The major advantage of animal models is their flexibility. Using recombinant DNA technologies the animals can be genetically altered, and it is possible to perform longitudinal studies. For example, the mouse models were proven to be very illustrative in demonstrating the roles of the two ER isoforms, $\operatorname{ER} \alpha$ and $\operatorname{ER} \beta$, in endometrial regulation. The availability of mouse strains in which the $\mathrm{ER} \alpha(\alpha \mathrm{ERKO}$ mice) or $\mathrm{ER} \beta$ ( $\beta \mathrm{ERKO}$ mice) has been ablated, paved the way to study the selective actions of $\operatorname{ER} \alpha$ and $\operatorname{ER} \beta$ [116]. The early and late responses of the $\beta E R K O$ mice were indistinguishable from those of wild type samples, whereas the $\alpha$ ERKO mice showed little response to oestradiol[116]. These observations indicate that $\mathrm{ER} \alpha$ is essential for mediating the actions of oestradiol.

Using the same mouse models, Hewitt and coworkers [121] also showed that IGF-1 and ER signalling pathways act in parallel with regard to the regulation of gene expression, and that treating $\alpha \mathrm{ERKO}$ mice with IGF-1 elicited certain responses that closely resembled the response induced by oestradiol in wild type mice. Certain genes were regulated similarly (up: Igfbp5, Cyr61, p21, c-fos; down: Txnip, Igfbp3, Sox4) by oestradiol and growth factors in wild type mice, and retained growth factor responsiveness in the $\alpha \mathrm{ERKO}$ mice. However, another group of genes was only regulated by oestradiol and only in the wild type mice (Mad2, Ramp3, lactoferrin, Igf-1, Krt1-19), and therefore depend on the presence of ER $\alpha$. The third group of genes was regulated only by the growth factors (Baiap2, Kruppellike factor 9). This confirms earlier findings that growth factors and ER signalling pathways converge in the regulation of some uterine functions, which still depend on a correct ER pathway. EGF and IGF-1 treatment of ovariectomized mice resulted in increased uterine weight and proliferation of uterine epithelial cells [126, 127], but these responses were not observed in the $\alpha \mathrm{ERKO}$ mice $[126,128]$. 


\section{Phenotypic anchoring}

To understand complex mechanisms, relationships must be defined between the changes in gene expression and the alterations that occur in the cells or tissues [4]. In toxicogenomics this is termed 'phenotypic anchoring' [129]. Moggs and coworkers applied this approach to define the transcriptional program associated with the response of the rodent uterus to oestradiol and to identify groups of genes that result in specific histological changes [4]. A single high dose of oestradiol (400 $\mathrm{g} / \mathrm{ml}$ ) was administered to immature mice, which induced a sustained increase in uterine weight. In addition, uterine expression profiles were assessed after 1, 2, 4, 8, 24, 48 and 72 hours. The 3538 oestradiol-responsive genes were subjected to hierarchical clustering to identify the temporarily co-regulated genes and the clustered genes were further interrogated using the GOStat gene ontology mining tool to gain an overview of the predominant molecular functions and biological pathways that were regulated at the transcriptional level. The temporal associations in gene expression were anchored to distinct alterations in uterine phenotype. The authors found that oestradiol regulates different classes of genes during narrow time windows, and suggested that oestradiol induces uterine growth and maturation by successively regulating the activities of different biological pathways. The first four hours after injection of oestradiol, a major influx of fluid into the uterus is seen, most likely due to an increase in vascular permeability due to increased expression of VEGF. Many genes that have roles in the regulation of vascular permeability were up-regulated (e.g. angiogenic/vascular cell growth factors VEGF, PlGf, ADM, ANG2, TGF $\beta 2$, the vasoactive serine protease KLK2, $-6,-9$ and -22 , and vascular endothelial receptors IL17R, BDKRB1, ENG, and GNA13). Next to these vasoactive substances a rapid induction of transcriptional regulators and signalling components involved in regulating growth and differentiation is observed.

Moggs and coworkers also reported that between four and eight hours after oestradiol injection no obvious changes in uterine histology occurred [4]. However, many genes involved in mRNA (and protein synthesis) are induced, whereas a number of known transcriptional repressors (i.e. TGIF, MAD4, EZH1) are suppressed. These changes are required to increase the mass of uterine cells to provide sufficient cellular components required for survival of the daughter cells [130]. These events occur immediately preceding the up-regulation of genes involved in controlling chromosome replication and the cell cycle. Luminal epithelial height doubled between 8 and 24 hours and mitotic activity was dramatically increased 24 hours after oestradiol injection, and decreased again at 48 hours. This agrees with the contention that most cells in the rodent uterus are stimulated to leave their quiescent state and divide synchronously after exposure to oestradiol [131]. After induction, the expression of most genes decreased to levels well below that of the control animals, suggesting active repression to prevent further rounds of proliferation.

In parallel oestradiol appeared to suppress the apoptotic process by inducing the expression of anti-apoptotic genes and simultaneously down-regulating the expression of pro-apoptotic genes. The investigators were able to provide more 
insight into the possible mechanisms that may be involved in the various events that lead to a receptive endometrium.

In this particular study [4], the experiment was performed three times, and the observed uterine weight responses as well as the expression profiles of the oestrogen-responsive reference genes including c-fos and LTF were highly reproducible. The combination of independent experiments and the use of stringent selection criteria have increased the reliability of the findings. One would expect than that in independent studies performed in other laboratories some agreement exists. In a similar study also performed in ovex immature mice by Fertuck et al., temporal patterns of gene expression were identified after oral administration of EE instead of oestradiol [5]. Using functional gene annotation information from public databases, Fertuck and coworkers established associations between changes in gene expression and the pathways involved in the uterotrophic response [5]. After Kmeans clustering, seven temporal gene expression patterns could be distinguished: genes induced at 2, 8, 12, 24 and 72 hours, genes induced at 8 and 3x24 hours, genes induced at 24 and $3 \times 24$ hours. Even these rigorous experimental and bioinformatics approaches resulted in only 31 genes that were reported by Moggs et al. (Table 2.3). Of these 31 oestrogen-regulated genes, only 14 showed similar temporal changes in gene expression. Two of the genes that were down-regulated were cell cycle-related, CCNG2 and GADD45. These genes were also reported to be down-regulated prior to the induction of proliferation in other mouse studies [114].

The difference in gene expression profiles could be explained by the fact that Fertuck and coworkers used EE, a synthetic steroid which is significantly more stable than oestradiol. This is somewhat surprising since in the rat the transcriptional profile induced by EE is very similar to that of the endogenous oestradiol [132].

\section{Oestrogen regulation of gene expression in human endometrium}

The exposure of the human endometrium to oestrogen increases after about five to six days after the onset of menstruation. At this point the endometrial surface repair is already completed [10], and a major role has been indicated for the bone marrow-derived cells, which constitute about half the endometrial cell population [97]. The major role of oestrogen is supposedly to modulate the growth of the human endometrium by inducing proliferation. Proliferation index peaks between eight and ten days after the onset of menstruation in the upper one third of the functional layer [10]. At the same time blood vessels have to develop to supply the growing tissue with nutrients and oxygen. This process appears to occur mostly as the result of vessel elongation rather than increased endothelial cell proliferation. The fact that endothelial cells only express ER $\beta$ and not ER $\alpha$ [133] supports the contention that these cells are not primary targets of the proliferative effects of oestradiol, which is mostly mediated by $\operatorname{ER} \alpha$ and not $\operatorname{ER} \beta$. Following the increase in mitotic activity in the endometrium, stromal oedema increases [134], which is indicative of increased biological activity of VEGF-A leading to increased vascular 
permeability. However, we were not able to confirm that the expression of VEGF-A and its receptors show significant increases during this time [135].

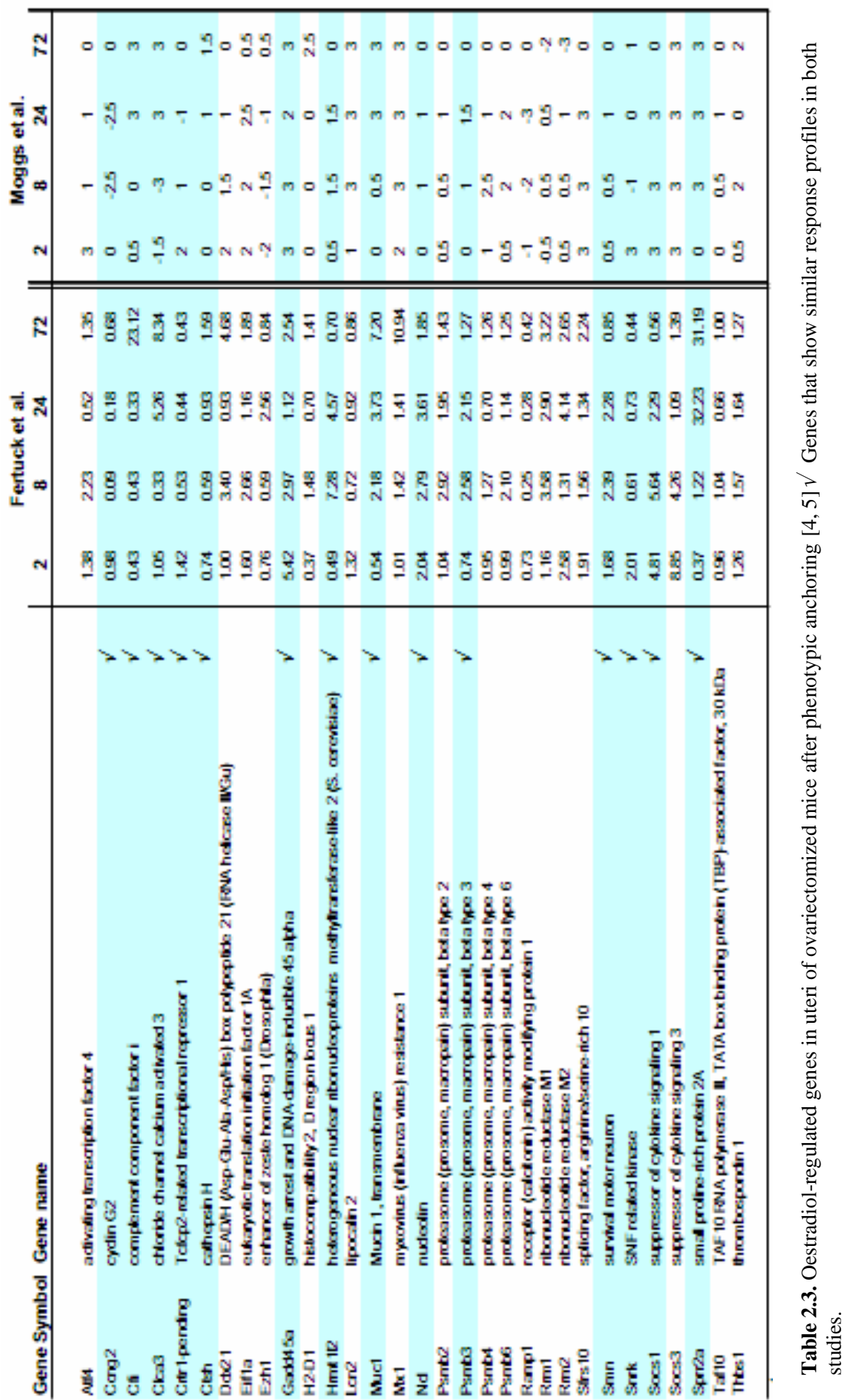


When searching the literature for microarray studies aimed at understanding the role of oestrogen in the regulation of endometrial function, only few studies are useful. Ethical restrictions limit the design of clinical studies, whereas in vitro models based on human endometrial cells have shown loss of steroid responsiveness. Only one study attempted to use a genomics approach to study the effects of oestrogens on gene expression in cultured endometrial cells. Pole and coworkers [124] sought to compare and characterise the transcript profile of tamoxifen, raloxifene, and the agonist oestradiol in human endometrial cells. Tissues $(n=3)$ were collected in the proliferative phase of the menstrual cycle. The authors found 230 significant changes in gene expression for epithelial cells and 83 in stromal cultures, either specific to oestradiol, tamoxifen or raloxifene, or changed across more than one treatment. Remarkable findings of this study are (1) the limited fold-changes observed, which did not exceed 2.5-fold, (2) the limited number of genes that are shared by oestradiol and tamoxifen (7/118) and oestradiol and raloxifene (6/94), (3) there were more genes comparably regulated between the SERMs tamoxifen and raloxifene, than between oestradiol and either tamoxifen or raloxifene, (4) only three genes were also differentially expressed in our study in endometrium tissues [1]. A drawback of this study is that no validation experiments were performed to confirm the findings of the microarray analysis, which limits the reliability of the data.

In vitro tests offer several advantages including a low intra-assay variability, however they do not reflect the sophisticated processes that occur in an intact tissue or animal, and therefore have often impaired steroid-responsiveness. In vitro studies based on whole tissue as we showed in an earlier study [33], and in vivo studies have the added advantage that they may offer the opportunity to project the findings to the human situation.

Yanaihara et al. used laser capture microdissection to study gene expression in epithelial and stromal cells of proliferative endometrium (CDs 6-9) of normal human endometrium from fertile women [117]. This approach also allows to study gene expression in individual cell populations at a given time point. Unfortunately, the investigators used BD Atlas Nylon cDNA Expression Arrays with a limited number of probes, which resulted in the identification of only 14 and 12 genes that were strongly expressed in epithelial and stromal cells respectively. Three of these genes are known cell cycle regulators, CDC28 protein kinase 2 (CKS2), CCNA1 and CCNB1. The objective of the study was to evaluate the gene expression profiles in epithelial and stromal cells, therefore no inferences could be made with regard to the actions of oestradiol. However, one gene was subsequently shown to be regulated by oestrogen in stromal cells, decorin.

There is only one study which has focussed on elucidating the actions of oestrogen in the human endometrium [1]. Gene expression profiles were compared between late proliferative (LP) and menstrual (M) phase endometrium. Genes expressed or suppressed in late proliferative endometrium would reflect genes that are expressed at a late stage of endometrium development. We identified 282 gene transcripts that were up-regulated and 512 gene transcripts that were down-regulated in the LP phase compared with the M phase endometrium. As expected, the gene 
transcripts elevated during menstruation (M phase endometrium) (e.g. inflammatory cytokines, enzymes involved in eicosanoid biosynthesis, and immunomodulators and their receptors). Also angiogenic modulators, hypoxia-induced proteins (i.e. heamoxygenase-1, adrenomedullin, carbonic anhydrase II, VEGF, CYR61 and hypoxia-induced protein-1) and MMP's were highly expressed in $M$ phase endometrium [1]. In turn, the expression of different cell cycle regulators was overexpressed in LP phase endometrium (Table 2.4).

Table 2.4. Cell cycle regulators differentially expressed in LP vs. M phase endometrium [1]

A. In vivo - LP phase vs. M phase endometrium

\begin{tabular}{lcc} 
Gene & Fold-change & \\
\hline CCNA1 & 3.4 & $*$ \\
CCNB1 & 4.3 & $*$ \\
CCNB2 & 4.3 & $*$ \\
CCNL1 & -3.3 & \\
CDC2 & 3.2 & $*$ \\
CDC20 & 6.8 & $*$ \\
CDC6 & 3.0 & $*$ \\
CDCA3 & 4.8 & \\
CKS2 (CDC28 kinase 2) & 2.3 & \\
CDKN1A (p21, CIP1) & -3.8 & \\
CDKN2C & 3.4 & $*$ \\
CDKN3 & 2.4 & $*$ \\
GADD45B & -6.2 & $*$
\end{tabular}

B. In vitro - M phase endometrium treated with $17 \beta-E 2$

\begin{tabular}{lr} 
Gene & Fold-change \\
\hline CCNA1 & 3.5 \\
CCNL2 & 2.2 \\
CDK10 & 4.4 \\
CDKN2B & 3.3
\end{tabular}

* Genes also found oppositely regulated in secretory when compared to proliferative endometrium

We compared these profiles also with the profiles of explant cultures prepared from the same biopsies ( $\mathrm{M}$ and LP phase endometrium) treated with oestradiol for twenty four hours. This approach would theoretically distinguish genes that are directly regulated by oestrogen from those that require extended exposure to oestrogen. We found 148 and 45 gene transcripts to be up- and downregulated, respectively, by oestradiol in $\mathrm{M}$ phase endometrium. In LP phase endometrium only 12 transcripts were up-regulated and 4 transcripts were downregulated by oestradiol. This clearly demonstrates that the responsiveness of the human endometrium is reduced after prolonged exposure to oestradiol in vivo, probably because all relevant genes have already been activated at this time.

In contrast, when these tissues are treated with progesterone, LP phase endometrium responds much better (219 vs. 117 genes in M phase endometrium) [136], indicating that the responsiveness of the endometrium to progesterone increases after extended periods of exposure to oestrogen. 
Indirectly, potential oestrogen regulated genes should also be extractable from studies investigating changes in gene expression throughout the menstrual cycle. Particularly from studies which have being performed on global gene profiling using endometrium collected in early and late proliferative phase. Only one study meets this criterion [82], even though the attention of these authors was mostly focussed on the secretory phase. With regard to the proliferative phase endometrium the authors stated that there is little evidence of major changes in gene expression that correlates with the rise in oestrogen during the proliferative phase of the cycle. However close examination of the clusters defined by the investigators clearly show differences between the menstrual, early/mid-proliferative, mid-proliferative, and late proliferative/early secretory stages. Comparing the genes to those identified in our study [1], we found 20 genes to be common to both studies (Table 2.5). In contrast to our expectations, none of these genes were cell cycle regulators.

\section{Oestrogen regulation of cell cycle regulators}

\section{Rodent uterus}

Oestrogen is the most important regulator of proliferation in endometrium. Yet, we know surprisingly little about the subcellular processes involved in oestrogen regulation of proliferation. Even in the microarray studies mentioned above, little attention has been given to this aspect of endometrial development. Four studies have attempted to extract information from the array data in order to understand how oestrogens affect the cell cycle: $[4,5,116,121]$. Only a small subset of genes was frequently affected by oestradiol in the murine or rat uterus. As indicated earlier, the expression of the cell cycle inhibitors GADD45 and CCNG2 is suppressed by oestradiol treatment prior to the upregulation of various cell cycle inducers. A direct involvement of oestradiol-occupied ER $\alpha$ in the down-regulation of CCNG2 was recently shown by Stossi et al. [137]. They observed that the suppression of CCNG2 is associated with the recruitment of the co-repressor N-CoR and histone deacetylases, leading to a hypoacetylated state of the chromatin [137]. Although GADD45 suppression by oestrogen in the rodent uterus has not yet been shown, these observations point to the fact that the proliferative response induced by oestrogen is initiated by the down-regulation of cell cycle inhibitors, rather than the induction or activation of cell cycle stimulators. This is further substantiated by the studies of Hewitt et al. [116, 121], Watanabe et al. [114], Moggs et al. [4] and Hong et al. [113]. The common denominators in these studies next to CCNG2, are $227^{\mathrm{KIP} 1}$ (CDKN1B) and GAS1. These cell cycle inhibitors are down-regulated during the first one to eight hours after oestrogen administration. Other negative regulators of the cell cycle reported in more than one study are $\mathrm{p} 21^{\mathrm{CIP1}}(\mathrm{CDKN} 1 \mathrm{~A})$ and MAD2. Upon administration of oestradiol, both $\mathrm{p} 21^{\mathrm{CPI}}$ (CDKN1A) and MAD2 expression peak during the first 6 hours, after which the expression decreases again. MAD2 
interacts with the anaphase-promoting complex (APC) which is required for anaphase initiation and exit of mitosis [138]. Upon binding of MAD2, activation of the APC is inhibited and the cells are arrested at the prometaphase. Upon the decrease in MAD2 these cells will enter mitosis which may result in the first wave of cell divisions observed after about 16 hours. Parallel to the decrease in MAD2, levels of CCNE1 (which is involved in the G1 to $S$ transition in the cell cycle) increased dramatically $[116,121]$. At this point levels of $\mathrm{p} 21^{\mathrm{CIP} 1}$, which inhibits Sphase entry, are still elevated. The levels start decreasing 15 hours post-oestradiol, at the same time CCNE1 and CCNG1 levels increase. This may allow cells to progress from the G1 to the S-phase and initiate the second wave of mitotic divisions. The increase in CCNE1 was also observed in response to IGF, indicating that this cyclin also mediates the growth factor induced proliferative response [121].

Table 2.5. Common genes in Ponnampalam et al. and Punydeera et al [1, 82]

\section{Ponnampalam et al.}

Punyadeera et al.

High menstrual, low proliferative (Clusters 2, 5, 6,7) Late proliferative vs. menstrual

$\begin{array}{ll}\text { CENPF } & +9.7 \\ \text { NCR3 } & -6.6 * \\ \text { SOX4 } & -4.58 * \\ \text { TYMS } & +5.2 \\ \text { TAC1 } & -5.9 * \\ \text { DNAJB1 } & -4.2 * \\ \text { STC1 } & -20.4 * \\ \text { DTR } & -12.6 * \\ \text { CD59 } & -2.5 * \\ \text { EDN2 } & -2.4 * \\ \text { S100P } & -6.8 * \\ \text { TGFA } & -3.0 * \\ \text { IL7R } & -4.9 * \\ \text { RAI3 } & -16.6 * \\ \text { ITGA2 } & -5.0 *\end{array}$

Low menstrual, up proliferative (Cluster 3)

$\begin{array}{ll}\text { DCI } & +3.5 * \\ \text { TRIP13 } & +2.0 *\end{array}$

Low early, high late proliferative (Cluster 4)

HMGB2

$+3.5 *$

CSTF2

$-3.2$

PDEF

$+5.4 *$

* Genes displaying similar changes in both studies.

\section{Human endometrium}

When comparing the gene expression profiles of LP phase and M phase endometrium, we observed that the expression of a subset of cell cycle regulators was differentially expressed (Table 2.4) [1]. Particularly interesting is the downregulation of the cell cycle inhibitors $\mathrm{p} 21^{\mathrm{CIP}}$ and GADD45, which were also 
implicated in the regulation of murine uterine growth by oestradiol. In addition, the expression of the cell cycle inducers CKS2, CCNA1 and CCNB1, also reported by Yanaihara et al [117], was elevated in LP phase endometrium as compared to $\mathrm{M}$ phase endometrium.

An alternative way to deduce candidate genes involved in oestrogenregulation of proliferation, is to evaluate expression profiles after exposure to the natural antagonist of oestradiol, progesterone. We generated gene expression profiles for two biopsies collected on cycle day 23 of the menstrual cycle, the end of the implantation window, and compared them with the profiles of two biopsies collected on cycle day 9 of the menstrual cycle, the mid-proliferative phase. We extracted the most common cell cycle regulators (more than 2 -fold difference), and found a total of 43 genes differentially expressed: 11 genes were up-regulated and 32 genes were down-regulated in secretory phase endometrium (Table 2.6; unpublished data). These genes were compared with the genes which were found to be elevated in LP phase endometrium when compared to $\mathrm{M}$ phase endometrium [1] and presumably induced by oestrogen. Eight genes were down-regulated and one gene was up-regulated (GADD45) in the secretory phase endometrium (Table 2.6). We also compared these findings with the results of the extensive study by Talbi et al. [139], who studied gene expression in histologically well defined biopsies of human endometrium throughout the menstrual cycle. In the gene list resulting from the comparison between the secretory and proliferative endometrium, 13 cell cycle related genes corresponded to our findings: 11 genes were down-regulated, and two genes were up-regulated in the secretory endometrium (Table 2.6). Interestingly, the expression of various cell cycle inhibitors, i.e. GADD45, GAS1, CDKN1C (KIP2), is dramatically induced in secretory endometrium, supporting the findings from the mouse studies indicating that the role of cell cycle inhibitors in the regulation of proliferation may have been underestimated thus far.

Oestrogen regulation of the cell cycle has been extensively studied in breast cancer cell lines (reviewed by Doisneau-Sixou et al. [140]), and central roles have been identified for CMYC, CCND1 and its binding partners CDK4 and CDK6, $\mathrm{CCNE}$ and its binding partner CDK2, and the CDK inhibitor $\mathrm{p} 21^{\mathrm{CIP}}$. In brief, CMYC and CCND1 can independently mediate the effects of oestrogen on cell cycle progression. These pathways converge at the CCNE-CDK2 complex, which is activated by stimulating the dissociation of $\mathrm{p} 21^{\mathrm{CIP}}$ from this complex. This dissociation is mostly a result of the down-regulation of $\mathrm{p} 21^{\mathrm{CIP}}$ gene transcription. After up-regulation by oestrogen, CCND1 complexes with CDK4 and CDK6, which are potent kinases, which, in turn, phosphorylate $\mathrm{pRb}$ and, within nine hours, the cell enters in the $\mathrm{S}$ phase. Even though CMYC does not enhance the expression of CCND1, however, suppression of CMYC expression reduced CCND1 expression and prevents oestrogen-stimulated cell cycle progression. 
Table 2.6. Cell cycle regulators differentially expressed in secretory vs. proliferative phase endometrium. Genes indicated (*) are also reported in the study of Talbi et al. [139]

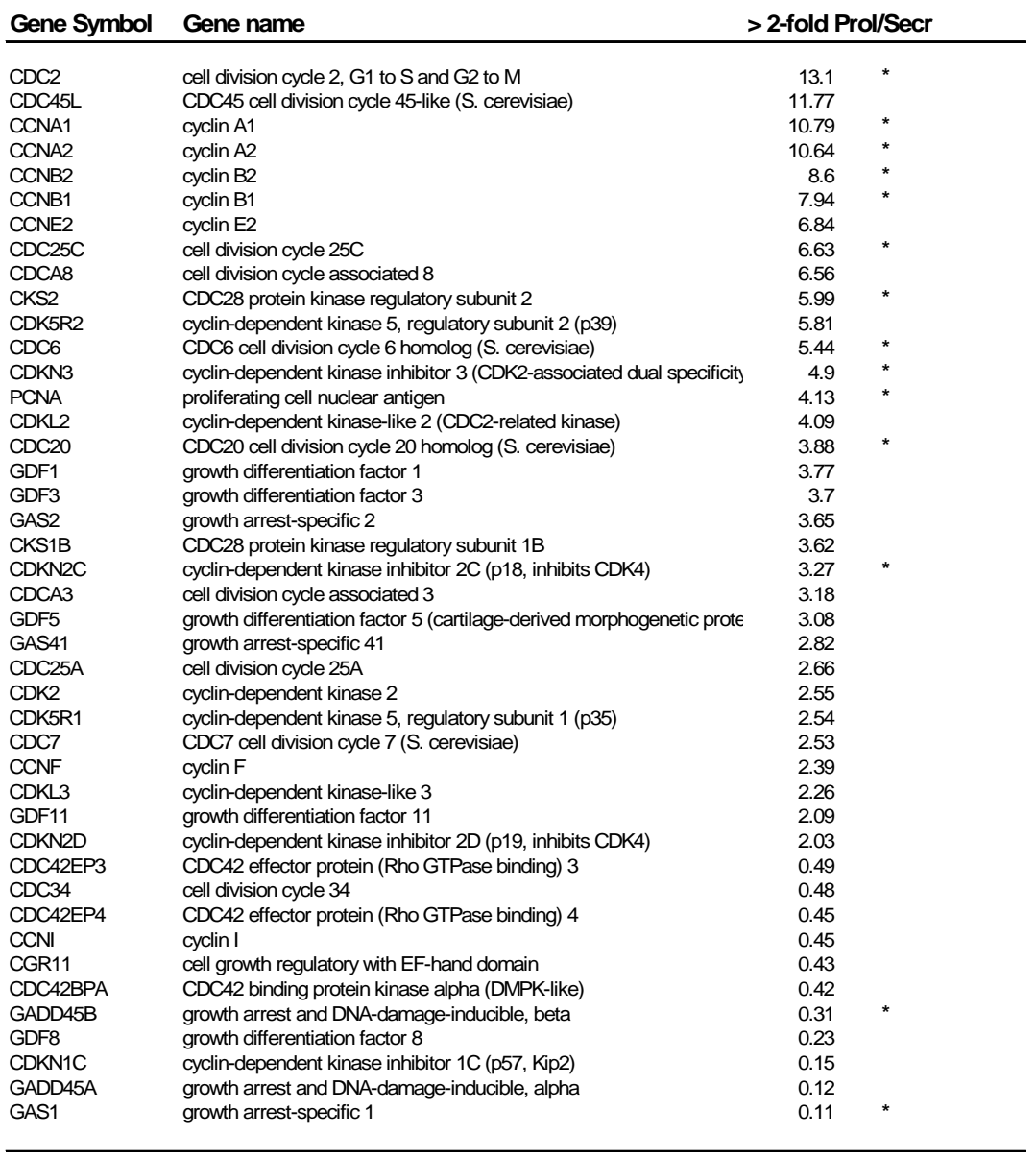

As a model to elucidate the mechanism of oestrogen-stimulated cell proliferation, we have investigated the expression of a subset of these cell cycle regulators in endometrial and breast cancer cell lines treated with oestradiol (1.0 $\mathrm{nM})$. The endometrial cancer cell line ECC1 and the breast cancer cell line T47D nicely respond to oestradiol treatment as illustrated by the induction of the transcription of the oestrogen-responsive gene pS2 in both cell lines (Figure 2.1a). Yet, T47D cells respond to oestrogen stimulation with strong cell proliferation, whereas ECC1 cells do not. In order to explain this we evaluated the expression of various cell cycle regulators in both cell lines. In both cell lines the key gene in the regulation of proliferation, CMYC is strongly induced in both cell lines with maximal expression 1 hour after oestradiol stimulation (Figure 2.1a). Subsequently, in T47D cells the expression of the cell cycle activators CCNA ( 2 hours), CCNB (6 hours) and CCND and CCNE (16 hours) is also induced (Figure 2.1b). When evaluating the expression of cell cycle suppressors, it was apparent that in the T47D cells the expression of GADD45A and GADD45B was down-regulated after 2 
hours, whereas in the ECC-1 cells the expression of GADD45B was not inhibited, whereas the expression of GADD45A was highly induced (Figure 2.1c). These evidences support the aforementioned hypothesis that the downregulation of cellcycle inhibitors is one of the first actions in oestradiol-induced cell proliferation.

Surprisingly however, we observed that in T47D cells the expression of CCNG2 is induced after 6 hours of oestradiol treatment $(1.0 \mathrm{nM})$. As this was not seen in the ECC-1 cells, we tend to believe that the CCNG2 is a cell cycle activator. This contradicts however, the finding of Stossi et al. in MCF-7 cells, which clearly indicated CCNG2 as a cell cycle suppressor [137]. These observations show that mechanisms of oestrogen control of proliferation as revealed in one breast cancer cell line can not habitually be extrapolated to other breast cancer cell lines or any other model system, without extensive validation.

Variations in the expression of cell cycle regulators in tissues may very well be masked during genomic profiling by their cell-specific expression patterns. There are multiple cell types present in the human endometrium that contribute to the growth of the endometrium tissue and studying gene expression on a tissue provides no information about the individual cell types. Moreover, expression has also to be confirmed at the protein level in order to draw any conclusions. For instance expression of CCNE implicated as a key regulator of oestrogen induced cell cycle progression, is most prominent in the glandular epithelium, and switches from the cytoplasm in the mid-proliferative phase to the nucleus in the secretory phase. This dramatic change in intracellular distribution may occur without alterations in mRNA levels. In addition, it is also strongly expressed in blood vessels, yet it is almost absent in the stromal cells. This would implicate a role for CCNE in endothelial and epithelial cells rather than the stromal cells.

\section{Should we translate information generated in rodent genomic profiling to humans?}

A rodent is not a human. Despite some similarities in hormonal regulation of the menstrual and oestrous cycles, there obviously are also major differences between the actions of oestrogen in the rodent and human uterus. In rodents oestrogen is essential for both epithelial proliferation and embryo implantation [141], whereas in humans prolonged oestrogen exposure is required for endometrial growth, but its presence is not required during embryo implantation. In addition, the first effects of oestrogen in the rodent uterus are effects on the vasculature resulting in increased vascular permeability and leakage of fluids into the interstitial space, whereas in the human endometrium angiogenic activity is initially triggered by the hypoxic milieu which results in the up-regulation of angiogenic factors, including VEGF-A [135, 142]. 

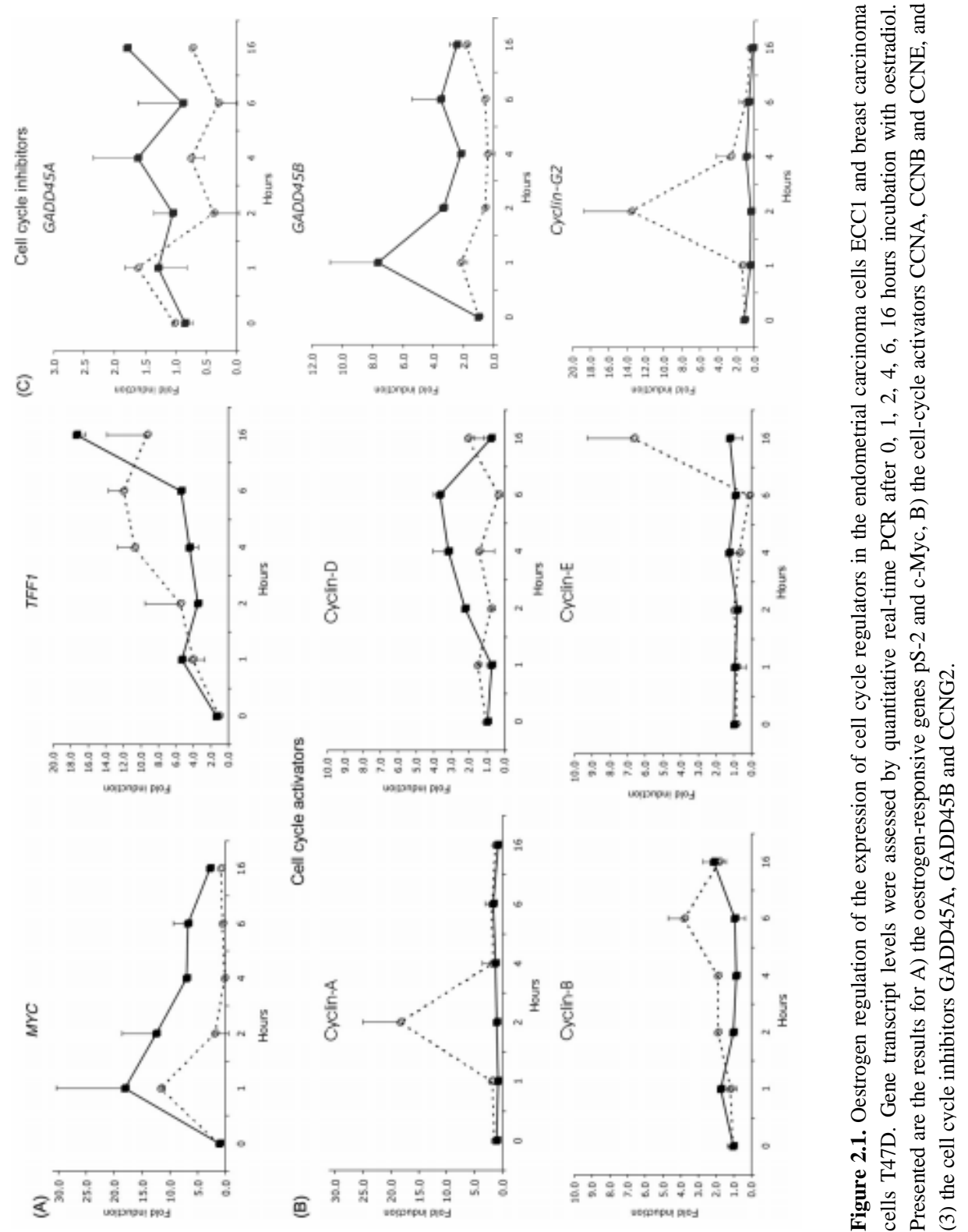

:

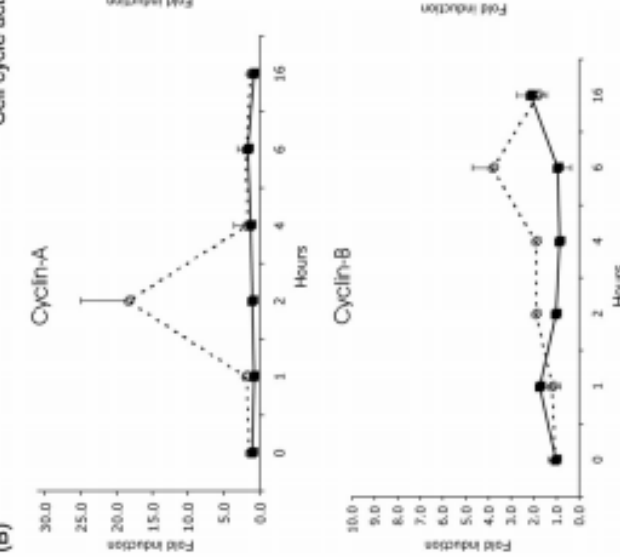

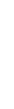


states. In addition, the studies in rodents are usually performed in preparations of the whole uterus and not only the endometrium. Therefore certain differences may be masked, and others may be the result of the inclusion of the myometrial tissue.

In an attempt to identify oestrogen-responsive genes in the human endometrium, we compared the gene expression profiles of late proliferative (LP) phase endometrium, during which oestrogen exposure of the endometrium has reached its maximum, with menstrual (M) phase endometrium (cycle day 3 and 4), during which oestrogen levels are at their lowest point during the menstrual cycle [1]. In analogy, these genes would have to be compared to murine genes which are modulated during the peak levels of pre-ovulatory oestrogen, such as in ovariectomized mice treated with oestradiol. When comparing the results of Moggs et al. [4] with our own data [1] we observed only 27 common genes, of which 14 were regulated similarly in both species. Some genes involved in DNA replication and cell division were also up-regulated in late proliferative phase endometrium (i.e. PCNA, CDC6, CCNB1; Table 2.7). Interestingly, the expression of the cell cycle inhibitors CDKN1A (p21 ${ }^{\mathrm{CIP}}$ ) and GADD45 was also down-regulated in the human endometrium during periods of high proliferative activity. None of the genes involved in the RNA and protein synthesis reported by Moggs and coworkers were common, whereas we did find various transcriptional regulators and signalling genes in our arrays (Table 2.7). As expected the expression of all of these early response genes was lower in late proliferative vs. menstrual phase endometrium, since at this stage mostly the late response genes are expected to be activated.

None of the genes from the study of Moggs et al. was modulated in cultured human endometrium tissue after short term treatment with oestradiol [1], further substantiating the findings of Kurita and coworkers that the human endometrium requires longer exposure to oestrogen to elicit a growth response [98].

The large variety of rodent models has allowed close investigation of the actions of ovarian steroid hormones with regard to the regulation of uterine function. Unfortunately, the limited analogy with the actions of oestrogen in the human endometrium, limits the possibilities to extrapolate findings from the rodent studies to the human situation.

One additional issue that has to be considered, is the problem of the differences in nomenclature of human and murine genes, which may not always be the same, resulting in incomplete comparisons. Initiatives are ongoing to synchronize gene naming of homologous genes (reviewed by Wright and Bruford [143]). 


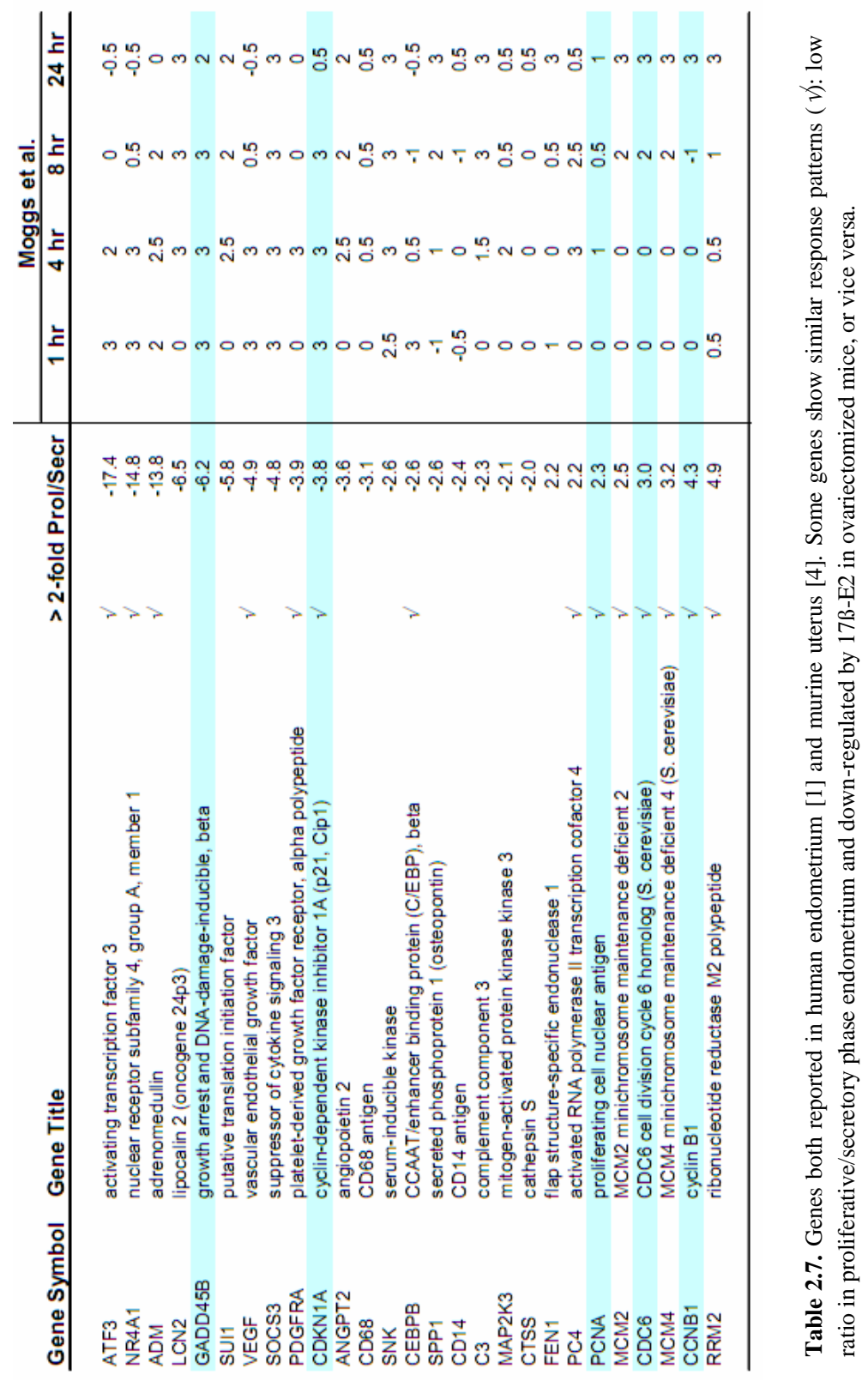

\section{Concluding remarks}

We are far from understanding the mechanisms by which oestradiol regulates endometrial growth and differentiation. Even though gene expression profiling can be beneficial in revealing the biological processes and cellular 
functions involved, they have not yet significantly contributed to better insights in the role of oestradiol. Thus far, we have learned more from 'hypothesis-driven' research approaches, whereas the validity of the findings of the 'hypothesisgenerating' genomics approaches have not yet improved our understanding of the regulation of endometrial function in humans.

The infrequent similarities between the responses of rodent and human uterus to oestrogen, limits extrapolation of findings in rodent models. In addition, the large differences between studies performed in different laboratories and the biological variation that exists between samples is a major issue of concern and calls for large multicenter collaborations to increase numbers of samples and reduce variations with regard to the choice of platform, sample and probe preparation and hybridization. Also the use of 'clean' samples consisting of individual cell types, such as those collected with laser capture microdissection, would provide more sensible information. However, technical restrictions have thus far prohibited such studies. 


\section{Chapter 3 \\ Oestrogen-modulated gene expression in the human endometrium}

C Punyadeera ${ }^{1,2}$, H Dassen ${ }^{2}$, J Klomp ${ }^{5}$, G Dunselman ${ }^{1,3}$, R Kamps ${ }^{1,2}$, F Dijcks $^{4}$, A Ederveen ${ }^{4}$, A de Goeij ${ }^{1,2}$, P Groothuis ${ }^{1,3}$

${ }^{1}$ Research Institute GROW, Departments of ${ }^{2}$ Pathology, ${ }^{3}$ Obstetrics and Gynaecology, University Hospital Maastricht University Maastricht; ${ }^{4}$ Department of Pharmacology and ${ }^{5}$ Pharmacogenomics, N.V. Organon, Oss, The Netherlands.

Published in: Cell Mol Life Sci. 2005; 62(2):239-50. 


\begin{abstract}
To identify key regulatory mechanisms in the growth and development of the human endometrium, microarray analysis was performed on uncultured human endometrium collected during menstruation (M) and the late-proliferative (LATE$\mathrm{P})$ phase of the menstrual cycle, as well as after $24 \mathrm{hrs}$ of incubation in the presence of oestradiol (17 $\beta-\mathrm{E} 2)$.

We demonstrate the expression of novel gene transcripts in the human endometrium i.e. mucin-9, novel oestrogen-responsive gene transcripts i.e. gelsolin, flotillin-1, and genes known to be expressed in human endometrium but not yet shown to be oestrogen responsive i.e. connexin-37, TFF1/pS2. Genes reported to be expressed during the implantation window and implicated in progesterone action i.e. secretoglobin family 2A, member 2 (mammaglobin), homeobox containing proteins, were up-regulated in uncultured LATE-P phase endometrium compared to $\mathrm{M}$ phase endometrium. Some gene transcripts are regulated directly by 17ß-E2 alone, others are influenced by the in vivo environment as well. These observations emphasise that the regulation of endometrium maturation by oestrogen entails more then just stimulating cell proliferation.
\end{abstract}

\title{
Introduction
}

During the menstrual cycle, the growth and differentiation of the human endometrium is controlled by oestrogen and progesterone. After shedding of the functional layer of the endometrium during menstruation, a series of events occurs in the proliferative phase of the menstrual cycle, aimed at regeneration of damaged endometrium, subsequently followed by the creation of a new functional layer. A variety of biological processes occurs during human endometrium maturation in the proliferative phase, mainly governed by oestrogen i.e. cell proliferation [144], cell differentiation, extracellular matrix remodelling, angiogenesis and vasculogenesis [145]. However, the genes, molecular mechanisms and pathways by which oestrogen regulates these events are only partly understood, mainly due to the complexity and the large number of factors acting in concert. Although endometrium physiology has been an important subject of research, most attention has been focussed on determining the expression of gene transcripts and proteins during the implantation window [7, 146-148]. Recent studies demonstrated that endometrium receptivity declines when primed inappropriately, i.e. exposed to either high [149] or low doses of oestrogen [16, 150] prior to ovulation.

The aim of this study is to unravel key mechanisms that underlie the 
oestrogen-controlled maturation in the human endometrium. In this study two approaches were taken to increase our current understanding of the role of oestrogen in regulating gene expression in the human endometrium. In the first approach, we compared the gene expression profiles of endometrium tissue in the menstrual phase that has not been exposed to increased peripheral concentrations of follicular oestrogens, with endometrium tissue that has been exposed to increased concentrations of follicular oestrogens for several days (late proliferative, LATE-P phase). In the second approach the gene transcripts that are directly modulated by oestrogens were discriminated from those that require in vivo oestrogen priming. To this end, we compared the expression profiles of endometrium explants cultured in the absence or presence of $17 \beta$-E2 for 24 hours.

\section{Material and Methods}

\section{Human endometrial tissue}

All patients were 20-45 years old, had regular ovulatory cycles and were not receiving hormonal treatment. Endometrium was collected by pipelle biopsy or from hysterectomy specimens. Endometrial biopsies were obtained with a Pipelle catheter (Unimar Inc., Prodimed, Neuilly-Enthelle, France) under sterile conditions, from female volunteers who came to the clinic for a diagnostic laparoscopy as part of their fertility work-up, or for a sterilisation procedure. Indications for hysterectomy were excessive menstrual bleeding or myomas. The endometrium was inspected macroscopically by the pathologist, and normal appearing endometrium was scraped gently from the surface of the uterine cavity with a sterile surgical blade. Part of the endometrial tissue used for the study was fixed in $4 \%$ formaldehyde for histological examination. Endometrium biopsies were dated according to microscopic criteria of Noyes [151], and the dating was adjusted finely according to clinical information with respect to the start of the last menstrual period whenever available. All women gave their written informed consent, according to a protocol approved by the Medical Ethical Committee of the Academic Hospital Maastricht.

A total of 24 biopsy samples was obtained during the $\mathrm{M}$ phase, i.e cycle days (CDs) 2-5 and LATE-P phase, i.e. CDs 11-14 (prior to ovulation). Of the 24 biopsies, 4 were used for microarray studies and 20 were used for validation with real-time PCR analysis. Tissue was transported to the laboratory in DMEM/Ham's F12 medium on ice. A portion of each sample was fixed in $10 \%$ buffered formaline for histology evaluation. The samples that were used to determine the in vivo oestrogen regulated genes (designated as uncultured) were immediately placed in lysis buffer and were stored at $-70^{\circ} \mathrm{C}$. A part of the explants were cultured on Millicell culture inserts as described previously [33]. 


\section{Human endometrial explant cultures and RNA extractions}

Human endometrium tissue was cut into pieces of $2-3 \mathrm{~mm}^{3}$. Twenty four explants were applied on Millicell-CM culture inserts (pore size of $0.4 \mu \mathrm{m}, 30 \mathrm{~mm}$ diameter, Milipore, France) in 6-well plates containing Phenol red-free DMEM/Ham's F12 medium (1.2ml) (Life Technologies, Grand Island, NY). The medium was supplemented with L-glutamine (1\%), penicillin and streptomycin $(1 \%, \mathrm{P} / \mathrm{S})$ and this was used in all stages of explant preparations. Cultures were performed for 20-24 hours. Previous experiments have shown that collagenase activity remains low in proliferative endometria during the first 24 hours of culture [152], and that the tissue viability is not affected after 24 hours of culture [153]. The treatments included: (1) control (0.1\% ethanol) and (2) oestradiol (1nM, 17 $\beta$ E2). The $17 \beta-E 2$ was a gift from Organon N.V. (Oss, The Netherlands).

Total cellular RNA was extracted from explants using the SV total RNA isolation kit (Promega, USA) according to the manufacturer's protocol, with slight modifications. The concentration of DNase-1 during DNase treatment of the RNA samples was doubled and the incubation time was extended by 15 minutes in order to completely remove genomic DNA. Total RNA was eluted from the column in $50 \mu \mathrm{l}$ RNase-free water and stored at $-70^{\circ} \mathrm{C}$ until further analysis. The quality of the RNA samples was determined with the Agilent bioanalyzer 2100 labon-a-chip (Agilent, USA). All the samples analysed gave $28 \mathrm{~S}$ to $18 \mathrm{~S}$ ratios higher than 1.5. A PCR for a housekeeping gene, GAPDH, was performed to confirm that the RNA samples were free of genomic DNA.

\section{Affymetrix gene chip microarrays}

The RNA samples were pooled according to the phase of the menstrual cycle and to the treatment conditions i.e. two RNA samples from the $M$ phase and two RNA samples from the LATE-P phase were pooled. From pooled RNA, cRNA was generated and was labelled with biotin according to the Affymetrix protocol (Santa Clara, USA). cDNA was hybridised to the Affymetrix HU-133A chips, which contain approximately 22,000 human oligonucleotide probe sets, including 68 controls. The chip hybridisations were carried out in triplicate. After washing, the chips were scanned and analysed using the MicroArray suite MAS5. A detailed description of the Affymetrix chip content is available at the NetAffy analysis web page (http://www.affymetrix.com/analysis/index.affx).

\section{Microarray data analysis}

Following Gene chip data quality control, data files (.EXP, .DAT, .CEL) generated by MAS5 were transferred by FTP to the server housing the Rosetta Resolver Gene Expression Data Analysis System. Resolver uses its Affymetrix 
gene chip error model to transform the raw data into a processed form that can be used in various expression analyses. Rosetta Resolver allows normalization of sample data of triplicate hybridizations using One-Way Analysis of Variance (ANOVA) [ 154 ]. After data transformation, the scatter plots of log relative intensities of all detected gene transcripts had slopes of around 1, indicating that hybridization efficiency was similar for the arrays in both groups and array comparisons could be made.

The use of microarrays results in a massive amount of data, which requires special tools to filter and extract the relevant information. By combining the fold changes or log ratios and the p-value we generated a so-called significance code, which simplified the selection and extraction of genes of interest, especially when analyzing various conditions. The significance code assigned to the genes, was based on ANOVA retrieved p-values, and up- or downregulation compared to the untreated samples. A significance code of +1 was used for genes with $\mathrm{p}<0.01$ and $\log$ ratio $>0$ (stimulated or up-regulated); a significance code of -1 was used for genes with $\mathrm{p}<0.01$ and $\log$ ratio $<0$ (inhibited or downregulated). Genes which did not show a significant regulation received the significance code of 0. Data were then exported from Rosetta Resolver to Spot fire decision site 7.1 (Spotfire, Göteborg, Sweden), in which gene sets of interest were visualized and subsequently selected. Figure 3.1 presents an illustrative example of using the significance code approach when comparing more than two treatments. Using this strategy, gene transcripts that are modulated under three different treatment conditions could easily be identified.

Figure 3.1. An illustrative example of using the significance code when comparing more than two treatment conditions. The coordinates $-1,0$ and +1 present the assigned significance codes (detailed description in Materials and Methods). The $\mathrm{Y}$-axis represents the ratio of $17 \beta-E 2 /$ control for $M$ phase endometrium explant cultures (treatment 1); the $\mathrm{X}$-axis represents the ratio of $17 \beta$ E2/control for LATE-P phase endometrium explant cultures (treatment 2); the Z-axis (colours) represents the ratio of uncultured LATE-P phase/uncultured M phase (treatment 3 ). The yellow dots represent the up-regulated genes; blue dots represent down-regulated genes and the grey dots represent genes that are

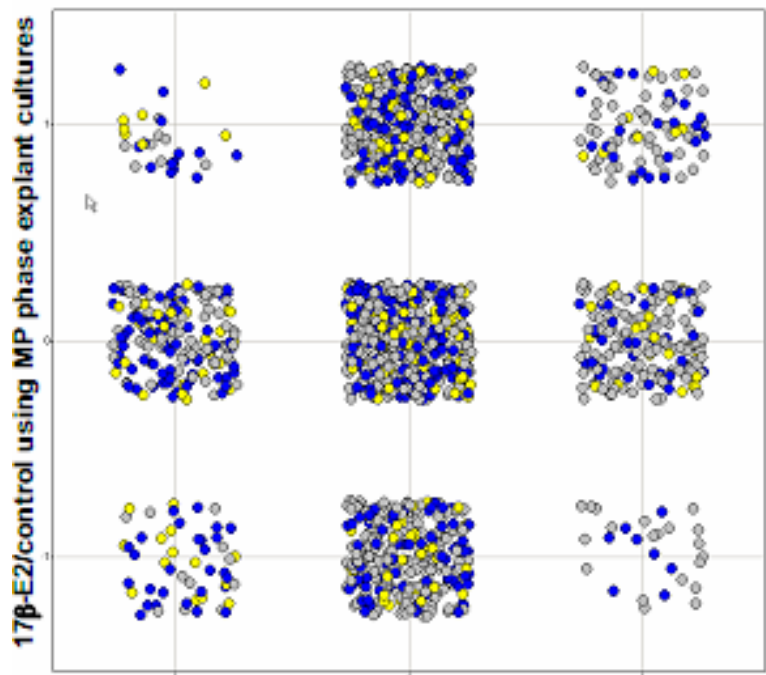

$17 \beta-E 2 /$ control using LP phase explant cultures not regulated. If the coordinates were $\mathbf{- 1}$ and $\mathbf{- 1}$ and the dot is blue, this would represent the downregulated genes by $17 \beta-\mathrm{E} 2$ treatment in both $\mathrm{M}$ and LATE-P phase endometrium tissue and expressed lower in LATE-P phase uncultured endometrium compared to M phase uncultured endometrium. 
The genes were annotated using the Affymetrix annotation data base [155]. After annotation, the genes were allocated to one of eighteen functional categories based either on the biological process or their cellular or molecular functions.

\section{Real-time PCR analysis}

Newly identified gene transcripts in the endometrium that showed more than a two-fold stimulation (or down-regulation), and gene transcripts with documented biological relevance to human endometrium physiology were selected for validation using real-time PCR analysis. Samples from additional experiments were analysed using endometrium tissue obtained throughout the proliferative phase to validate the micro array results. Total RNA $(1 \mu \mathrm{g})$ was incubated with random hexamers $\left(1 \mu \mathrm{g} / \mu \mathrm{l}\right.$, Promega, USA) at $70^{\circ} \mathrm{C}$ for $10 \mathrm{~min}$. The samples were chilled on ice for $5 \mathrm{~min}$. To this mixture, a reverse transcriptase (RT)-mix consisting of 5x RT-buffer $(4 \mu \mathrm{l}), 10 \mathrm{mM}$ dNTP mix (1 $\mu \mathrm{l})$ (Pharmacia, Uppsala, Sweden), 0.1M DTT ( $2 \mu 1)$ (Invitrogen, California, USA) and superscript II reverse transcriptase $(200 \mathrm{U} / \mu \mathrm{l})$ (Invitrogen, California, USA) was added and the samples were incubated at $42^{\circ} \mathrm{C}$ for one hour, after which the reverse transcriptase was inactivated by heating the samples at $95^{\circ} \mathrm{C}$ for $5 \mathrm{~min}$. The cDNA was stored at $-20^{\circ} \mathrm{C}$ until further use. In each real-time PCR reaction 50ng of cDNA template was used. Primers and probes were purchased from Perkin-Elmer Applied Biosystems as pre-developed assays. Human cyclophylin A was selected as an endogenous RNA control in order to correct for the differences in the amount of total RNA added to each reaction. Uncultured human endometrium tissues were included as positive controls. All PCR reactions were performed using an ABI Prism 7700 sequence detection system (Perkin-Elmer Applied Biosystems). The thermal cycling conditions comprised an initial decontamination step at $50^{\circ} \mathrm{C}$ for $2 \mathrm{~min}$, a denaturation step at $95^{\circ} \mathrm{C}$ for $10 \mathrm{~min}$ and 40 cycles of $15 \mathrm{sec}$ at $95^{\circ} \mathrm{C}$ followed by $1 \mathrm{~min}$ at $60^{\circ} \mathrm{C}$. Experiments were performed for each sample in duplicate. Quantitative values were obtained from the threshold cycle number $(\mathrm{Ct})$ at which the increase in the signal associated with exponential growth of PCR products is first detected with the ABI Prism 7700 sequence detector software (Perkin-Elmer, Foster city, CA). The relative expression of the target gene in the human endometrium tissue was calculated by $1 / 2^{\Delta \mathrm{Ct}}\left(\Delta \mathrm{C}_{\mathrm{t}}=\mathrm{C}_{\mathrm{t}}\right.$ target -

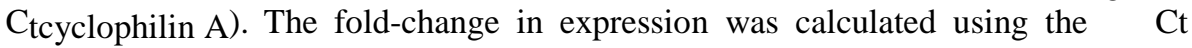
method, with cyclophylin A mRNA as an internal control [156]. For detailed description of the procedure please refer to the ABI user manual:

(http://www.uk1.unifreiburg.de/core/facility/tagman/userbulletin_2.pdf).

\section{Statistical analysis of quantitative real-time PCR data}

Statistical tests were carried out using the SPSS 10 (SPSS Inc., Chicago, IL) statistical analysis package. The nonparametric unpaired Mann-Whitney-U test at a confidence level of $95 \%$ was employed to analyse the real-time PCR data 
generated from uncultured LATE-P phase endometrium tissue and uncultured $\mathrm{M}$ phase endometrium tissue. The effects of $17 \beta-\mathrm{E} 2$ on cultured explants were analysed using the nonparametric paired Wilcoxon signed rank test at a confidence level of $95 \%$.

\section{Results}

Gene expression was studied in the human endometrium tissue, collected either directly from the M phase and LATE-P phase (uncultured) or after $24 \mathrm{hrs}$ of culture in the presence of $17 \beta$-E2 or vehicle. The differences in gene expression between groups (i.e. LATE-P phase vs. M phase, and 17 $\beta$-E2 vs. control for both $M$ and LATE-P phase explants cultures) were calculated, and gene transcripts with a significant decrease or increase of 2 -fold or more, were used.

\section{Validation of array data}

The expression of six genes was validated in the original RNA samples used for the array hybridisations (Table 3.1). In addition, eight additional samples were collected and analysed to evaluate the biological variation between women on the expression of the six genes validated from the array hybridisations (Table 3.1). The genes were selected based on known 17 $\beta$-E2 responsiveness i.e. progesterone receptor ( $\mathrm{PR})$, trefoil factor-1 (TFF1/pS2), and cyclin A1, on novelty i.e. Mucin-9, and on documented involvement in endometrial function i.e. connexin-37, matrix metalloproteinase-1 (MMP-1), cyclooxygenase-2 (COX-2), and $17 \beta$-HSD type 2 . In addition, two gene transcripts were selected that have not been previously documented to be expressed in the endometrium i.e. secretoglobin 1D, member 2 or lipophilin $\mathrm{B}$ and regarded as to be regulated by progesterone only i.e. secretoglobin $2 \mathrm{~A}$, family member 2 or mammaglobin $\mathrm{A}$.

The findings of the array results could be confirmed with real-time PCR (Table 3.1). However, when screening additional biopsies, only the expression of secretoglobulin 2A, family member 2 and MMP-1 was significantly higher in LATE-P phase endometrium compared with $\mathrm{M}$ phase endometrium. The differences detected with the arrays for PR, cyclin A1, connexin-37, and mucin-9, could not be confirmed in the extra set of tissues. This was due to the fact that in the array hybridisations one sample was expressed higher in LATE-P phase endometrium, and the other not.

In the cultured endometrial explants, however, the response to $17 \beta$-E2 as detected in the array hybridisations, could be confirmed for all selected genes (Table 3.2). In the independent set of experiments six of the seven tested genes 
were responsive to $17 \beta$-E2 (Figure 3.2). Only the secretoglobin family $2 \mathrm{~A}$, member 2 was not responsive to 17B-E2 in the additional set of experiments.

Table 3.1. Validation of microarray data for the uncultured $\mathrm{M}$ and LATE-P phase endometrium tissue. Real-time PCR was performed on the same samples as those used for the array hybridisations (A), as well as on an additional set of $\mathrm{M}$ and LATE-P phase endometrium samples (B). Validation of array data are presented as ratios of LATE-P phase/M, and data on the additional set are presented as

A

\begin{tabular}{lcc}
\hline Gene name & $\begin{array}{c}\text { Array data } \\
\text { (LP / M) phase } \\
\text { (Uncultured) }\end{array}$ & $\begin{array}{c}\text { Real-time PCR } \\
\text { (LP / M) phase } \\
\text { (Uncultured) }\end{array}$ \\
\hline Progesterone receptor & & 3.4 \\
Cyclin A1 & 9.1 & 2.2 \\
Secretoglobin family 1D, member 2 & 3.4 & 2.8 \\
Mucin-9 & 4.9 & 10.3 \\
Matrix metalloproteinase-1 & 36.3 & 0.002 \\
Connexin-37 & 0.01 & 3636 \\
\end{tabular}

relative expression levels $( \pm$ SEM).

Table 3.2. Validation of microarray data for the cultured $\mathrm{M}$ and Late-P phase endometrium explants in the presence or absence of $17 \beta-\mathrm{E} 2$. Values are presented as fold change in the induction by $17 \beta-\mathrm{E} 2( \pm$ SEM) compared to the control.

\begin{tabular}{|c|c|c|c|c|}
\hline Gene name & $\begin{array}{l}\text { Array data } \\
\text { M phase } \\
\text { (cultured) }\end{array}$ & $\begin{array}{c}\text { Real-time PCR } \\
\text { M phase } \\
\text { (cultured) }\end{array}$ & $\begin{array}{l}\text { Array data } \\
\text { LP phase } \\
\text { (cultured) }\end{array}$ & $\begin{array}{c}\text { Real-time PCR } \\
\text { LP phase } \\
\text { (cultured) }\end{array}$ \\
\hline Progesterone receotor & 3.0 & 2.0 & 1.1 & 1.3 \\
\hline Cyclin A1 & 3.5 & 5.9 & 1.1 & 1.6 \\
\hline Secretoglobin family $1 \mathrm{D}$, member 2 & 8.9 & 6.4 & 1.9 & 2.1 \\
\hline Secretoglobin family $2 \mathrm{~A}$, menber 2 & 3.7 & 6.7 & 1.6 & 1.4 \\
\hline Trefoil factor 1 & 7.8 & 50.0 & 1.2 & 5.0 \\
\hline Cyclooxygenase-2 & 3.5 & 6.5 & 1.2 & 1.3 \\
\hline $17 \beta$-HSD Type 2 & 2.5 & 2.0 & 1.4 & 1.3 \\
\hline Connexin-37 & 3.5 & 3.5 & 0.9 & 2.2 \\
\hline Progesterone receptor & \multirow{2}{*}{\multicolumn{2}{|c|}{$\begin{array}{c}0.23 \pm 0.08 \\
0.015 \pm 0.003\end{array}$}} & $0.38 \pm 0.15$ & $p=N S$ \\
\hline Cyclin A1 & & & $0.021 \pm 0.057$ & $\mathrm{p}=\mathrm{NS}$ \\
\hline Secretoglobin family $1 D$, member 2 & \multicolumn{2}{|c|}{$0.111 \pm 0.008$} & $0.725 \pm 0.402$ & $p<0.01$ \\
\hline Mucin-9 & \multicolumn{2}{|c|}{$0.30 \pm 0.20$} & $0.09 \pm 0.04$ & $p=N S$ \\
\hline Matrix metalloproteinase- 1 & \multicolumn{2}{|c|}{$0.6 \hat{0} \pm 0.49$} & $0.0004 \pm 0.0002$ & $p<0.01$ \\
\hline Conาexin-37 & \multicolumn{2}{|c|}{$0.019 \pm 0.0089$} & $0.015=0.0053$ & $\mathrm{p}=\mathrm{NS}$ \\
\hline
\end{tabular}


Figure 3.2. Validation of the micro array findings with quantitative real-time PCR analysis in an independent set of experiments. Endometrium tissue collected from M phase ( , n = 9 or 10) and LATE$\mathrm{P}$ phase $(, \mathrm{n}=8)$ was cultured in the presence of $17 \beta-\mathrm{E} 2$ or vehicle. Values are expressed as foldchanges relative to the vehicle and the average values are presented by a horizontal bar. A: Progesterone receptor, B: Cyclin A1, C: Secretoglobin family 2A, member 2, D: Secretoglobin family 1D, member 2, E: Trefoil factor-1, F: Cyclooxygenase-2, G: Connexin-37
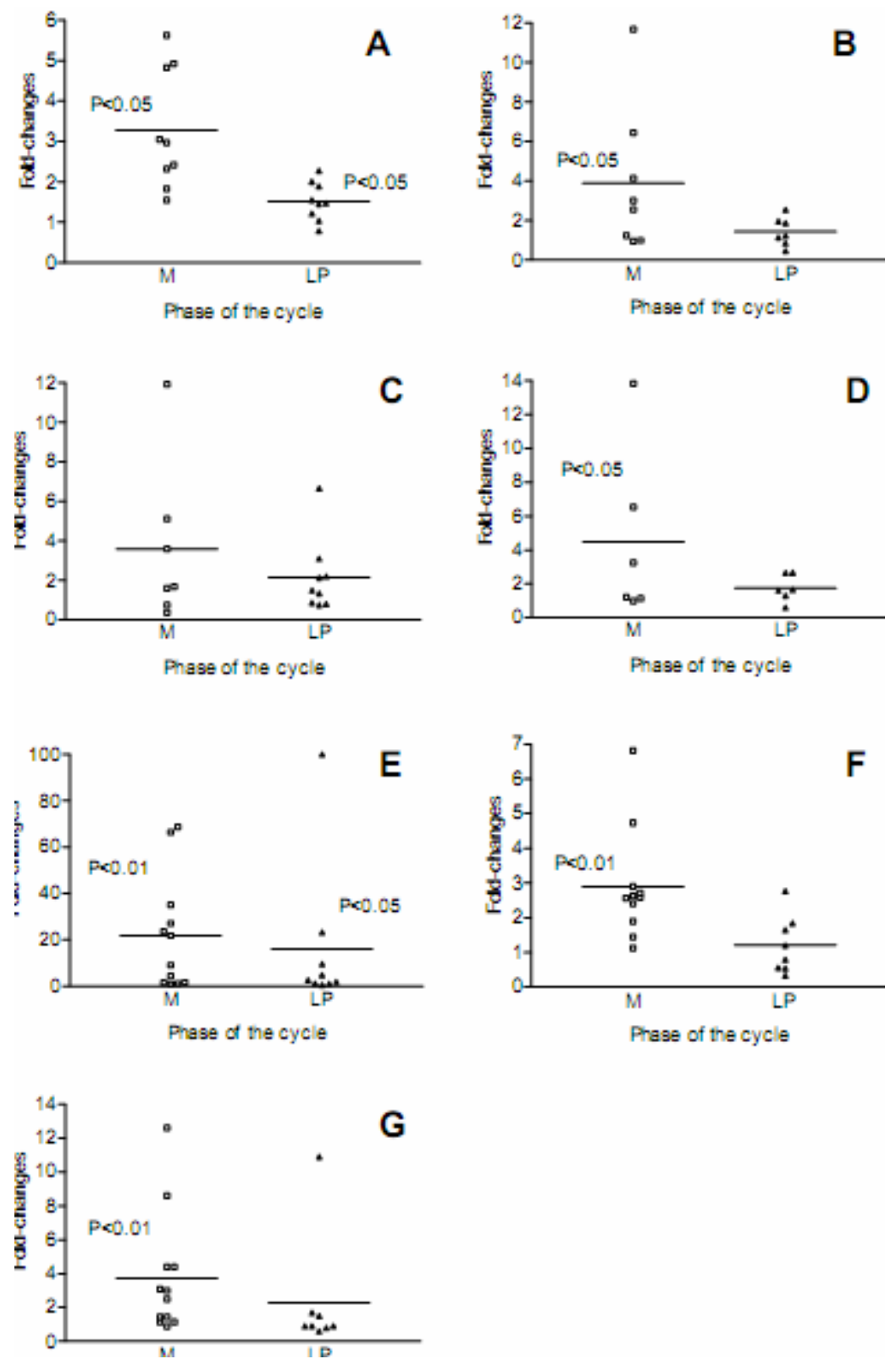


\section{Long-term oestrogen exposure (uncultured)}

Of the 22,000 transcripts present on the HU133A chip, 282 transcripts were found to be up-regulated in LATE-P phase $v$ s. M phase and 512 transcripts were down-regulated in the LATE-P phase $v s$. the M phase endometrium biopsies. In Tables $3.3 \mathrm{~A}$ and $3.3 \mathrm{~B}$ the ten most regulated genes are presented.

\section{Short-term oestrogen exposure (cultured)}

In order to distinguish the genes that are directly regulated by $17 \beta$-E2, from those affected by the in vivo uterine environment, the differential gene expression profiles were determined for endometrium tissue fragments that were incubated with or without $17 \beta-\mathrm{E} 2$ for 24 hours of culture. After incubation of $\mathrm{M}$ phase endometrium explants with 17 $\beta$-E2, 148 transcripts were found to be stimulated and 45 transcripts were inhibited (for the top ten regulated genes see Tables 3.3C and 3.3D). In contrast, in LATE-P phase endometrium cultures, the expression of a lower number of genes was changed, only 12 transcripts were stimulated and four transcripts were inhibited. In Tables $3.3 \mathrm{E}$ and $3.3 \mathrm{~F}$ the most regulated genes are presented.

The expression of six genes was stimulated by $17 \beta-\mathrm{E} 2$ in both $\mathrm{M}$ and LATE-P phase endometrium explants indicating gene transcripts that are directly regulated by oestrogens, whereas the expression of two genes was inhibited by $17 \beta-\mathrm{E} 2$ in both $\mathrm{M}$ and LATE-P phase endometrium explants (Table 3.4). Thirteen genes were stimulated by $17 ß-\mathrm{E} 2$ in cultures of $\mathrm{M}$ phase endometrium ànd upregulated in vivo (LATE-P phase vs. M). Seven genes were inhibited by 17ß-E2 in vitro ànd down-regulated in vivo (LATE-P phase vs. M) (Table 3.5).

In contrast, fifteen genes were stimulated by $17 ß-\mathrm{E} 2$ in cultures of $\mathrm{M}$ phase endometrium and down-regulated in vivo (LATE-P phase vs. M). Three gene transcripts were inhibited by $17 \beta-\mathrm{E} 2$ in vitro and up-regulated in vivo (LATE-P phase vs. M) (Table 3.5, bold font). 


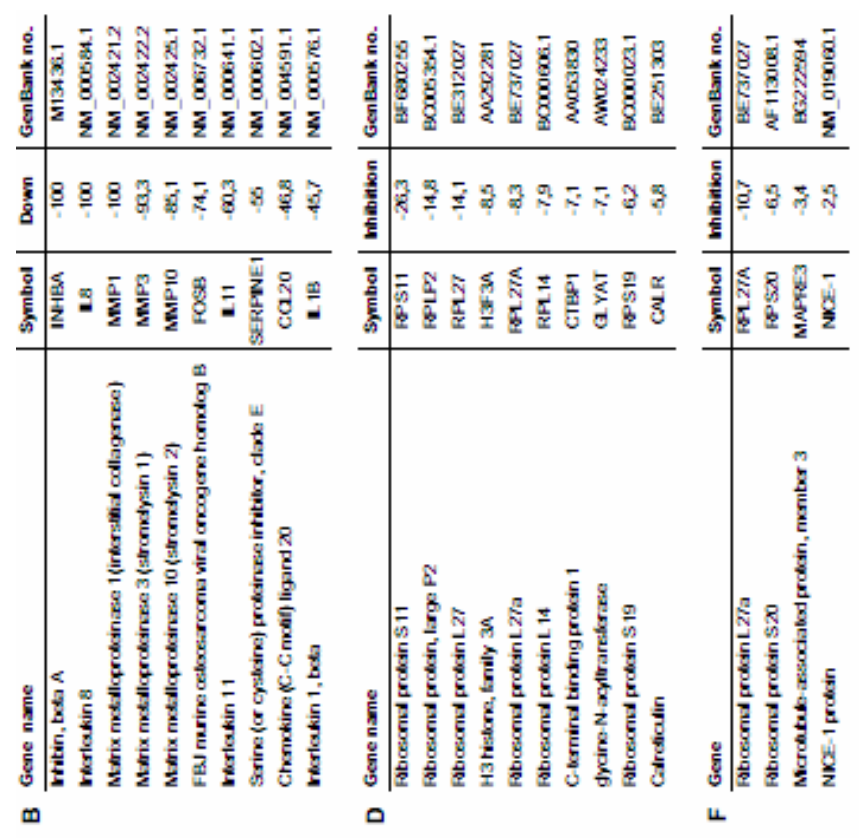

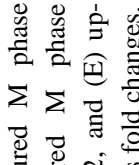

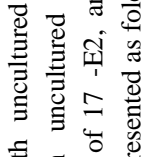
言势

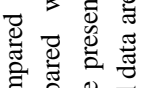

흥 ڤ્च

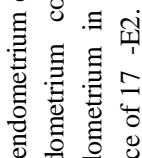

एँ

需密

究云

岁和

总过参

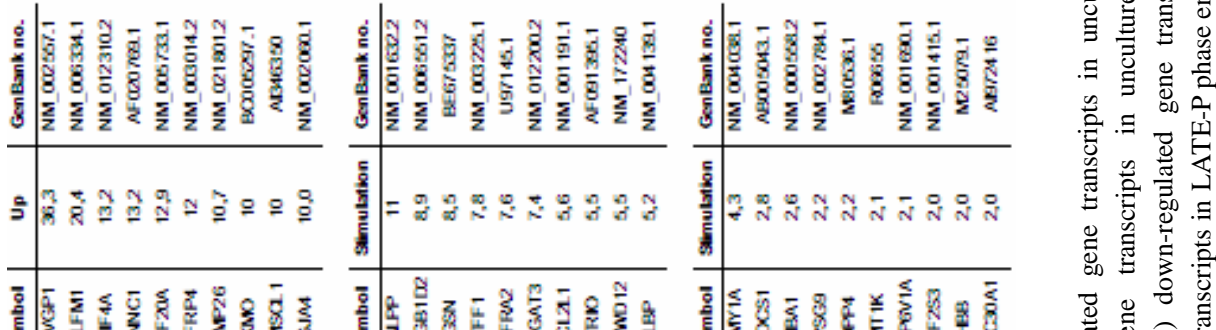

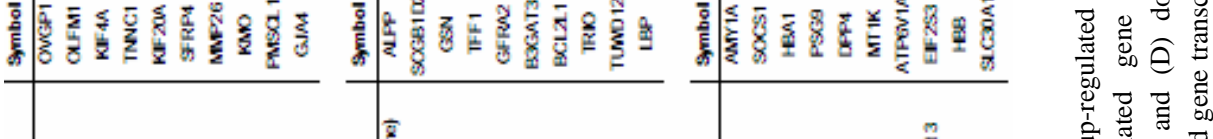

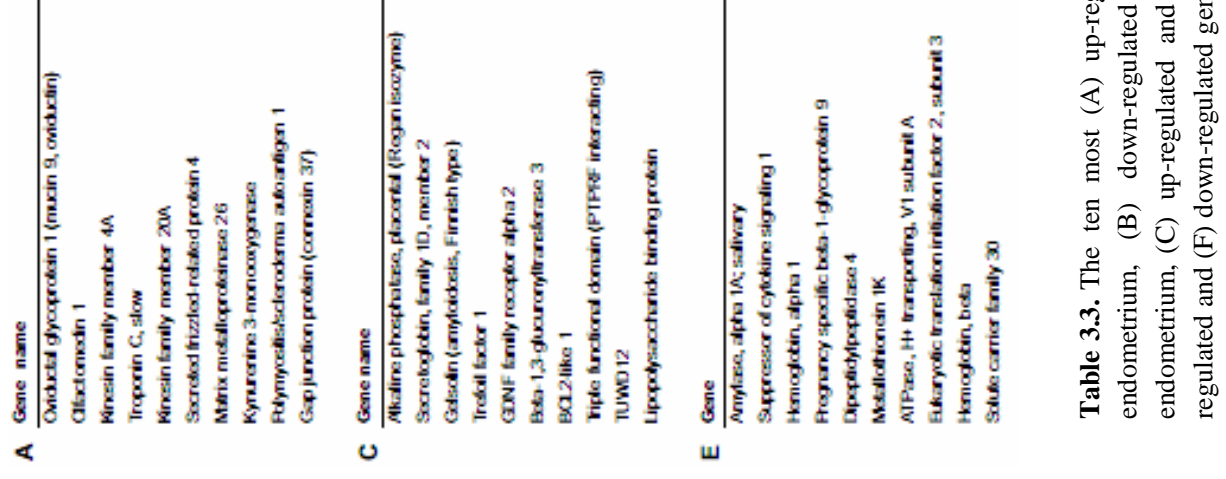


Table 3.4. Gene transcripts that responded similarly to $17 \beta-\mathrm{E} 2$ treatment in explant cultures of both $\mathrm{M}$ and LATE-P phase endometrium tissue. Data are presented as fold changes.

\begin{tabular}{|c|c|c|c|c|}
\hline Gene & Symbol & M phase & LP phase & GenBank no. \\
\hline Fibosomal prctein L27a & R.P_27A & $-6,3$ & $\therefore 0,7$ & BE737027 \\
\hline Ribosomal protein S20 & RPS?0 & $-5,5$ & $-6,5$ & $A=113008.1$ \\
\hline Orosonucoid 1 & ORM' & 2, & 1,7 & NM_200607.1 \\
\hline Secretcglobin, famly $2 A$, rember ${ }^{-}$ & SCGB2A1 & 2,6 & 1,5 & NM_2024C7.1 \\
\hline Ras-related asscclated wlth clabetes & RRAD & 2,6 & 1,8 & NM_-204165.1 \\
\hline Chromosome 14 ope reading frame 137 & C14s+137 & 3,5 & 1,7 & NM_J23112.1 \\
\hline Lipcpolysascาaride onding protein & LEP & 5,2 & 1,6 & NM_204139.1 \\
\hline Secretcglobin, famly $1 \mathrm{D}$, nember 2 & SCGB1D2 & 8,9 & 1,8 & NM_- 006551.2 \\
\hline
\end{tabular}

\section{Discussion}

To enhance our current understanding of the role of oestrogen in the development of the human endometrium during the proliferative phase of the menstrual cycle, gene expression profiles were compared between uncultured menstrual (M) phase and uncultured late proliferative phase (LATE-P phase) endometria, and between $M$ phase and LATE-P phase endometrium tissue explants after short term incubation with 17ß-E2.

This study revealed the expression of a number of novel gene transcripts in the human endometrium (i.e. mucin-9, dipeptidyl peptidase VI). In addition, we found novel genes that were oestrogen responsive (gelsolin, flotillin-1, TUWD12), and genes known to be expressed in human endometrium (TFF1/pS2, connexin-37, placental alkaline phosphatase) but not yet shown to be oestrogen responsive. Based on the observed in vitro responses and in vivo differences in $\mathrm{M}$ and LATE-P phase, it is apparent that some gene transcripts are either regulated directly by $17 ß-\mathrm{E} 2$, or by $17 ß-\mathrm{E} 2$ in concert with the changing uterine environment. Genes reported to be expressed during the implantation window and implicated in progesterone action, i.e. secretoglobin family $2 \mathrm{~A}$, member 2 (mammaglobin) and homeobox containing proteins, were up-regulated in uncultured LATE-P phase endometrium compared with uncultured $\mathrm{M}$ phase endometrium, implicating that these genes may also be regulated by oestrogens. These observations emphasise that the regulation of endometrium maturation by oestrogen entails more then just stimulating cell proliferation and growth.

To study the effects of oestrogens on human endometrium an explant culture system was used. The advantage of using explant cultures over other systems is the fact that no enzymatic manipulations are used, leaving the original structure intact. To find oestrogen responsive genes it was imperative that we selected tissues that had not been exposed to oestrogens produced by the ovaries. Only menstrual endometrium meets this criterion. The findings in this study justify our choices. Even though the menstrual endometrium was sometimes 
partly ischemic, which impairs the tissue structure, we showed that the menstrual phase endometrium was superior with regard to oestrogen responsiveness (the number of differentially expressed transcripts 200 vs 4 transcripts respectively). Also, when repeating the experiments using a selection of genes, most of the $\mathrm{M}$ phase explants responded to $17 ß-E 2$.

Table 3.5. Gene transcripts that were affected by $17 \beta-\mathrm{E} 2$ treatment in $\mathrm{M}$ phase endometrium explants, and that were also increased or decreased in LATE-P phase endometrium when compared to $\mathrm{M}$ phase endometrium. The bold text indicates genes that are oppositely regulated in vitro and in vivo. The expression of these genes is induced by 17ß-E2 in vitro in $\mathrm{M}$ phase endometrium, but reduced in LATE-P phase endometrium when compared to $\mathrm{M}$ phase endometrium, or reduced by 17ß-E2 in vitro in $\mathrm{M}$ phase endometrium, but induced in LATE-P phase endometrium.

\begin{tabular}{|c|c|c|c|c|}
\hline Gene & Symbol & Uncultured & Cultured & GenBank no. \\
\hline Acidic (leucine-rich) nuclear phosphoprotein 32 family, member A & ANP32A & 2,0 & 3,0 & NM_006305.1 \\
\hline Carboxypeptidase M & CPM & 6,3 & 2,5 & NM_001874.1 \\
\hline CD44 antigen (homing function and Indian blood group system) & $\mathrm{CD} 44$ & $-3,2$ & $-2,0$ & AW851559 \\
\hline Cyclin A1 & CCNA1 & 3,4 & 3,5 & NM_003914.1 \\
\hline Dual specificity phosphatase 1 & DUSP1 & $-6,5$ & 2,3 & AÄ530892 \\
\hline Eyes absent homolog 2 (Drosophila) & EYA2 & 4,7 & 3,0 & U71207.1 \\
\hline Fibroblast growth factor 18 & FGF18 & $-6,9$ & $\cdot 2,2$ & BC006245.1 \\
\hline Fibroblast growth factor 9 (glia-activating factor) & FGF9 & $-3,6$ & $-2,1$ & NM_002010.1 \\
\hline Gap junction protein, alpha $4,37 \mathrm{kDa}$ (connexin 37 ) & GJA4 & 10,0 & 3,5 & NM_002060.1 \\
\hline Glycerol kinase & GK & $-5,8$ & 2,1 & Al 830490 \\
\hline GREB1 protein & GREB1 & 2,6 & $-2,1$ & AF245390.1 \\
\hline Histone 1, H2bh & HIST1H2BH & $-2,6$ & 2,1 & NM_003524.1 \\
\hline Insulin-like growth factor binding protein 3 & IGFBP3 & $-4,1$ & $-2,5$ & BF 340228 \\
\hline Inter-alpha trypsin inhibitor heavy chain precursor 5 & ITIH5 & 8,9 & 2,5 & NM_030569.1 \\
\hline Interferon-induced protein with tetratricopeptide repeats 1 & $\mathbf{I F I T} 1$ & $-2,6$ & 2,6 & NM_001548.1 \\
\hline Keratin 7 & KRT7 & $-2,4$ & $.4,5$ & Al920979 \\
\hline Leukocyte specific transcript 1 & LST1 & $-11,2$ & 2,6 & AV713720 \\
\hline Leukocyte-derived arginine aminopeptidase & LRAP & 3,2 & 3,6 & NM_022350.1 \\
\hline Lysyl oxidase-like 2 & LOXL2 & $-6,9$ & 2,4 & BE251211 \\
\hline Major histocompatibility complex, class II, DQ beta 1 & HLA-DQB1 & $-11,5$ & 2,3 & M16276.1 \\
\hline Mitochondrial solute carrier protein & MSCP & $-2,3$ & 2,6 & NM_018586.1 \\
\hline Natriuretic peptide receptor B/guanylate cyclase B & NPR2 & 4,6 & 2,3 & NM_003995.2 \\
\hline Natural cytotoxicity triggering receptor 3 & NCR3 & $-6,6$ & 2,3 & Al735692 \\
\hline PiggyBac transposable element derived 5 & PGBD5 & 2,6 & 2,5 & NM_024554.1 \\
\hline Pituitary tumor-transforming 1 & PTTG1 & 3,9 & $-2,0$ & NM_004219.2 \\
\hline Pituitary tumor-transforming 3 & PTTG3 & 2,7 & $-2,2$ & NM_021000.1 \\
\hline Pleckstrin & PLEK & $-3,9$ & 2,6 & $\mathrm{Al} 433595$ \\
\hline Progesterone receptor & PGR & 9,1 & 3,0 & NM_000926.1 \\
\hline protein (peptidyl-prolyl cis/trans isomerase) NIMA-interacting 1 & PIN1 & 2,0 & 2,2 & NM_006221.1 \\
\hline Prostaglandin-endoperoxide synthase 2 & PTGS2 & $-14,8$ & 3,5 & NM_000963.1 \\
\hline Ras-related associated with diabetes & RRAD & $-4,0$ & 2,6 & NM_004165.1 \\
\hline Ras-related GTP binding D & RRAGD & $.7,6$ & 2,8 & AF272036.1 \\
\hline Ribosomal protein L37a & RPL37A & $-2,6$ & $-8,3$ & BE857772 \\
\hline S100 calcium binding protein A8 (calgranulin A) & S100A8 & $-26,9$ & $\cdot 2,1$ & AW 238654 \\
\hline Secretoglobin, family $1 \mathrm{D}$, member 2 & SCGB1D2 & 4,9 & 8,9 & NM_006551.2 \\
\hline Solute carrier family 15 , member 3 & SLC15A3 & $.5,9$ & 2,3 & NM_016582.1 \\
\hline SRY (sex determining region Y)-box 4 & SOX4 & $-4,5$ & 2,0 & Al989477 \\
\hline TUWD12 & TUWD12 & 2,6 & 5,5 & NM_003774.2 \\
\hline
\end{tabular}


The fact that ER levels in M and LATE-P phase were similar [33] can therefore not explain the difference in responsiveness, indicating that other influences determine the high sensitivity of the menstrual endometrium. If an intact tissue structure was an important determinant in regulating gene expression, LATE-P phase endometrium should be more responsive to oestradiol. However, this appeared not to be the case in this study.

A stringent scoring system was employed when filtering the array data to minimize the occurrence of false positive results, as a limited number of samples were used in the array hybridizations. The validity of this filtering system is confirmed by the finding that a number of genes known to be regulated by oestrogen were also revealed in the comparisons in this study (PR [157], TFF1/pS2 [158] and secreted frizzled-related protein 1 [159]). In addition, the responses found for the selected genes in the array comparisons, were verified using quantitative real-time PCR as an independent technique. It was apparent that the stringent scoring system could not account for all biological variation. In the additional uncultured endometrial tissues the expression of not all selected genes corroborated with the array findings, which shows that the use of limited numbers of samples in the array hybridisations requires more elaborate validation. However, in the cultured biopsies, the findings in the independent experiments corroborated much better. Six of the seven tested genes also responded in the additional series of experiments. Apparently, the culture conditions alleviate some of the biological variability between biopsies.

Of the 794 transcripts differentially regulated when comparing uncultured endometrium tissue obtained from LATE-P phase and $\mathrm{M}$ phase uncultured endometrium tissue, the majority was down-regulated (64\%) in LATE-P phase endometrium tissue. This may be due to the multiple processes that are ongoing during menstruation i.e. tissue degeneration, inflammation, hypoxia, epithelial repair and angiogenesis. As expected, many inflammatory cytokines, enzymes involved in eicosanoid biosynthesis, and immunomodulators and their receptors, as well as various angiogenic modulators were highly expressed in $M$ phase endometrium compared to LATE-P phase endometrium. In addition, the destruction of the vasculature during menstruation creates a hypoxic environment which is illustrated by the elevated expression of hypoxia-induced proteins in $M$ phase endometrium i.e. heme oxygenase-1 [ 1600 , adrenomedullin [ 1616 ], carbonic anhydrase II [ 1162 ], VEGF and hypoxia-inducible protein-2 [163].

The breakdown of the endometrium prior to and during menstruation involves matrix metalloproteinases (MMPs) [164]. In this study a number of MMPs were found to be expressed significantly higher in $\mathrm{M}$ phase endometrium as compared to LATE-P phase endometrium. In contrast, MMP-26 (endometase) expression was higher in LATE-P phase endometrium tissue as compared to $\mathrm{M}$ phase endometrium. Endometase is an epithelial MMP, and is highly expressed around the period of implantation $[165,166]$. This suggests that MMP-26 may not be involved in the endometrial breakdown process, but in endometrial remodelling prior to and during trophoblast invasion. 
The wound healing process after menstruation begins with the reepithelialization of the uterine surface [167]. This process is complete on day 5 or 6 of the menstrual cycle. In the absence of oestrogen (i.e. after ovariectomy), the endometrium has the capacity to end endometrial bleeding and to begin the healing process, indicating that other factors are involved. Factors that have been implicated in epithelial cell repair are the trefoil peptides. Three trefoil peptides, TFF1/pS2, TFF2/SP and TFF3/ITF were found to be stimulated by $17 ß-\mathrm{E} 2$ in $\mathrm{M}$ phase endometrium. The trefoil family of peptides consists of mucin-associated peptides found predominantly in mucus secreting cells of the gastrointestinal mucosa [168] and have been implicated in the regeneration of the mucosal surface after damage [ 169 ]. It is possible that the trefoil factors play a similar role in the regeneration of the endometrium.

Oestrogen responsiveness was also demonstrated for three members of the uteroglobin family: secretoglobin 1D2 (lipophilin B), secretoglobin 2A1 (mammoglobin B) and secretoglobin 2A2 (mammoglobin). Mammaglobins were first identified in glandular epithelium of the breast [170], and were later also described in human endometrium [171]. This study shows that this family of genes is regulated by oestrogen. Mammaglobin B forms covalent heteroduplexes with the lipophilin B [172] and this complex was found to be the biologically relevant form of mammaglobin. No detailed information is available with regard to the functions of lipophilin $\mathrm{B}$ and the mammaglobins. However, uteroglobin or lipophilin A was shown to inhibit tumour [173] and trophoblast invasion [173], to inhibit tumour angiogenesis and transform normal tissue into a neoplastic phenotype [173]. In other words, the secretoglobins may transform the proliferating cells into a differentiated state. Furthermore, roles as immunoregulators and anti-inflammatory proteins have also been suggested [174].

Analogous to the reduced expression of the majority of genes in LATE-P phase endometrium compared to $\mathrm{M}$ phase endometrium, the responsiveness of LATE-P phase endometrium to $173-\mathrm{E} 2$ in vitro was also much lower compared to that of $\mathrm{M}$ phase endometrium (16 vs. 193 genes). The reduced responsiveness of the LATE-P phase endometrium is in line with the supposition that prolonged exposure to oestrogen desensitizes the endometrium $[175,176]$. It is tempting to suggest that this may be an intrinsic mechanism that maintains the endometrium in a proper state of differentiation. This is further supported by the findings of Younis et al and others who demonstrated that oestrogen exposure for less than six days is not sufficient to support successful implantation, whereas after prolonged exposure to oestrogen, ( 35 days) the endometrium is still responsive to progesterone and is receptive $[9,18,177]$.

Two groups of genes that were shown to be involved in the morphogenesis of the urogenital tract and adult uteri and that were shown to be differentially expressed in uncultured LATE-P phase endometrium tissue when compared to uncultured $\mathrm{M}$ phase endometrium tissue, are mediators of Wnt signalling and the homeobox containing genes. Expression of Wnt5a and Wnt7a genes was lower in LATE-P phase endometrium, whereas the expression of secreted frizzled-related proteins 1 and 4 (sFRP) and Wnt inhibitory factor-1 (WIF- 
1), which are known Wnt antagonists [178], was significantly higher in LATE-P phase endometrium. The homeobox-containing proteins Hoxa10, Hoxa11 and Hoxb7 were all increased in LATE-P phase compared to M phase endometria.

The Wnt5a is predominantly expressed in stroma, whereas Wnt7a is mostly expressed in luminal epithelium $[179,180]$ and play crucial roles in uterine gland development in the mouse. As these genes are also expressed in a similar manner in human endometrium [181], it is likely that Wnt5a and Wnt7a are also involved in gland development in the human endometrium. Carta and Sassoon [182] demonstrated that exposure to diethylstilbestrol (DES), an oestrogen agonist, reduces Wnt7a expression in the murine uterus, and this response is dependent on the presence of Wnt5a [180]. The expression of Hoxa10 and Hoxa11 genes is down-regulated by DES in normal mice [183], but not in Wnt5a and Wnt7a -/mice $[180,182]$. It is tempting to suggest that low oestrogen levels during the menstrual period may allow expression of Wnt5a and Wnt7a, which initiate gland development and that increasing levels of circulating oestrogens suppress the expression of Wnt5a and Wnt7a to allow expression of Hoxa10 and Hoxa11, which complete the gland development and differentiation process. However, it has to be kept in mind that even though DES is a potent oestrogen agonist, its effects are not always similar to that of oestradiol $[183,184]$. These findings do illustrate, however, the importance of concerted actions between the stroma (Wnt5a) and epithelium (Wnt7a) in the regulation of endometrial development.

Surprisingly, we also observed up-regulation of several inhibitors of Wnt signalling, sFRP1, sFRP4 and WIF-1 in LATE-P phase endometrium. Their significance is not known, however, they may protect the silencing of Wnt signalling to allow the expression of Hoxa10 and Hoxa11 promoting endometrium differentiation. Recently, evidence was provided that sFRP1 is also directly involved in vascular remodelling and maturation. sFRP1 expression was highest in vascular endothelium [185], expression could be stimulated by oestrogens [159], and sFRP1 induces larger, longer vessels and is apparently associated with more pericytes compared with vessels formed under control conditions [186]. sFRP4 expression is particularly high in proliferating stroma [187] and may be a paracrine factor involved in the stimulation of endometrial growth. The gene coding for the homeobox-containing protein Hoxb7, also shown to be an inducer of vascular development [188], was up-regulated in LATE-P phase compared to $\mathrm{M}$ phase endometria as well. The elevated expression in LATE-P phase endometrium suggests a role for Hoxb7 in the vascular development under normoxic conditions.

With regard to the differentiative actions of oestrogen in the human endometrium it is interesting to note that the expression of connexin-37 is upregulated by $17 \beta-\mathrm{E} 2$ in $\mathrm{M}$ phase endometrial explants. Connexin-37 is a gap junction protein expressed in endometrium, predominantly in endothelial cells [189]. In connexin-37 knockout mice early vasculogenesis proceeds normally, but by the age of 18.5 days animals display abnormal vascular channels with localized hemorrhages in various organs $[190,191]$. As a result of these developmental defects, the mice lack mature Graaffian follicles, fail to ovulate and 
develop numerous inappropriate corpora lutea [192]. Therefore, it is likely that connexin-37 plays a role in the oestrogen-dependent regeneration of the vasculature after menstruation, and is thus involved in the development of the endometrium.

In summary, we have shown that the role of $17 ß-\mathrm{E} 2$ in the repair and development of the endometrium during the proliferative phase of the menstrual cycle is certainly not limited to just the regulation of proliferation. This is illustrated by the differential expression of genes involved in processes such as blood vessel growth and maturation, and morphogenesis of the endometrium in the late proliferative phase. Some genes are regulated directly by $173-E 2$, whereas the expression of others is modulated by the changing uterine environment. This study emphasizes the importance of oestrogen with regard to endometrium maturation and differentiation.

\section{Acknowledgements}

The authors thank A Nap and K van Kaam for collecting endometrium biopsies. 


\section{Chapter 4}

\section{Olfactomedin- 4 regulation by estrogen in the human endometrium requires epidermal growth factor signalling}

H Dassen ${ }^{1,2}$, C Punyadeera ${ }^{1,2, \S,}$, B Delvoux ${ }^{1,3, \#}$, I Schulkens ${ }^{1,3}$, C Marchetti ${ }^{1,3}, \mathrm{R}$ Kamps $^{1,2}$, J Klomp ${ }^{4}$, F Dijcks ${ }^{4}$, A de Goeij ${ }^{1,2}$, TM D'Hooghe ${ }^{5}$, CM Kyama ${ }^{5}$, A Ederveen $^{4}$, G Dunselman ${ }^{1,3}$, P Groothuis $^{1,3, \S \S}$ and A Romano ${ }^{1,3}$.

${ }^{1}$ GROW - School for Oncology and Developmental Biology, Departments of ${ }^{2}$ Pathology and ${ }^{3}$ Obstetrics and Gynaecology, Maastricht University and Medical Centre, The Netherlands ${ }^{4}$ Women's Health Department, Schering-Plough Corp., Oss, The Netherlands, ${ }^{5}$ Department of Obstetrics and Gynaecology, University Hospital Gasthuisberg Leuven, Belgium.

\# These authors contributed equally to the study

Published in: Am J Pathol. 2010 Nov;177(5):2495-508

\footnotetext{
$\S$ Current address: Tissue Engineering and Microfluidics Laboratory, Australian Institute for Bioengineering and Nanotechnology, The University of Queensland, Queensland, Australia $\S \S$ Current address: Women's Health Department, Schering-Plough Corp., Oss, The Netherlands
} 


\section{Abstract}

Olfactomedin-4 (OLFM-4) is an extracellular matrix protein highly expressed in the human endometrium. Nevertheless, the endometrial functions of OLFM-4 are unknown. Here, we examined the regulation, the cellular function and the expression of OLFM-4 in normal endometrium, endometriosis and endometrial cancer.

In healthy endometrium, OLFM-4 expression is highest during the menstrual late proliferative phase, and $17 \beta$-estradiol up-regulates OLFM-4 mRNA in endometrial explant cultures. OLFM-4 regulation was further examined using the luciferase reporter under OLFM-4 promoter control. Both $17 \beta$-estradiol and $\mathrm{OH}-$ tamoxifen induce luciferase activity and epidermal growth factor receptor-1 (EGFR1) is required for this oestrogenic response. In turn, EGF also activates the OLFM-4 promoter and oestrogen receptor- $\alpha(E R-\alpha)$ is needed for the complete EGF response.

The cellular functions of OLFM-4 were examined by re-expressing it (transient transfection) in OLFM-4-negative cells (HEK293). OLFM-4 decreased vimentin expression and cell adherence and increased apoptosis resistance.

In endometriosis and endometrial cancer, OLFM-4 expression correlates with the presence of EGFR1 and ER- $\alpha$ (or oestrogen signalling). A slight increase of OLFM-4 mRNA was observed in endometriosis patients, whereas no association was found in endometrial cancer.

In conclusion, oestrogen and EGF signalling crosstalk to fully regulate OLFM-4 expression. Together, the effects on vimentin, cell adherence and apoptosis and the expression at the late proliferative phase suggest a possible role in tissue remodelling prior to the secretory phase.

\section{Introduction}

We have recently performed a gene expression profiling study to identify genes regulated by $17 \beta$-oestradiol during endometrial growth and differentiation: global gene expression in the menstrual phase endometrium ([cycle days (CD) 1-5] when the concentration of circulating $17 \beta$-oestradiol is low) was compared to that during late proliferative phase ([CD 11-14] highest 17 $\beta$-oestradiol level). Olfactomedin-4 (OLFM-4) gene was highly expressed in late proliferative phase compared to menstrual phase endometrium indicating a possible oestrogen sensitivity. Subsequently, the oestrogen responsiveness of OLFM-4 was confirmed 
by examining global gene expression after in vitro exposure of human endometrial explants to $17 \beta$-oestradiol or vehicle ( 24 hours). Results of these microarray studies are partly published [1].

The OLFM-4 gene, also called human granulocyte colony stimulating clone-1 (hGC-1) or GW112, is located on chromosome 13q21.1 and encodes for the 510 amino acid-long (55 kDa) extracellular matrix protein olfactomedin-4 (OLFM4) [193, 194]. NCBI databases [195] revealed that OLFM-4 is expressed in human bone marrow, prostate, breast, pancreas, stomach and colon [193, 195]. Moreover, this protein is over-expressed in gastrointestinal cancers [195-201], in inflamed colonic mucosa [202] and in gastric biopsies from patients infected with Helicobacter pylori [203]. Transcript levels of OLFM-4 are also higher in breast tumours compared to normal breast [195, 204].

Several authors have investigated the cellular functions of OLFM-4, but results do not always agree. Zhang and co-workers [195] over-expressed OLFM-4 cDNA in HEK-293 cells and described an anti-apoptotic action of this protein. In another study on pancreatic cancer cells, down-regulation of OLFM-4 by siRNA resulted in impaired S-phase transition and inhibition of proliferation but no effect on apoptosis was observed [205]. Liu and co-workers used HEK-293 and NIH3T3 cells and showed that OLFM-4 directly binds to lectins and E-cadherin and results in increased cell-cell interaction [194]. The same authors in a separate study using myeloma cells, showed that OLFM-4 represses both motility and cell adherence [200]. Therefore, this protein seems to play important roles in cell-cycle control, cell adherence and motility, cell-cell interaction and tissue architecture but probably its role may depend on the tissue type.

Because of the important role in multiple cellular functions and because of its strong association with oestrogen exposure in human endometrium, we further investigated the regulation and the role of OLFM-4 in this tissue. We examined its expression throughout the menstrual cycle. In addition, we investigated the regulation of the OLFM-4 promoter using a luciferase reporter system. These experiments showed that the OLFM- 4 promoter is responsive to both $17 \beta$-oestradiol and $\mathrm{OH}$-tamoxifen, but this regulation depends on the cross-talk with the epidermal growth factor receptor-1 (EGFR1). In OLFM-4 negative cells, its re-expression decreased vimentin level and cell adherence and increased resistance to apoptosis. OLFM-4 expression was also observed in clinical samples of endometriosis and endometrial cancer patients and correlated with the presence of oestrogen receptor- $\alpha$ $(\mathrm{ER}-\alpha)$ and EGFR1. 


\section{Material and methods}

\section{Human endometrial tissue}

Normal cycling and post menopausal endometrial samples. Endometrial tissues were collected from healthy volunteers $(n=48)$ of $26-52$ years of age with regular menstrual cycles. Twelve samples were collected during the menstrual phase (cycle day -CD- 1-5); 18 during the proliferative phase, subdivided into early (CD 6$10, n=9)$ and late (CD 11-14, n=9); 18 samples were collected in the secretory phase: early secretory phase (CD 15-19, $n=8)$, mid-secretory phase (CD 20-24, $n=8$ ) and from the late secretory phase $(\mathrm{CD} 25-28, \mathrm{n}=2)$. The endometrial tissues were dated based on the start of the last menstrual period and confirmed by histological examination of the tissue by a pathologist as previously described [151]. All women were documented not to be pregnant.

Additional endometrial samples were obtained from 13 post-menopausal women. Pre- and post-menopausal tissue was collected from hysterectomy specimens or by pipelle biopsies during laparoscopy (Pipelle catheter, Unimar Inc., Prodimed, Neuilly-Enthelle, France) in women who underwent surgery for benign indications other than endometriosis. After macroscopic inspection for abnormalities by a pathologist, the tissue was transported to the laboratory. Portions of each sample were fixed in $10 \%$ buffered formalin for histological examinations, frozen in liquid nitrogen for DNA, RNA and protein isolation and frozen by immersion in isopentane $\left(-80{ }^{\circ} \mathrm{C}\right)$ for cryosectioning and microscopy. Tissue from the menstrual and proliferative phase endometrium was also used for the preparation of explant cultures (see below).

Endometriosis samples. An independent group of biopsies was used for the endometriosis study and consisted of eutopic and ectopic endometrial tissues from endometriosis patients and eutopic tissues from controls. Biopsies were collected at the University Hospital Gasthuisberg Leuven, Belgium, and clinicopathological characteristics of these patients and controls have previously been described [206]. In brief, controls consisted of 20 normal endometrial tissues from women with regular menstrual cycles undergoing surgery for benign indications and found free of endometriosis at laparoscopy/laparotomy. Samples of eutopic and ectopic endometrial tissue from endometriosis patients were collected from 14 women. Patients had moderate to severe disease, classified according to the revised system of the American Society for Reproductive Medicine [207]. All samples were collected during the proliferative phase of the menstrual cycle as determined by the start of the last menstrual period and confirmed by histological examination by a pathologist [151].

Endometrial cancers and controls. An additional group of biopsies was used for the endometrial cancer study. Endometrial tumours were primary and type I. Cancer samples ( $n=9$ age at diagnosis ranges between 50-81; mean age: 64 . Additional clinical features are in Table 4.1) and post-menopausal endometrial control tissues with no malignancy $(n=14$; age range: 50-80; mean age: 65$)$ were collected from women undergoing hysterectomy at the Maastricht University 
Medical Centre. Tissues were fixed in formalin for immunohistochemistry and immediately frozen in liquid nitrogen for RNA/DNA/protein isolation. A pathologist confirmed the presence of endometrial cancer in all specimens and the grade and stage of the disease (FIGO criteria 2009 [208]).

Table 4.1. Clinical features of endometrial cancer (according to FIGO criteria 2009 [208]). * indicates that the precise age at diagnosis was not recorded but it was documented to be after menopause.

\begin{tabular}{|c|c|c|c|c|}
\hline & SPECIMEN & $\begin{array}{c}\text { AGE AT } \\
\text { DIAGNOSIS }\end{array}$ & STAGE & GRADE \\
\hline \multirow{9}{*}{ 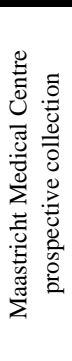 } & 1 & 50 & II & 3 \\
\hline & 2 & 58 & IA & 2 \\
\hline & 3 & 61 & IB & 2 \\
\hline & 4 & 62 & $\mathrm{IB}$ & 2 \\
\hline & 5 & 62 & IB & 2 \\
\hline & 6 & 67 & IB & 1 \\
\hline & 7 & 70 & IA & 1 \\
\hline & 8 & 76 & IVB & 1 \\
\hline & 9 & 81 & IA & 1 \\
\hline \multirow{21}{*}{ 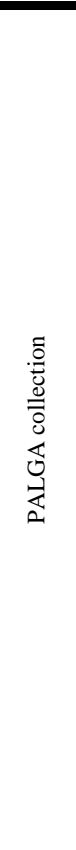 } & 1 & 54 & $\mathrm{IA}$ & 1 \\
\hline & 2 & 59 & IA & 2 \\
\hline & 3 & 60 & III & 3 \\
\hline & 4 & 62 & IB & 3 \\
\hline & 5 & 68 & IA & 2 \\
\hline & 6 & 68 & IA & 1 \\
\hline & 7 & 68 & IA & 1 \\
\hline & 8 & 69 & IB & 2 \\
\hline & 9 & 71 & IA & 2 \\
\hline & 10 & 78 & II & 3 \\
\hline & 11 & 79 & IB & 2 \\
\hline & 12 & 90 & IB & 2 \\
\hline & 13 & $\mathrm{PM}^{*}$ & IA & 2 \\
\hline & 14 & $\mathrm{PM}^{*}$ & IB & 1 \\
\hline & 15 & $\mathrm{PM}^{*}$ & IA & 3 \\
\hline & 16 & $\mathrm{PM}^{*}$ & IB & 1 \\
\hline & 17 & $\mathrm{PM}^{*}$ & IA & 2 \\
\hline & 18 & $\mathrm{PM}^{*}$ & IB & 3 \\
\hline & 19 & $\mathrm{PM}^{*}$ & IA & 1 \\
\hline & 20 & $\mathrm{PM}^{*}$ & IB & 1 \\
\hline & 21 & $\mathrm{PM}^{*}$ & IB & 1 \\
\hline
\end{tabular}

An additional group of endometrial cancers was used for immunohistochemistry analysis only and consisted of archival material selected from the Dutch national pathology database (PALGA) and described in an earlier study [209]. For the present investigation, 21 type I endometrial cancer biopsies were used. Clinical features according to FIGO criteria 2009 [208] are shown in 
Table 4.1. All specimens used in the present study originated from primary tumours. Nine patients developed recurrent disease.

All women prospectively enrolled in the present study did not receive steroid medications during the six months prior to tissue collection. All women agreed to participate in the study by signing an informed consent, according to a protocol approved by the local Medical Ethical Committee.

\section{Steroid hormones and chemicals}

OH-tamoxifen and 17 $\beta$-oestradiol were purchased from Sigma-Aldrich Chemie BV (Zwijndrecht, The Netherlands). ICI-164384 was a gift from ScheringPlough (Oss, The Netherlands). Human recombinant EGF was purchased from R\&D Systems (Minneapolis, USA). The EGFR1 and ERBB2 inhibitor GW2974 was purchased from Sigma-Aldrich Chemie B.V. (Zwijndrecht, The Netherlands). The inhibitors SB20190 (p38 MAPK), PD98059 (ERK1), U-0126 (MEK1/2) and Ly294002 (PI3K) were purchased from Calbiochem, La Jolla, CA, USA.

\section{Explant cultures}

Tissues from the menstrual and proliferative phase endometrium used for explant cultures were collected and transported to the laboratory in DMEM/Ham's F12 medium (Life Technologies, Grand Island, NY) on ice. Explant cultures were prepared as described by Punyadeera and co-workers [33].

\section{Cell culture}

Human endometrial cancer cell line ECC1, embryonic kidney cell line HEK-293, breast cancer cell line T47D and cervical cancer cell line HeLa were purchased from the American Type Culture Collection (ATCC; Rockville, Md. USA) and used for in vitro experiments. Cell maintenance, transfection, luciferase assay and other in vitro procedures have been described previously [210, 211].

\section{Plasmids}

The expression plasmid for the ER- $\alpha$ was a gift from Prof. R. Schüle (Freiburg University, Germany) and has been described elsewhere [212]. Expression plasmids for the EGFR1 and the EGFR-dominant negative variant (CD-533) were gifts from Dr. J. Theys (Maastricht University) and are described elsewhere [213, 214]. 
Luciferase reporter plasmids driven by OLFM-4 promoter. Nucleotide numbering refers to the study by Chin et al. [215]. The $1.3 \mathrm{~Kb}$ fragment at 5' of OLFM-4 was cloned by PCR (Taq DNA polymerase; Fermentas GMBH, St LeonRot, Germany) as follows: two PCR fragments corresponding to the nucleotides 1357/-606 (primers OLM-1/OLM-2; Table 4.2) and -816/+24 (primers OLM3/OLM-4; Table 4.2) were amplified, cloned into vector pGEM-T-easy (Promega, Madison, USA) and re-assembled after digestion with restriction enzyme BglII (779). The complete $1.3 \mathrm{~Kb}$ promoter or the $0.8 \mathrm{~Kb}$ promoter proximal to the start site of transcription (fragment generated with primers OLM-3/OLM-4) was cloned in pGL3 basic vector (Promega, Madison, USA). To delete the AP1 site, the $137 \mathrm{bp}$ EcoRV/NcoI fragment (nucleotides -56/-192) from the $1.3 \mathrm{~Kb}$ promoter vector (EcoRV lies $46 \mathrm{bp}$ at the 5' of the AP1 site) was substituted with the $47 \mathrm{bp}$ EcoRV/NcoI fragment corresponding to nucleotides -56/-102, located at the 3' of the AP1 site and therefore missing the AP1 site. This fragment was generated by PCR (primers OLM-5/OLM-6; Table 4.2) and the EcoRV site was included by primer extension at the 3 ' of the fragment (primer OLM-5).

Olfactomedin-4 expression plasmids. OLFM-4 cDNA was amplified by PCR (Taq DNA polymerase; Fermentas GMBH, St Leon-Rot, Germany) as two fragments (nucleotides -12/+648 with primer pairs OLM-7/OLM-8 and nucleotides +558/+1546 with OLM-9/OLM-10; numbering from accession NCBI NM_006418: $+1=$ translation start site; stop codon: 1531 ; primers are listed in Table 4.2). PCR fragments were cloned in pGEM-T-easy (Promega, Madison, USA) and the complete cDNA was recomposed using HindIII restriction site (nucleotide +597). Restriction sites EcoRI (-9) and XhoI (+1538) were included by primer extension at the 5' and 3' respectively of the cDNA, and used to clone the complete cDNA in pCDNA3.1 (Invitrogen, Breda, The Netherlands). Given that two EcoRI sites (-9 and +84 ) are present in the 5' part of the cDNA, partial digestion was performed. To introduce the PY tag sequence, the BamHI restriction site was introduced at the 3' of the OLFM-4 cDNA before the stop codon (nucleotide +1531) using primer OLM-11 in combination with primer OLM-9 (Table 4.2). The BamHI was used to clone the PY sequence generated by oligo PY (Table 4.2). All plasmids were checked by sequencing.

\section{Total RNA extraction and cDNA synthesis}

Total RNA was extracted from explants cultures and endometrial tissues using the SV total RNA isolation kit (Promega, Madison, USA) according to the manufacturer's protocol. RNA from the cell lines was isolated using the Trizol reagent (Invitrogen, Life Technologies, Inc., Carlsbad, CA) as recommended by the manufacturer. Complementary DNA (cDNA) was synthesised using the M-MLV reverse transcriptase (Invitrogen, Life Technologies, Inc., Carlsbad, CA) as described earlier [210, 211]. 
Table 4.2. Primers used for cloning.

\begin{tabular}{|c|c|c|}
\hline name & sequence & \\
\hline & CLONING & Cloned fragments* \\
\hline OLM-1 & 5' GACAAGCTTACTCTGTCACCCATGCTGCAGTG 3' & $-1357 /--606$ \\
\hline OLM-2 & 5' GAGAAAACACCCAAATAAACAAAG 3' & \\
\hline OLM-3 & 5' TGCATCTTATTTCTCAGTTTTATG 3' & $-816 / 24$ \\
\hline OLM-4 & 5' TGTTTTTGGCGTCTTCCATCTTGTCCTCTTAGCTGGAGC 3' & \\
\hline OLM-5 & 5' GGTGTTCTAGATATCGCAGTTCACAGTTCCCTGGC 3' & AP1 site deletion \\
\hline OLM-6 & 5' GTGATTTCCCCATGGCCAGCAT 3' & \\
\hline OLM-7 & 5' AAGAATTCCACCATGAGGCCCGGCCTCTCATTTCT 3' & CDNA 5' \\
\hline OLM-8 & 5' GATTTCTCGGCGAATGGCAAGG 3' & \\
\hline OLM-9 & 5' GCTGGAGGTGGAGATAAGAAATATG 3' & CDNA 3' \\
\hline OLM-10 & 5' CTCCTCGAGACATTTACTGGGGCTTCTGCAAGACAG 3' & \\
\hline OLM-11 & 5' CTAAACAGGATCCCTGGGGCTTCTGCAAGACAG 3' & cDNA 3' TAA-less \\
\hline$\overline{P Y}$ & $\begin{array}{l}\text { 5'CAGGGATCCATGGAATATATGCCAATGGAAATGGAATATATGCCAATGGAACA } \\
\text { TATATGA 3' }\end{array}$ & PY-tag \\
\hline & REAL TIME PCR & \\
\hline EGFR1 & 5' GGGCTCTGGAGGAAAAGAAA 3' & EGFR1 expression \\
\hline EGFR2 & 5' AAATTCCCAAGGACCACCTCA 3' & \\
\hline
\end{tabular}

\section{Real-time PCR}

Primers and probes for OLFM-4 (GW112: Hs00197437-m1) were purchased from Perkin-Elmer Applied Biosystems as a pre-developed assay. EGFR1 was amplified using the Syber-green ABGene system (ABGene Limited, Epsom, United Kingdom), as recommended by the manufacturer. Primers EGFR1/EGFR2 (Table 4.2) purchased from MWG-Biotech AG (Ebersberg, Germany) were used. Primers for TFF1, and for the house-keeping genes $\beta$-actin and cyclophilin, have previously been published [210]. All real time-PCRs were performed using the BioRad MyIQ apparatus. Fold changes in the gene expression were assessed by comparing the ct values between the gene of interest and two house-keeping genes ( $\beta$-actin and cyclophilin).

\section{Additional molecular biology and biochemistry}

All molecular biology techniques were performed using standard protocols and have previously been described [210, 211]. For western blots of OLFM-4, primary rabbit polyclonal antibody (1:500, IMG-5983, Imgenex, California, USA) was used; EGFR1 was visualised with rabbit polyclonal antibody AB-6 (1:100; Oncogene, San Diego, USA); ERBB2 and ER- $\alpha$ were visualised with mouse monoclonal antibodies CB11 (1:250; GenWay Biotech, Inc. San Diego, USA) and rabbit polyclonal HC20 (1:1000; Santa Cruz Biotechnologies, Heidelberg, Germany), respectively. Rabbit polyclonal antibodies against Akt, phospho-Akt (Ser473), phospho-p42/44 (Thr202/Tyr204) and phospho-p38 MAPK (Thr180/Tyr182) were purchased from Cell Signalling Technology Inc. (Danvers, MA, USA) and used according to the manufacturer's recommendations. As loading 
control, mouse monoclonal $\beta$-actin antibody AC-15 (Sigma-Aldrich Chemie B.V., Zwijndrecht, The Netherlands) was used.

\section{Proliferation, apoptosis and adherence assay}

Cell viability was assessed with the MTT assay (3-[4,5-dimethylthiazol-2yl]-2,5-diphenyltetrazolium bromide; Sigma-Aldrich Chemie B.V., Zwijndrecht, The Netherlands) as described earlier [211]. The cell cycle was analysed using flow cytometry after propidium-iodide staining as previously described [211] with aid of the computer programs WinMDI 2.9 and Cylchred. Cell apoptosis was also measured by flow cytometry after labelling the apoptotic cells with the M30 antibody (Roche Diagnostics Nederland BV, Almere, The Netherlands) as previously described [216].

Cell adherence was assessed by plating equal numbers of cells in a 24 wellplate and allowing cells to attach to the surface for different periods of time (as indicated). Wells were rinsed with PBS and the number of viable adhering cells was assessed with the MTT assay.

\section{Immunohistochemistry, fluorescence and confocal laser microscopy}

Paraffin sections were stained using standard protocols. Sections were dewaxed and endogenous peroxidases were blocked. Pepsin was used as antigen retrieval method for OLFM-4 and EGFR1, whereas Tris-EDTA buffer was used to retrieve the antigen for staining with ER- $\alpha$. Antibodies IMG-5983 (1:40 rabbit polyclonal; Imgenex, California, USA), $31 \mathrm{G} 7$ (1:20; monoclonal; Zymed/Invitrogen, Breda, The Netherlands) and D-5 (1:100; monoclonal; DAKO, Glostrup, Denmark) were used to detect OLFM-4, EGFR1 and ER- $\alpha$, respectively. Chemate Envision and 3,3-diaminobenzidine (DAB) solution (Dako, Glostrup, Denmark) were used to visualize antibody binding.

Immunofluorescence staining for microscopy and for confocal laser scanning microscopy was performed on frozen endometrial tissue $(5 \mathrm{~m}$ sections or $10 \mathrm{~m}$ in case of confocal laser scanning microscopy) or on cells plated on microscope cover glasses. Tissue and cells were fixed in $4 \%$ paraformaldehyde (10 minutes at RT) followed by permeabilisation with PBS supplemented with $0.1 \%$ tween-100.

OLFM-4 was stained with the IMG-5983 antibody (1:40), E-cadherin with the G-10 antibody (1:500, monoclonal; Santa Cruz Biotechnologies, Heidelberg, Germany) and vimentin with the M0725 antibody (1:500, monoclonal; Dako, Glostrup, Denmark). Mouse- $\alpha-2$ PY was used to detect the PY tag. Goat- $\alpha$-mouse IgG-FITC (1:100, Dako, Glostrup, Denmark) and swine- $\alpha$-rabbit IgG-FITC (1:100, Dako, Glostrup, Denmark) were used as secondary antibodies. For the co-staining protocols we combined the swine- $\alpha$-rabbit-FITC antibody (1:100, Dako, Glostrup, 
Denmark) and goat- $\boldsymbol{\alpha}$-mouse-Texas Red antibody (1:80, ITK Diagnostics, Uithoorn, The Netherlands).

Confocal laser scanning microscopy was performed using the Leica CTR 4000/CTC SPE and the Leica Application Suite/advance fluorescence software package (Leica Microsystems B.V., Rijswijk, The Netherlands). The Image-J programme was used to make 3-D images.

\section{Accession numbers}

NCBI (http://www.ncbi.nlm.nih.gov ) entries for human olfactomedin-4 gene name: OLFM4 (additional names GC1; OLM4; OlfD; GW112; hGC-1; hOLfD; UNQ362; KIAA4294; bA209J19.1; OLFM4). GeneID: 10562.

\section{Results}

\section{OLFM-4 expression in the endometrium during the menstrual cycle}

Expression of OLFM-4-mRNA is significantly increased in the early and late proliferative phase compared to the menstrual phase endometrium and it remains elevated during the early secretory phase (though non-statistically significant compared to the menstrual phase). Messenger-RNA is back to menstrual phase level in medium and late secretory endometrium (Figure 4.1a).

Figure 4.1. Olfactomedin-4 expression in the human endometrium.

A

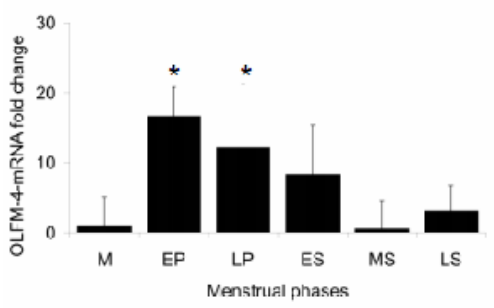

B

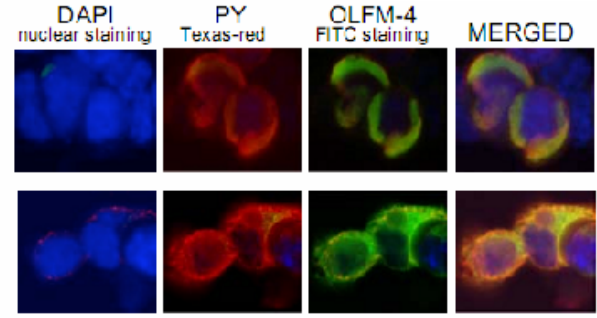

A. OLFM-4 mRNA expression in healthy cyclic endometrium. M: menstrual phase $(n=12)$; EP: early proliferative $(n=9)$; LP: late proliferative $(n=9)$; ES: early secretory $(n=8)$; MS: mid secretory $(n=8)$; LS: late secretory $(n=2)$. mRNA levels were determined by realtime PCR. * $\mathrm{p}<0.05$ versus menstrual phase (Mann Whitney U test).

B. Specificity of the IMG-5983 antibody for OLFM-4. We confirm perfect co-localisation of OLFM-4 (polyclonal IM G-5983, Swine- $\alpha-$ rabbit-FITC, green) and the PY tag (mouse- $\alpha$-2PY MMS-115R, goat- $\alpha$ mouse-Texas-red, red). 
For immunohistochemistry of OLFM-4, antibody IMG-5983 was used. This antibody was previously employed for western blot only. Therefore, its specificity to detect the correct protein in whole cells was confirmed in the HEK-293 cells transfected with the OLFM-4 cDNA fused to a PY tag. Antibody IMG-5983 and the anti-PY antibody co-localised perfectly in co-staining experiments (Figure 4.1b).

\section{Figure 4.1. Continued}

C

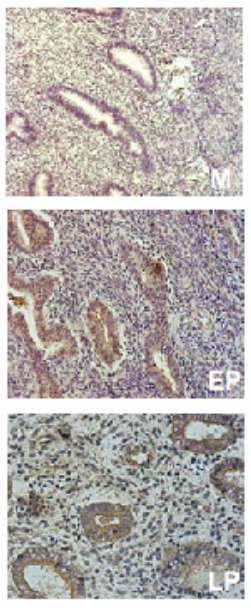

E
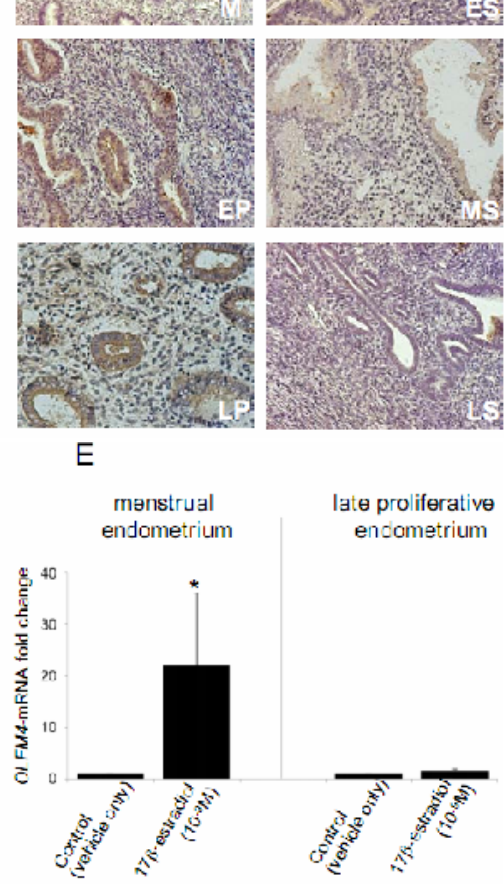

C. OLFM-4 protein expression during the menstrual cycle determined by immunohistochemistry. M, EP, LP, ES, MS and LS stand for menstrual, early proliferative, late proliferative, early secretory, mid secretory and late secretory endometrium.$$
\text { D }
$$
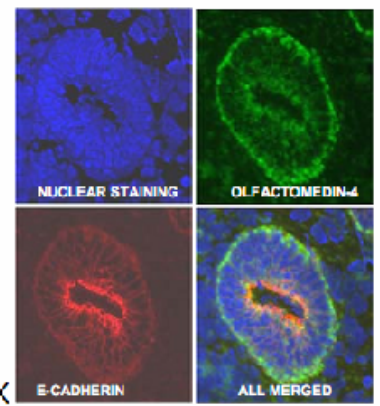

E. OLFM-4 mRNA expression in explant cultures of menstrual and late proliferative-phase endometrium exposed for 24 hours to vehicle $(0.1 \%$ ethanol) or $17 \beta$ oestradiol $(1 \mathrm{nM})$. mRNA levels were determined by realtime PCR. ${ }^{*} \mathrm{p}<0.05$ (Wilcoxon signed rank test).

In the human endometrium, OLFM-4 protein is localised in the cytoplasm and the cell membrane of the glandular epithelium, though some immunoreactivity in the stroma cells is also observed (Figures 4.1c and d). Its expression is highest in the late proliferative phase (Figure 4.1c). Furthermore, OLFM-4 does not co-localise with E-cadherin in the endometrium, contrarily to what was observed in an earlier study on cell lines [194]. OLFM-4 is mostly expressed at the interface between the glandular epithelium and the stroma compartment, whereas E-cadherin is predominantly expressed at the luminal side of the glands (Figure 4.1d).

Using endometrial explant cultures, we confirmed the oestrogendependence of OLFM-4: its mRNA level is induced significantly by $17 \beta$-oestradiol 
in explant cultures prepared from menstrual phase endometrium but not in explants prepared from late proliferative phase endometrium (Figure 4.1e; see discussion).

\section{Regulation of the OLFM-4 gene promoter}

To further investigate the transcriptional regulation of OLFM-4, we cloned the $1.3 \mathrm{~Kb}$ fragment upstream the transcription start site in front of the luciferase gene (Figure 4.2a). The OLFM-4 promoter does not contain any canonical ERE, but instead it has three half EREs (AGGTCA) and an AP1 site (TGACTCA). We transfected this construct into the ER- $\alpha$ positive cell lines ECC1 (endometrial cancer cell line) and T47D (breast cancer cell line) as well as in two ER- $\alpha$ negative cell lines (endometrial cancer RL95.2 and cervical cancer HeLa cells) along with the ER- $\alpha$ expression plasmid (results not shown).

Figure 4.2. Olfactomedin-4 is regulated by oestrogen and EGFR signalling.

A
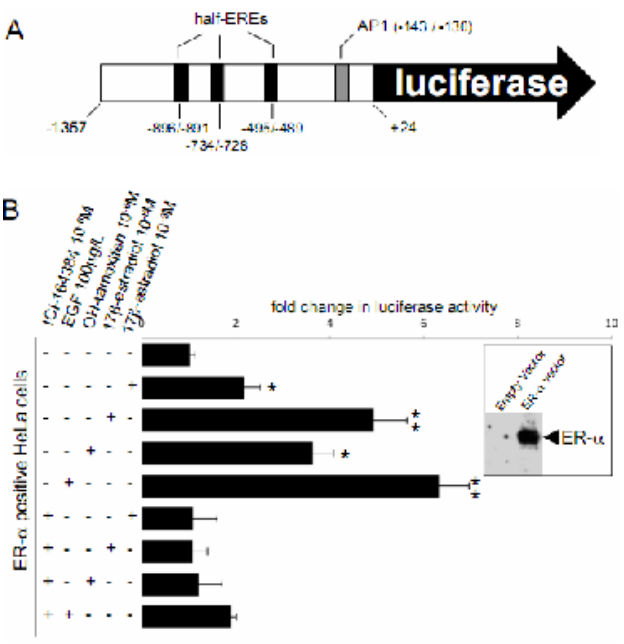

C

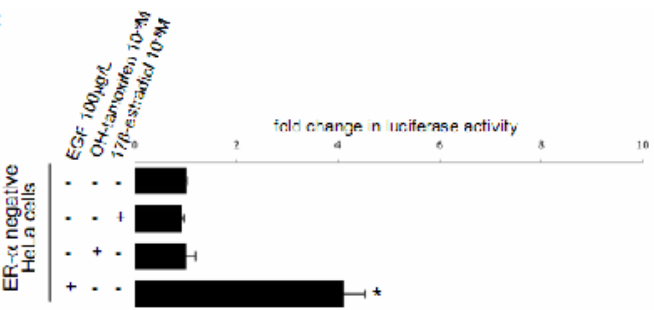

A . Scheme of the $1.3 \mathrm{~Kb}$ fragment upstream the OLFM-4 gene that was cloned in front of the luciferase reporter. Nucleotide numbering as in the study of Chin et al. [215].

B-E. Luciferase response in HeLa cells transfected with the OLFM-4 promoterluciferase along with:

B. The expression plasmid for ER- $\alpha$ (the panel on the right shows ER- $\alpha$ expression after transfection with ER- $\alpha$ plasmid or with an empty vector). ICI-164384 alone had no effect on the luciferase activity (not in figure). Bars indicate mean values $(n=3) \pm$ standard deviation. P-values were calculated with the Ttest; *: p-value < 0.05; **: p-value < 0.01. All results were repeated in at least two independent experiments.

C. The empty vector (without the expression plasmid for ER- $\alpha$ ). 
Surprisingly, the OLFM-4 promoter responds to estrogens only in HeLa cells, which are co-transfected with the OLFM-4-luciferase and the ER- $\alpha$ expression plasmid. Both $17 \beta$-oestradiol and $\mathrm{OH}$-tamoxifen induce luciferase activity and this response is antagonised by ICI-134384 (anti-oestrogenic action; Figure 4.2b).

Figure 4.2. Continued

D

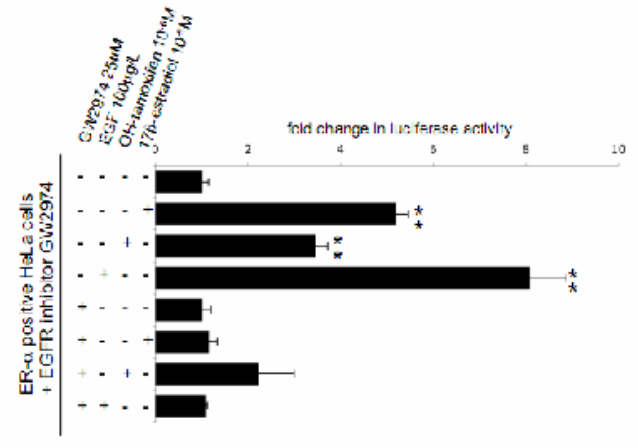

$E$

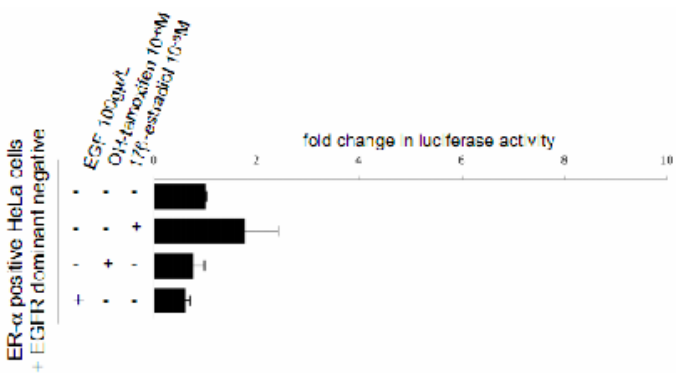

D. The expression plasmid for ER- $\alpha$ in presence or absence of the tyrosine kinase inhibitor GW2974.

E. The ER- $\alpha$ expression plasmid and a dominant negative variant for of the EGFR (CD-533).

Given that an agonistic action of $\mathrm{OH}$-tamoxifen is frequently associated with cross talks between ER- $\alpha$ and kinase pathways, and given that AP1 binding sites (activated by kinase cascades) are frequently functionally linked to half-EREs (both AP1 and half-EREs are present in the OLFM-4 3'; Figure 4.2a), we examined whether growth factor signalling is involved in the regulation of OLFM-4. EGF, but not IGF (results not shown) strongly enhances OLFM-4 promoter luciferase activity (Figure 4.2b). Interestingly, ICI-164384 is able to almost completely impair the response to EGF, besides the inhibition of the oestrogen signalling.

The interaction between the ER- $\alpha$ and the EGFR signalling pathways were further explored. ER- $\alpha$ is necessary for the oestrogenic response of OLFM-4, because when ER- $\alpha$ is not co-transfected into the HeLa cells, the responses to $17 \beta$ oestradiol and $\mathrm{OH}$-tamoxifen are completely abolished (Figure 4.2c). Under these circumstances, also the response to EGF is partly impaired ( 50\%; Figure $4.2 \mathrm{c})$, indicating that ER- $\alpha$ is required for the full EGF response. This is further illustrated by the fact that the ER antagonist ICI-164384 abolishes the EGF-mediated response (Figure 4.2b).

Similarly, EGF signalling is needed for the oestrogen response. Pre-treating HeLa cells with a general inhibitor of the membrane EGFR family (GW2974) 
inhibits the response to EGF as well as to $17 \beta$-oestradiol and $\mathrm{OH}$-tamoxifen (Figure 4.2d). To confirm this observation, we used a dominant negative variant of EGFR (EGFR-CD-533). The activation of the OLFM-4 promoter by EGF, 17 $\beta$-oestradiol and $\mathrm{OH}$-tamoxifen is impaired when HeLa cells are co-transfected with EGFR-CD533 (Figure 4.2e).

Several members of the EGFR family are known. Among them, EGFR1 and ERBB2 (HER2/NEU) are the most important ones. Western blot analysis (Figure 4.3a) revealed that ERBB2 is expressed in HeLa (OLFM-4 promoter responsive to both oestrogens and EGF) as well as in ECC1 and T47D cells (OLFM4 promoter neither responsive to oestrogens nor to EGF), whereas EGFR1 is expressed in HeLa cells only, and not in ECC1 and T47D cells. Therefore, we hypothesised that EGFR1 is involved in the regulation of OLFM-4. Re-expression of EGFR1 by transient transfection in T47D cells is sufficient to recover the EGF response. However, EGFR1 re-expression recovers only partly (non significantly) the oestrogenic response of the OLFM-4 promoter (Figure 4.3b). Similar results were obtained with ECC1 cells (results not shown).

Figure 4.3. Intra-cellular regulation of the olfactomedin-4 promoter.

B

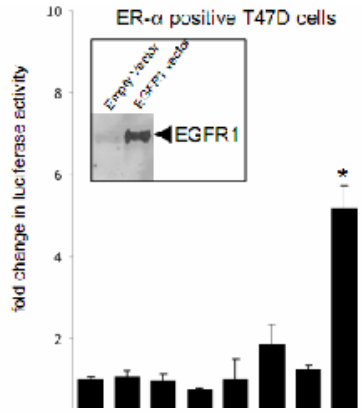

A. Western blot EGFR1 and HeLa, ECC1 and

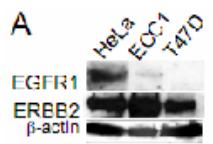

analysis for ERBB2 in T47D cells.

B. Luciferase

response in T47D cells transfected with the OLFM-4 promoterluciferase along with the expression plasmid for EGFR1 (the panel on the left shows the EGFR1 expression after transfection with EGFR1 plasmid of with an empty vector).

C. Luciferase response of HeLa cells transfected with

C ER-c positive HeLa cells plus inhibitors:

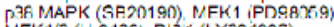
MEK 1/2 (J-0 126), PI3K (LY29 4002)
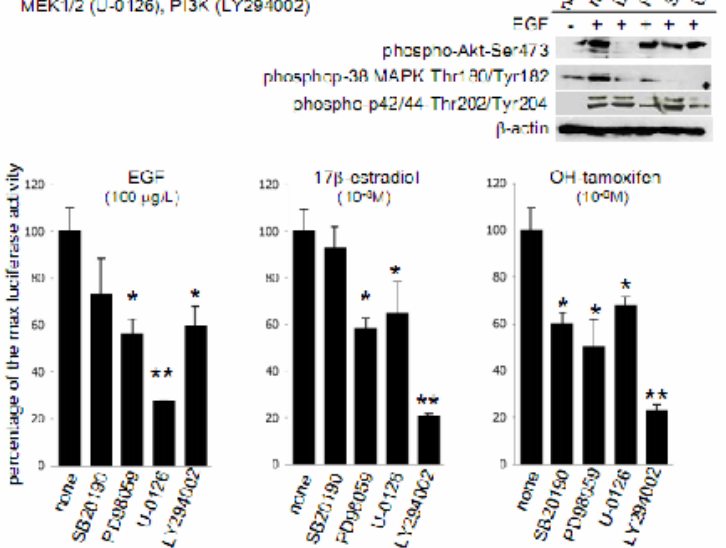

the OLFM-4 promoterluciferase and the expression plasmid for ER- $\alpha$. Cells were preincubated with the inhibitors for p38 MAPK (SB20190, 20 $\mu \mathrm{M})$, MEK1 (PD98059, 50 $\mu \mathrm{M}$ ), MEK1/2 (which is upstream both p38 MAPK and p42/44; U0126, $10 \mu \mathrm{M})$ and PI3K (Ly294002, $10 \mu \mathrm{M})$. The western blot on the top indicates that the inhibitory conditions used were efficient and specific: Ly294002 completely blocked EGF-induced phosphorylation of Akt (downstream of PI3K); PD98059 and U-0126 blocked phosphorylation of p42/44 MAPK; phosphorylation of $\mathrm{p} 38$ MAPK is partly inhibited by Ly294002, PD98059 and U-

0126 as this kinase lies downstream both PI3K/Akt and MEK1/2, but not by SB20190, which blocks phosphorylation downstream of p38 MAPK. 
We next investigated which pathways are involved in the EGFR-ER- $\alpha$ cross-talk using specific inhibitors of EGFR-mediated intracellular signalling cascades. The signalling induced by EGF is only partially blocked by inhibition of PI3K (LY294002) and is not influenced by p38 MAPK inhibition (SB20190). The results show that the signalling induced by EGF is inhibited most prominently by MEK1/2 inhibitor (U-0126, Figure 4.3c; top panel indicates that the used inhibitors were specific and efficient in our experimental conditions). The induction of the OLFM-4 promoter by $17 \beta$-oestradiol and $\mathrm{OH}$-tamoxifen is blocked by pre-treatment with the PI3K inhibitor LY294002 (Figure 4.3c). Inhibition of the MAPK pathway by MEK1/2 (U-0126) or MEK1 (PD98059) inhibitors reduces oestrogen signalling by $50 \%$. The p38 MAPK inhibitor SB20190 represses the activity of OH-tamoxifen only. The activation by $17 \beta$-oestradiol and $\mathrm{OH}$-tamoxifen of PI3K/Akt was confirmed by western blot using phospho-Akt-Ser473 antibody (Figure 4.3d). In addition, western blotting using phospho-p38 MAPK (Thr180/Tyr182) antibodies confirmed that this protein is activated by OH-tamoxifen only (Figure 4.3d).

Figure 4.3. Continued

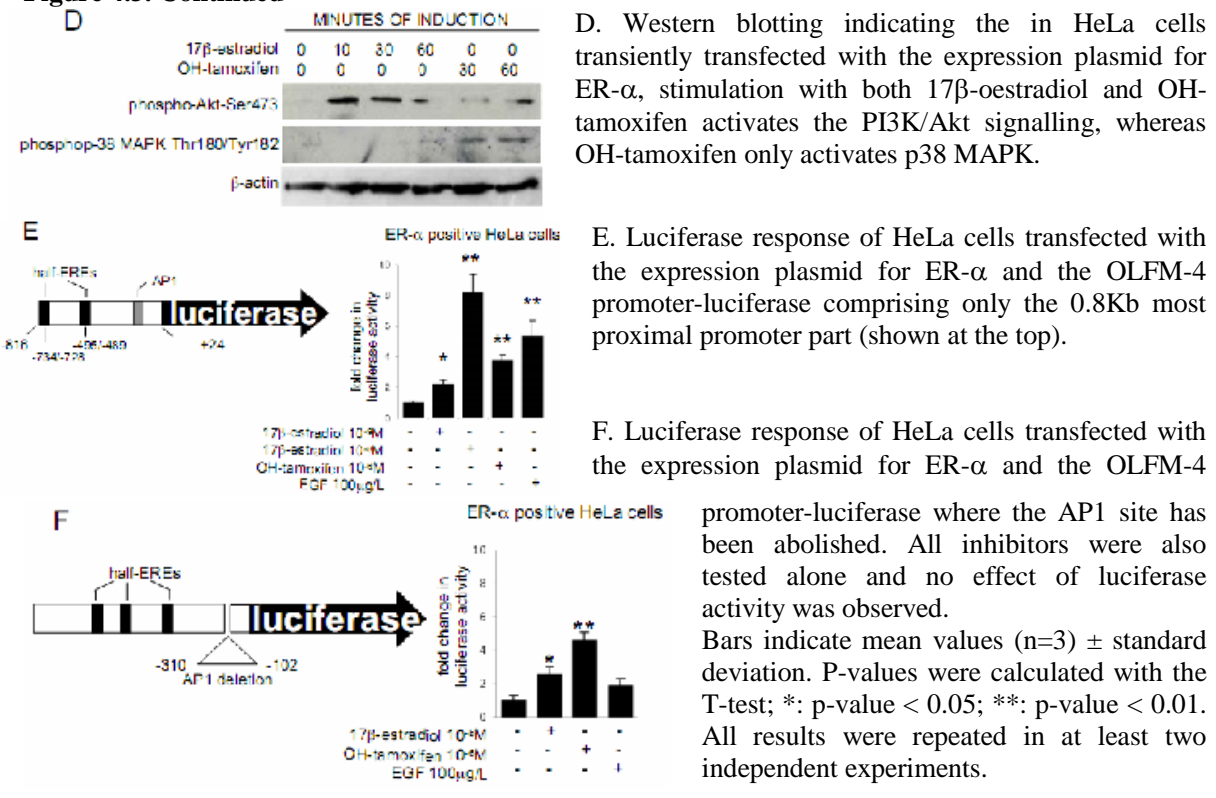

Finally, we investigated the promoter sequences that are needed for oestrogen and EGF responses. A truncated form of the $1.3 \mathrm{~Kb}$ OLFM-4 promoter was generated, which contains the first $0.8 \mathrm{~Kb}$ promoter fragment. This is enough to mediate the complete response of oestrogen, but only part of the EGF response (Figure 4.3e). The AP1 site is present in this $0.8 \mathrm{~Kb}$ promoter (Figure 4.3e). Therefore, to examine whether this site is needed to mediate the oestrogenic and the partial EGF response, the AP1 site was deleted from the $1.3 \mathrm{~Kb}$ OLFM-4 promoter (Figure 4.3f). The responses to EGF and to $17 \beta$-oestradiol are completely abolished after deletion of the AP1 binding sequence. The response to $\mathrm{OH}$-tamoxifen however, 
appears to be independent from the presence or absence of the AP1 transcription factor binding site (Figure 4.3f).

OLFM-4 decreases cell adherence and vimentin expression and protects against apoptosis

The functional role of this protein was assessed by transient transfection with OLFM-4 expression plasmid of OLFM-4 negative HEK-293 cells. After transfection, the protein is highly expressed both as native and as PY tagged (Figures $4.4 \mathrm{a}$ and $4.4 \mathrm{~b}$ ) and is mainly present in the cytoplasm and the cell membrane. We observed that when OLFM-4 is expressed on the cell membrane (Figure $4.4 \mathrm{~b}$ right panels), cells assume a spherical shape and clearly detach from the plate surface, whereas in cells with a more adherent phenotype (Figure $4.4 \mathrm{~b}$, left panels) OLFM-4 is present throughout the cytoplasm (see the 3-D reconstruction in Figure 4.4b). In line with this observation, re-expression of OLFM-4 (native or PY fused) decreases the ability of cells to adhere to the plate surface compared to cells transfected with the empty vector (Figure $4.4 \mathrm{c}$ ).

Re-expressing OLFM-4 in HEK-293 cells also results in increased cell numbers compared to untransfected or empty vector transfected cells (Figure 4.4d). We did not find increased proliferative activity as determined by the DNAhistograms generated with flow cytometry (results not shown), however, HEK-293 cells re-expressing OLFM-4 are slightly, but significantly, more resistant to topotecan induced apoptosis (Figure 4.4e).

Intermediate filaments, i.e. vimentin, establish intimate interactions with extracellular matrix components (such as OLFM-4) and can influence a large number of cellular events including cell differentiation, adherence and apoptosis [217, 218]. Therefore, we examine whether vimentin expression and filament organisation were affected by OLFM-4. The level of vimentin in OLFM-4 positive and negative cells was assessed by immunostaining (Figures $4.4 \mathrm{f}$ and $4.4 \mathrm{~g}$ ). HEK293 cells transiently transfected with the OLFM-4 cDNA were co-stained with the OLFM-4 antibody (green fluorescence) and with the vimentin antibody (red fluorescence). The efficiency of transient transfection never reaches $100 \%$, therefore, we could observe in the same microscopic preparation cells expressing and cells non-expressing the transfected plasmid. Using confocal-laser-scanningmicroscopy, the amount of red fluorescence (vimentin expression) was quantified through the complete volume of cells expressing OLFM-4 (green) or not (cells without green fluorescence) in the same transfection plate/reaction. Expression of OLFM-4 clearly results in reduced staining for vimentin (Figures $4.4 \mathrm{f}$ and $4.4 \mathrm{~g}$ ). When we performed the same experiment in HEK-293 cells transfected with the green-fluorescence-protein (GFP) expression vector, the vimentin staining in cells expressing and in cells non-expressing GFP did not differ (Figure 4.4g). 
Figure 4.4. Olfactomedin-4 re-expression in HEK293 cells infers apoptosis resistance and reduces cell adherence and vimentin expression.

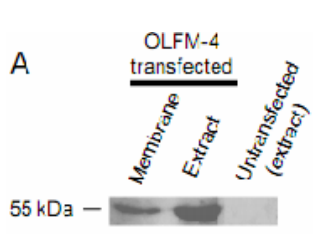

B ADHERENT CELL

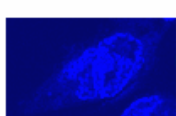
$<$ (nAPIei)

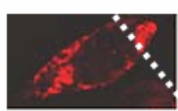

$<P Y>$
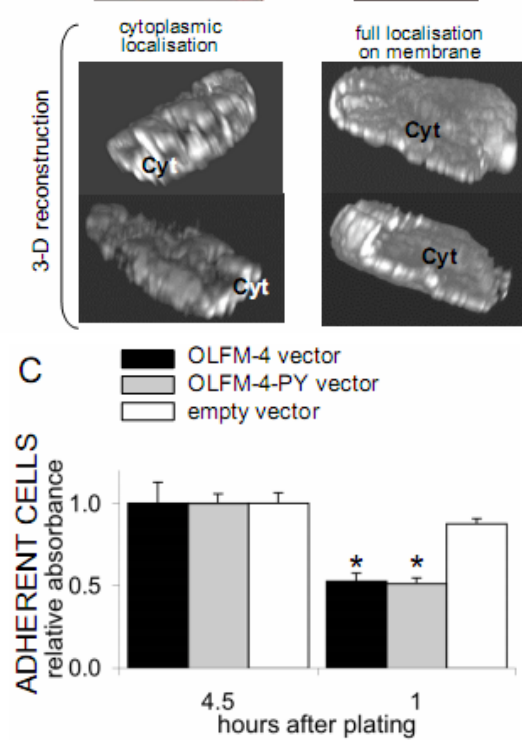

A-E. OLFM-4 was re-expressed in HEK-293 cells (originally negative) by transient transfection with the OLFM-4 expression plasmid (or empty vector as control).

A. Western blot with antibody IMG-5983 against the native OLFM-4. Equal amounts of protein were loaded on the 'extract fractions'.

B. Confocal laser scanning microscopy of HEK-293 cells transfected with SPHERICAL CELL

OLFM-4 cDNA fused to PY tagging and detected with the anti-PY antibody (similar results were obtained with the native non-tagged protein). On the left panel, a cell with predominant cytoplasmic localisation of OLFM-4. On the right: membrane localisation of OLFM-4. After 3-D reconstruction, cells were (virtually) sectioned through the plane indicated on the top image (dashed line). The cell on the left is well attached to the plate surface and staining for OLFM-4 is seen through the cytoplasmic section (Cyt). On the right, the OLFM-4 protein is fully localised on the membrane and this is accompanied by detachment (spherical shape) of the cell. We exclude that the rounded shape of the cell was associated to apoptosis because nuclear morphology looked normal, and apoptosis was diminished rather than augmented in cells overexpressing OLFM-4 (see panel E).

C. Adherence of cells to the culture plate is decreased after re-expression of OLFM-4 compared to cells transfected with the empty vector. ${ }^{*} \mathrm{P}<0.05$ versus empty vector, T-test.

Transfected cells were let seed on a 24 well plate and the number of attached cells was determined by MTT after different periods of time. Four hour and half after plating, all cells are seeded.

D. The number of viable cells (MTT assay) increases after OLFM-4 re-expression compared to cells transfected with the empty vector. $* \mathrm{P}<0.05$ versus empty vector, T-test.

E

OLFM-4 vector OLFM-4-PY vector empty vector

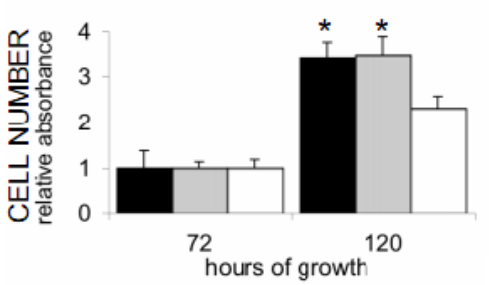

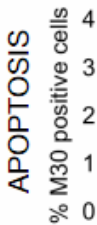

0

non treated topotecan
E. HEK-293 cells reexpressing OLFM-4 are more resistant to topotecan-induced apoptosis (M30 staining/FACS analysis) compared to cells transfected with the empty vector. $* \mathrm{P}<0.05$ versus empty vector, $\mathrm{T}$ test. 
Figure 4.4. Continued

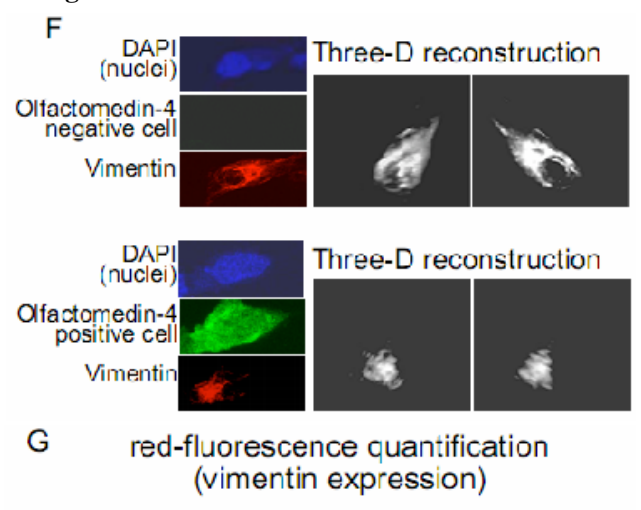

F. HEK-293 cells were transiently transfected with OLFM-4 cDNA and co-stained for olfactomedin-4 (FITC-green) and vimentin (Texas-red). Confocal laser scanning microscopy was used to visualise and quantify vimentin filament throughout the whole volume of cells that re-expressed OLFM-4 and in cells that did not. The Image-J programme was used to make 3-D images.

G. Quantification of the vimentin expression in cells transfected as described in panel $\mathrm{F}$ that were positive or negative for OLFM-4 expression. The same experiment was performed by tranfecting HEK293 cells with GFP expression plasmid and no reduction in vimentin expression could be observed (GFP positive cells).

\section{OLFM-4 expression in endometriosis and endometrial cancer}

OLFM-4 and EGFR1 are expressed in pre- and post-menopausal endometrium (Figures 4.1, 4.5a and 4.5b), although significant individual variations were observed. OLFM-4 is mostly localised in the glands. EGFR1 stains the cell membrane of the stroma cells and with less intensity the epithelial cells, with the strongest immunoreactivity during the proliferative phase. Maximum EGFR1 staining is observed in the interface between the glandular epithelium and the stroma (Figure 4.5a).

OLFM-4 is also expressed in endometriosis (Figures 4.5c) and endometrial cancer (Figure 4.5d). Similarly to the endometrium of healthy women, it is mostly present in the glandular compartment. We did not observe any difference in the OLFM-4 staining intensities between normal endometrium and endometriosis lesions or endometrial cancer. 
Figure 4.5. Olfactomedin-4 and EGFR1 expression in endometriosis and endometrial cancer.

A.

A EGFR1 expression healthy pre-menopausal endometrium

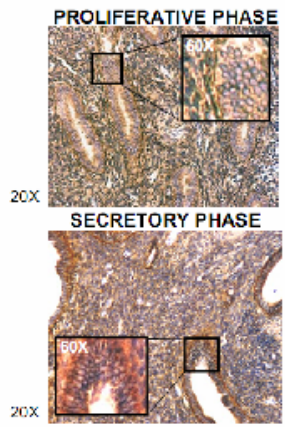

B OLFM-4 and EGFR1 in healthy post-menopausal endometrium OLFM-4

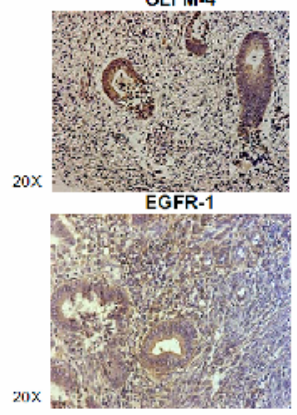

C OLFM-4 and EGFR1 in endometriosis

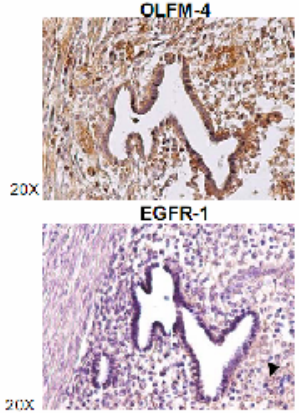

EGFR1 expression in healthy pre-menopausal endometrium. Enlarged panels (60X) show the membrane expression of EGFR1.

B. OLFM-4 and EGFR1 expression in post-menopausal endometrium.

C. OLFM-4 and EGFR1 expression in endometriosis lesions. Little expression of EGFR1 is evident (area indicated with the arrowhead).

$\mathrm{D}$

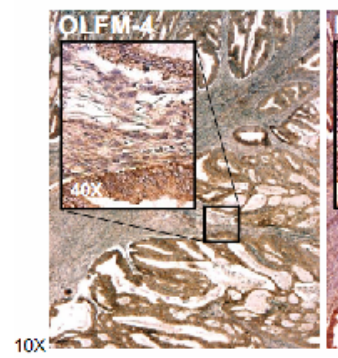

Endometrial cancer
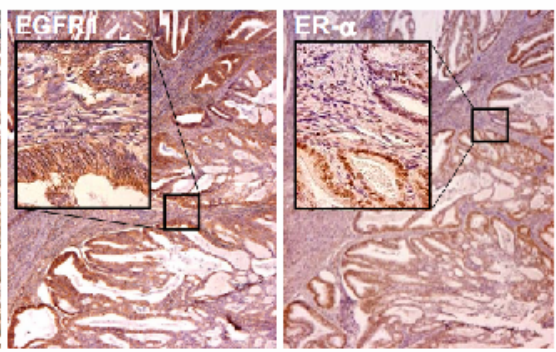

D. OLFM-4, EGFR1 and

ER- $\alpha$ expression in endometrial cancer.
E

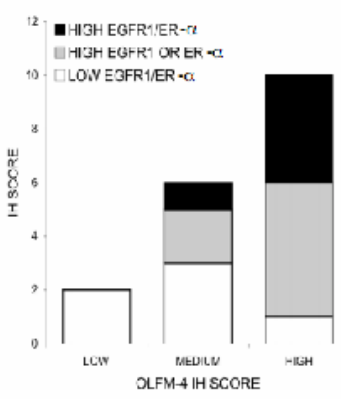

E. Correlation between OLFM-4, EGFR1 and ER- $\alpha$ expression in endometrial cancer. Protein expression was semi-quantitatively assessed by calculating a staining index as described earlier [66]. Afterwards, samples were grouped in three categories for OLFM-4 expression (low, medium, high; $\mathrm{X}$ axis) and in two for EGFR1 and ER- $\alpha$ (low and high). A combination of different expression levels of EGFR1 and ER- $\alpha$ are plotted on the Y-axis. IH SCORE $=$ staining index.

EGFR1 expression in endometriotic tissue is very weak (based on immunohistochemistry; Figure 4.5c) whereas it is comparable to the healthy endometrium in endometrial cancer (Figure 4.5d). When comparing the immunohistochemical staining scores of OLFM-4 with that of EGFR1 and ER $\alpha$, we observed that high OLFM-4 stainings correlate with high staining scores of EGFR1 and $\mathrm{ER} \alpha$ (Figure 4.5e). Quantifying immunohistochemical stainings is semi- 
quantitative at best, therefore we also assessed the mRNA levels of OLFM-4 and EGFR1 by real-time PCR. Moreover, we examined the expression of the oestrogen responsive gene TFF1. These values were used as a measurement of the activation of ER $\alpha$ signalling, as previously described [206].

At the mRNA level, OLFM-4 expression is similar in endometriotic tissue compared to the endometrium of healthy women. However, it is significantly higher in the eutopic endometrium of patients when compared to the endometriotic tissue and compared to the endometrium of controls (Figure 4.6a). EGFR1 mRNA levels are significantly lower in the eutopic and ectopic endometrium of patients when compared to the normal endometrium (Figure 4.6b), confirming the immunostaining.

We next examined the fold-change of the expression of TFF1, OLFM-4 and EGFR1 between the eutopic and ectopic endometrium in each single patient. In this way we assessed if the expression of these genes differs in the endometrium located inside the uterus (eutopic) compared to the endometriotic lesions. As previously shown [206], TFF1 expression is lower in the eutopic compared to the ectopic endometrial tissue of each single patient (expression ratios lower than one; Figure 4.6d). However, OLFM-4 expression shows the opposite trend and is higher in the eutopic endometrial tissue compared with the levels in the ectopic endometrium in the same patient. The levels of EGFR1 mRNA are also slightly higher in the eutopic than in the ectopic lesions.

In contrast to the differences in expression levels observed in endometriotic tissue, mRNA levels of OLFM-4, EGFR1 and TFF1 are comparable in endometrial cancer and healthy post- menopausal endometrium (Figure 4.6e). In line with the correlation of high OLFM-4 protein level and high expression of EGFR1 and/or ER$\alpha$, the same relationship becomes evident in both healthy post-menopausal endometrium and endometrial cancer when the OLFM-4 mRNA levels are plotted against the product of the mRNA levels of EGFR1 and TFF1 (Figure 4.6f).

\section{Discussion}

OLFM-4 is an oestrogen-responsive gene, highly up-regulated during the proliferative phase of the menstrual cycle. The response to $17 \beta$-oestradiol was confirmed in vitro using explant-cultures of human endometrial tissue (Figure 4.1e). The magnitude of the in vitro response was higher using menstrual phase endometrial explants compared to late-proliferative phase explants. This phenomenon of differences in oestrogen-sensitivity in different preovulatory stages has previously been described [33]. It can be attributed to the fact that lateproliferative phase endometrium has been exposed in vivo to $17 \beta$-oestradiol for an 
extended period of time. This renders the endometrium refractory to further stimulation in vitro.

Figure 4.6. mRNA levels of OLFM-4, EGFR1 and TFF1 in endometriosis and endometrial cancer. All mRNA values were calculated by real-time PCR and were normalised using cyclophilin as house keeping gene. Results did not change when $\beta$-actin was used for normalisation; not shown). Ns: non significant.

A OLFM-4 MRNA

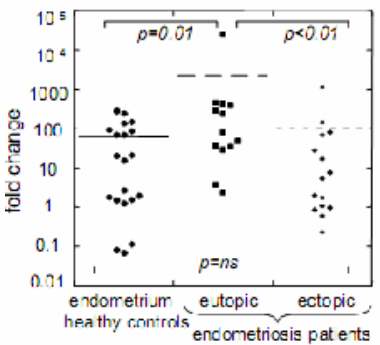

B EGFR1 MRNA

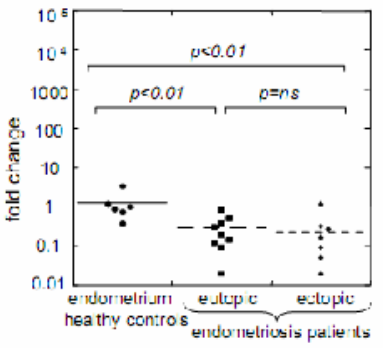

C $17 \beta-H S D-4$ mRNA

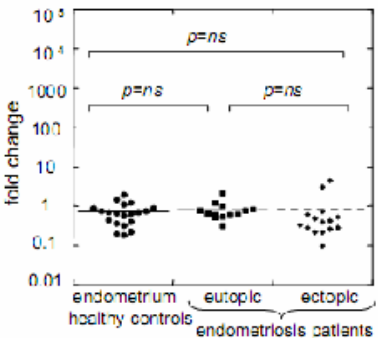

A. OLFM-4 mRNA levels in the endometrium of healthy controls, and ectopic/eutopic endometrium of endometriosis patients (statistic significance was maintained after removal of the outsider sample with a fold change $>10^{4}$ in the 'eutopic' group).

B. EGFR1 mRNA levels in the endometrium of healthy controls, and ectopic/eutopic endometrium of endometriosis patients.

C. 17 $\beta$-HSD4 mRNA in the endometrium of healthy controls, and ectopic/eutopic endometrium of endometriosis patients. This enzyme is known to be expressed at comparable levels in the eutopic and ectopic endometrium [66] and it was used as a control for the presence of endometrial tissue in the ectopic lesions.

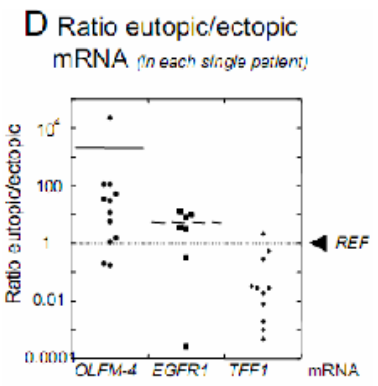

D. Ratios between the levels of mRNA in the eutopic versus the corresponding ectopic endometrium (matched samples in each patient) for OLFM-4, EGFR1 and TFF1. The levels in the eutopic tissues are set to one (REF, indicated); therefore, a value higher than one indicates that in that patient the level of expression of the gene under investigation is higher inside the uterus than in the lesion; vice versa, a value lower than one indicates higher expression in the lesion compared to the endometrium at its normal location.

Despite its oestrogenic response, the promoter region of the OLFM-4 gene does not contain any perfect oestrogen response elements (EREs). Three halfpalindromic EREs are present plus an AP-1 binding site. The presence of the AP1 site suggests that growth factor signalling pathways may be involved in the full regulation of this gene. Indeed, OLFM-4 gene transcription is induced by EGF, 17 $\beta$ oestradiol and $\mathrm{OH}$-tamoxifen. From our experiments we can infer that the signalling pathways activated by these three compounds are distinct but merge at various levels. 


\section{Figure 4.6. Continued}

E. OLFM-4, TFF1 and EGFR1 mRNA levels in the endometrium of post-menopausal healthy controls and endometrial cancer (none is significantly different between the two groups).

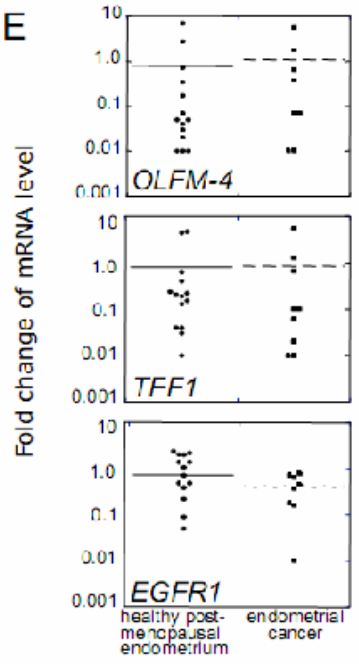

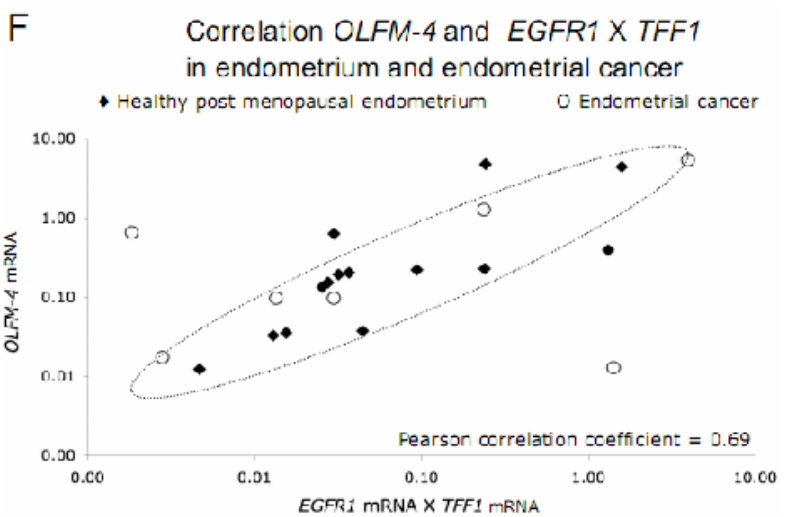

F. Correlation between OLFM-4 mRNA levels and the product of EGFR1 and TFF1 mRNA levels in endometrium of healthy postmenopausal women $(\mathrm{R}$-squared value $=0.3)$ and endometrial cancer $(\mathrm{R}$ squared value $=0.8$ ).

In addition, both ER- $\alpha$ and EGFR signalling are required for full activation of the OLFM-4 promoter. The responses to EGF, $17 \beta$-oestradiol and OH-tamoxifen are impaired when EGFR is blocked by the dominant negative receptor variant, or cells are pre-treated with an EGFR inhibitor (GW2974). These same responses are also impaired when ER- $\alpha$ is not expressed (partly only in case of EGF) or when cells are exposed to the anti-oestrogen ICI-164384 (Figures 4.1b and 4.1c).

With respect to the EGF response, EGFR1 is the major transduction pathway. Re-expression of this receptor in cell that are originally negative for it (T47D cells) is sufficient to recover the EGF response (Figure 4.3b). The main signalling route of EGF-EGFR1 appears to be via MEK1/2, p42/44 MAPK and AP1 activation (Figures $4.3 \mathrm{c}$ and $4.3 \mathrm{f}$ ). Taking together, the fact that full EGF response requires the presence of both ER- $\alpha$ and AP1, suggests that the tethering mechanism of ER- $\alpha$ by c-Fos/c-Jun at the AP1 region [219] may control OLFM-4 promoter activation. In addition, since the truncated $0.8 \mathrm{~Kb}$ promoter fails to result in the response observed with the $1.3 \mathrm{~Kb}$ promoter (Figure 4.3e), additional DNA motives located more distal to the AP1 site are needed.

With respect to the oestrogenic response, ER- $\alpha$ is the main mediator of the oestrogen signalling. For these experiments, we used a HeLa clone in which neither ER- $\alpha$ nor ER- $\beta$ are endogenously expressed (as visualised by western blot). Reexpression of ER- $\alpha$ clearly recovers the the OLFM-4 promoter response to oestrogens, which is completely absent in cells not transfected with the ER- $\alpha$ expression plasmid. In these experiments, we have not assessed whether ER- $\beta$ could also activate OLFM-4 promoter. 
Though the oestrogenic response requires full EGFR signalling, EGFR1 reexpression in T47D (Figure 4.3b) or in ECC1 cells (not shown) is not enough to reestablish the OLFM-4 promoter oestrogenic response, contrarily to what is observed for the EGF response. Therefore, additional signalling paths are needed for oestrogenic activation. It is unlikely that other members of the EGFR family such as ERBB2, ERBB3 or ERBB4 may be involved. Indeed, ERBB3 is expressed in T47D breast cancer cells but not in HeLa (where we observed high OLFM-4 promoter activation); ERBB2 is expressed in both cells (Figure 4.3a) whereas ERBB4 is neither expressed in HeLa nor in T47D cell (expression data for ERBB3 and ERBB4 derived from GNF SymAtlas: http://biogps.gnf.org/). Interestingly, preliminary results of our group have indicated that Akt is constitutively phosphorylated at the Thr-308 in HeLa cells (whereas Ser-473 becomes phosphorylated in a EGF/oestrogen dependent manner) but not in ECC1 or in T47D cells. PI3K-Akt signalling via Thr-308 may be therefore needed for the oestrogenic response of OLFM-4.

The oestrogenic response further requires PI3K-Akt/PKB and MEK1/2 activation (Figures $4.3 \mathrm{c}$ and $4.3 \mathrm{~d}$ ). Both the Akt/PKB and MEK1/2 pathways contribute to ER- $\alpha$ mediated transcriptional activity through phosphorylation of serine 167 and 118, respectively [219]. Considering that the largest decrease of oestrogen mediated transcriptional activity was observed using the Akt/PKB inhibitor (Figure 4.3c), it is likely that ER- $\alpha$ phosphorylation at serine 167 is needed for the oestrogenic response of the OLFM-4 promoter. However, whether ER- $\alpha$ is phosphorylated by Akt/PKB and MEK1/2 remains to be determined.

The further downstream events leading to the regulation of OLFM-4 transcription are not the same for $17 \beta$-oestradiol and $\mathrm{OH}$-tamoxifen. In case of $17 \beta$ oestradiol-bound ER- $\alpha$, the AP1 site in the promoter region is necessary. The obligatory actions of EGFR in this regard, suggest again that ER- $\alpha$ at the AP-1 site interacts with c-Fos/c-Jun as described earlier. However, induction of the OLFM-4 promoter by $\mathrm{OH}$-tamoxifen-bound ER- $\alpha$ does not require the interaction with AP1. Instead, after activation of $\mathrm{Akt} / \mathrm{PKB}$ and $\mathrm{MEK} 1 / 2$, it depends on p38 MAPK activation.

As validation of our findings we examined the conservation of the halfEREs and the AP1 site in rat and mouse. Both half-EREs and the AP1 sites are conserved between human, rat and mouse. AP1 sites are found at -131 TAGGGTGGGTCACATGTTCC in mouse and at -131 TAGGGTGGGTCACATGTTCCT in rat (Genomatix search; +1 nucleotide is the start of translation). Four and two half-EREs are present in the rat and mouse OLFM-4 promoter ( $1 \mathrm{~Kb}$ upstream the protein start), respectively, however their position is less conserved than the AP1 site.

The function of OLFM-4 in the endometrium is still elusive. Liu et al. showed that OLFM-4 interacts with E-cadherin and increases cell-cell adhesion [200], however in the human endometrium this interaction is marginal or absent because E-cadherin and OLFM-4 do not co-localise (Figure 4.1d). In HEK-293 cells, OLFM-4 localises in the cell membrane. Its overexpression decreases the 
adherence capability of cells and confers slight resistance to apoptosis, confirming other reports $[195,201]$.

We have not investigated why in some cells OLFM-4 localises in cell membrane, whereas in other cells the protein seems to remain trapped inside the cytoplasm (Figure 4.4b). Most probably, in this latter case, OLFM-4 is not correctly processed due to its overexpression after transient transfection. The effects of OLFM-4 seem to be mediated by decreased vimentin expression (or filament organisation). Similar results with respect to cell number/apoptosis and celladherence were also obtained using ECC1 endometrial cancer cells. However, results are not shown due to the very low expression of OLFM-4, which could be achieved in this cell line. Other authors have observed similar effects using colon cancer cells: OLFM-4 re-expression caused cells to round up and interfered with cytoskeleton filaments [200].

OLFM-4 is particularly associated with tissues, with high regenerative potential (i.e. bone marrow, the gastrointestinal tract, prostate, murine ovaries and rat testis [220] and endometrium). In addition, the fact that OLFM-4 affects processes such as cell adherence, cell-cell interaction, motility and apoptosis, rather than proliferation, implies that this protein plays a determining role in differentiation of cells. Accordingly, Liu and co-workers have reported that OLFM-4 expression in colon carcinoma correlates with well-differentiated tumours [201]. Vimentin, which is down-regulated by OLFM-4 re-expression, is up-regulated during epithelialmesenchymal transition [de-differentiation of cells; [221]]. These evidences and the fact that OLFM-4 expression is highest in the endometrium during the late proliferative phase, support the contention that OLFM-4 promotes differentiation of endometrial epithelial cells at the late proliferative phase, when the endometrium has finished the exponential growth and is preparing to respond to the luteal progesterone.

Our results are in line with previous investigations. Cross talks between oestrogens and EGF signalling are well documented in the literature [219]. Moreover, an intimate interaction between oestrogen signalling, PI3K and ERK1/2 in cell migration and other remodelling features of the endometrium has been recently shown [222]. It remains to be determined whether OLFM-4 is the downstream mediator of these events.

The human clinical samples we have examined support our in vitro studies on the regulation and function of OLFM-4. The synergy between ER- $\alpha$ and EGFR is corroborated by the fact that OLFM-4 expression in the human endometrium is highest in the (late) proliferative phase (Figures 4.1a and 4.1c). At this time, the levels of $17 \beta$-oestradiol in the circulation are peaking, and the expression of EGFR, in particular EGFR1 [223], and its ligands (EGF and TGF $\alpha$ ) are also significantly higher compared to the early proliferative phase [224, 225]. In addition maximum EGFR1 staining is observed in the interface between the glandular epithelium and the stroma (Figure 4.5a), exactly where OLFM-4 is also highly expressed (Figure 4.1d). 
Also in clinical samples, OLFM-4, ER $\alpha$ and EGFR1 are correlated. OLFM4 expression in endometrial cancer is associated with elevated EGFR1 and ER $\alpha$ or TFF1 expression (activation of oestrogen signalling; Figures 4.5d, 4.5e and 4.6f). Expression levels however, are comparable between normal endometrium and the tumours indicating that it is not likely that OLFM-4 plays a decisive role in the carcinogenesis of the endometrium.

In endometriosis patients, TFF1 expression is lower in the eutopic tissue compared to the corresponding endometriotic tissue in the same patient. This is indicative of elevated intrinsic oestrogenic activity in the ectopic locations [[206]; Figure 4.6d). Unexpectedly, OLFM-4 mRNA levels are not elevated in these lesions. This can be explained by the fact that EGFR1 mRNA expression is also not elevated in the lesions (Figure 4.6d). Therefore, in the ectopic location, there may be not enough EGF signalling needed to support the oestrogen action on the OLFM-4 promoter.

In addition, OLFM-4 mRNA levels are elevated in the eutopic endometrium of endometriosis patients compared to the endometrium of healthy controls (Figure 4.6a). Interestingly, OLFM-4 confers resistance to apoptosis. Apoptosis resistance in endometriosis is well documented in literature [226, 227]. In addition, OLFM-4 reduces the adherence of cells. Therefore, it can be speculated that endometrial cells located inside the uterus from endometriosis patients may have increased ability to detach and to move into the peritoneum compared to endometrial cells of healthy women. Interestingly, MEK1/2-p42/44 MAPK is elevated in endometrial stromal fibroblasts of women with endometriosis compared to women without disease. This may support an increased expression of OLFM-4 in the endometrium of patients [228]. It remains to be determined why OLFM-4 mRNA is back to the levels of healthy controls once endometrial cells are seated outside the uterus (Figure 4.6a).

\section{Acknowledgements}

This work was funded by the Maastricht University Medical Centre (MUMC). In addition, the authors are grateful to Dr K. van de Vijver (Dep. Pathology, MUMC) for helping in the analysis of clinical samples; Dr B Schutte and M. Hefling (Dep. Molecular Cell Biology, MUMC) for helping with the FACS analysis; Dr J. Broers and F. Houben (Dep. Molecular Cell Biology, MUMC) for helping with the confocal laser scanning microscope; Dr J. Theys (MAASTRO Lab, MUMC) for providing the expression plasmids for EGFR1 (wild type and dominant negative variant); Prof R. Schüle (Freiburg University, Germany) for providing the ER- $\alpha$ expression plasmid; Dr Rodgers and Dr Liu (NIH, Bethesda, USA) for useful discussions and advices for the functional studies. 


\section{Chapter 5}

\section{Oestrogen metabolizing enzymes in endometrium and endometriosis}

H. Dassen ${ }^{1,2}$, C. Punyadeera ${ }^{1,2}$, R. Kamps ${ }^{1,3}$, B. Delvoux ${ }^{3}$, A. Van Langendonckt ${ }^{4}$, J. Donnez $^{4}$, B. Husen ${ }^{5}$, H. Thole ${ }^{5}$, G. Dunselman ${ }^{1,3}$, P. Groothuis ${ }^{1,3}$

${ }^{1}$ Research Institute GROW, Department of Pathology ${ }^{2}$ and Obstetrics and Gynaecology, University Hospital Maastricht/University Maastricht, The Netherlands; ${ }^{4}$ Department of Gynaecology, Université de Catholique de Louvain, Brussels, Belgium; ${ }^{5}$ Solvay Pharmaceuticals Research Laboratories, Hannover, Germany.

Published in: Hum Reprod. 2007 Dec;22(12):3148-58. 


\section{Abstract}

Oestradiol is an important promoter of the growth of both eutopic and ectopic endometrium. The findings with regard to the expression and activity of steroidogenic enzymes in endometrium of controls, in endometrium of endometriosis patients and in endometriotic lesions are not consistent. In this study we have looked at the expression of a range of steroidogenic enzymes (aromatase, $17 \beta$-hydroxysteroid dehydrogenases (17 $\beta$-HSD) type 1, 2 and 4 , oestrogen sulfotransferase (EST) and steroid sulfatase (STS)) in eutopic and ectopic endometrium of patients with deep-infiltrative endometriosis as well as in diseasefree endometrium. In addition, we evaluated their menstrual cycle related expression patterns, and investigated their steroid responsiveness.

Aromatase and $17 \beta$-HSD type $1 \mathrm{mRNA}$ levels were extremely low in normal human endometrium, mRNAs for type 2 and 4 17 $\beta$-HSD, EST and STS were readily detectable. Only $17 \beta-\mathrm{HSD}$ type 2 and EST genes showed sensitivity to progesterone in normal endometrium. Type 1 and 2 17 $\beta$-HSD and STS protein was detected in normal endometrium using new polyclonal antibodies. In endometriosis lesions the balance is tilted in favour of enzymes producing oestradiol. This is due to a suppression of type 2 and $417 \beta$-HSD, and an increased expression of aromatase and type $117 \beta$-HSD in ectopic endometrium.

\section{Introduction}

An estimated six percent of women suffer from endometriosis and have complaints such as chronic pelvic pain and some are even infertile because of this disease [229-231]. Endometriosis is defined as the presence of endometrial glands and stroma in extra-uterine sites, mostly the pelvic peritoneum, ovaries and rectovaginal space [230, 232-234].

Endometriosis is an oestrogen-dependent disease [79, 235]. The primary source of oestradiol is the ovary, and therapies aimed at suppressing ovarian function or antagonizing the actions of oestrogens, have proven to be effective. It has long been known that the endometrium itself is a source of $17 \beta$-oestradiol, oestrone, oestrone sulfate and oestrone-3-sulfate $[50,236]$ and that elevated aromatase activity is associated with malignancies of the endometrium [236, 237]. It took however, another ten years for investigators to suspect that endometriotic lesions may be self-supporting as evidenced by aromatase overexpression [74, 76, 238]. Aromatase overexpression has now indeed been confirmed in numerous reports at the transcript level [65, 74, 75, 239], at the protein level [77, 240-242], as well as at the activity level [76, 240, 242]. The clinical relevance of these 
observations was illustrated by the fact that aromatase inhibitors were effective in the treatment of endometriosis, particularly in those cases where GnRH agonist treatment failed [243, 244], supporting the notion that significant oestrogen production continues at extraovarian sites, including adrenals, adipose tissue, skin and endometriotic lesions.

The net production of $17 \beta$-oestradiol is the result of a delicate balance between the synthesis and the inactivation of $17 \beta$-oestradiol. Next to aromatase, the production of $17 \beta$-oestradiol is also mediated through the $17 \beta$-hydroxysteroid dehydrogenases (HSD) types 1, 3, 5, 7 and 12, as well as steroid sulfatase (STS) which converts the sulphated oestrogens to biological active oestrogens [245, 246]. Gene transcripts for types 1 and $717 \beta$-HSD and oestrogen sulfatase [65, 247] were found to be overexpressed in endometriotic tissues when compared to normal endometrium. In the human, aromatase produces mainly oestrone and not oestradiol, which would support a key role for the type $117 \beta$-HSD as well.

Another key protein, which is believed to be involved in a rate limiting step in steroid biosynthesis, is the steroidogenic acute regulatory protein (StAR). Even though StAR is not an enzyme, it is responsible for the transport of the substrate for steroid synthesis, cholesterol, across the mitochondrial membrane. StAR is highly overexpressed in endometriotic lesions [248].

The conversion of $17 \beta$-oestradiol into less active metabolites in endometrium tissue is believed to be mediated for a large part by $17 \beta$-HSDs types 2 , 4 and 8 , which form by an oxidative reaction androstenedione and oestrone [40, 5255], and by the oestrogen sulfotransferase (EST) which conjugates sulphate groups to the 3-hydroxyl position [49].

The $17 \beta$-HSDs types 4 and 8 are constitutively expressed in normal human endometrium [28, 54]. No information is available with regard to the expression levels of these two genes in endometriosis. Oestrogen sulfotransferase (EST) is also expressed in normal endometrium [249]. It is expressed in the secretory phase only, suggesting that it is regulated by progestins. In the study of Smuc and co-workers [65] no differences were observed in the expression of EST in normal endometrium and ovarian endometriosis.

The type $217 \beta$-HSD is believed to be one of the most important $17 \beta$ oestradiol-inactivating enzymes in the endometrium [250, 251]. There is clear evidence that transcription of the $17 H S D 2$ gene is regulated by progesterone [251$255]$, even though some inconsistent findings have been reported [239, 256].

Such contrasting reports were also published with regard to the expression of $17 \beta$-HSD type 2 in eutopic and ectopic endometrium of endometriosis patients. The general consensus is that the expression of type $217 \beta$-HSD is reduced or absent in eutopic and ectopic endometrium of endometriosis patients [54, 232], and that $17 \beta$-HSD type 2 gene expression is insensitive to progestins [79, 257], indicating that endometriotic tissue may have reduced capacity to inactivate $17 \beta$-oestradiol. Kitawaki and co-workers [256] however, described exactly the opposite: in 
endometrium of patients $17 \beta$-HSD type 2 expression was increased in secretory endometrium of endometriosis patients. Also Smuc et al. [65] did not observe differences in type $217 \beta$-HSD expression levels between normal endometrium and endometriosis. Similar discrepancies were reported for aromatase. Kitawaki and coworkers [77, 240] and Matsuzaki and co-workers [239] found no aromatase expression in endometrium of disease-free women, whereas Tseng et al. [50, 236] clearly showed aromatase activity in normal cycling endometrium.

The inconsistent findings with regard to the expression and activity of steroidogenic enzymes in endometrium of controls and endometriosis patients and endometriotic lesions, can be attributed to a variety of factors including the use of different technologies, the quality of the samples (i.e. is the endometriotic tissue contaminated with normal tissue from the local environment), and the lesion types studied. More efforts are needed to address these issues.

Most studies have focussed on adenomyosis, leiomyomas and ovarian and peritoneal endometriosis, but little information is available about steroidogenic enzymes in the severe deep-infiltrative type of endometriosis. In the current study we evaluated the expression of aromatase, STS, EST, and the types 1, 2 and $417 \beta$ HSD in eutopic endometrium and endometriotic tissues of patients with deepinfiltrative endometriosis. In addition, expression was assessed in endometria from disease-free women. Hormonal regulation of the expression of these enzymes was also investigated in explant cultures of normal human endometrium.

\section{Materials and methods}

Tissues

Endometrial tissue was collected in 48 women of 26-52 years of age with regular menstrual cycles, who underwent surgery for benign indications other than endometriosis. The tissue was collected from hysterectomy specimens or by pipelle biopsies during laparoscopy (Pipelle catheter, Unimar Inc., Prodimed, NeuillyEnthelle, France). The women were documented not to be on any kind of steroid medication. All women signed an informed consent, as required by the protocol approved by the Medical Ethical Committee of the University Hospital Maastricht.

Forty eight biopsies of normal human endometrium were collected. Twelve were collected in the menstrual $(\mathrm{M})$ phase, 18 were collected in the proliferative phase: early proliferative phase (EP phase), $n=9$; late proliferative phase (LP phase), $\mathrm{n}=9$. Another 18 were collected in the secretory phase: early secretory phase (ES phase), $n=8$; mid-secretory phase (MS phase), $n=8$; late secretory phase (LS phase), $n=2$. After macroscopic inspection of the uteri by a pathologist, endometrium tissue was collected. The endometrium was dated according to clinical information with 
respect to the start of the last menstrual period, which was reconfirmed by histological examination of the tissue [258].

Endometrium and endometriotic lesions were collected in 14 women of 2239 years of age who underwent laparoscopic surgery to remove rectovaginal endometriosis. The endometrium was collected by pipelle biopsies during the operation (Pipelle catheter, Unimar Inc., Prodimed, Neuilly-Enthelle, France). The collected tissues were frozen in Tripure Isolation Reagent TM (Roche, Basel, Switzerland) at $-80{ }^{\circ} \mathrm{C}$ until RNA isolation.

From each biopsy part of the tissue was fixed in $10 \%$ buffered formalin for histology and immunohistochemistry and another part of the tissue was snap frozen in lysis buffer (Tripure Isolation Reagent ${ }^{\mathrm{TM}}$, Roche) and stored at $-80{ }^{\circ} \mathrm{C}$ for RNA isolation.

\section{Explant culture}

Endometrium tissues from M-phase $(n=8)$ and LP-phase $(n=8)$ biopsies were collected and transported to the laboratory in DMEM/Ham's F12 medium on ice. The tissue was minced into pieces of 2-3 $\mathrm{mm}^{3}$. Twenty four explants were placed in Millicell-CM culture inserts (pore size of $0.4 \mathrm{~m}, 30 \mathrm{~mm}$ diameter, Millipore, Billerica, MA, USA) which were placed in 6-well plates containing phenol red-free DMEM/Ham's F12 medium $(1.5 \mathrm{ml})$ (Life Technologies, Grand Island, NY). The medium was supplemented with L-glutamine (1\%), penicillin and streptomycin $(1 \%, \mathrm{P} / \mathrm{S})$. The tissue was cultured for 24 hours. At the end of the experiment, part of the explants was collected in formalin and embedded in paraffin, the rest was collected in lysis buffer (SV Total RNA Isolation Kit, Promega, Madison, WI, USA) and stored at $-80{ }^{\circ} \mathrm{C}$ until RNA-isolation.

Previous experiments have shown that collagenase activity remains very low in proliferative endometria during the first 24 hours of culture [152], and that the tissue viability is not affected after 24 hours of culture [153]. Treatments included: control (0.1\% ethanol); $17 \beta$-oestradiol (17 $\beta$-E2, $1 \mathrm{nM})$; progesterone $(\mathrm{P}, 1$ $\mathrm{nM})$ and $17 \beta-\mathrm{E}_{2}$ plus $\mathrm{P}(1 \mathrm{nM}$ each). The steroid hormones were gifts from Organon pharmaceuticals (Oss, The Netherlands).

\section{RNA isolation from normal endometrium}

Total cellular RNA from explants and uncultured endometrium was extracted using the SV total RNA isolation kit (Promega) according to the manufacturer's protocol, with slight modifications. The concentration of DNase-1 during DNase treatment of the RNA samples was doubled and the incubation time was extended by 15 minutes in order to completely remove genomic DNA. Total RNA was eluted from the column in 501 RNase-free water and stored at $-80{ }^{\circ} \mathrm{C}$ until further analysis. The quality of the RNA samples was determined with a spectrophotometer and agarose gel electrophoresis. All the samples analysed gave RNA to DNA ratios higher than 1.5. Although primer/probes were design to overlap exon boundaries, a PCR for a housekeeping gene glyceraldehyde-3-phosphate 
dehydrogenase (GAPDH) was performed on the RNA samples to verify that the samples were free of genomic DNA.

\section{RNA isolation from endometriotic tissue}

Prior to RNA isolation, the tissue was thawed at $4{ }^{0} \mathrm{C}$, cut into small pieces and homogenized 2 times 30 seconds with an Ultra-Turrax homogenizer (Rose Scientific, Edmonton, Alberta, Canada). The samples were centrifuged 10 minutes at $12,000 \mathrm{~g}$. To the supernatant 2001 chloroform was added. The samples were vortexed 15 seconds and incubated at RT for 10 minutes. The samples were centrifuged 15 minutes at 12,000 g. The aqueous upper phase was collected and 500 1 isopropanol was added to precipitate the RNA. The samples were vortexed 10 seconds and incubated 10 minutes at RT. The samples were centrifuged 10 minutes at $12,000 \mathrm{~g}$. The pellets were washed with $1 \mathrm{ml} 75 \%$ ethanol. After air-drying, the pellets were collected in RNase-free water and incubated for 10 minutes at $60{ }^{\circ} \mathrm{C}$.

cDNA synthesis

Total RNA $(1 \mu \mathrm{g})$ was incubated with random hexamers ( $1 \mathrm{~g} / 1$, Promega) at $70{ }^{0} \mathrm{C}$ for $10 \mathrm{~min}$. The samples were chilled on ice for $5 \mathrm{~min}$. To this mixture, a reverse transcriptase (RT)-mix consisting of 5x RT-buffer $(4 \mu \mathrm{l}), 5 \mathrm{mM}$ dNTP mix $(2 \mu \mathrm{l})$ (Pharmacia, Uppsala, Sweden), 0.1 M DTT $(2 \mu \mathrm{l})$ (Invitrogen, Breda, The Netherlands) and superscript II reverse transcriptase (200 U) (Invitrogen) was added and the samples were incubated at $42{ }^{\circ} \mathrm{C}$ for 1.5 hours, after which the reverse transcriptase was inactivated by heating the samples at $95{ }^{\circ} \mathrm{C}$ for $5 \mathrm{~min}$. The cDNA was stored at $-20{ }^{0} \mathrm{C}$ until further use. In each real-time PCR reaction $50 \mathrm{ng}$ of cDNA template was used.

\section{Real-time PCR}

Primers and probes for 17 $\beta$-HSD-1 (Hs00166219-g1), 17 $\beta$-HSD-2 (Hs00157993-m1), 17ß-HSD-4 (Hs00264973-m1), STS (Hs00165853-m1), EST (Hs00193690-m1) and aromatase (Hs00240671-m1) were purchased from PerkinElmer Applied Biosystems as pre-developed assays. Human cyclophylin A (Hs99999904-m1) was selected as an endogenous RNA control in order to normalize for the differences in the amount of total RNA added to each reaction. A pool of total RNA obtained from uncultured human endometrium tissues was included as positive control. All PCR reactions were performed using an ABI Prism 7700 sequence detection system (Perkin-Elmer Applied Biosystems). The thermal cycling conditions comprised an initial decontamination step at $50{ }^{\circ} \mathrm{C}$ for $2 \mathrm{~min}$, a denaturing step at $95{ }^{\circ} \mathrm{C}$ for $10 \mathrm{~min}$ and 40 cycles of $15 \mathrm{sec}$ at $95{ }^{\circ} \mathrm{C}$ followed by 1 $\min$ at $60{ }^{0} \mathrm{C}$. Experiments were performed for each sample in duplicate. Quantitative values were obtained from the threshold cycle number $(\mathrm{Ct})$ at which the increase in the signal associated with exponential increase of the number of PCR products was first detected with the ABI Prism 7700 sequence detector software 
(Perkin-Elmer, Foster city, CA). The fold-change in expression was calculated using the $\mathrm{Ct}$ method, with cyclophylin A mRNA as an internal control [156]. For detailed description of the procedure please refer to the ABI user manual.

http://www.uk1.unifreiburg.de/core/facility/tagman/user_bulletin_2.pdf.

\section{Immunohistochemistry and western blotting}

Novel polyclonal antibodies (pAb) were generated against $17 \beta$-HSD type 1 , type 2 and STS (prepared at Pineda Antikörper-Service, Berlin, Germany, on behalf of Solvay Pharmaceuticals). The pAb against type $117 \beta$-HSD (protein accession number NP_000404) was generated by injecting rabbits with a recombinant $17 \beta$ HSD type 1 peptide (h17HSD) which lacked 42 amino acids at the C-terminus (generously provided by Christina Fischer, University of Frankfurt, Germany). The pAb against type 2 17 $\beta$-HSD (protein accession number NP_002144) was generated by injecting a cocktail of the three synthetic peptides, NENGPGAEELRRTC (peptide A), CNIAGTSDKWEKLEKD (peptide B) and CAKRHFGQDKPMPRALR (peptide C). The pAb against STS (protein accession number NP_000342) was generated by injecting a cocktail of the three synthetic peptides, CLWEAESHAASRPNII (peptide A), CAHVEEVSSKGEIHGGS (peptide B) and CSSKGEIHGGSNGIYK (peptide C). The peptides were conjugated to a protein carrier $(\mathrm{KLH})$. Three rabbits were injected with the peptide-conjugate cocktails for each antigen, and from each rabbit preimmune serum was collected. The generated antibodies were affinity purified using the immunizing peptides.

Specificity of the pAbs was demonstrated by western blotting and immunohistochemistry. To confirm specificity of the $17 \beta$-HSD type $1 \mathrm{pAb}$, gels were loaded with $10 \mu \mathrm{l}(1 \mu \mathrm{g} / \mu \mathrm{l}) \mathrm{HSD} 1$-containing tumour cytosol (figure 5.1A, lane 1), $20 \mu \mathrm{l}$ homogenate $(0.55 \mu \mathrm{g} / \mu \mathrm{l})$ from a HSD1-positive-cell line (figure $5.1 \mathrm{~A}$, lane 2) and $10 \mu \mathrm{l}$ homogenate $(1 \mu \mathrm{g} / \mu \mathrm{l})$ from a HSD1-negative-cell line [259], and subsequently probed with the preimmune serum, the pAb or the pAb after preincubation with the immunizing peptides. Antibody binding was visualized with an alkaline phosphatase-conjugated anti-rabbit IgG (1:10,000, Sigma-Aldrich, St. Louis, MO, USA) and incubation with NBT/BCIP-substrate solution (SigmaAldrich). Specific binding of the pAb against type $217 \beta$-HSD was shown by loading the individual immunizing peptides, as well as lysates prepared from placenta. The pAb and pre-immune serum were applied at a 1:5000 dilution. Antibody binding was visualized with anti-rabbit HRP (1:10,000; Dako, Glostrup, Denmark) and incubation in a chemiluminescent substrate (SuperSignal West Pico Chemiluminescent Substrate, Pierce, Rockford, USA). Specific binding of the antiSTS pAb was demonstrated by loading lysates prepared from endometrium and placenta and purified arylsulfatase $\mathrm{C}$ (Sigma-Aldrich) on the gels. The affinity purified antibody was applied at a dilution of 1:1000. Antibody binding was visualized in the same way as for the type $217 \beta$-HSD. 
Figure 5.1: Western blot analysis (A) and immunohistochemistry (B) with the polyclonal antibody

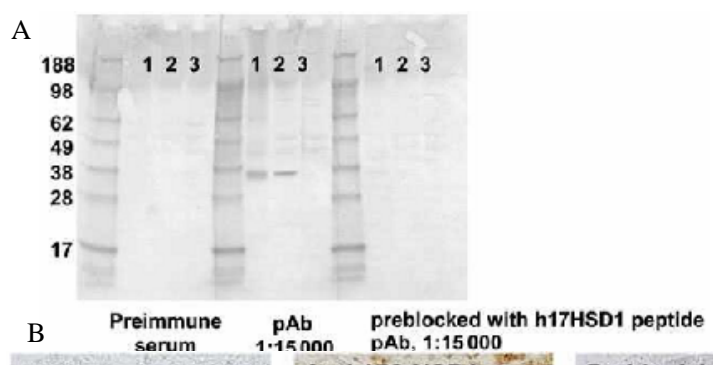

Preimmune Anti-17 $\beta$-HSD1

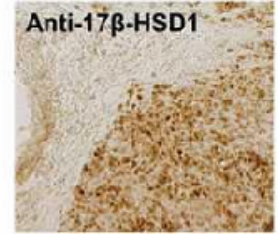

against $17 \beta-\mathrm{HSD}$ type 1 . The pAb shows a specific band at the expected molecular weight (A) and specific staining in subcutaneous tumors in immunodeficient mice generated from 17 $\beta$-HSD type 1-transfected MCF-7 human breast cancer cells (B). Preincubation with the h17HSD1 fusion protein prevented antibody binding in both the western blot (A) and immunostaining (B). Lane $1=10 \mu 1$

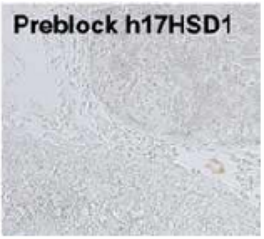

$(1 \mu \mathrm{g} / \mu \mathrm{l}) \mathrm{HSD} 1$-containing tumour cytosol; lane $2=20$ $\mu 1$ homogenate $(0.55 \mu \mathrm{g} / \mu \mathrm{l})$ from a HSD1-positive-cell line; lane $3=10 \mu 1$ homogenate $(1 \mu \mathrm{g} / \mu \mathrm{l})$ from a HSD1-negative-cell line

For immunostaining paraffin sections of $5 \mathrm{~m}$ were cut from uncultured and cultured explants and from the deep invasive endometriotic lesions and uterus from endometriosis patients. In addition, sections were prepared from placenta and breast cancer tissue to serve as positive tissue controls. The sections were deparaffinised $2 \times 5 \mathrm{~min}$ in xylene and $2 \times 5 \mathrm{~min}$ in $100 \%$ ethanol. The endogenous peroxidases were blocked by incubating $30 \mathrm{~min}$ in $0.3 \% \mathrm{H}_{2} \mathrm{O}_{2}$ in methanol. For antigen retrieval the sections were boiled in TE-buffer $(\mathrm{pH} 9.0)$ in a microwave oven for $20 \mathrm{~min}$. In the preliminary stainings a 1:1000 dilution was used for the anti-17 $\beta$ HSD type $1 \mathrm{pAb}$ and preimmune serum. The Dako-Envision protocol (Dako Diagnostika, Hamburg, Germany) was used to visualize antibody binding. The preimmune serum and pAbs against 17 $\beta$-HSD type 2 and STS were diluted 1:2000 and 1:1000 respectively. Antibody binding was visualized with the Chemate ${ }^{\mathrm{TM}}$ Envision kit (Dako).

After assessing specificity, the immunohistochemistry procedure was further optimized. The conditions used to stain the clinical specimens were the following. The anti-17 $\beta$-HSD type $1 \mathrm{pAb}$ and preimmune serum was used at 1:4000 and sections were incubated for $1 \mathrm{hr}$ at room temperature. The anti-17 $\beta$-HSD type 2 $\mathrm{pAb}$ and preimmune serum were incubated for $2 \mathrm{hrs}$ at room temperature at a dilution of 1:2000. The anti-STS polyclonal antibody and preimmune serum were diluted 1:1000 and sections were incubated overnight at $4{ }^{\circ} \mathrm{C}$. Antibody binding was visualized by incubating $30 \mathrm{~min}$ with Chemate ${ }^{\mathrm{TM}}$ Envision (Dako) and staining with diaminobenzidine solution. The reaction was stopped in water. The sections were briefly counter-stained in haematoxylin, dehydrated and sealed in Entellan (Merck, Whitehouse Station, NJ, USA).

Staining intensitiy was scored in epithelial and stromal cells separately on a 5 point scale: negative $(0)$; weak (1); weak-moderate (2); moderate (3); moderatestrong (4) and strong (5). In addition, the percentage of postively stained cells within each compartment was assessed. 


\section{Statistical tests}

Statistical tests were carried out using the SPSS 11 (SPSS Inc., Chicago, IL) statistical analysis package. To evaluate whether expression levels varied significantly throughout the menstrual cycle, the nonparametric unpaired Mann Whitney $\mathrm{U}$ test was used to test for differences between the expression levels versus the expression level in the menstrual phase. This was done for both the mRNA and protein data. This test was also used to test for differences in the expression of the oestrogenic enzymes in normal endometrium versus eutopic and ectopic endometrium of endometriosis patients. The nonparametric Wilcoxon signed rank test was used to test for differences between steroid treated explants and controls at a confidence level of $95 \%$.

\section{Results}

Validation of the antibodies against 17ß-HSD types 1 and 2 and STS

With immunoblotting a specific band at the expected molecular weight of $37 \mathrm{kD}$ was visible in the cytosol of the tumour cell line and cells known to express $17 \beta$-HSD type 1 , which was not visible with the preimmune serum, and which disappeared after preincubation with the 17 $\beta$-HSD type 1 fusion protein (figure 5.1A). Immunostaining in paraffin sections of breast cancer tissue also disappeared after preincubation of the pAb with excess h17HSD fusion protein (figure 5.1B) indicating the specificity of the generated $\mathrm{pAb}$.

Only one of the three pAbs generated against $17 \beta$-HSD type 2 showed cross reactivity with one of the three peptides (NENGPGAEELRRTC, peptide A; figure 5.2A). A specific band was also present in the placenta lysate at the expected molecular weight of $43 \mathrm{kD}$. The other pAbs only gave a non-specific band in placental lysates around $75 \mathrm{kD}$, which was also seen with the preimmune serum (results not shown). These antibodies also showed strong staining in the syncytiotrophoblast, which could not be displaced by any of the three peptides (figure 5.2B, polyclonal 2). The candidate antibody however, showed immunostaining mostly in the vessels, which was completely abolished by preincubation with the immunizing peptides (figure 5.2B, polyclonal 1).

To check specificity of the STS pAb, western blot analysis was performed on purified microsomal steroid sulfatase (arylsulfatase $\mathrm{C}$; figure 5.3A). Besides the expected bands at $63 \mathrm{kD}$, other bands $(\sim 40$ and $50 \mathrm{kD})$ were visible as well. A similar pattern was observed when incubated with the preimmune serum (figure 5.3A) and lower dilutions of the pAb (results not shown), and these bands could not be blocked with the immunizing peptides. In lysates of endometrium and placenta tissues also the $63 \mathrm{kD}$ band is visible (figure 5.3B), however, the 40 and $50 \mathrm{kD}$ 
bands were more abundant. Based on the known size of the active enzyme and the post-translational modifications that could occur, it is not possible that the 40 and 50 $\mathrm{kD}$ bands represent STS. In contrast, immunohistochemical staining was completely prevented after preincubation of the $\mathrm{pAb}$ with the immunizing peptide $\mathrm{A}$, but not peptides B and C (figure 5.3C). This antibody appears therefore to be suitable for immunohistochemistry and not for western blotting.

Figure 5.2. Western blot analysis (A) and immunohistochemistry (B) with the polyclonal antibody against $17 \beta$-HSD type 2 . Immunostaining of pAb 1 can be prevented by preincubation with the A

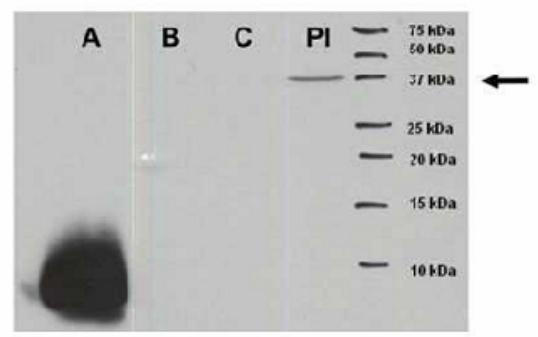
immunizing peptides (B); this is not the case for $\mathrm{pAb} 2$. The anti-type 2 17 $\beta$-HSD pAb 1, cross reacted with immunizing peptide $\mathrm{A}(\mathrm{A})$.

B

\section{Polycional 1}

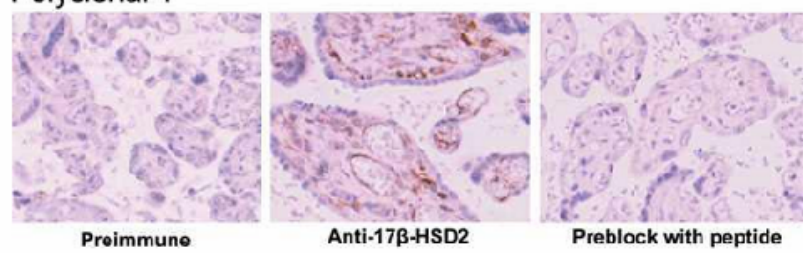

\section{Polyclonal 2}

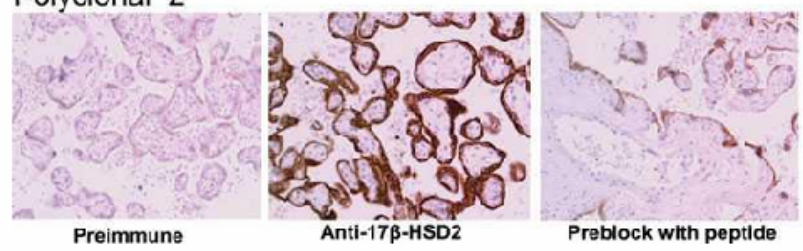

Expression of 17ß-oestradiol synthesizing and metabolizing enzymes throughout the menstrual cycle

The expression of $17 \beta$-HSD type 2 mRNA increased during the secretory phase of the menstrual cycle compared to the proliferative phase of the cycle (figure 5.4). Transcript levels increased in the ES phase and remained high throughout the secretory phase. At the protein level however, 17 $\beta$-HSD type 2 expression was observed mostly in the glandular epithelium (figure 5.5). Levels peaked during the MS phase, the implantation window (figure 5.6). Little staining was also observed in 
the stroma, but expression in the stroma did not change throughout the menstrual cycle.

Figure 5.3. Western blot analysis (A, B) and immunohistochemistry in placenta (C) with the polyclonal antibody against STS. The immunostaining pattern is similar to that of the type $217 \beta$-HSD pAb, and can

A

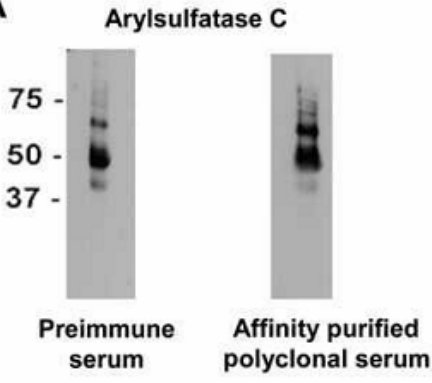

B
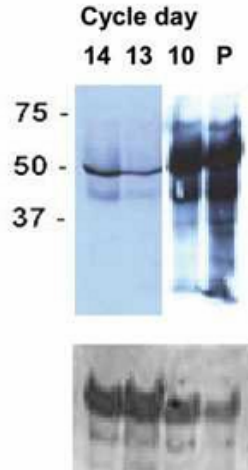

Ponceau stained blot also be completely blocked with the immunizing peptides (C). (A) Western blotting showed specific bands around 63,50 and $40 \mathrm{kD}$ in the blot loaded with arylsulfatase C. (B) The same bands were also present in homogenates of endometrial tissues and placenta $(\mathrm{P})$.

C
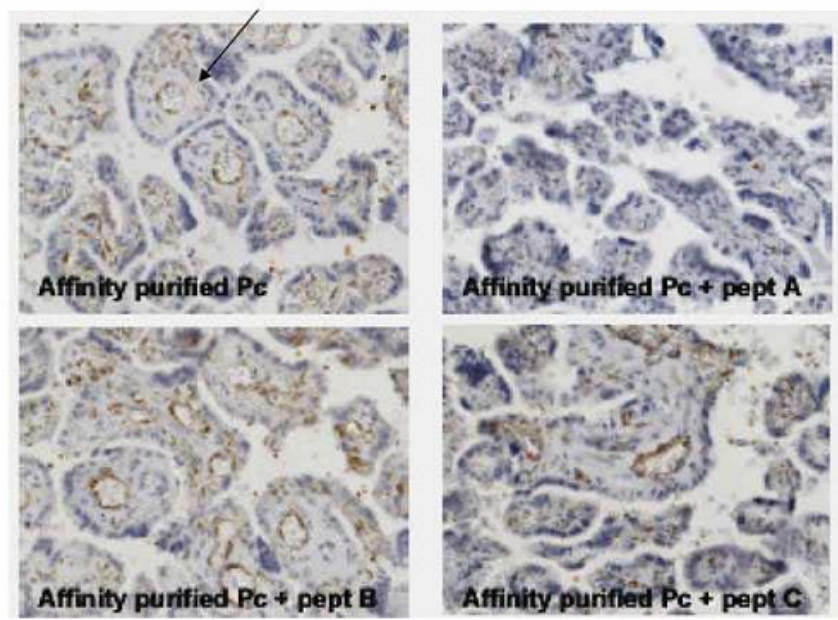

Aromatase gene transcript levels in normal endometrium were near the detection limit, and no cyclical variations were observed.

No expression of $17 \beta$-HSD type 1 mRNA was observed (results not shown). Surprisingly however, prominent expression was observed at the protein level (figures 5.5 and 5.6). These levels did not vary between stages of the cycle (figures 5.5 and 5.6).

Transcript levels of $17 \beta$-HSD type 4 and STS were similar to that of $17 \beta-$ HSD type 2, but the levels did not increase in the secretory phase (results not shown). Expression of STS protein did also not change during the menstrual cycle (figures 5.5 and 5.6). STS protein was expressed in both epithelial and stromal cells. 
Figure 5.4. Gene transcript levels of 17ß-HSD type 2 and EST in the normal human endometrium

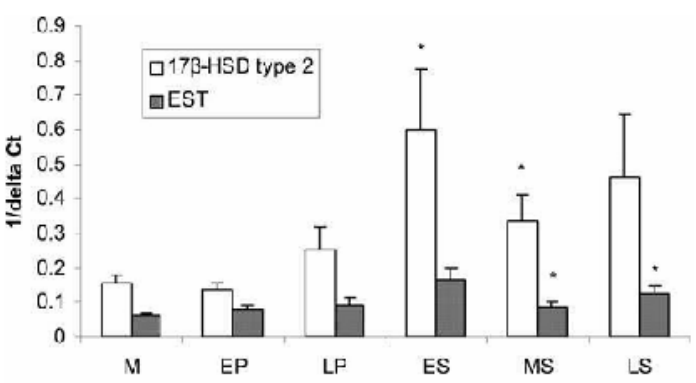
throughout the menstrual cycle. Data are presented as means \pm SEM. $*=$ vs. $\mathrm{M}$ phase $(\mathrm{p}<0.05)$

Figure 5.5. Representative photographs of 17ß-HSD type 1, type 2 and STS protein expression in normal endometrium collected on menstrual cycle days 11,17 and 21 .

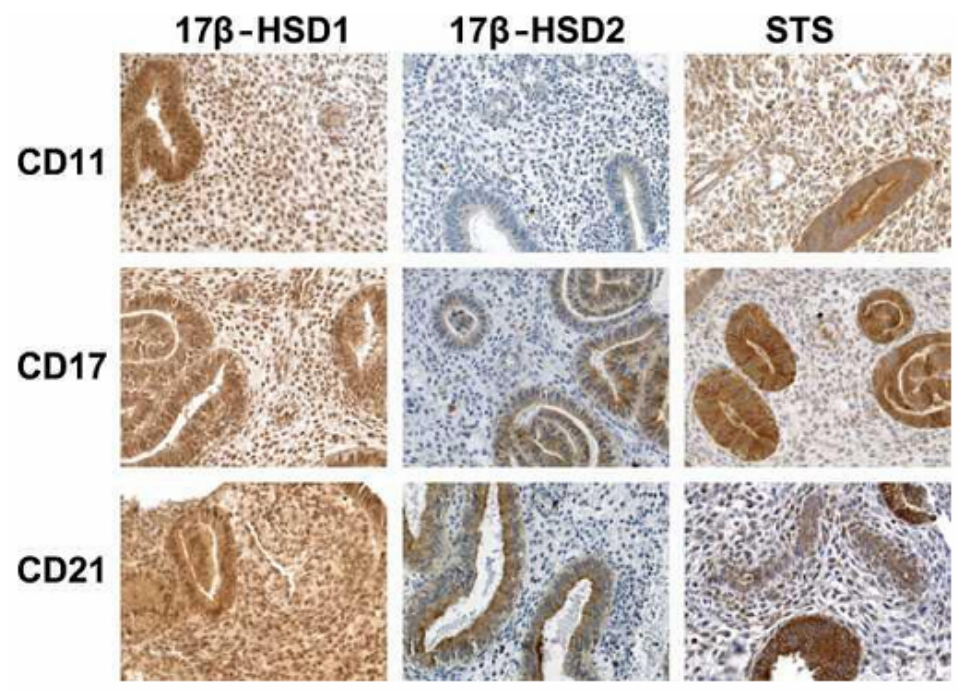

EST transcript levels were lower $(\mathrm{P}<0.05)$ than that of $17 \beta$-HSD types 2 and 4 , but expression levels increased significantly in the secretory phase (figure 5.4). Despite these differences in expression levels, a highly significant correlation was found between the cyclic variations in mRNA expression of $17 \beta$-HSD type 2 and EST (correlation 0.79, $\mathrm{p}<0.0001$ ).

Steroid regulation of $17 \beta$-oestradiol synthesizing and metabolizing enzymes

The production of aromatase, the $17 \beta$-HSD types 1 and 4 and STS mRNA in cultured endometrium explants prepared from M-phase and LP-phase explants was not affected by $17 \beta$-oestradiol or progesterone. 
Figure 5.6. Expression of $17 \beta-\mathrm{HSD}$ type 1, type 2 and STS protein throughout the menstrual cycle. The staining intensity and the percentage of cells stained are presented and analysed separately. Data are presented as means \pm SEM. $*$ p $<0.05$ vs. M phase.
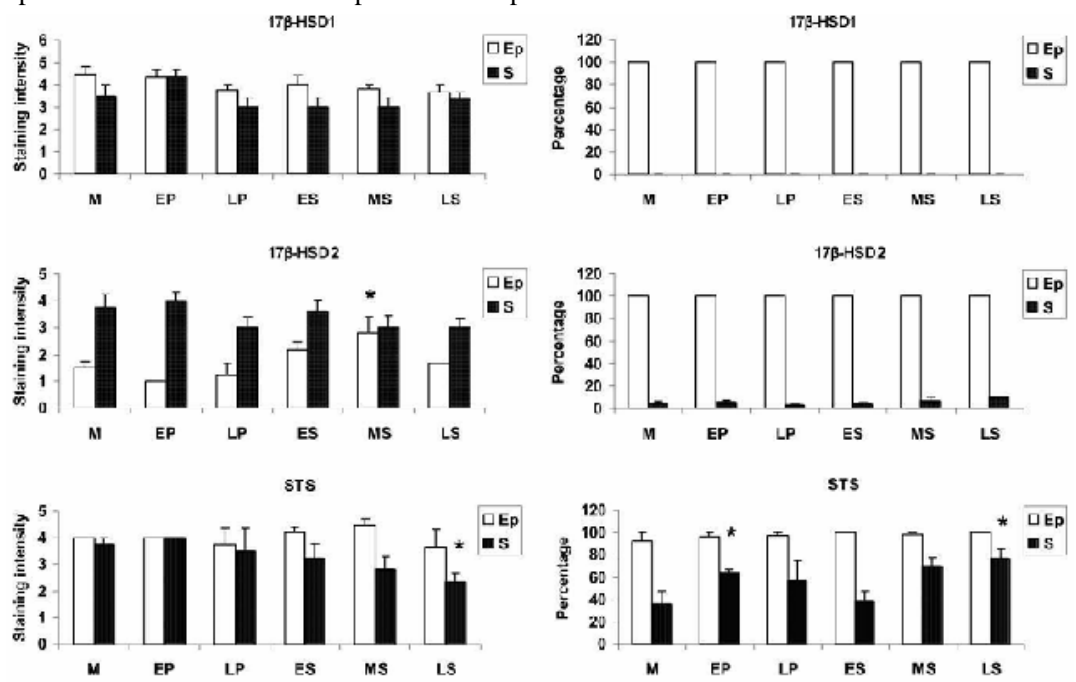

The levels of EST and 17 $\beta$-HSD type 2 gene transcripts were significantly induced by progesterone in both, M-phase and LP-phase explants (figure 5.7). Treatment with $17 \beta$-oestradiol alone had no effect on the $17 \beta$-HSD type 2 mRNA expression in M-phase and LP-phase explants. Tissues collected from the LP phase were significantly $(\mathrm{P}<0.05)$ more responsive to the action of progesterone for both EST and $17 \beta$-HSD type 2 .

Steroid regulation at the protein level in these short term cultures was not confirmed with the semi-quantitative immunohistochemistry.

Figure 5.7. Effects of oestradiol and progesterone on gene transcript levels of 17 $\beta$-HSD-2 and EST in M

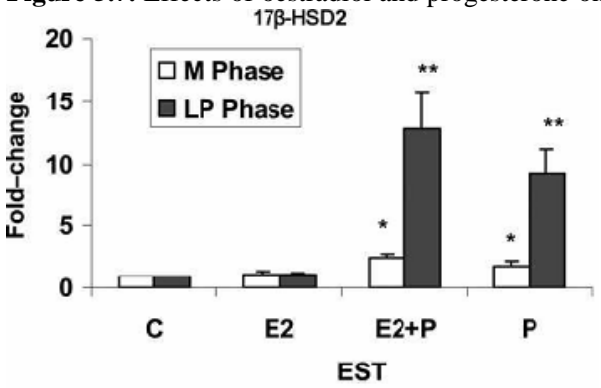
and LP phase explants. Data are presented as means \pm SEM. $* \mathrm{p}<0.05$ vs. control. $* * \mathrm{p}<0.05$ vs. M phase explants.

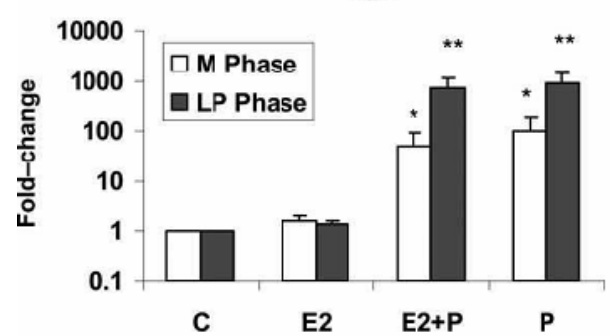


Figure 5.8. Gene transcript levels of steroidogenic enzymes in eutopic and ectopic endometrium from endometriosis patients and normal endometrium. Data are presented as means \pm SEM. $* \mathrm{p}<0.05$, ** $\mathrm{p}<0.01$ vs. normal endometrium; \# $\mathrm{p}<0.05$, \#\# $\mathrm{p}<0.01$ vs. eutopic endometrium of the same patient.

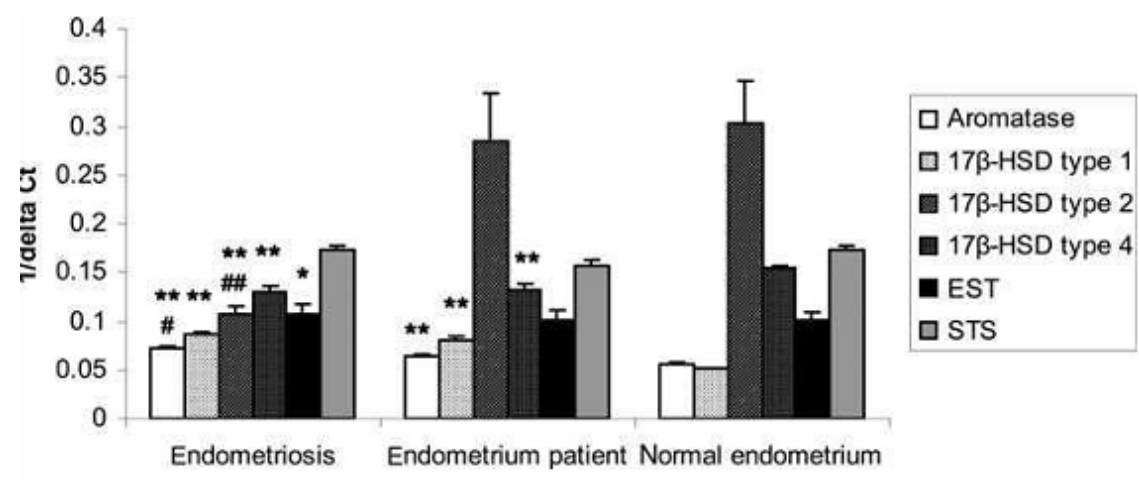

$17 \beta$-oestradiol synthesizing and metabolizing enzymes in endometriotic tissues

Compared to normal endometrium, transcript levels of $17 \beta$-HSD type 1 and aromatase were significantly higher in the endometrium $(\mathrm{P}<0.01)$ and endometriotic lesions $(\mathrm{P}<0.01)$ of endometriosis patients compared with normal endometrium (figure 5.8). Aromatase mRNA levels were found also to be significant higher in the endometriotic lesions compared to the endometrium of endometriosis patients (figure 5.8). 17 $\beta$-HSD type 1 protein is expressed in all cells, but staining intensity is significantly lower in epithelial $(\mathrm{P}<0.01)$ and stromal cells $(\mathrm{P}<0.01)$ of the eutopic and ectopic endometrium of the endometriosis patients compared with the normal endometrium (figures 5.9a and 5.10).

Transcript levels of $17 \beta$-HSD type 2 were significantly lower $(\mathrm{P}<0.01)$ in the endometriotic lesions than in the endometrium of patients and controls. No significant differences were found between the normal endometrium and the eutopic endometrium of patients (figure 5.8). 17 $\beta$-HSD type 2 protein is expressed mostly in epithelial cells. However, the number of positive stromal cells was slightly increased $(\mathrm{P}<0.05)$ in the eutopic endometrium of patients, whereas staining intensity was significantly reduced $(\mathrm{P}<0.05)$ in stromal cells of the lesions compared with the normal endometrium (figures $5.9 \mathrm{~b}$ and 5.10 ).

The mRNA levels of $17 \beta$-HSD type 4 were significantly $(\mathrm{P}<0.01)$ lower in the lesions and endometrium of endometriosis patients when compared with the normal endometrium. No difference was found between the lesions and the endometrium of endometriosis patients (figure 5.8). 
Figure 5.9. Protein expression of 17 $\beta$-HSD-1 (A), 17 $\beta$-HSD-2 (B) and STS (C) in eutopic and ectopic

A
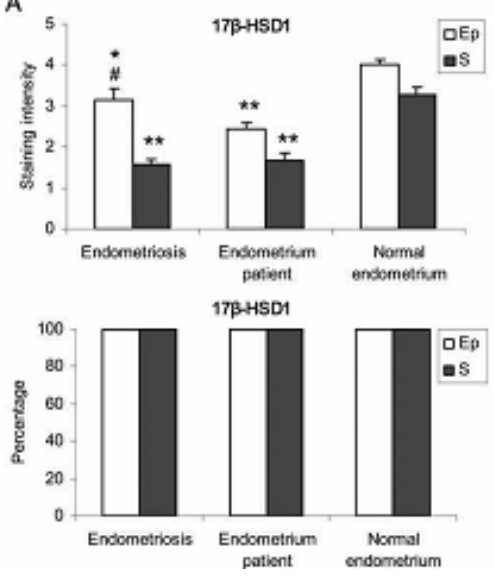

C
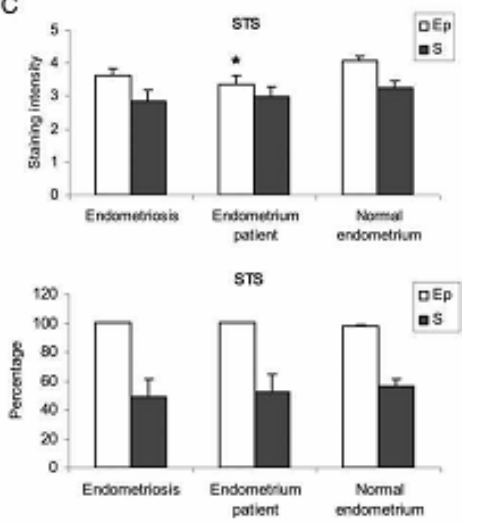

endometrium from endometriosis patients and normal endometrium. Staining intensity and the percentage of stained cells are analysed and presented separately. Data are presented as means \pm SEM. $* \mathrm{p}<0.05, * * \mathrm{p}<0.01$ vs. normal endometrium; \# p<0.05 vs. eutopic endometrium of the same patient. Ep = epithelium, $\mathrm{S}=$ stroma.

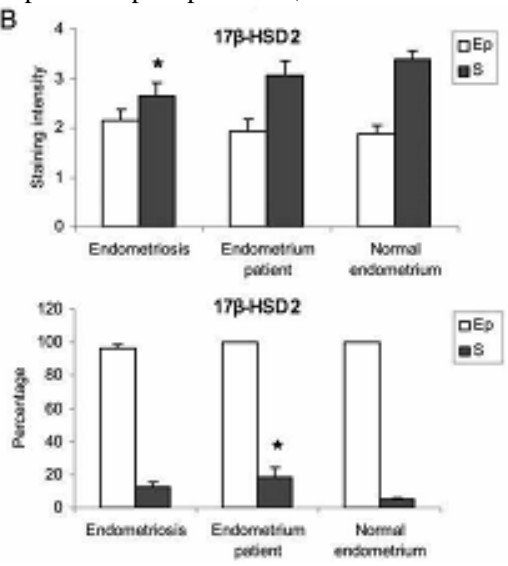

Figure 5.10. Representative photographs of immunostainings for $17 \beta$-HSD type 1, type 2 and STS in eutopic and ectopic endometrium of endometriosis patients.

\section{Eutopic}

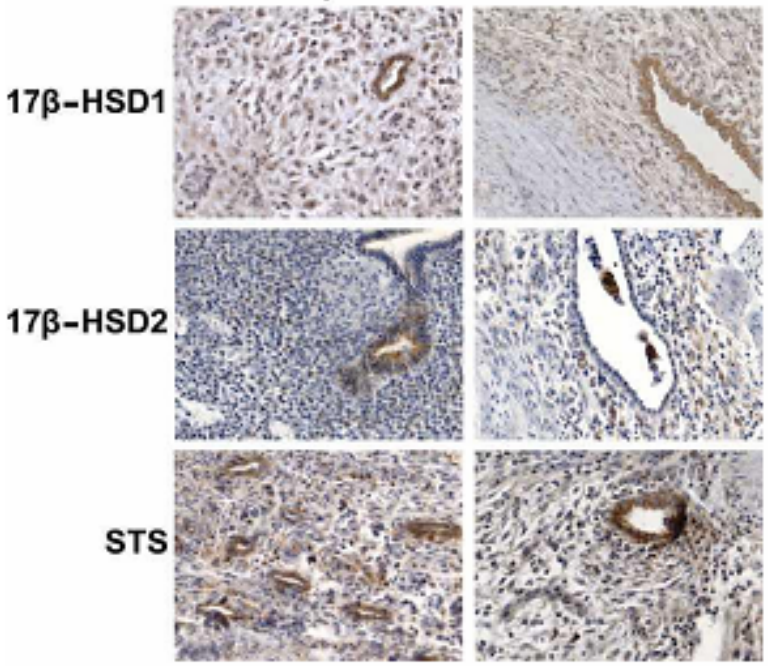


No differences were observed between the STS mRNA levels of endometrium and lesions of endometriosis patients and endometrium of patients without endometriosis (figure 5.8). STS protein was expressed both by stroma and epithelium. STS protein levels were significantly $(\mathrm{P}<0.05)$ lower in epithelial cells of endometrium of endometriosis patients compared to the epithelial cells in normal endometrium (Figure 5.9 and 5.10). No difference in STS protein levels was observed between epithelial cells of the lesions and the normal endometrium (figure 5.9).

EST mRNA levels were significantly $(\mathrm{P}<0.05)$ higher in endometriotic tissue when compared to normal endometrium (figure 5.8).

\section{Discussion}

In this study we have investigated the expression of six enzymes involved in the synthesis and inactivation of 17 $\beta$-oestradiol in eutopic and ectopic endometrium of patients with deep-infiltrative endometriosis. Three polyclonal antibodies were generated to study type 1 and 2 17 $\beta$-HSD and STS protein expression in the tissues. We show that there are parallels between deep-infiltrative endometriosis and the reports on adenomyosis, ovarian and peritoneal endometriosis, with regard to the expression of steroidogenic enzymes, but we also report some novel findings.

With regard to the oestradiol synthesizing enzymes, we found very low levels of aromatase and 17 $\beta$-HSD type 1 mRNA in normal human endometrium, which is in line with earlier reports [239, 260]. Aromatase and 17 $\beta$-HSD type 1 expression was not responsive to oestradiol and progesterone in the explant cultures. This is in contrast with finding of Tseng and coworkers [64] who showed that aromatase activity in isolated endometrial stromal cells was induced up to 40-fold by progesterone, which was further enhanced 20 to 100 -fold by oestradiol. Whether this is due to the fact that in the tissue context, oestrogen metabolism may be different than in isolated cell compartments, or that prolonged exposure is needed to induce aromatase expression remains to be elucidated.

In contrast to the low levels of $17 \beta$-HSD type 1 mRNA in the normal human endometrium, we did however detect $17 \beta$-HSD type 1 protein. The fact that we were unable to determine $17 \beta$-HSD type $1 \mathrm{mRNA}$ transcripts in the endometrium of disease-free women, suggests that these transcripts either degraded quickly or are synthesised in low quantities. Reports on the expression of $17 \beta$-HSD type 1 in normal endometrium are conflicting. Miettinen et al. [55] reported low expression of $17 \beta$-HSD type 1 mRNA in endometrium, whereas Casey and co-workers [253] found no expression of $17 \beta$-HSD type $1 \mathrm{mRNA}$ in normal human endometrium, and Utsunomiya et al. [261] found no $17 \beta$-HSD type 1 protein expression in normal 
endometrium. In this study we used a new polyclonal antibody and we clearly demonstrated expression of type $117 \beta$-HSD in normal endometrium. Steroidal regulation however, was not observed in the explant cultures. The presence of type 1 $17 \beta$-HSD protein agrees with the observed $17 \beta$-oestradiol conversion into oestrone in normal proliferative endometrium [262].

Aromatase and type $117 \beta$-HSD mRNA levels were higher in eutopic and ectopic endometrium of endometriosis patients than in the endometrium of controls, which is in agreement with the findings of others [74, 239]. Surprisingly however, $17 \beta$-HSD type 1 protein levels were lower in epithelial and stromal cells of endometrium and lesions of endometriosis patients compared with the normal endometrium. For $17 \beta$-HSD type $1 \mathrm{mRNA}$ two isoforms have been described, 1.3 and $2.3 \mathrm{~kb}$ [55]. Only the $1.3 \mathrm{~kb}$ mRNA is correlated with $17 \beta$-HSD type 1 protein expression and activity [55]. In normal human endometrium the $1.3 \mathrm{~kb} 17 \beta$-HSD type 1 mRNA expression is low in normal human endometrium, but the $2.3 \mathrm{~kb}$ mRNA is abundantly present [55]. Expression of the type $117 \beta-\mathrm{HSD}$ gene may therefore not necessarily reflect changes at the functional protein level. The type 1 $17 \beta$-HSD is still considered a rate-limiting enzyme in the production of oestradiol, since the major product of the aromatase activity in humans is oestrone and not oestradiol [263], and is therefore still an interesting alternative target for therapy.

At the IXth World Congress on Endometriosis in Maastricht, The Netherlands (2005), Fusi and coworkers showed that both endometrium and endometriotic tissues have high steroid sulfatase activity, which suggests that these tissues can generate high levels of oestrone from the serum pool of oestrone-3sulfate. This agrees with the report of Benedetto and co-workers [264], who also showed STS activity in human endometrial cells, but is not in line with the finding of Utsunomiya et al. [249], who showed immunohistochemically that STS protein is not present in normal human endometrium using another pAb directed against STS purified from placenta. In this study however, we demonstrated STS gene expression in disease-free endometrium, but in contrast to the finding of Smuc et al. [65] in ovarian endometriosis, we did not observe higher STS mRNA levels in endometriotic lesions. Using our own polyclonal antibody, we clearly demonstrated immunostaining in the endometrium. In contrast to Benedetto et al. [264] who showed that STS activity increased in the presence of oestradiol and medroxyprogesterone acetate, we did not observe steroid responsiveness in our short term explant cultures. This may be due to the fact that prolonged incubation (8-15 days) was required to evoke this response, which would not be visible in the 24 hour explant cultures.

The differences we observed in the expression levels of aromatase, type 1 $17 \beta$-HSD and STS between eutopic and ectopic endometrium from endometriosis patients and normal endometrium are significant, but small. In deep-infiltrative endometriosis it is possible that differences in gene expression may be masked due to the presence of normal tissue from the local environment, which does not express steroidogenic enzymes [74]. This also explains why Matsuzaki and co-workers [239] found much higher levels of aromatase in the ectopic than the eutopic endometrium, because the ectopic endometrium was isolated from its environment with laser 
capture microdissection. Despite the relatively small effects, we still observed significantly higher levels of aromatase and type $117 \beta$-HSD levels in deepinfiltrative endometriosis.

With regard to the $17 \beta$-oestradiol inactivating enzymes we confirmed that type $217 \beta$-HSD mRNA levels are significantly lower in endometriotic lesions compared to levels in normal endometrium [79, 239]. We also show for the first time that the type $417 \beta$-HSD is expressed in endometriotic lesions and that the mRNA levels are lower than in normal endometrium. EST mRNA levels were not different between the groups, which agrees with the findings of Smuc et al. [65]. Using a new antibody however, we could not confirm that type $217 \beta$-HSD protein is expressed at lower levels in endometriotic tissue, which is in contrast to the observation of Zeitoun and co-workers [79].

We showed in our steroid-responsive explant cultures that of all enzymes investigated, only the $17 \beta$-HSD type 2 and EST were responsive to progesterone which agrees with the findings of others [54, 73, 250, 253, 265, 266]. The lower expression of $17 \beta$-HSD type 2 in the ectopic endometrium in patients was postulated to be the result of reduced sensitivity to progesterone [81, 232, 234]. We observed however, that in contrast to type $217 \beta$-HSD, expression levels of EST were not reduced in the endometriotic lesions, whereas in normal endometrium the expression patterns of $17 \beta$-HSD type 2 and EST were strongly correlated. This suggests that the expression of $17 \beta$-HSD type 2 is selectively suppressed.

It is clear that enzyme activities are different in the epithelial and stromal compartments, as is the expression of the different steroidogenic enzymes. Aromatase activity was shown to be present in both stroma and epithelium, but activity in the stroma was approximately 3-4 times higher [50]. For this reason most in vitro studies have been performed with stromal cells isolated from the endometriotic lesions. Aromatase mRNA [239] and protein [240] however, were found to be expressed mostly in the epithelial cells. The importance of intercellular communication with regard to the regulation of steroidogenesis was illustrated by for instance the paracrine regulation of type $217 \beta$-HSD expression in epithelial cells by factors released by the stroma [267], and the presence of PR in the stromal cells [40]. Endometrial cell-specific production of metabolites was demonstrated for tibolone [268]. Stromal cells were shown to contain $3 \alpha$ - and $\beta$-aldoketoreductases which converted tibolone into $3 \alpha$ - and $3 \beta$-hydroxytibolone, whereas in the epithelial cells tibolone is directly converted into ${ }^{4}$-tibolone. It is therefore important to consider that the net production of $17 \beta$-oestradiol synthesis is also influenced by cellular interactions, which has to be accounted for in the experimental designs, i.e. by using co-cultures or explant cultures.

Finally, it has to be noted that even though much attention was given to the expression and activities of individual enzymes, there is no information with regard to the actual output of $17 \beta$-oestradiol by the ectopic endometrium. An important aspect in this regard is the fact that the intracellular redox state of cells is an important determinant of the enzymatic conversions by HSDs [269]. The nicotinamide cofactors required for the reduction and oxidization activities are 
abundant in cells, reaching millimolar concentrations. In cells the major reducing cofactor is NADPH (NADPH/NADP ${ }^{+}$ratio $\sim 100: 1$ ) and the major oxidizing cofactor is $\mathrm{NAD}^{+}\left(\mathrm{NADH} / \mathrm{NAD}^{+}\right.$ratio $\sim 1: 1000$; [270, 271]. In addition, it was shown that low micromolar concentrations of NADPH potently inhibits $\mathrm{NAD}^{+}$dependent oxidative reactions [272]. Collectively, this suggests that in vivo the reductive activity is dominant [272]. This would for instance mean that the type 1 $17 \beta$-HSD activity would dominate type 2 activity. In addition, P450 enzymes like aromatase also need NADPH and molecular oxygen and will irreversibly oxidize the steroid nucleus [273]. These observations indicate that increases in the expression of oestradiol-generating enzymes will have a greater impact on the net production of $17 \beta$-oestradiol than a reduction in the expression of oestradiol-inactivating enzymes.

The endometrium is also a source of drug metabolizing enzymes usually present in the liver. Reddy et al [56] showed that human endometrial tissue was able to metabolise $17 \beta$-oestradiol into the catecholoestrogens 2-hydroxy- and 4hydroxyoestradiol. It has now been shown that the human endometrium expresses CYP3A4 known to convert oestrone in $16 \alpha$-hydroxyoestrone and $17 \beta$-oestradiol into 2-hydroxyoestradiol [57], and CYP1B1 known to convert 17 $\beta$-oestradiol into 4hydroxyoestradiol [58]. Furthermore, the human endometrium expresses catechol Omethyltransferase, which converts the 2-hydroxy- and 4-hydroxyoestradiol into 2and 4-methoxyoestradiol [274]. Another group of potential 17 $\beta$-oestradiol inactivating enzymes was also identified in the endometrium, the uridine diphosphoglucuronosyltransferases (UGTs) [51]. The endometrium appears to be a rich source of UGTs which are able to conjugate both oestrogens and catecholestrogens on different positions. However, their relevance with regard to the development of endometrial pathologies is not known.

\section{Summary}

We confirm that aromatase and 17 $\beta$-HSD type 1 expression is higher in deep-invasive endometriosis than in eutopic and normal endometrium. Even though no $17 \beta$-HSD type 1 gene transcripts were detected in normal endometrium, we did observe a clear expression of the $17 \beta$-HSD type 1 protein, which was not elevated in the ectopic endometrium. Expression of the STS was prominent at both the mRNA and protein level, but was not elevated in endometriotic tissues. Type $217 \beta$-HSD gene transcript levels were lower in deep-invasive endometriosis. Type 2 17 $\beta$-HSD protein levels however, were not lower in lesion compared to the eutopic or normal endometrium. We show for the first time that the $17 \beta$-oestradiol inactivating enzyme $17 \beta$-HSD type 4 is expressed in deep-invasive endometriosis, and that it is also down-regulated in endometriosis. Together with the continuous presence of aromatase and the substantial levels of STS, this may result in an increase in the local production of $17 \beta$-oestradiol in the endometriotic lesions. Inventarization of 
the net metabolic conversions in the whole endometriotic tissue, would aid in the selection of the appropriate combination of enzyme inhibitors to optimize medical therapy of endometriosis.

In normal endometrium both the $17 \beta$-HSD type 2 and EST were responsive to progesterone. The fact that in deep-infiltrative endometriosis only the expression of type $217 \beta$-HSD was suppressed and not that of EST, suggests local and selective dysregulation of type $217 \beta$-HSD expression. 


\section{Chapter 6}

\section{Progesterone regulation of implantation related genes: new insights into the role of oestrogen}

H Dassen ${ }^{1,2^{*}}$, C Punyadeera ${ }^{1,2^{*}}$, R Kamps ${ }^{1,2}, \mathrm{~J} \mathrm{Klomp}^{4}$, G Dunselman ${ }^{1,3}$, F Dijcks ${ }^{4}$, A de Goeij $^{1,2}$, A Ederveen ${ }^{4}$ and P Groothuis ${ }^{1,3}$

* First and second authors contributed equally in realising this article

${ }^{1}$ Research Institute GROW; Departments of ${ }^{2}$ Pathology and ${ }^{3}$ Obstetrics and Gynaecology, University Hospital Maastricht/University Maastricht; ${ }^{4}$ Department of Pharmacology, Organon N.V., Oss, The Netherlands

Published in: Cell Mol Life Sci. 2007 Apr;64(7-8):1009-32 


\begin{abstract}
Genomic profiling was performed on explants of late proliferative phase human endometrium after 24 hour treatment with progesterone $(\mathrm{P})$ or oestradiol and progesterone $\left(17 \beta-\mathrm{E}_{2}+\mathrm{P}\right)$, and on explants of menstrual phase endometrium treated with $17 \beta-E_{2}+P$. Gene expression was validated with real-time PCR in the samples used for the arrays, in endometrium collected from early and mid-secretory phase endometrium, and in additional experiments performed on new samples collected in the menstrual and late proliferative phase.

The results show that late proliferative phase human endometrium is more responsive to progestins than menstrual phase endometrium, that the expression of several genes associated with embryo implantation (i.e. thrombomodulin, monoamine oxidase A, SPARC-like 1) can be induced by $\mathrm{P}$ in vitro, and that genes can be distinguished that are fully dependent on the continuous presence of oestradiol during $\mathrm{P}$ exposure from those that are $\mathrm{P}$ dependent to a lesser extent. Therefore $17 \beta-E_{2}$ selectively primes implantation-related genes for the effects of progesterone.
\end{abstract}

\title{
Introduction
}

Optimal development of the endometrium is an essential prerequisite for successful blastocyst implantation. Progesterone is essential for secretory differentiation of endometrium, and the need for oestrogen in cooperation with progesterone in regulating implantation process is species-specific [275]. Our current knowledge of the cellular and molecular events orchestrating endometrium growth and differentiation prior to implantation is limited.

In the natural cycle the human endometrium is receptive during a short period, approximately 19 to 24 days after the onset of menstruation [7, 8, 13-15]. Prior to and during this period, the endometrium undergoes extensive morphological and physiological changes to facilitate the implanting embryo [7-9]. These changes are tightly controlled by oestrogen and progesterone [8, 276, 277]. The responsiveness of the endometrium to progesterone is partly dependent upon the preovulatory changes that have occurred under the influence of oestrogen. This is illustrated by the fact that high oestrogen levels and/or prolonged oestrogen exposure accelerates endometrial maturation thus disturbing the synchrony of embryo and endometrium development and subsequent implantation [17, 18]. Currently, there is no clear definition and understanding of human endometrium maturation, and more so, only limited knowledge about the cellular mechanisms involved. We define mature endometrium tissue as the physiological state of the 
human endometrium, which allows a correct response to the luteal progesterone, resulting in implantation of the embryo and maintenance of pregnancy.

Our limited understanding of the processes underlying endometrium maturation and progesterone-controlled differentiation prior to and during implantation is largely due to the lack of relevant model systems to evaluate endometrium responses under physiologically relevant conditions. Previous work has demonstrated that the explant culture system of human endometrium tissue is a suitable model to study the response to oestrogen and progesterone, most likely due to the preservation of the tissue context $[1,153,278]$. Using this model we showed previously that the responsiveness of the endometrium to oestrogen changes throughout the proliferative phase with regard to the regulation of gene expression and proliferation [1].

The present study was designed to gain more insight into the responses of human endometrium to progesterone with regard to gene expression and into the influence of oestradiol on this process. To this end global gene expression analysis was performed on human endometrium tissue fragments collected from the menstrual and late proliferative phase after short term culture in the presence of progesterone $(\mathrm{P})$ and $17 \beta$-oestradiol $\left(17 \beta-\mathrm{E}_{2}\right)$.

\section{Materials and methods}

\section{Human endometrial tissue}

Endometrium tissue was collected in 26 women of 20-45 years of age with regular menstrual cycles, who underwent surgery for benign indications. The tissue was collected from hysterectomy specimens for benign indications or by pipelle biopsies during laparoscopy for sterilisation (Pipelle catheter, Unimar Inc., Prodimed, Neuilly-Enthelle, France). The women were documented not to be on any kind of steroid medication. All women accepted to participate in the study by signing an informed consent form, according to a protocol approved by the Medical Ethical Committee of the Academic Hospital Maastricht.

Tissue was transported to the laboratory in DMEM/Ham's F12 medium on ice. A portion of each sample was fixed in $10 \%$ buffered formalin for histology evaluation. The endometrium was dated according to clinical information with respect to the start of the last menstrual period, which was reconfirmed by histological examination of the tissue [258]. Of the 26 biopsies that were collected, 11 were collected in the proliferative phase (menstrual phase, cycle days [CD] 1-5, $\mathrm{n}=6$; late proliferative phase, $\mathrm{CD} 11-14, \mathrm{n}=5$ ), and 15 were collected in the secretory phase (early secretory (ES), CD15-18, n=7; mid-secretory (MS), CD19-24, n=8). Of the 11 biopsies collected from the proliferative phase, 4 were used for microarray 
studies and 7 were used for validation purposes with real-time PCR analysis. The biopsies collected from the secretory phase were used for validation only.

\section{Explant cultures}

Human endometrium explant cultures were prepared from menstrual phase and late proliferative phase endometrium as described by Punyadeera et al. [33]. In brief, human endometrium tissue was cut into pieces of $2-3 \mathrm{~mm}^{3}$. Twenty-four explants were placed in Millicell-CM culture inserts (pore size of $0.4 \mathrm{~m}, 30 \mathrm{~mm}$ diameter, Millipore, France) in 6-well plates containing $1.2 \mathrm{ml}$ phenol red-free DMEM/Ham's F12 medium (Life Technologies, Grand Island, NY), supplemented with L-glutamine (1\%), penicillin and streptomycin $(1 \%, \mathrm{P} / \mathrm{S})$. Cultures were performed for 24 hours. Previous experiments have shown that collagenase activity remains very low in proliferative endometria during the first 24 hours of culture [152], and that the tissue viability is not affected after 24 hours of culture [153].

The explants prepared from late proliferative phase endometrium were cultured in the presence of vehicle ( $0.1 \%$ ethanol), $17 \beta-\mathrm{E}_{2}$ and $\mathrm{P}(1 \mathrm{nM}$ each) or $\mathrm{P}$ alone $(1 \mathrm{nM})$. The $17 \beta-\mathrm{E}_{2}$ was included to maintain the in vivo oestrogen support. In order to make inferences with regard to the responsiveness of the endometrium before and after prolonged in vivo oestrogen exposure, we also treated explant cultures prepared from menstrual phase endometrium (cycle day 3 and 4) with $17 \beta$ $\mathrm{E}_{2}$ and $\mathrm{P}$. To test the importance of $17 \beta-\mathrm{E}_{2}$ in the response of late proliferative phase endometrium to progesterone, $17 \beta-\mathrm{E}_{2}$ was also omitted from the cultures. The steroid hormones were provided by Organon N.V. (Oss, The Netherlands).

\section{Total RNA extraction and cDNA synthesis}

Total cellular RNA from explants was extracted using the SV total RNA isolation kit (Promega, USA) according to the manufacturer's protocol, with slight modifications. The concentration of DNase-1 during DNase treatment of the RNA samples was doubled and the incubation time was extended by 15 minutes in order to completely remove genomic DNA. Total RNA was eluted from the column in 50

1 RNase-free water and stored at $-70{ }^{\circ} \mathrm{C}$ until further analysis. The quality of the RNA samples was determined with the Agilent bioanalyzer 2100 lab-on-a-chip (Agilent, USA). All the samples analysed gave $28 \mathrm{~S}$ to $18 \mathrm{~S}$ ratios higher than 1.5. A PCR for a housekeeping gene, GAPDH, was performed to confirm that the RNA samples were free of genomic DNA.

Total RNA (1 $\mu \mathrm{g})$ was incubated with random hexamers (1 g/ 1, Promega, USA) at $70{ }^{0} \mathrm{C}$ for $10 \mathrm{~min}$. The samples were chilled on ice for $5 \mathrm{~min}$. To this mixture, a reverse transcriptase (RT)-mix consisting of 5x RT-buffer $(4 \mu \mathrm{l}), 10 \mathrm{mM}$ dNTP mix (1 $\mu$ l) (Pharmacia, Uppsala, Sweden), 0.1 M DTT $(2 \mu \mathrm{l})$ (Invitrogen, California, USA) and superscript II reverse transcriptase $(200 \mathrm{U} / \mu \mathrm{l})$ (Invitrogen, California, USA) was added and the samples were incubated at $42{ }^{\circ} \mathrm{C}$ for one hour, after which the reverse transcriptase was inactivated by heating the samples at $95{ }^{\circ} \mathrm{C}$ 
for 5 min. The cDNA was stored at $-20{ }^{\circ} \mathrm{C}$ until further use. In each real-time PCR reaction $50 \mathrm{ng}$ of cDNA template was used.

\section{Affymetrix gene chip microarrays}

Pooling of the RNA samples was performed according to the phase of the menstrual cycle and treatment conditions i.e. two RNA samples from the menstrual phase phase (CDs 3 and 4) and two RNA samples from the late proliferative phase (CDs 12 and 13) were pooled. From pooled RNA, cRNA was generated and was labelled with biotin according to the Affymetrix protocol (Santa Clara, USA). cDNA was hybridised to the Affymetrix HU-133A chips, which contains approximately 22,000 human oligonucleotide probe sets, including 68 controls. The chip hybridisations were carried out in triplicate. After washing, the chips were scanned and analysed using the MicroArray suite MAS5. The detail description of the Affymetrix chip content is available at the NetAffy analysis web page (http://www.affymetrix.com/analysis/index.affx).

\section{Microarray data analysis}

Following Gene chip data quality control, data files (.EXP, .DAT, .CEL) generated by MAS5 were transferred by FTP to the server housing the Rosetta Resolver, Gene Expression Data Analysis System. Rosetta Resolver uses its Affymetrix gene chip error models to transform the raw data into a processed form that can be used in various expression analyses. Rosetta Resolver allows normalization of sample data of triplicate hybridizations using one-way Analysis of Variance (ANOVA) [279]. Changes in expression levels were calculated between the control and the treated samples using two criteria: (1) the absolute fold change (>2-fold) (e.g. the ratio between treated and the control) and (2) the corresponding p-value less than 0.01 .

The use of microarrays results in a massive amount of data, which requires special tools to filter and extract the relevant information. By combining the fold changes or log ratios and the p-value we generated a so-called significance code, which simplifies the selection and extraction of genes of interest especially when analyzing various conditions. The significance code assigned to the genes, was based on ANOVA retrieved p-values, and up- or down-regulation compared to the untreated samples. A significance code of 1 was used for genes with $\mathrm{p}<0.01$ and $\log$ ratio $>0$ (increased or up-regulated); significance code -1 (decreased or downregulated) for genes with $\mathrm{p}<0.01$ and $\log$ ratio $<0$. Genes which didn't show a significant regulation the significance code was 0 (and $\log$ ratio $=0$ and $p>0.01$ independent of $\log$ ratio).

Data were then exported from Rosetta Resolver to Spot fire decision site 7.1 (Spotfire, Göteborg, Sweden), in which gene sets of interest were visualized and subsequently selected. Data were analyzed through the use of Ingenuity Pathways Analysis (IPA, Ingenuity® Systems, www.ingenuity.com). The data set containing the significantly up- and down-regulated genes and the corresponding expression 
values are uploaded into the application. Each gene identifier was mapped to its corresponding gene object in the Ingenuity Pathways Knowledge Base. These genes, called focus genes, were overlaid onto a global molecular network developed from information contained in the Ingenuity Pathways Knowledge Base. Networks of these focus genes were then algorithmically generated based on their connectivity.

A network is a graphical representation of the molecular relationships between gene products. The gene products are represented as nodes, and the biological relationship between two nodes is represented as a line. All lines are supported by at least one reference in literature, textbook or from canonical information stored in the Ingenuity Pathways Knowledge Base. The intensity of the node colour indicates the degree of up- (red) or down- (green) regulation. Nodes are displayed using various shapes that represent the functional class of the gene product.

\section{Validation of array data using real-time PCR analysis}

A selection of genes was validated with q-PCR to confirm expression in the samples used for microarray analysis. In addition, the expression of these genes was evaluated in an independent series of experiments. To confirm that the genes induced by progesterone in vitro are indeed upregulated during the implantation window, we also assessed their expression levels in endometrium tissue collected in the ES and MS phase of the cycle.

Primers and probes were purchased from Perkin-Elmer Applied Biosystems as pre-developed assays. Human cyclophilin A was selected as an endogenous RNA control in order to normalize for the differences in the amount of total RNA added to each reaction. Uncultured human endometrium tissues were included as positive controls. All PCR reactions were performed using an ABI Prism 7700 sequence detection system (Perkin-Elmer Applied Biosystems). The thermal cycling conditions comprised an initial decontamination step at $50{ }^{0} \mathrm{C}$ for $2 \mathrm{~min}$, a denaturation step at $95{ }^{\circ} \mathrm{C}$ for $10 \mathrm{~min}$ and 40 cycles of $15 \mathrm{sec}$ at $95{ }^{0} \mathrm{C}$ followed by 1 $\min$ at $60{ }^{0} \mathrm{C}$. Experiments were performed for each sample in duplicate. Quantitative values were obtained from the threshold cycle number $(\mathrm{Ct})$ at which the increase in the signal associated with exponential growth of PCR products was first detected with the ABI Prism 7700 sequence detector software (Perkin-Elmer, Foster city, CA) The fold-change in expression was calculated using the $\mathrm{Ct}$ method, with cyclophilin A mRNA as an internal control [156]. For detailed description of the procedure please refer to the ABI user manual http://www.uk1.unifreiburg.de/core/facility/tagman/user_bulletin_2.pdf.

\section{Statistical analysis of real-time PCR results}

Statistical tests were carried out using the SPSS 11 (SPSS Inc., Chicago, IL) statistical analysis package. The effects of $17 \beta-\mathrm{E}_{2}+\mathrm{P}$ and $\mathrm{P}$ alone on cultured explants were analysed using the nonparametric paired Wilcoxon signed rank test at 
a confidence level of $95 \%$. The nonparametric unpaired Mann-Whitney-U test at a confidence level of $95 \%$ was employed to analyse the real-time PCR data generated from uncultured ES phase endometrium tissue and uncultured MS phase endometrium tissue.

\section{Results}

\section{Validation of array data with quantitative real-time PCR}

Eight genes were selected from the initial dataset on the basis of foldchange ( $\geq 2$-fold) and on literature documented expression during the implantation window: (1) four genes previously described in literature to be up-regulated during the implantation window and selectively stimulated by $17 \beta-\mathrm{E}_{2}+\mathrm{P}$ in late proliferative phase but not menstrual phase endometrium (Dickkopf homolog 1, DDK1; thrombomodulin, THBD; monoamine oxidase A, MAOA; gastrin, GAS) [7, 147, 148], (2) two genes not yet reported that were selectively stimulated by $17 \beta-E_{2}+P$ in late proliferative phase explants but not in menstrual phase explants (cytidine deaminase, CDA; SPARC-like 1, SPARCL1), (3) two genes that were selectively stimulated by $17 \beta-\mathrm{E}_{2}+\mathrm{P}$ in menstrual phase explants, and not late proliferative phase explants (trefoil factor 1, TFF1; mammaglobin 1)

Table 6.1. Validation results of the microarray findings for selected genes. Gene transcript levels of DKK1, THBD, MAOA, GAS, CDA, and SPARC1 were assessed with quantitative real-time PCR in the individual samples that were used for microarray hybridization. Data are presented as fold change. $\mathrm{CD}=$ cycle day, $\mathrm{M}=$ menstrual $(\mathrm{n}=2), \mathrm{LP}=$ late proliferative $(\mathrm{n}=2)$.

\begin{tabular}{|c|c|c|c|c|c|c|c|c|c|c|c|}
\hline \multirow{3}{*}{$\begin{array}{l}\text { gene } \\
\text { cycle day }\end{array}$} & \multicolumn{8}{|c|}{ Real-time PCR } & \multicolumn{3}{|c|}{ Arrays } \\
\hline & \multicolumn{2}{|c|}{$\mathrm{E} 2+\mathrm{P} M P$} & \multicolumn{2}{|c|}{$\mathrm{E} 2+\mathrm{P}$ LP } & \multicolumn{2}{|c|}{$\mathrm{P}$ alone MP } & \multicolumn{2}{|c|}{$\mathrm{P}$ alone LP } & $\mathrm{E} 2+\mathrm{P}$ MP & E2+P LP & $\begin{array}{l}\text { P alone } \\
\text { LP }\end{array}$ \\
\hline & $\mathrm{Cd} 3$ & & 12 & 13) & 3 & 4 & 12 & 13 & & & \\
\hline DKK1 & 1,8 & 1,93 & 2,67 & 12,68 & 3,2 & 2,96 & 4,27 & 13,69 & 1,58 & 6,03 & 5,01 \\
\hline THBD & 1,11 & 1,14 & 2,72 & 4,08 & 2,24 & 3,59 & 2,67 & 3,48 & 1,3 & 2,95 & 2,43 \\
\hline MAOA & 0,97 & 1,19 & 5,64 & 1,85 & 1,82 & 1,8 & 6,36 & 1,19 & 1,1 & 2,59 & 2 \\
\hline GAS & 0,69 & 0,26 & 1,07 & 3,07 & 1,51 & 0,57 & 1,95 & 2,49 & 1 & 2,19 & 1,58 \\
\hline $\mathrm{CDA}$ & 1,27 & 0,62 & 1,97 & 4,01 & 1,09 & 1,34 & 1,02 & 3,61 & 0,32 & 2,82 & 1,86 \\
\hline SPARCL1 & 1,47 & 2,43 & 6,96 & 3,02 & 1,11 & 1,87 & 4,07 & 2,36 & 1,29 & & 2,04 \\
\hline
\end{tabular}

The real-time PCR results corroborated well with the array data (Table 6.1). We performed additional independent experiments to validate the observed effects of treatment with $17 \beta-\mathrm{E}_{2}+\mathrm{P}$ and $\mathrm{P}$ alone (Figure 6.1). From the validated genes, DKK1, MAOA and SPARCL1 were significantly stimulated by $P$ in late proliferative and menstrual phase explants both in the presence and absence of $17 \beta$ $\mathrm{E}_{2}$. The induction of SPARCL1 expression by $\mathrm{P}$ was significantly decreased in the presence of $17 \beta-E_{2}$ in both menstrual and late proliferative phase explants. 
The response of DKK1 to $\mathrm{P}$ was higher in the late proliferative phase explants than in the menstrual phase explants, whereas the induction of mammaglobin expression by $17 \beta-\mathrm{E}_{2}+\mathrm{P}$ and $\mathrm{P}$ alone was more pronounced in menstrual phase than in late proliferative phase endometrium. Thrombomodulin expression was induced only by $\mathrm{P}$ in late proliferative phase explants.

Figure 6.1 Mean fold changes found for DKK1, THBD, MAOA, GAS, CDA and SPARCL1 in menstrual phase $(n=4)$ and late proliferative phase $(n=3)$ explants treated with $17 \beta-E_{2}+P$ and $P$ alone. Data are presented as fold changes. Open bars $=$ controls; light grey bars $=\mathrm{P}$; dark grey bars $=17 \beta-\mathrm{E}_{2}+\mathrm{P}$. ${ }^{*}=$ $\mathrm{p}<0.05$

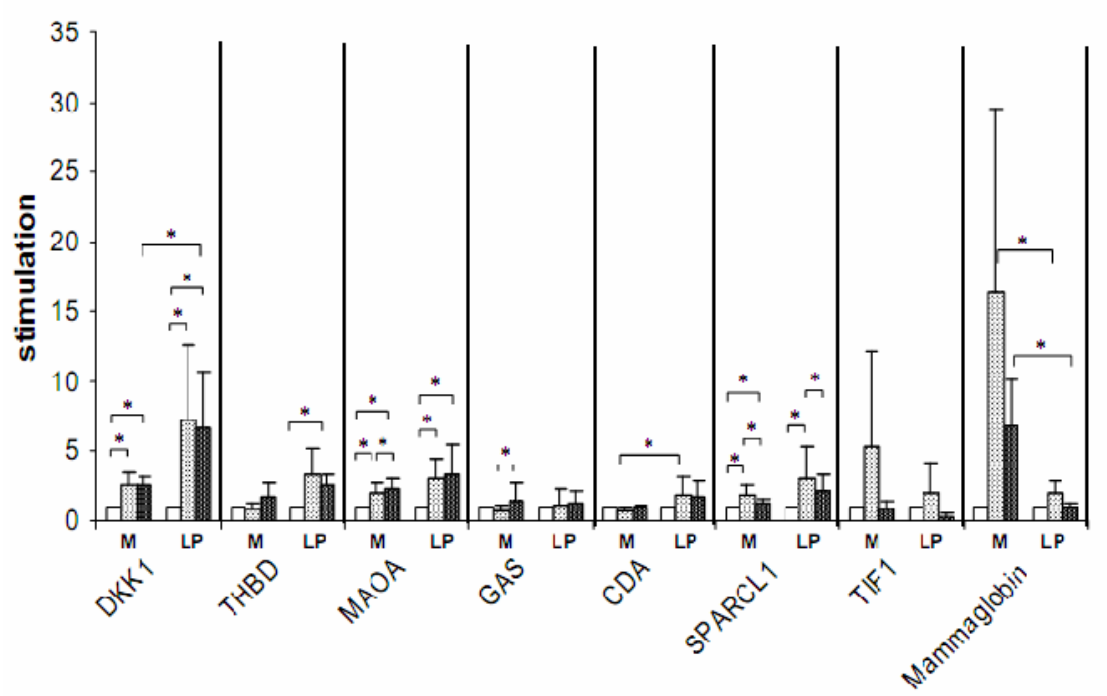

The expression of DKK1, THBD, MAOA, GAS, CDA and SPARCL1 was also assessed in an independent series of ES and MS endometrium samples to confirm selective up-regulation in the implantation window. The expression levels are presented in Figure 6.2. The expression of DKK1, MAOA, CDA and SPARCL1 was significantly higher in MS endometrium compared to ES endometrium.

Gene expression in menstrual and late proliferative phase endometrium tissue explants after $17 \beta-E_{2}+P$ or $P$ treatment

Treatment of late proliferative phase endometrium tissue with $17 \beta-\mathrm{E}_{2}+\mathrm{P}$, up-regulated ( $\geq 2$-fold) the expression of 110 gene transcripts and down-regulated ( $\geq 2$-fold) the expression of 109 gene transcripts when compared to the control (vehicle) (Table 6.2). Treating late proliferative phase explants with $\mathrm{P}$ alone upregulated ( $>2$-fold) the expression of 107 gene transcripts and down-regulated ( $\geq 2$ fold) the expression of 54 gene transcripts when compared to the control (vehicle) (Table 6.3). A total of 77/107 up-regulated and 42/54 down-regulated genes were also modulated by $17 \beta-\mathrm{E}_{2}+\mathrm{P}$ treatment in late proliferative phase explants (Table $6.3)$. 
Figure 6.2 Relative expression levels of gene transcripts for DKK1, THBD, MAOA, GAS, CDA and SPARCL1 in early secretory $(n=7)$ and mid-secretory $(n=8)$ endometrium, which represent endometrium tissues exposed to low (pre-implantation window) and high $\mathrm{P}$ (implantation window) concentrations respectively. $*=\mathrm{p}<0.05$

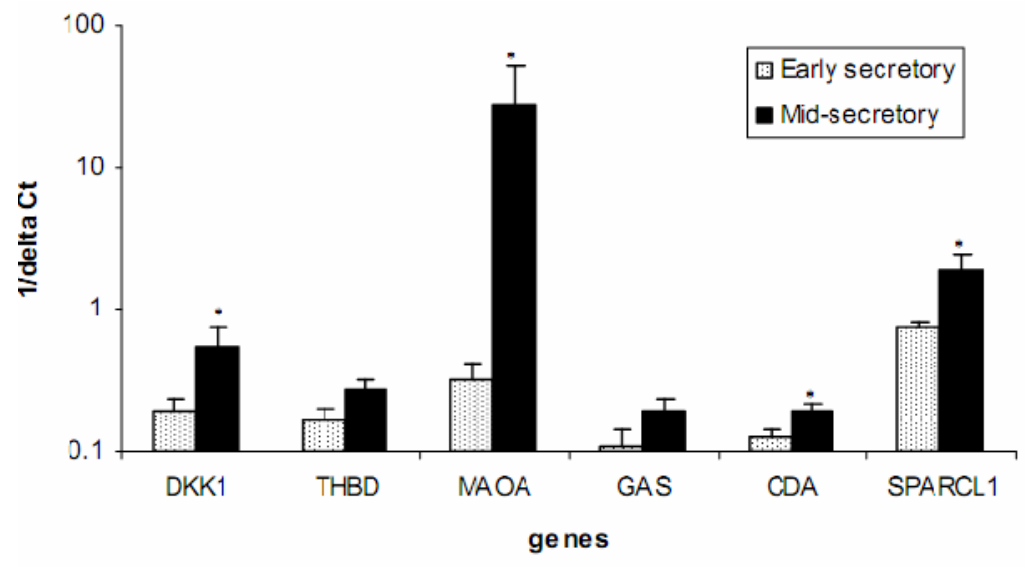

Table 6.2 Gene transcripts regulated ( $\geq 2$-fold) by $17 \beta-\mathrm{E}_{2}+\mathrm{P}$ in late proliferative phase explants when compared to the vehicle treated controls. Data are presented as fold changes.

\begin{tabular}{|c|c|c|c|c|}
\hline Title & Gene Symbol & fold change & Accession \# & Function \\
\hline cytochrome P450, family 26 , subfamily A, polypeptide 1 & CYP26A1 & 33,11 & NM_000783.1 & metabolism \\
\hline hemoglobin, alpha 2 & - & 28,18 & V00489 & - \\
\hline calpain 6 & CAPN6 & 19,05 & NM_014289.2 & metabolism \\
\hline heart and neural crest derivatives expressed 2 & HAND2 & 10,47 & NM_021973.1 & transcription factor \\
\hline secretoglobin, family $1 \mathrm{D}$, member 2 & SCGB1D2 & 10 & NM_006551.2 & extracellular matrix \\
\hline hemoglobin, alpha 1 & HBA1 & 9,55 & AF105974.1 & transport \\
\hline FK506 binding protein 5 & FKBP5 & 7,76 & NM_004117.1 & metabolism \\
\hline chemokine ( $\mathrm{C}-\mathrm{X}-\mathrm{C}$ motif) ligand 11 & CXCL11 & 7,59 & AF030514.1 & signal transduction \\
\hline carbohydrate ( $\mathrm{N}$-acetylglucosamine 6-0) sulfotransferase 7 & CHST7 & 7,08 & NM_019886.1 & metabolism \\
\hline glycine-N-acyltransferase & GLYAT & 6,17 & AW024233 & metabolism \\
\hline hemoglobin, beta & HBB & 6,17 & M25079.1 & transport \\
\hline dickkopf homolog 1 (Xenopus laevis) & DKK1 & 6,03 & NM_012242.1 & growth factor \\
\hline Homo sapiens mutant beta-globin (HBB) gene, complete cds. & - & 5,5 & AF059180 & - \\
\hline neuronal pentraxin ॥ & NPTX2 & 5,5 & U26662.1 & cell adhesion \\
\hline PDZ domain containing 3 & PDZK3 & 5,5 & AF338650.1 & signal transduction \\
\hline apolipoprotein D & APOD & 4,9 & NM_001647.1 & transport \\
\hline alkaline phosphatase, placental (Regan isozyme) & ALPP & 4,79 & NM_001632.2 & metabolism \\
\hline keratin $6 \mathrm{~A}$ & KRT6A & 4,68 & J00269.1 & structural protein \\
\hline G protein-coupled receptor 105 & GPR105 & 4,47 & NM_014879.1 & signal transduction \\
\hline solute carrier family 7 , member 8 & SLC7A8 & 4,37 & NM_012244.1 & transport \\
\hline hypothetical protein FLJ11539 & FLJ11539 & 4,17 & NM_024748.1 & $\ldots$ \\
\hline a disintegrin-like and metalloprotease with thrombospondin type 1 motif, 8 & ADAMTS8 & 3,98 & NM_007037.1 & cell growth \\
\hline integrin, beta-like 1 & TIGBL1 & 3,8 & NM_004791.1 & cell adhesion \\
\hline potassium inwardly-rectifying channel, subfamily J, member 8 & KCNJ8 & 3,8 & NM_004982.1 & transport \\
\hline RGC32 protein & RGC32 & 3,8 & NM_014059.1 & cell growth \\
\hline prostaglandin-endoperoxide synthase 1 & PTGS1 & 3,72 & NM_000962.1 & metabolism \\
\hline regulator of G-protein signalling $2,24 \mathrm{kDa}$ & RGS2 & 3,72 & NM_002923.1 & signal transduction \\
\hline cannabinoid receptor 1 (brain) & CNR1 & 3,55 & U73304 & signal transduction \\
\hline hemoglobin, delta & HBD & 3,39 & NM_000519.2 & transport \\
\hline keratin $6 \mathrm{~B}$ & KRT6B & 3,39 & L42612.1 & structural protein \\
\hline sushi-repeat-containing protein, $\mathrm{X}$-linked & SRPX & 3,24 & NM_006307.1 & cell adhesion \\
\hline Thrombomodulin & THBD & 3,24 & NM_000361.1 & membrane protein \\
\hline delta sleep inducing peptide, immunoreactor & DSIPI & 3,16 & AL110191.1 & transcription factor \\
\hline cytochrome P450, family 4, subfamily B, polypeptide 1 & CYP4B1 & 3,09 & J02871.1 & metabolism \\
\hline hemoglobin, gamma A & HBG1 & 3,09 & NM_000559.1 & transport \\
\hline
\end{tabular}


Table 6.2. Continued

\begin{tabular}{|c|c|c|c|c|}
\hline Title & Gene Symbol & fold change & Accession \# & Function \\
\hline paired basic amino acid cleaving system 4 & PACE4 & 3,09 & NM__002570.1 & signal transduction \\
\hline insulin receptor substrate 2 & IRS2 & 3,02 & BF700086 & signal transduction \\
\hline metallothionein $1 \mathrm{~K}$ & MT1K & 2,95 & R06655 & transport \\
\hline amylase, alpha $1 \mathrm{~A}$; salivary & AMY1A & 2,88 & NM_004038.1 & metabolism \\
\hline fibrinogen-like 2 & FGL2 & 2,88 & NM_006682.1 & extracellular matrix \\
\hline latent transforming growth factor beta binding protein 1 & LTBP1 & 2,88 & NM_000627.1 & protein binding \\
\hline monoamine oxidase $\mathrm{A}$ & MAOA & 2,88 & NM_000240.1 & transport \\
\hline retinol binding protein 4 , plasma & RBP4 & 2,88 & NM_006744.2 & transport \\
\hline cytidine deaminase & CDA & 2,82 & NM_001785.1 & metabolism \\
\hline potassium voltage-gated channel, subfamily G, member 1 & KCNG1 & 2,82 & Al332979 & transport \\
\hline mitogen-activated protein kinase kinase 6 & MAP2K6 & 2,82 & NM_002758.1 & signal transduction \\
\hline solute carrier family $15(\mathrm{H}+/$ peptide transporter), member 2 & SLC15A2 & 2,82 & BF223679 & transport \\
\hline hemoglobin, gamma G & HBG2 & 2,75 & Al133353 & transport \\
\hline protein kinase, $\mathrm{X}$-linked & PRKX & 2,75 & NM_005044.1 & metabolism \\
\hline suppressor of cytokine signaling 1 & socs1 & 2,75 & AB005043.1 & signal transduction \\
\hline KIAA0924 protein & KIAA0924 & 2,69 & NM_014897.1 & nucleair \\
\hline secretoglobin, family $1 \mathrm{D}$, member 1 & SCGB1D1 & 2,69 & NM__006552.1 & extracellular matrix \\
\hline serine (or cysteine) proteinase inhibitor, clade $\mathrm{E}$, member 1 & SERPINE1 & 2,69 & NM_000602.1 & metabolism \\
\hline chloride channel 4 & CLCN4 & 2,63 & AA071195 & transport \\
\hline fatty-acid-Coenzyme A ligase, long-chain 2 & FACL2 & 2,63 & NM_001995.1 & metabolism \\
\hline monoamine oxidase $B$ & MAOB & 2,63 & NM_000898.1 & transport \\
\hline secretoglobin, family $2 \mathrm{~A}$, member 1 & SCGB2A1 & 2,63 & NM_002407.1 & hormone binding \\
\hline ATPase, $\mathrm{H}+$ transporting, lysosomal $70 \mathrm{kDa}, \mathrm{V} 1$ subunit $\mathrm{A}$ & ATP6V1A & 2,57 & NM_001690.1 & transport \\
\hline dipeptidylpeptidase 4 & DPP4 & 2,57 & M80536.1 & metabolism \\
\hline nuclear factor VB & NFIB & 2,57 & Al186739 & transcription factor \\
\hline creatine kinase, brain & CKB & 2,51 & NM_001823.1 & metabolism \\
\hline cytokine receptor-like factor 1 & CRLF1 & 2,51 & NM_004750.1 & signal transduction \\
\hline iroquois homeobox protein 4 & IRX4 & 2,51 & NM_016358.1 & transcription factor \\
\hline Homo sapiens mRNA; cDNA DKFZp586B0220 & - & 2,45 & AL049435.1 & - \\
\hline chemokine ( $\mathrm{C}-\mathrm{X}-\mathrm{C}$ motif) ligand 10 & CXCL10 & 2,45 & NM_001565.1 & signal transduction \\
\hline hypothetical protein FLJ20701 & FLJ 20701 & 2,45 & NM_017933.1 & - \\
\hline insulin-like growth factor binding protein 1 & IGFBP1 & 2,45 & NM_000596.1 & signal transduction \\
\hline Norrie disease (pseudoglioma) & NDP & 2,45 & NM__000266.1 & signal transduction \\
\hline zinc finger protein 145 & ZNF145 & 2,45 & NM__006006.1 & protein binding \\
\hline hypothetical protein FLJ20366 & FLJ20366 & 2,4 & NM_017786.1 & - \\
\hline peroxisome proliferative activated receptor, gamma, coactivator 1 & PPARGC1 & 2,4 & NM__013261.1 & DNA binding \\
\hline S100 calcium binding protein $\mathrm{A} 2$ & S100A2 & 2,4 & NM_005978.2 & transport \\
\hline Arg/Abl-interacting protein ArgBP2 & ARGBP2 & 2,34 & NM_021069.1 & structural protein \\
\hline interleukin 1 receptor-like 1 & |L1RL1 & 2,34 & NM__003856.1 & signal transduction \\
\hline NPD009 protein & NPD009 & 2,34 & AF237813.1 & - \\
\hline $\begin{array}{l}\mathrm{Cbp} / \mathrm{p} 300 \text {-interacting transactivator, with Glu/Asp-rich carboxy-terminal } \\
\text { domain,2 }\end{array}$ & CITED2 & 2,29 & NM_006079.1 & transcription factor \\
\hline colony stimulating factor 2 receptor, alpha, low-affinity & CSF2RA & 2,29 & BC002635.1 & immune response \\
\hline secreted and transmembrane 1 & SECTM1 & 2,29 & BF939675 & membrane protein \\
\hline H.sapiens mRNA for interleukin-15 & - & 2,24 & Y09908.1 & - \\
\hline GREB1 protein & GREB1 & 2,24 & NM_014668.1 & - \\
\hline adiponectin receptor 2 & ADIPOR2 & 2,19 & NM_024551.1 & membrane protein \\
\hline hypothetical protein DKFZp434B044 & DKFZP434B044 & 2,19 & AL136861.1 & extracellular matrix \\
\hline Gastrin & GAS & 2,19 & NM_000805.2 & signal transduction \\
\hline alkaline phosphatase, liver/bone/kidney & ALPL & 2,14 & X14174.1 & metabolism \\
\hline chromosome 1 open reading frame 29 & C1orf29 & 2,14 & NM_006820.1 & - \\
\hline Fas apoptotic inhibitory molecule & FAlM & 2,14 & NM_018147.1 & - \\
\hline KIAA0089 protein & KLAA0089 & 2,14 & AA135522 & metabolism \\
\hline POU domain, class 5 , transcription factor 1 & POU5F1 & 2,14 & NM_002701.1 & transcription factor \\
\hline serum amyloid A2 & SAA2 & 2,14 & M23699.1 & immune response \\
\hline SEC14-like 1 (S. cerevisiae) & SEC14L1 & 2,14 & AV7 78469 & transport \\
\hline solute carrier family 26 (sulfate transporter), member 2 & SLC26A2 & 2,14 & Al025519 & transport \\
\hline CDC14 cell division cycle 14 homolog B (S. cerevisiae) & CDC14B & 2,09 & AU145941 & metabolism \\
\hline hypothetical protein FLJ11795 & FLJ11795 & 2,09 & NM_024669.1 & - \\
\hline $\begin{array}{l}\text { likely ortholog of mouse tumor necrosis-alpha-induced adipose-re } \\
\text { protein }\end{array}$ & FLJ23153 & 2,09 & NM_024636.1 & transport \\
\hline KIAA0960 protein & KIAA0960 & 2,09 & BF 447246 & - \\
\hline oxysterol binding protein-like 11 & OSBPL11 & 2,09 & NM_022776.1 & transport \\
\hline
\end{tabular}


Table 6.2. Continued

\begin{tabular}{|c|c|c|c|c|}
\hline Title & Gene Symbol & fold change & Accession \# & Function \\
\hline protein tyrosine phosphatase, receptor type, $R$ & PTPRR & 2,09 & NM_002849.1 & signal transduction \\
\hline fibrinogen, A alpha polypeptide & FGA & 2,04 & NM_021871.1 & cell adhesion \\
\hline interleukin 6 signal transducer ( $\mathrm{gp} 130$, oncostatin M receptor) & IL6ST & 2,04 & AB015706.1 & signal transduction \\
\hline KIAA0367 protein & KIAA0367 & 2,04 & AL138349 & - \\
\hline KLAA0711 gene product & KIAA0711 & 2,04 & NM_014867.1 & protein binding \\
\hline ADP-ribosyltransferase 3 & ART3 & 2 & U47054.1 & metabolism \\
\hline cut-like 2 (Drosophila) & CUTL2 & 2 & AB006631.1 & transcription factor \\
\hline dual specificity phosphatase 1 & DUSP1 & 2 & AA530892 & metabolism \\
\hline eukaryotic translation initiation factor 2 , subunit 3 gamma, $52 \mathrm{kDa}$ & EIF2S3 & 2 & NM_001415.1 & translation \\
\hline interleukin 20 receptor, alpha & IL20RA & 2 & NM_014432.1 & signal transduction \\
\hline PRO2000 protein & PRO2000 & 2 & NM_014109.1 & DNA binding \\
\hline solute carrier family 7 , member 2 & SLC7A2 & 2 & NM_003046.1 & transport \\
\hline SPARC-like 1 (mast9, hevin) & SPARCL1 & 2 & NM_004684.1 & - \\
\hline toll-like receptor 2 & TLR2 & 2 & NM_003264.1 & immune response \\
\hline coagulation factor XIII, A1 polypeptide & F13A1 & -2 & NM_000129.2 & metabolism \\
\hline protein kinase (CAMP-dependent, catalytic) inhibitor alpha & PKIA & -2 & NM_006823.1 & metabolism \\
\hline glutaminyl-peptide cyclotransferase (glutaminyl cyclase) & QPCT & -2 & NM_012413.2 & metabolism \\
\hline TGF2_HUMAN Transforming growth factor beta 2 precursor (TGF-beta 2) & - & $-2,04$ & BF061658 & - \\
\hline cadherin 5 , type 2 , VE-cadherin (vascular epithelium) & $\mathrm{CDH} 5$ & $-2,04$ & NM_001795.1 & cell adhesion \\
\hline cellular retinoic acid binding protein 2 & CRABP2 & $-2,04$ & NM_001878.2 & signal transduction \\
\hline drebrin 1 & DBN1 & $-2,04$ & NM_004395.1 & structural protein \\
\hline dimethylarginine dimethylaminohydrolase 2 & DDAH2 & $-2,04$ & AJ012008 & metabolism \\
\hline early growth response 1 & EGR1 & $-2,04$ & NM_001964.1 & transcription factor \\
\hline hypothetical protein FLJ11082 & FLJ11082 & $-2,04$ & NM_018317.1 & - \\
\hline matrix metalloproteinase 1 (interstitial collagenase) & MMP1 & $-2,04$ & NM_002421.2 & metabolism \\
\hline matrix metalloproteinase 3 (stromelysin 1, progelatinase) & MMP3 & $-2,04$ & NM_O002422.2 & metabolism \\
\hline matrix metalloproteinase 9 & MMP9 & $-2,04$ & NM_004994.1 & metabolism \\
\hline reticulon 3 & RTN3 & $-2,04$ & NM_023941.1 & membrane protein \\
\hline stanniocalcin 1 & STC1 & $-2,04$ & U46768.1 & signal transduction \\
\hline Thy- 1 cell surface antigen & THY1 & $-2,04$ & AL558479 & membrane protein \\
\hline tumor necrosis factor receptor superfamily, member 21 & TNFRSF21 & $-2,04$ & NM_016629.1 & signal transduction \\
\hline basic helix-loop-helix domain containing, class B, 3 & BHLHB3 & $-2,09$ & BE 857425 & transcription factor \\
\hline chromosome 21 open reading frame 7 & C21 orf7 & $-2,09$ & NM_020152.1 & - \\
\hline glycoprotein A repetitions predominant & GARP & $-2,09$ & NM_005512.1 & - \\
\hline regulator of G-protein signalling 3 & RGS3 & $-2,09$ & NM_021106.1 & signal transduction \\
\hline trefoil factor 1 & TFF1 & $-2,09$ & NM_003225.1 & growth factor \\
\hline ATP-binding cassette, sub-family A (ABC1), member 8 & ABCA8 & $-2,14$ & NM_007168.1 & transport \\
\hline hypothetical gene BC008967 & $B C 008967$ & $-2,14$ & BE299456 & - \\
\hline solute carrier family 14 (urea transporter), member 1 & SLC14A1 & $-2,14$ & NM_015865.1 & transport \\
\hline a disintegrin and metalloproteinase domain 12 (meltrin alpha) & ADAM12 & $-2,19$ & NM_003474.2 & metabolism \\
\hline aquaporin 3 & AQP3 & $-2,19$ & AB001325 & transport \\
\hline carcinoembryonic antigen-related cell adhesion molecule 6 & CEACAM6 & $-2,19$ & BC005008.1 & signal transduction \\
\hline chloride channel, calcium activated, family member 4 & CLCA4 & $-2,19$ & NM_012128.2 & transport \\
\hline chloride intracellular channel 2 & CLIC2 & $-2,19$ & Al768628 & transport \\
\hline DVS27-related protein & DVS27 & $-2,19$ & AB 024518.1 & - \\
\hline hypothetical protein FLJ31737 & FLJ31737 & $-2,19$ & N91149 & - \\
\hline fascin homolog 1, actin-bundling protein & FSCN1 & $-2,19$ & NM_003088.1 & structural protein \\
\hline synuclein, alpha interacting protein (synphilin) & SNCAIP & $-2,19$ & NM_005460.1 & protein binding \\
\hline embryonal Fyn-associated substrate & EFS & $-2,24$ & NM__005864.1 & cell adhesion \\
\hline integral membrane protein $2 \mathrm{C}$ & ITM2C & $-2,24$ & NM_030926.1 & - \\
\hline keratin 23 (histone deacetylase inducible) & KRT23 & $-2,24$ & NM_015515.1 & - \\
\hline matrix metalloproteinase 27 & MMP27 & $-2,24$ & NM_022122.1 & metabolism \\
\hline pre-B-cell leukemia transcription factor 1 & PBX1 & $-2,24$ & BF967998 & transcription factor \\
\hline suppression of tumorigenicity & ST7 & $-2,24$ & NM_013437.1 & - \\
\hline Homo sapiens mRNA, chromosome 1 specific transcript KIAA0509. & - & $-2,29$ & AB007978.1 & - \\
\hline apolipoprotein B mRNA editing enzyme, catalytic polypeptide-like 3B & APOBEC 3B & $-2,29$ & NM_004900.1 & metabolism \\
\hline $\begin{array}{l}\text { ARF-GAP, RHO-GAP, ankyrin repeat and plekstrin homology domains- } \\
\text { containing }\end{array}$ & ARAP3 & $-2,29$ & NM_022481.1 & signal transduction \\
\hline carboxypeptidase Z & $\mathrm{CPZ}$ & $-2,29$ & BC006393.1 & metabolism \\
\hline melanoma antigen, family $D, 4$ & MAGED4 & $-2,29$ & NM_030801.1 & - \\
\hline matrilin 4 & MATN4 & $-2,29$ & NM_003833.2 & extracellular matrix \\
\hline regulator of G-protein signalling 4 & RGS4 & $-2,29$ & AL514445 & signal transduction \\
\hline chromosome 6 open reading frame 59 & C6orf59 & $-2,34$ & NM_020133.1 & - \\
\hline
\end{tabular}


Table 6.2. Continued

\begin{tabular}{|c|c|c|c|c|}
\hline Title & Gene Symbol & fold change & Accession \# & Function \\
\hline aldo-keto reductase family 1 , member B10 (aldose reductase) & AKR1B10 & $-2,4$ & NM_020299.1 & metabolism \\
\hline angiopoietin 2 & ANGPT2 & $-2,4$ & AF187858.1 & signal transduction \\
\hline dapper homolog 1, antagonist of beta-catenin (xenopus) & DACT1 & $-2,4$ & NM_016651.2 & nucleair \\
\hline G protein-coupled receptor 17 & GPR17 & $-2,4$ & NM_005291.1 & signal transduction \\
\hline glutathione peroxidase 2 (gastrointestinal) & GPX2 & $-2,4$ & NM__002083.1 & metabolism \\
\hline microfibrillar-associated protein 2 & MFAP2 & $-2,4$ & NM_017459.1 & extracellular matrix \\
\hline transforming growth factor, beta 3 & TGFB3 & $-2,4$ & J03241.1 & growth factor \\
\hline WNT1 inducible signaling pathway protein 2 & WISP2 & $-2,4$ & NM_003881.1 & signal transduction \\
\hline hepatocyte growth factor (hepapoietin A; scatter factor) & HGF & $-2,45$ & M77227.1 & growth factor \\
\hline KIAA1277 protein & KIAA1277 & $-2,45$ & AA127623 & - \\
\hline matrix metalloproteinase 14 (membrane-inserted) & MMP14 & $-2,45$ & AU149305 & metabolism \\
\hline Ras family member Ris & RIS & $-2,45$ & NM_016563.1 & signal transduction \\
\hline thymosin, beta, identified in neuroblastoma cells & TMSNB & $-2,45$ & NM_021992.1 & structural protein \\
\hline latexin protein & LXN & $-2,51$ & NM_020169.1 & - \\
\hline serine (or cysteine) proteinase inhibitor, clade B (ovalbumin), member 2 & SERPINB2 & $-2,51$ & NM_002575.1 & cell growth \\
\hline carbonic anhydrase II & CA2 & $-2,57$ & M36532.1 & metabolism \\
\hline deleted in malignant brain tumors 1 & DMBT1 & $-2,57$ & NM_004406.1 & cell growth \\
\hline fibronectin leucine rich transmembrane protein 2 & FLRT2 & $-2,57$ & NM_013231.1 & cell adhesion \\
\hline orosomucoid 1 & ORM1 & $-2,57$ & NM_000608.1 & transport \\
\hline stathmin-like 2 & STMN2 & $-2,57$ & BF967657 & signal transduction \\
\hline synaptojanin 2 & SYNJ2 & $-2,57$ & AF318616.1 & metabolism \\
\hline carcinoembryonic antigen-related cell adhesion molecule 5 & CEACAM5 & $-2,63$ & NM_004363.1 & membrane protein \\
\hline ectodermal-neural cortex (with BTB-like domain) & ENC1 & $-2,63$ & NM_003633.1 & protein binding \\
\hline mucin 4 , tracheobronchial & MUC4 & $-2,63$ & AJ 242547.1 & signal transduction \\
\hline protocadherin 16 dachsous-like (Drosophila) & PCDH16 & $-2,63$ & BF222893 & cell adhesion \\
\hline interleukin 24 & IL24 & $-2,69$ & NM_006850.1 & signal transduction \\
\hline transforming growth factor, beta 2 & TGFB2 & $-2,69$ & NM_003238.1 & growth factor \\
\hline integrin, beta 3 (platelet glycoprotein Illa, antigen CD61) & пाGB3 & $-2,75$ & M35999.1 & cell adhesion \\
\hline plasminogen activator, urokinase & PLAU & $-2,75$ & NM_002658.1 & metabolism \\
\hline chromosome 20 open reading frame 42 & C20orf42 & $-2,82$ & NM_017671.1 & - \\
\hline four jointed box 1 (Drosophila) & FJX1 & $-2,82$ & NM_014344.1 & - \\
\hline ephrin-B2 & EFNB2 & $-2,88$ & BF001670 & cell growth \\
\hline parathyroid hormone-like hormone & PTHLH & $-2,88$ & BC005961.1 & signal transduction \\
\hline tribbles homolog 2 & TRB2 & $-2,88$ & NM_021643.1 & metabolism \\
\hline twist homolog 1 & TWIST1 & $-2,88$ & X99268.1 & DNA binding \\
\hline gap junction protein, alpha $4,37 \mathrm{kDa}$ (connexin 37 ) & GJA4 & $-2,95$ & NM__002060.1 & transport \\
\hline integrin, beta 6 & ITGB6 & $-2,95$ & NM_000888.3 & cell adhesion \\
\hline bradykinin receptor B1 & BDKRB1 & $-3,02$ & NM_000710.1 & signal transduction \\
\hline solute carrier family 21 (organic anion transporter), member 11 & SLC21A11 & $-3,02$ & NM_013272.2 & transport \\
\hline myristoylated alanine-rich protein kinase $\mathrm{C}$ substrate & MARCKS & $-3,09$ & M68956.1 & membrane protein \\
\hline angiopoietin-like 2 & ANGPTL2 & $-3,16$ & NM_012098.1 & signal transduction \\
\hline tumor necrosis factor receptor superfamily, member $11 \mathrm{~b}$ (osteoprotegerin) & TNFRSF11B & $-3,16$ & NM_002546.1 & signal transduction \\
\hline acid phosphatase, prostate & ACPP & $-3,24$ & NM_001099.2 & metabolism \\
\hline homeo box A11 & HOXA11 & $-3,24$ & NM_005523.3 & transcription factor \\
\hline hypothetical protein FLJ38993 & FLJ 38993 & $-3,31$ & AF070524.1 & signal transduction \\
\hline matrix metalloproteinase 11 (stromelysin 3 ) & MMP11 & $-3,31$ & Al761713 & metabolism \\
\hline pleckstrin 2 & PLEK2 & $-3,31$ & NM_016445.1 & signal transduction \\
\hline SRY (sex determining region $Y$ )-box 9 & sox9 & $-3,31$ & NM_000346.1 & DNA binding \\
\hline lymphocyte-specific protein tyrosine kinase & LCK & $-3,39$ & NM_005356.1 & signal transduction \\
\hline BDG-29 proten & BDG29 & $-3,47$ & AL117532.1 & DNA binding \\
\hline deiodinase, iodothyronine, type II & $\mathrm{DIO} 2$ & $-3,47$ & U53506.1 & metabolism \\
\hline SRY (sex determining region Y)-box 4 & $50 \times 4$ & $-3,47$ & Al989477 & transcription factor \\
\hline cysteine knot superfamily 1, BMP antagonist 1 & CKTSF1B1 & $-3,63$ & AF154054.1 & - \\
\hline chromogranin A (parathyroid secretory protein 1) & CHGA & $-3,72$ & NM_001275.2 & transport \\
\hline $\begin{array}{c}\text { cystic fibrosis transmembrane conductance regulator, ATP-binding } \\
\text { cassette }\end{array}$ & CFTR & $-4,07$ & NM_000492.2 & transport \\
\hline Ras-induced senescence 1 & RIS1 & $-4,07$ & BF062629 & - \\
\hline hypothetical protein FLJ10640 & FLJ 10640 & $-4,17$ & NM_024703.1 & metabolism \\
\hline ribosomal protein $\mathrm{S} 20$ & RPS20 & $-4,27$ & AF113008.1 & protein biosynthesis \\
\hline SRY (sex determining region Y)-box 11 & sox11 & $-4,68$ & AB028641.1 & transcription factor \\
\hline platelet-derived growth factor beta polypeptide & PDGFB & $-5,75$ & NM_002608.1 & growth factor \\
\hline ribosomal protein $\mathrm{L} 27 \mathrm{a}$ & RPL27A & $-5,75$ & BE737027 & protein biosynthesis \\
\hline
\end{tabular}


Table 6.3 Gene transcripts regulated ( 2 -fold) by $\mathrm{P}$ alone in late proliferative phase explants when compared to the vehicle treated controls. Data are presented as fold changes. The genes in bold were not found to be modulated by $17 \beta-\mathrm{E}_{2}+\mathrm{P}$.

\begin{tabular}{|c|c|c|c|c|}
\hline Title & Gene Symbol & fold change & Accession \# & Function \\
\hline cytochrome P450, family 26 , subfamily A, polypeptide 1 & CYP26A1 & 28,84 & NM_000783.1 & metabolism \\
\hline calpain 6 & CAPN6 & 19,5 & NM_014289.2 & metabolism \\
\hline hemoglobin, alpha 2 & - & 12,88 & V00489 & $\ldots$ \\
\hline heart and neural crest derivatives expressed 2 & HAND2 & 10,96 & NM_021973.1 & transcription factor \\
\hline secretoglobin, family $1 \mathrm{D}$, member 2 & SCGB1D2 & 9,55 & NM_006551.2 & extracellular matrix \\
\hline carbohydrate ( $\mathrm{N}$-acetylglucosamine 6-0) sulfotransferase 7 & CHST7 & 7,59 & NM_019886.1 & metabolism \\
\hline glycine-N-acyltransferase & GLYAT & 7,08 & AW024233 & metabolism \\
\hline FK506 binding protein 5 & FKBP5 & 6,31 & NM_004117.1 & metabolism \\
\hline PDZ domain containing 3 & PDZK3 & 6,17 & AF 338650.1 & signal transduction \\
\hline neuronal pentraxin II & NPTX2 & 6,03 & U26662.1 & cell adhesion \\
\hline chemokine (C-X-C motif) ligand 11 & CXCL11 & 5,5 & AF030514.1 & signal transduction \\
\hline solute carrier family 7 , member 8 & SLC7A8 & 5,25 & NM_012244.1 & transport \\
\hline a disintegrin-like and metalloprotease with thrombospondin type 1 motif, 8 & ADAMTS8 & 5,01 & NM_007037.1 & metabolism \\
\hline dickkopf homolog 1 (Xenopus laevis) & DKK1 & 5,01 & NM_012242.1 & growth factor \\
\hline keratin $6 \mathrm{~A}$ & KRT6A & 4,9 & J00269.1 & structural protein \\
\hline alkaline phosphatase, placental (Regan isozyme) & ALPP & 4,79 & NM_001632.2 & metabolism \\
\hline apolipoprotein D & APOD & 4,68 & NM_001647.1 & transport \\
\hline G protein-coupled receptor 105 & GPR105 & 4,68 & NM_014879.1 & signal transduction \\
\hline prostaglandin-endoperoxide synthase 1 & PTGS1 & 4,68 & NM_000962.1 & metabolism \\
\hline TU3A protein & TU3A & 4,68 & AL050264.1 & - \\
\hline hemoglobin, alpha 1 & HBA1 & 4,57 & AF105974.1 & transport \\
\hline mitogen-activated protein kinase kinase 6 & MAP2K6 & 4,27 & NM_002758.1 & signal transduction \\
\hline keratin $6 \mathrm{~B}$ & KRT6B & 4,07 & L42612.1 & structural protein \\
\hline claudin 5 & CLDN5 & 3,98 & NM_003277.1 & structural protein \\
\hline regulator of G-protein signalling $2,24 \mathrm{kDa}$ & RGS2 & 3,98 & NM_002923.1 & signal transduction \\
\hline RGC32 protein & RGC32 & 3,89 & NM_014059.1 & cell growth \\
\hline integrin, beta-like 1 & חாGBL1 & 3,8 & NM_004791.1 & cell adhesion \\
\hline solute carrier family 15 , member 2 & SLC15A2 & 3,72 & BF223679 & transport \\
\hline delta sleep inducing peptide, immunoreactor & DSIPI & 3,55 & AL110191.1 & transcription factor \\
\hline myosin heavy chain Myr 8 & MYR8 & 3,55 & Al522028 & metabolism \\
\hline potassium inwardly-rectifying channel, subfamily J, member 8 & KCNJ8 & 3,31 & NM_004982.1 & transport \\
\hline paired basic amino acid cleaving system 4 & PACE4 & 3,31 & NM_002570.1 & signal transduction \\
\hline cannabinoid receptor 1 (brain) & CNR1 & 3,24 & U73304 & signal transduction \\
\hline hypothetical protein FLJ11539 & FLJ11539 & 3,24 & NM_024748.1 & - \\
\hline protein kinase, $\mathrm{X}$-linked & PRKX & 3,24 & NM_005044.1 & metabolism \\
\hline latent transforming growth factor beta binding protein 1 & LTBP1 & 3,16 & NM_000627.1 & protein binding \\
\hline KIAA0960 protein & KIAA0960 & 3,09 & BF 447246 & - \\
\hline nuclear factor VB & NFIB & 3,02 & Al186739 & transcription factor \\
\hline sushi-repeat-containing protein, $\mathrm{X}$-linked & SRPX & 3,02 & NM_006307.1 & cell adhesion \\
\hline cytochrome P450, family 4 , subfamily B, polypeptide 1 & CYP4B1 & 2,95 & J02871.1 & metabolism \\
\hline insulin receptor substrate 2 & IRS2 & 2,95 & BF700086 & signal transduction \\
\hline potassium voltage-gated channel, subfamily G, member 1 & KCNG1 & 2,95 & Al332979 & transport \\
\hline Arg/Abl-interacting protein ArgBP2 & ARGBP2 & 2,88 & NM_021069.1 & structural protein \\
\hline hemoglobin, beta & HBB & 2,88 & M25079.1 & transport \\
\hline Homo sapiens mutant beta-globin (HBB) gene, complete cds. & $\ldots$ & 2,82 & AF059180 & - \\
\hline RAR-related orphan receptor B & RORB & 2,82 & NM_006914.1 & transcription factor \\
\hline S100 calcium binding protein $\mathrm{A} 2$ & S100A2 & 2,75 & NM_005978.2 & transport \\
\hline serum amyloid A2 & SAA2 & 2,75 & NM_030754.1 & immune response \\
\hline absent in melanoma 1-like & AIM1L & 2,69 & NM_017977.1 & - \\
\hline RIM binding protein 2 & KIAA0318 & 2,69 & AB002316.1 & transport \\
\hline Thrombomodulin & THBD & 2,69 & NM_000361.1 & signal transduction \\
\hline cytokine receptor-like factor 1 & CRLF1 & 2,63 & NM_004750.1 & signal transduction \\
\hline $\begin{array}{l}\text { v-maf musculoaponeurotic fibrosarcoma oncogene homolog } \\
\text { (avian) }\end{array}$ & MAF & 2,51 & NM_005360.2 & transcription factor \\
\hline monoamine oxidase $B$ & MAOB & 2,51 & NM_000898.1 & transport \\
\hline secretoglobin, family $1 \mathrm{D}$, member 1 & SCGB1D1 & 2,51 & NM_006552.1 & extracellular matrix \\
\hline interleukin 15 & IL15 & 2,45 & NM_000585.1 & signal transduction \\
\hline hypothetical protein FLJ20701 & FLJ20701 & 2,45 & NM_017933.1 & - \\
\hline secretoglobin, family $2 \mathrm{~A}$, member 1 & SCGB2A1 & 2,45 & NM_002407.1 & hormone binding \\
\hline dipeptidylpeptidase 4 & DPP4 & 2,4 & M80536.1 & metabolism \\
\hline Immunoglobulin kappa constant & IGKC & 2,4 & BC 005332.1 & immune response \\
\hline Immunoglobulin heavy constant gamma 3 (G3m marker) & IGHG3 & 2,34 & M87789.1 & immune response \\
\hline
\end{tabular}


Table 6.3. Continued

\begin{tabular}{|c|c|c|c|c|}
\hline Title & Gene Symbol & fold change & Accession \# & Function \\
\hline iroquois homeobox protein 4 & IRX4 & 2,34 & NM_016358.1 & transcription factor \\
\hline $\begin{array}{l}\text { killer cell immunoglobulin-like receptor, two domains, short } \\
\text { cytoplasmic } \\
\text { tail, }\end{array}$ & KIR2DS1 & 2,34 & NM_014512.1 & immune response \\
\hline metallothionein $1 \mathrm{~K}$ & MT1K & 2,34 & R06655 & transport \\
\hline amylase, alpha $1 \mathrm{~A}$; salivary & AMY1A & 2,29 & NM_004038.1 & metabolism \\
\hline creatine kinase, brain & CKB & 2,29 & NM_001823.1 & metabolism \\
\hline cut-like 2 (Drosophila) & CUTL2 & 2,29 & AB006631.1 & transcription factor \\
\hline fatty-acid-Coenzyme A ligase, long-chain 2 & FACL2 & 2,29 & NM_001995.1 & metabolism \\
\hline PRO2000 protein & PRO2000 & 2,29 & NM_014109.1 & DNA binding \\
\hline serine (or cysteine) proteinase inhibitor, clade $E$, member 1 & SERPINE1 & 2,29 & NM_ 000602.1 & metabolism \\
\hline adiponectin receptor 2 & ADIPOR2 & 2,24 & NM_024551.1 & membrane protein \\
\hline alkaline phosphatase, liver/bone/kidney & ALPL & 2,24 & $\mathrm{X} 14174.1$ & metabolism \\
\hline N-acylsphingosine amidohydrolase (acid ceramidase)-like & ASAHL & 2,24 & AK024677.1 & metabolism \\
\hline hypothetical protein FLJ20366 & FLJ 20366 & 2,24 & NM_017786.1 & - \\
\hline Norrie disease (pseudoglioma) & NDP & 2,24 & NM_000266.1 & signal transduction \\
\hline zinc finger, BED domain containing 2 & ZBED2 & 2,24 & NM_024508.1 & DNA binding \\
\hline zinc finger protein 145 & ZNF145 & 2,24 & NM_006006.1 & protein binding \\
\hline Fas apoptotic inhibitory molecule & FAll & 2,19 & NM_018147.1 & - \\
\hline insulin-like growth factor binding protein 1 & IGFBP1 & 2,19 & NM_000596.1 & signal transduction \\
\hline interleukin 20 receptor, alpha & IL20RA & 2,19 & NM_014432.1 & signal transduction \\
\hline Mesothelin & MSLN & 2,19 & NM_005823.2 & - \\
\hline secreted and transmembrane 1 & SECTM1 & 2,19 & BF939675 & membrane protein \\
\hline CDC14 cell division cycle 14 homolog B & CDC14B & 2,14 & AU145941 & metabolism \\
\hline cathepsin $\mathrm{E}$ & CTSE & 2,14 & NM_001910.1 & metabolism \\
\hline LIM and cysteine-rich domains 1 & LMCD1 & 2,14 & NM_014583.1 & $\ldots$ \\
\hline monoamine oxidase $\mathrm{A}$ & MAOA & 2,14 & NM_000240.1 & transport \\
\hline toll-like receptor 2 & TLR2 & 2,14 & NM_003264.1 & signal transduction \\
\hline Homo sapiens mRNA; cDNA DKFZp586B0220 & $\ldots$ & 2,09 & AL 049435.1 & - \\
\hline hypothetical protein DKFZp434B044 & DKFZP434B044 & 2,09 & AL136861.1 & extracellular matrix \\
\hline glutamyl aminopeptidase & ENPEP & 2,09 & L12468.1 & metabolism \\
\hline epithelial V-like antigen 1 & EVA1 & 2,09 & NM_005797.1 & cell adhesion \\
\hline fibulin 2 & FBLN2 & 2,09 & NM_001998.1 & extracellular matrix \\
\hline KIAA0924 protein & KIAA0924 & 2,09 & NM_014897.1 & nucleair \\
\hline KIAA1609 protein & KIAA1609 & 2,09 & AA195017 & - \\
\hline neuroligin 4 & NLGN4 & 2,09 & Al338338 & cell adhesion \\
\hline peroxisome proliferative activated receptor, gamma, coactivator 1 & PPARGC1 & 2,09 & NM_013261.1 & DNA binding \\
\hline solute carrier family 26 , member 2 & SLC26A2 & 2,09 & Al025519 & transport \\
\hline CDC42 effector protein 3 & CDC42EP3 & 2,04 & Al754416 & - \\
\hline GREB1 protein & GREB1 & 2,04 & NM_014668.1 & - \\
\hline interleukin 1 receptor-like 1 & IL1RL1 & 2,04 & NM_003856.1 & signal transduction \\
\hline leucine-rich repeat-containing 1 & LRRC1 & 2,04 & NM_018214.1 & - \\
\hline protein kinase, AMP-activated, gamma 2 non-catalytic subunit & PRKAG2 & 2,04 & NM_016203.1 & metabolism \\
\hline SPARC-like 1 (mast9, hevin) & SPARCL1 & 2,04 & NM_004684.1 & - \\
\hline chromosome 18 open reading frame 1 & C18orf1 & 2 & NM_004338.1 & membrane protein \\
\hline choline phosphotransferase 1 & CHPT1 & 2 & AF195624.1 & metabolism \\
\hline $\begin{array}{l}\begin{array}{l}\text { endothelial differentiation, } \\
\text { coupled }\end{array} \\
\begin{array}{l}\text { receptor, } \\
\text { recephosphatidic acid }\end{array}\end{array}$ & EDG7 & 2 & NM_012152.1 & signal transduction \\
\hline retinol binding protein 4 , plasma & RBP4 & 2 & NM_006744.2 & transport \\
\hline carcinoembryonic antigen-related cell adhesion molecule 5 & CEACAM5 & -2 & NM_004363.1 & membrane protein \\
\hline chromosome condensation 1 & $\mathrm{CHC} 1$ & -2 & NM_001269.1 & cell growth \\
\hline cytochrome P450, family 27 , subfamily B, polypeptide 1 & CYP27B1 & -2 & NM_000785.1 & metabolism \\
\hline DVS27-related protein & DVS27 & -2 & AB024518.1 & - \\
\hline four jointed box 1 (Drosophila) & FJX1 & -2 & NM_014344.1 & - \\
\hline interleukin 24 & IL24 & -2 & NM_006850.1 & cell growth \\
\hline matrix metalloproteinase 11 (stromelysin 3 ) & MMP11 & -2 & Al761713 & metabolism \\
\hline synaptojanin 2 & SYNJ2 & -2 & AF318616.1 & metabolism \\
\hline aldo-keto reductase family 1 , member $\mathrm{B} 10$ (aldose reductase) & AKR1B10 & $-2,04$ & NM_020299.1 & metabolism \\
\hline neuromedin B & NMB & $-2,04$ & NM_021077.1 & signal transduction \\
\hline pleckstrin 2 & PLEK2 & $-2,04$ & NM_016445.1 & structural protein \\
\hline Transmembrane protease, serine 3 & TMPRSS3 & $-2,04$ & NM_024022.1 & metabolism \\
\hline twist homolog 1 & TWIST1 & $-2,04$ & X99268.1 & DNA binding \\
\hline hypothetical protein FLJ38993 & FLJ338993 & $-2,09$ & AF070524.1 & signal transduction \\
\hline Somatostatin & SST & $-2,09$ & NM_001048.1 & signal transduction \\
\hline chromosome 21 open reading frame 7 & C21orf7 & $-2,14$ & NM_020152.1 & - \\
\hline carboxypeptidase M & CPM & $-2,14$ & NM_001874.1 & metabolism \\
\hline
\end{tabular}


Table 6.3. Continued

\begin{tabular}{|c|c|c|c|c|}
\hline Title & Gene Symbol & fold change & Accession \# & Function \\
\hline glutathione peroxidase 2 (gastrointestinal) & GPX2 & $-2,14$ & NM_002083.1 & metabolism \\
\hline orosomucoid 1 & ORM1 & $-2,14$ & NM_000607.1 & transport \\
\hline serine (or cysteine) proteinase inhibitor, clade B (ovalbumin), member 2 & SERPINB2 & $-2,14$ & NM_002575.1 & cell growth \\
\hline solute carrier family 14 (urea transporter), member 1 & SLC14A1 & $-2,14$ & NM_015865.1 & transport \\
\hline SRY (sex determining region Y)-box 4 & $50 \times 4$ & $-2,14$ & Al989477 & transcription factor \\
\hline tribbles homolog 2 & TRB2 & $-2,14$ & NM_021643.1 & metabolism \\
\hline chromosome 20 open reading frame 42 & C20orf42 & $-2,19$ & NM_017671.1 & - \\
\hline dapper homolog 1, antagonist of beta-catenin (xenopus) & DACT1 & $-2,19$ & NM_016651.2 & nucleair \\
\hline ectodermal-neural cortex & ENC1 & $-2,24$ & AF010314.1 & protein binding \\
\hline keratin 23 & KRT23 & $-2,24$ & NM_015515.1 & - \\
\hline deiodinase, iodothyronine, type II & $\mathrm{DIO} 2$ & $-2,29$ & U53506.1 & metabolism \\
\hline plasminogen activator, urokinase & PLAU & $-2,29$ & NM_002658.1 & metabolism \\
\hline NY-REN-7 antigen & NY-REN-7 & $-2,34$ & AL117630.1 & - \\
\hline stanniocalcin 1 & STC1 & $-2,4$ & U46768.1 & signal transduction \\
\hline carbonic anhydrase \| & CA2 & $-2,45$ & M36532.1 & metabolism \\
\hline G protein-coupled receptor 17 & GPR17 & $-2,45$ & NM_005291.1 & signal transduction \\
\hline high mobility group AT-hook 1 & HMGA1 & $-2,45$ & AF176039.1 & transcription factor \\
\hline Ras-induced senescence 1 & RIS1 & $-2,45$ & BF062629 & $\ldots$ \\
\hline trefoil factor 1 & TFF1 & $-2,45$ & NM_003225.1 & growth factor \\
\hline WNT1 inducible signaling pathway protein 2 & WISP2 & $-2,45$ & NM_003881.1 & signal transduction \\
\hline aquaporin 3 & $A Q P 3$ & $-2,51$ & AB001325 & transport \\
\hline SRY (sex determining region Y)-box 9 & $50 \times 9$ & $-2,51$ & NM_000346.1 & transcription factor \\
\hline bradykinin receptor B1 & BDKRB1 & $-2,57$ & NM_000710.1 & signal transduction \\
\hline ephrin-B2 & EFNB2 & $-2,57$ & U16797.1 & signal transduction \\
\hline gap junction protein, alpha $4,37 \mathrm{kDa}$ (connexin 37 ) & GJA4 & $-2,57$ & NM_002060.1 & transport \\
\hline myristoylated alanine-rich protein kinase $\mathrm{C}$ substrate & MARCKS & $-2,88$ & AW163148 & structural protein \\
\hline tumor necrosis factor receptor superfamily, member $11 \mathrm{~b}$ (osteoprotegerin) & TNFRSF11B & $-2,88$ & NM_002546.1 & signal transduction \\
\hline small proline-rich protein $2 \mathrm{~B}$ & SPRR2B & $-2,95$ & NM_006945.1 & structural protein \\
\hline chromogranin A (parathyroid secretory protein 1) & CHGA & $-3,02$ & NM_001275.2 & transport \\
\hline Homo sapiens non-functional folate binding protein (HSAF000381), mRNA & - & $-3,16$ & NM_013307.1 & - \\
\hline acid phosphatase, prostate & ACPP & $-3,31$ & NM_001099.2 & metabolism \\
\hline integrin, beta 3 & пाGB3 & $-3,47$ & M35999.1 & cell adhesion \\
\hline platelet-derived growth factor beta polypeptide & PDGFB & $-3,47$ & NM_002608.1 & growth factor \\
\hline SRY (sex determining region Y)-box 11 & sox11 & $-3,72$ & AB028641.1 & transcription factor \\
\hline cysteine knot superfamily 1 , BMP antagonist 1 & CKTSF1B1 & $-3,89$ & AF154054.1 & - \\
\hline ribosomal protein $\mathrm{S} 20$ & RPS20 & $-6,17$ & AF113008.1 & protein biosynthesis \\
\hline ribosomal protein L27a & RPL27A & $-7,59$ & BE737027 & protein biosynthesis \\
\hline
\end{tabular}

The response of menstrual phase endometrium to $17 \beta-E_{2}+P$ was less pronounced than that of late proliferative phase endometrium. Treatment of menstrual phase endometrium tissue with $17 \beta-\mathrm{E}_{2}+\mathrm{P}$ up-regulated ( $\geq 2$-fold) the expression of only 38 gene transcripts and down-regulated ( $\geq 2$-fold) the expression of 79 gene transcripts when compared to the control sample (i.e. vehicle) (Table 6.4).

Table 6.4. Gene transcripts regulated ( 22 -fold) by $17 \beta-E_{2}+P$ in menstrual phase explants, when compared to the vehicle treated controls. Data are presented as fold changes.

\begin{tabular}{|l|l|r|r|l|}
\hline Title & Gene Symbol & fold change & Accession \# & function \\
\hline secretoglobin, family 1D, member 2 & SCGB1D2 & 60,26 & NM_006551.2 & extracellular matrix \\
\hline alkaline phosphatase, placental (Regan isozyme) & ALPP & 10 & NM_001632.2 & metabolism \\
\hline hypothetical protein FLJ10847 & FLJ10847 & 7,08 & NM_018242.1 & transport \\
\hline secretoglobin, family 2A, member 1 & SCGB2A1 & 6,92 & NM_002407.1 & hormone binding \\
\hline secretoglobin, family 2A, member 2 & SCGB2A2 & 6,03 & NM_002411.1 & hormone binding \\
\hline trefoil factor 1 & TFF1 & 5,13 & NM_003225.1 & growth factor \\
\hline cytochrome P450, family 26, subfamily A, polypeptide 1 & CYP26A1 & 4,68 & NM_000783.1 & transport \\
\hline carbohydrate (N-acetylglucosamine 6-O) sulfotransferase 7 & CHST7 & 4,57 & NM_019886.1 & metabolism \\
\hline hypothetical protein FLJ10640 & FLJ10640 & 3,47 & NM_024703.1 & metabolism \\
hydroxysteroid (17-beta) dehydrogenase 2 & HSD17B2 & 3,39 & NM_002153.1 & metabolism \\
\hline paired box gene 5 (B-cell lineage specific activator protein) & PAX5 & 3,31 & NM_016734.1 & transcription factor \\
\hline apolipoprotein D & APOD & 3,09 & NM_001647.1 & transport \\
\hline
\end{tabular}


Table 6.4. Continued

\begin{tabular}{|c|c|c|c|c|}
\hline Title & Gene Symbol & fold change & Accession \# & function \\
\hline solute carrier family 7 (cationic amino acid transporter, $y+$ system), member 8 & SLC7A8 & 2,75 & NM_012244.1 & transport \\
\hline DNA segment on chromosome 4 (unique) 234 expressed sequence & D4S234E & 2,69 & NM_014392.1 & nucleair \\
\hline GREB1 protein & GREB1 & 2,69 & NM_014668.1 & - \\
\hline anthrax toxin receptor 1 & ANTXR1 & 2,63 & NM_018153.1 & membrane protein \\
\hline histone $1, \mathrm{H} 2 \mathrm{bd}$ & HIST1H2BD & 2,63 & AL353759 & DNA binding \\
\hline prostaglandin-endoperoxide synthase 2 & PTGS2 & 2,63 & NM_000963.1 & metabolism \\
\hline heat shock 70kDa protein 6 (HSP70B') & HSPA6 & 2,57 & NM_002155.1 & metabolism \\
\hline cyclin A1 & CCNA1 & 2,45 & NM_003914.1 & cell growth \\
\hline asparaginase like 1 & ASRGL1 & 2,4 & NM_025080.1 & metabolism \\
\hline apolipoprotein B mRNA editing enzyme, catalytic polypeptide-like 3B & APOBEC $3 \mathrm{~B}$ & 2,34 & NM_004900.1 & metabolism \\
\hline hypothetical protein FLJ20152 & FLJ20152 & 2,34 & Al816291 & - \\
\hline histone $1, \mathrm{H} 2 \mathrm{bh}$ & HIST1H2BH & 2,34 & NM_003524.1 & DNA binding \\
\hline Homo sapiens mRNA; cDNA DKFZp564G112 & - & 2,24 & AA053967 & - \\
\hline crystallin, alpha B & CRYAB & 2,19 & AF007162.1 & structural protein \\
\hline colony stimulating factor 3 (granulocyte) & CSF3 & 2,19 & NM_000759.1 & signal transduction \\
\hline histone $1, \mathrm{H} 1 \mathrm{c}$ & HIST1H1C & 2,19 & BC002649.1 & DNA binding \\
\hline insulin-like growth factor binding protein 1 & IGFBP1 & 2,19 & NM_000596.1 & signal transduction \\
\hline serine (or cysteine) proteinase inhibitor, clade $A$, member 3 & SERPINA3 & 2,19 & NM_001085.2 & immune respons \\
\hline apolipoprotein M & APOM & 2,14 & NM_019101.1 & transport \\
\hline piggyBac transposable element derived 5 & PGBD5 & 2,14 & NM_024554.1 & - \\
\hline trefoil factor 3 (intestinal) & TFF3 & 2,14 & NM_003226.1 & immune respons \\
\hline histone $1, \mathrm{H} 2 \mathrm{bi}$ & HIST1H2BI & 2,04 & NM_003525.1 & DNA binding \\
\hline $\mathrm{H} 2 \mathrm{~B}$ histone family, member $\mathrm{S}$ & H2BFS & 2 & NM_017445.1 & DNA binding \\
\hline putative chemokine receptor & HM74 & 2 & NM_006018.1 & signal transduction \\
\hline metallothionein $1 \mathrm{X}$ & MT1X & 2 & NM_002450.1 & transport \\
\hline TUWD12 & TUWD12 & 2 & NM_003774.2 & - \\
\hline hyaluronan binding protein 2 & HABP2 & -2 & NM_004132.1 & metabolism \\
\hline interleukin 2 receptor, beta & IL2RB & -2 & NM_000878.1 & immune respons \\
\hline myosin, light polypeptide kinase & MYLK & -2 & NM_005965.1 & signal transduction \\
\hline SAM and SH3 domain containing 1 & SASH1 & -2 & AK025495.1 & cell growth \\
\hline transglutaminase 2 & TGM2 & -2 & $\mathrm{BC} 003551.1$ & metabolism \\
\hline adipose specific 2 & APM2 & $-2,04$ & NM_006829.1 & - \\
\hline Microfibril-associated glycoprotein-2 & MAGP2 & $-2,04$ & AW665892 & extracellular matrix \\
\hline 3-phosphoinositide dependent protein kinase-1 & PDPK1 & $-2,04$ & NM_002613.1 & signal transduction \\
\hline polymerase (RNA) II (DNA directed) polypeptide J, 13.3kDa & POLR2J & $-2,04$ & Al738591 & DNA binding \\
\hline preferentially expressed antigen in melanoma & PRAME & $-2,04$ & NM_006115.1 & - \\
\hline Transmembrane protein 5 & TMEM5 & $-2,04$ & BF224146 & membrane protein \\
\hline leucine-rich repeat-containing 5 & LRRC5 & $-2,09$ & NM_018103.1 & - \\
\hline parathyroid hormone receptor 2 & PTHR2 & $-2,09$ & NM_005048.1 & signal transduction \\
\hline retinoblastoma binding protein 6 & RBBP6 & $-2,09$ & NM_006910.1 & cell growth \\
\hline cadherin 6, type 2, K-cadherin (fetal kidney) & $\mathrm{CDH} 6$ & $-2,14$ & AU151483 & cell adhesion \\
\hline $\begin{array}{c}\text { v-myc myelocytomatosis viral related oncogene, neuroblastoma derived } \\
\text { (avian) }\end{array}$ & $M Y C N$ & $-2,14$ & BC002712.1 & transcription factor \\
\hline SRY (sex determining region Y)-box 4 & Sox4 & $-2,14$ & Al989477 & transcription factor \\
\hline zinc finger, BED domain containing 2 & ZBED2 & $-2,14$ & NM_024508.1 & DNA binding \\
\hline ATP-binding cassette, sub-family C (CFTR/MRP), member 3 & $\mathrm{ABCC} 3$ & $-2,19$ & AF009670.1 & transport \\
\hline hypothetical protein LOC 339290 & LOC339290 & $-2,19$ & $\mathrm{H} 49382$ & - \\
\hline hypothetical protein MGC29643 & MGC29643 & $-2,19$ & AL567376 & - \\
\hline transcription factor 4 & TCF4 & $-2,19$ & AU118026 & transcription factor \\
\hline nudix (nucleoside diphosphate linked moiety X)-type motif 6 & NUDT6 & $-2,24$ & NM_007083.1 & growth factor \\
\hline ribosomal protein S6 kinase, $90 \mathrm{kDa}$, polypeptide 5 & RPS6KA5 & $-2,24$ & AF074393.1 & metabolism \\
\hline heme oxygenase (decycling) 1 & HMOX1 & $-2,29$ & NM_002133.1 & metabolism \\
\hline killer cell lectin-like receptor subfamily B, member 1 & KLRB1 & $-2,29$ & NM_002258.1 & signal transduction \\
\hline PTPRF interacting protein, binding protein 2 (liprin beta 2 ) & PPFIBP2 & $-2,29$ & Al692180 & DNA binding \\
\hline ubiquitin D & UBD & $-2,29$ & NM_006398.1 & - \\
\hline laminin, alpha 3 & LAMA3 & $-2,34$ & NM_000227.1 & structural protein \\
\hline ribonucleotide reductase $M 2$ polypeptide & RRM2 & $-2,34$ & BE966236 & metabolism \\
\hline Rho guanine nucleotide exchange factor (GEF) 17 & ARHGEF17 & $-2,4$ & NM_014786.1 & - \\
\hline N-myristoyltransferase 1 & NMT1 & $-2,4$ & Al570834 & metabolism \\
\hline Homo sapiens cDNA: FLJ22812 fis, clone KAIA2955 & - & $-2,45$ & AK026465.1 & - \\
\hline solute carrier family 16 (monocarboxylic acid transporters), member 6 & SLC16A6 & $-2,45$ & NM_004694.1 & transport \\
\hline spondin 1, (f-spondin) extracellular matrix protein & SPON1 & $-2,45$ & Al885290 & extracellular matrix \\
\hline ATP synthase, $\mathrm{H}+$ transporting, mitochondrial F0 complex, subunit s (factor B) & ATP5S & $-2,51$ & NM_015684.1 & - \\
\hline chemokine ( $\mathrm{C}-\mathrm{C}$ motif) ligand 5 & CCL5 & $-2,51$ & M21121 & signal transduction \\
\hline
\end{tabular}


Table 6.4. Continued

\begin{tabular}{|c|c|c|c|c|}
\hline Title & Gene Symbol & fold change & Accession \# & function \\
\hline CD96 antigen & $\operatorname{CD} 96$ & $-2,51$ & NM_005816.1 & cell adhesion \\
\hline growth associated protein 43 & GAP43 & $-2,51$ & NM_002045.1 & cell growth \\
\hline histone $H 2 A . F / Z$ variant & H2AV & $-2,51$ & BF343852 & DNA binding \\
\hline tumor necrosis factor receptor superfamily, member 4 & TNFRSF 4 & $-2,51$ & AJJ277151 & immune respons \\
\hline chemokine ( $\mathrm{C}$ motif) ligand 1 & $\mathrm{XCL} 1$ & $-2,57$ & U23772.1 & signal transduction \\
\hline Homo sapiens transcribed sequences & - & $-2,63$ & BE045982 & - \\
\hline C-terminal binding protein 1 & СTBP1 & $-2,63$ & AA053830 & metabolism \\
\hline fibroblast growth factor 9 (glia-activating factor) & FGF9 & $-2,63$ & NM_002010.1 & growth factor \\
\hline latexin protein & LXN & $-2,63$ & NM_020169.1 & - \\
\hline protocadherin gamma subfamily $\mathrm{C}, 3$ & PCDHGC3 & $-2,63$ & AB002325.1 & transport \\
\hline cathepsin W (lymphopain) & CTSW & $-2,75$ & NM_001335.1 & metabolism \\
\hline dual-specificity tyrosine-(Y)-phosphorylation regulated kinase 2 & DYRK2 & $-2,75$ & NM_006482.1 & metabolism \\
\hline integrin, beta 6 & ITGB6 & $-2,75$ & NM_000888.3 & signal transduction \\
\hline hypothetical protein LOC284266 & LOC284266 & $-2,75$ & AK025833.1 & - \\
\hline platelet-derived growth factor alpha polypeptide & PDGFA & $-2,75$ & X03795.1 & growth factor \\
\hline chromosome 14 open reading frame 117 & C14orf117 & $-2,82$ & NM_018678.1 & - \\
\hline chromosome 20 open reading frame 42 & C20orf42 & $-2,82$ & NM_017671.1 & - \\
\hline insulin-like growth factor binding protein 3 & IGFBP3 & $-2,82$ & BF340228 & signal transduction \\
\hline chloride intracellular channel 3 & CLIC3 & $-2,88$ & NM_004669.1 & signal transduction \\
\hline hypothetical protein FLJ11082 & FLJ 11082 & $-2,88$ & NM_018317.1 & - \\
\hline glutathione S-transferase theta 1 & GSTT1 & $-2,88$ & NM_000853.1 & metabolism \\
\hline $\mathrm{B} / \mathrm{K}$ protein & LOC51760 & $-2,95$ & NM_016524.1 & transport \\
\hline retinoic acid receptor responder (tazarotene induced) 1 & RARRES1 & $-2,95$ & Al669229 & cell growth \\
\hline Homo sapiens, clone IMAGE:4866926, mRNA & - & $-3,09$ & AA631242 & - \\
\hline chemokine (C-X-C motif) ligand 14 & CXCL14 & $-3,09$ & NM_004887.1 & signal transduction \\
\hline chemokine ( $\mathrm{C}$ motif) ligand 2 & $\mathrm{XCL} 2$ & $-3,09$ & NM_003175.1 & signal transduction \\
\hline cytidine deaminase & CDA & $-3,16$ & NM_001785.1 & metabolism \\
\hline erythrocyte membrane protein band 4.1 like $4 \mathrm{~A}$ & EPB41L4A & $-3,39$ & NM_022140.1 & structural protein \\
\hline zinc finger protein 426 & ZNF426 & $-3,39$ & NM_024106.1 & transcription factor \\
\hline regulator of G-protein signalling 5 & RGS5 & $-3,63$ & Al183997 & signal transduction \\
\hline KIAA0924 protein & KLAA0924 & $-3,72$ & NM_014897.1 & nucleair \\
\hline serine (or cysteine) proteinase inhibitor, clade B (ovalbumin), member 5 & SERPINB5 & $-4,07$ & NM_002639.1 & cell adhesion \\
\hline killer cell lectin-like receptor subfamily C, member 3 & KLRC3 & $-4,17$ & NM_002260.2 & immune respons \\
\hline calcium channel, voltage-dependent, alpha $1 \mathrm{G}$ subunit & CACNA1G & $-4,27$ & NM_018896.1 & transport \\
\hline protein phosphatase 1 , regulatory (inhibitor) subunit $16 \mathrm{~B}$ & PPP1R16B & $-4,47$ & AB020630 & signal transduction \\
\hline Homo sapiens mRNA; cDNA DKFZp564N1116 & - & $-4,68$ & BF 344237 & - \\
\hline integral membrane protein $2 \mathrm{~A}$ & ITM2A & $-4,79$ & NM_004867.1 & membrane protein \\
\hline phosphoribosylformylglycinamidine synthase (FGAR amidotransferase) & PFAS & $-4,9$ & AL044326 & metabolism \\
\hline major histocompatibility complex, class II, DR beta 3 & HLA-DRB3 & $-5,13$ & BC005312.1 & immune respons \\
\hline Immunoglobulin lambda joining 3 & IGLJ3 & $-5,62$ & X57812.1 & - \\
\hline fibroblast growth factor 18 & FGF18 & $-6,92$ & BC006245.1 & growth factor \\
\hline cystic fibrosis transmembrane conductance regulator, ATP-binding cassette & CFTR & $-8,32$ & NM_000492.2 & transport \\
\hline
\end{tabular}

Almost all genes modulated by $17 \beta-\mathrm{E}_{2}+\mathrm{P}$ in late proliferative phase endometrium were specific for that phase of the cycle. Of the 110 up-regulated ( $>2$ fold) gene transcripts, 100 were expressed in late proliferative phase explants and not menstrual phase explants. Of these 10 gene transcripts were documented to be up-regulated during the window of implantation (Table 6.5). Of the 107 downregulated ( 2 -fold) gene transcripts, 102 were selective for late proliferative phase explants. Of these, 7 genes were documented to be down-regulated during the implantation window (Table 6.5). The genes regulated by $17 \beta-\mathrm{E}_{2}+\mathrm{P}$ in both menstrual and late proliferative phase explants are presented in table 6.6. 
Table 6.5 Gene transcripts regulated ( $\geq 2$-fold) by $17 \beta-\mathrm{E}_{2}+\mathrm{P}$, which were also reported to be altered in the implantation window.

\begin{tabular}{|l|l|c|c|c|c|c|}
\hline Gene title & Symbol & fold change & Accession \# & Kao et al & Riesewijk et al & Carson et al \\
\hline dickkopf homolog 1 & DKK1 & 6,03 & NM_012242.1 & 12,1 & 7 & 12,6 \\
\hline Thrombomodulin & THBD & 3,24 & NM_000361.1 & & 10 & \\
\hline fibrinogen-like 2 & FGL2 & 2,88 & NM_006682.1 & & 5 & \\
\hline monoamine oxidase A & MAOA & 2,88 & NM_000240.1 & 7,5 & 15 & \\
\hline retinol binding protein 4, plasma & RBP4 & 2,88 & NM_006744.2 & & 6 & \\
\hline dipeptidylpeptidase 4 & DPP4 & 2,57 & M80536.1 & & 15 & \\
\hline nuclear factor VB & NFIB & 2,57 & Al186739 & & 10 & \\
\hline H.sapiens mRNA for interleukin-15 & - & 2,24 & Y09908.1 & 3,7 & 3 & 2,2 \\
\hline Gastrin & GAS & 2,19 & NM_000805.2 & & 11 & \\
\hline KlAA0367 protein & KIAA0367 & 2,04 & AL138349 & & 4 & \\
\hline coagulation factor XIII, A1 polypeptide & F13A1 & -2 & NM_000129.2 & $-4,1$ & & \\
\hline microfibrillar-associated protein 2 & MFAP2 & $-2,4$ & NM_017459.1 & -3 & & \\
\hline transforming growth factor, beta 3 & TGFB3 & $-2,4$ & J03241.1 & & & $-2,44$ \\
\hline gap junction protein, alpha 4, 37kDa (connexin 37) & GJA4 & $-2,95$ & NM_002060.1 & & & -20 \\
\hline myristoylated alanine-rich protein kinase C substrate & MARCKS & $-3,09$ & M68956.1 & $-2,2$ & & \\
\hline matrix metalloproteinase 11 (stromelysin 3) & MMP11 & $-3,31$ & Al761713 & & & -10 \\
\hline deiodinase, iodothyronine, type II & DIO2 & $-3,47$ & U53506.1 & $-2,4$ & & \\
\hline
\end{tabular}

\section{Ingenuity Pathways Analysis}

Ingenuity Pathways Analysis revealed various significant networks of interconnected focus genes after treatment with $17 \beta-E_{2}+P$. In late proliferative phase endometrium five highly significant networks were identified. Network 1 connected nodes IL1B, PLAU, MMP1, MMP3, MMP7, MMP9, SERPINE1, and EDN1; network 2 connected IL8, MMP14, FGF2, PDGFB, ITGB3, PDGFRA, PDGFRB, PTGS2, EGR1; network 3 related TGF $\beta 2$, TGF $\beta 3$, INHBA, PTHLH, JUN, SMAD3, SMAD7; network 4 linked IGF1, TNFSF11 and HOXA9; network 5 coupled ICAM1, CXCL10, IL15, SOCS1, RAR $\alpha$ and ARNT2. Network 1 is illustrated in Figure 6.4.

Table 6.6 Gene transcripts regulated ( 2 -fold) by $17 \beta-\mathrm{E}_{2}+\mathrm{P}$ in both menstrual and late proliferative phase explants, when compared to their respective vehicle treated controls. Data are presented as fold changes.

\begin{tabular}{|c|c|c|c|c|c|}
\hline Gene title & Gene symbol & fold change early & fold change late & Accession $¥$ & Function \\
\hline secretıglobin, family $1 \mathrm{D}$, nenber 2 & SCGB1D2 & 60,26 & 10 & NM_0J6551.2 & - \\
\hline alkaline phosphatase, plazental (Regan isozyme) & ALFP & 0 & 4,79 & NM_0J1632.2 & retabolism \\
\hline secretıglobin, family $2 \mathrm{~A}$, membe -1 & SCGB2A1 & 6,92 & 2,63 & NM_0J2407: & hormone binding \\
\hline cylochrome P450, fanily 26 , subfamily A, polypeptide 1 & CYP26A1 & 4,68 & 33,11 & NM_0J0783.' & transport \\
\hline carbolydrate ( $\mathrm{N}$-acetylglucosamine 6-0) sulfotransferase 7 & CHST7 & 4,57 & 7,03 & NM_019886.' & metabolism \\
\hline apolipcprotein D & APOD & 3,09 & 4,9 & NM_0J1647: & transport \\
\hline $\begin{array}{l}\text { soute carrler famlly } 7 \text { (cationic amino acld transporter, y+ } \\
\text { eyetem), } \\
\text { eyembar }\end{array}$ & SLC7^8 & 2,75 & 1,37 & NM_012211: & traneport \\
\hline GREB1 proteir & GREB1 & 2,69 & 2,24 & NM_014668: & - \\
\hline insullin-like grnwth factor hinding prote.in 1 & GFAP1 & 2,19 & 2,45 & NM_OMO596. & sgnal transductinn \\
\hline latexin protein & $\mathrm{XN}$ & $-2,6.3$ & $-2,51$ & NM_חPก16.9. & - \\
\hline intearin, beta 6 & TGB6 & $-2,75$ & $-2,95$ & NM 050888.3 & c=ll adhesion \\
\hline chromosome 20 open reading frame 42 & $\mathrm{C} 20 \mathrm{orf} 42$ & $-2,82$ & $-2,82$ & NM_017671.: & - \\
\hline hypothetical protein F_J11082 & FLJ11082 & $-2,88$ & $-2,04$ & NM_018317: & - \\
\hline $\begin{array}{l}\text { cystic fibrosis transmembrane conductance regulator, ATP- } \\
\text { bindino cassete (sub-fanily C, memper } 7 \text { ) }\end{array}$ & CFTR & $-8,32$ & $-4,07$ & NM_0J0492.2 & transport \\
\hline
\end{tabular}


In contrast, in menstrual phase endometrium only two highly significant networks were extracted from the data. One network connected CCL5, TNFS11, INTGB3, MAPK8 and ESR1. The second network linked IFGBP3, TGF 32 , FGF2, HGF, PDGFA, MMP9, PTGS2, RAR $\beta$ and EGR1. The latter network is presented in Figure 6.3.

\section{Discussion}

Previous work in our laboratory has shown that explant cultures of human endometrium tissue are biologically relevant in vitro models to investigate oestrogen regulation of gene expression and proliferation $[1,33]$. With regard to progestins, it has been shown that tissue cultures of human endometrium are also responsive, as evidenced by the suppressive effects on the production and activation of MMPs [1, $153,278]$. The present study was designed to gain more insight into the responses of human endometrium to progesterone with regard to gene expression and the influence of $17 \beta-\mathrm{E}_{2}$. The results show that in explant cultures of human endometrium the expression of genes that have been implicated in the process of embryo implantation can be modulated by $17 \beta-\mathrm{E}_{2}$ and $\mathrm{P}$.

The number of gene transcripts regulated by $\mathrm{P}$ in late proliferative phase explants was almost twice that of menstrual phase explants, indicating that oestrogen priming sensitizes the endometrium for $\mathrm{P}$ regulation, most likely by induction of PR gene expression [33]. In addition, most of these genes were specifically modulated in the late proliferative phase endometrium. Of these genes $(n=100)$, at least 17 were previously described to be regulated in the implantation window (Table 6.5) [7, 147, 148]. Three examples of such genes are DKK1, MAOA and SPARCL1. Regulation of expression by $17 \beta-\mathrm{E}_{2}+\mathrm{P}$ and $\mathrm{P}$ alone was confirmed with real-time PCR in both explant cultures and endometrium biopsies collected during the implantation window and ES phase. These findings demonstrate that the expression of genes associated with the implantation window can be modulated in explant cultures of human endometrium, and that for most of these genes prolonged in vivo exposure to $17 \beta-\mathrm{E}_{2}$ is required for adequate $\mathrm{P}$ regulation. These findings also support the hypothesis that variations in the duration of $17 \beta-\mathrm{E}_{2}$ priming can affect the response of the endometrium to $\mathrm{P}$ and therefore the subsequent implantation process [18, 21].

The number of implantation-associated gene transcripts, however, was rather low. This could be due to the fact that culturing explants alters the physiology of the tissue and therefore its steroid responsiveness, or, and this has been shown for prolactin and IGFBP1, in some cases prolonged exposure to $\mathrm{P}$ is required for genes to respond [280]. 


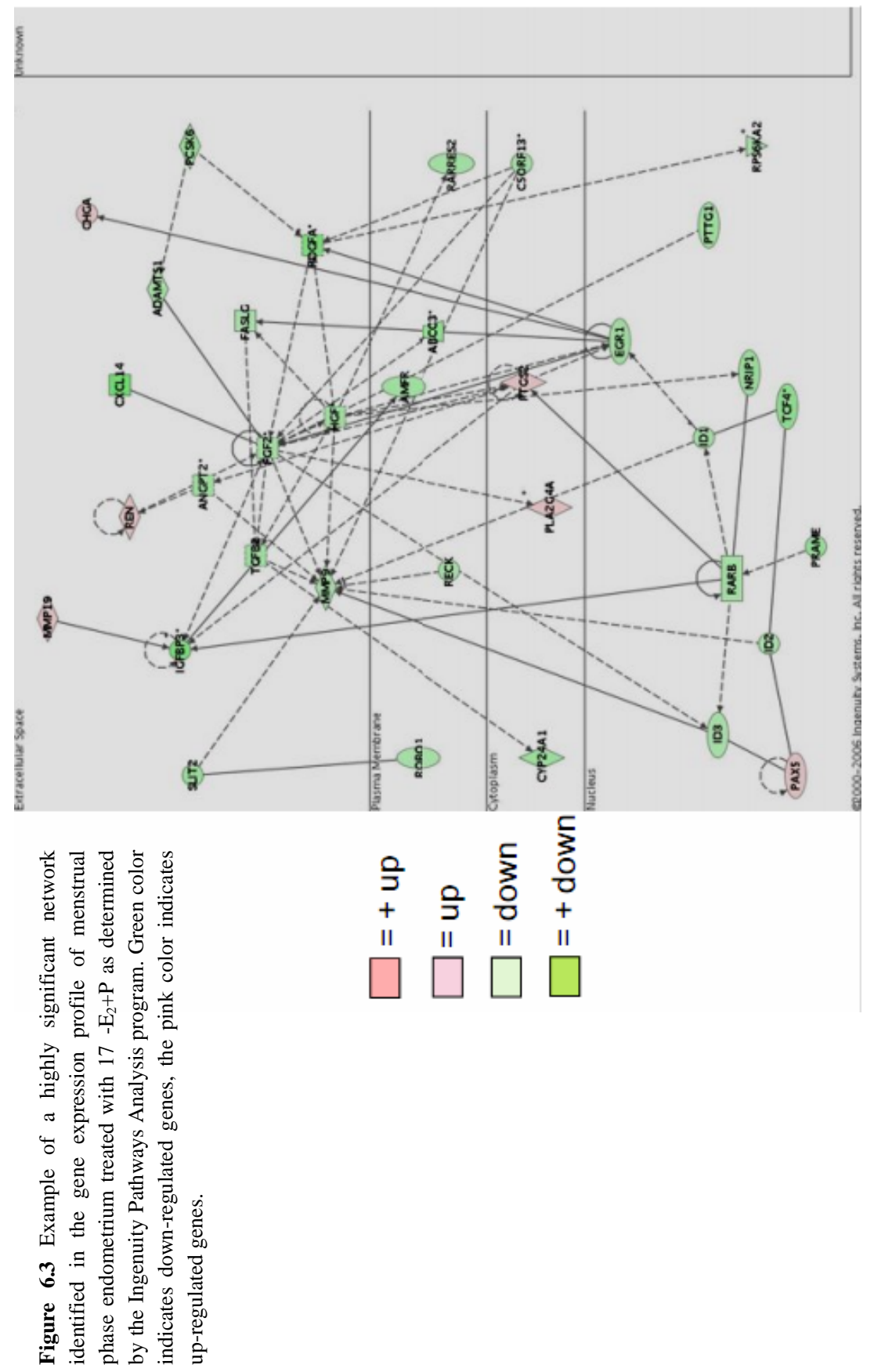




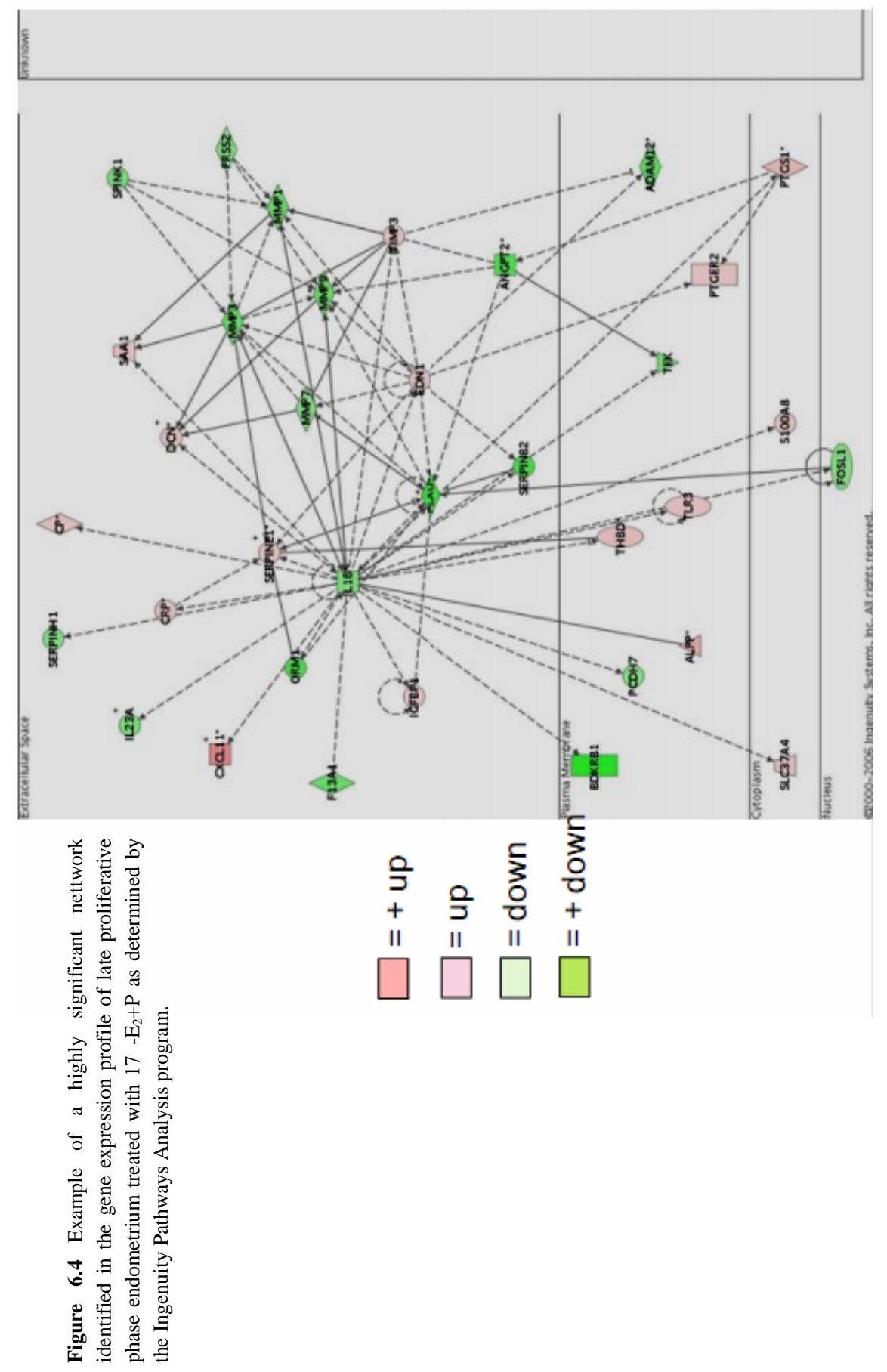


This is also supported by the report from Kao and coworkers who showed that many genes up-regulated in the implantation window are not regulated yet in early secretory endometrium, at which time the endometrium has been exposed to progesterone for a short time. Explant cultures are therefore appropriate models to study immediate responses of human endometrium to estrogens and progestins ex vivo. However, it does not allow the investigation of the entire spectrum of implantation-associated genes.

The low number of implantation-related genes identified may also be the result of the relatively low number of samples used for the initial microarray hybridizations. This increases the likelihood of missing relevant genes and the chance of generating false positives. At the time the microarray experiments were performed we opted for a limited number of array hybridizations, to apply rigorous statistical procedures, and to perform extensive validation of selected genes; both on the array samples and on samples from independent additional experiments. Rockett and Hellmann asked the question: how many genes should we pick for validation and which genes to pick? The authors argued that the genes can be selected to ensure successful confirmation, i.e. by selecting genes that have changed more than fourfold [281], or by selecting genes that have been reported to be changed in similar models or conditions. We selected six genes primarily based on the fact that their expression is altered during the implantation window. In addition, we selected two genes which have not yet been reported in the endometrium. With the exception of DKK1 (more than five-fold induction), the expression of the selected genes was less than three-fold. We could confirm steroid regulation for 4 of 8 genes in independent experiments, which justifies our approach.

Rockett and Hellmann also questioned the additive value of corroborating the findings of microarray experiments with alternative means of quantitating mRNA abundance of a limited number of genes of the array [282]. The vast majority of studies published state that the DNA array data can be corroborated, indicating that the array data are reliable as long as the experimental design and statistical analysis is sound. Even in high impact journals studies are being published that have not been validated. Goodman (2003) illustrated this by showing that of 28 microarray papers in Science, Cell and Nature published in 2002, only 11 reported corroborative studies [283]. It is evident that clear standards such as the guideline Minimal Information about a Microarray Experiment (MIAME) in the confirmatory studies area are mandatory [282].

A clear distinction could be made between genes that are regulated by progesterone irrespective of the presence of $17 \beta-\mathrm{E}_{2}$, and genes of which the expression clearly is influenced by the continuous presence of $17 \beta-\mathrm{E}_{2}$. Many genes modulated by $\mathrm{P}$ alone, were similarly modulated in the $17 \beta-\mathrm{E}_{2}+\mathrm{P}$ treated explants (119/161 P-modulated genes), however, 42 of the P-modulated genes were not affected in the $17 \beta-\mathrm{E}_{2}+\mathrm{P}$-treated explants. Also, of the $21917 \beta-\mathrm{E}_{2}+\mathrm{P}-$ modulated genes, 117 were not modulated by treatment with $\mathrm{P}$ alone. This clearly indicates that the expression of a subset of genes is sensitive for the continuing presence of $17 \beta$ $\mathrm{E}_{2}$. It also indicates that in vivo priming of cycles day 12 and 13 endometrium is 
remembered by the tissue in vitro, leading to similar expression patterns for certain genes induced both in the absence and presence of $17 \beta-\mathrm{E}_{2}$.

A good example of genes of which the expression is known to be suppressed by $\mathrm{P}$, but which were only suppressed by $\mathrm{P}$ in the presence of $17 \beta-\mathrm{E}_{2}$ are various members of the MMP family [1, 153, 278]. The expression of MMP11 was the only one to be suppressed by $\mathrm{P}$ alone. The expression of MMP1, $-3,-14$ and -27 was only suppressed in the presence of $17 \beta-\mathrm{E}_{2}$. Similarly, cystic fibrosis transmembrane conductance regulator (CFTR) is only suppressed in the $17 \beta-\mathrm{E}_{2}+\mathrm{P}$ treated explants and not the $\mathrm{P}$ treated explants suggesting that continued presence of $17 \beta-E_{2}$ is required for the down-regulation of CFTR. This agrees with the finding that CFTR is highly expressed in the human endometrium around the ovulatory period [284], and that it is responsive to both $17 \beta-E_{2}$ and $P$.

Some genes were induced by $17 \beta-\mathrm{E}_{2}+\mathrm{P}$ in both menstrual and late proliferative phase explants (i.e. alkaline phosphatase, ALPP; monoamine oxidase, MAOA; secretoglobin family 1, member D, SCGB1D2; cystic fibrosis transmembrane conductance regulator, CFTR; P450 cytochrome family 26 subfamily A, CYP26A), indicating that the expression of these genes does not depend on prolonged in vivo oestrogen priming of the endometrium.

A particularly interesting observation in this regard is the up-regulation of the expression of the CYP26A gene in both menstrual and late proliferative phase endometrium by $17 \beta-\mathrm{E}_{2}+\mathrm{P}$, and to a lesser extent, by $\mathrm{P}$ alone. This enzyme is responsible for the metabolism of the active retinoid metabolite, all-trans retinoic acid. The importance of controlling retinoid levels in the uterus is illustrated by the fact that vitamin A deficiency in women, nonhuman primates and laboratory animals is associated with pregnancy failure and developmental defects [285-287], whereas excess vitamin A levels are detrimental to blastocyst development [288] and the decidualization process [289].

Uterine vitamin A levels in women increase in the presence of oestrogens [290, 291], most likely as the result of up-regulation of retinaldehyde dehydrogenase (RALDH2), a critical enzyme in retinoic acid biosynthesis [292]. Since retinoids are morphogens and essential for epithelial cell growth [293] they may be involved in the regeneration, growth and differentiation of the endometrial epithelium after menstruation. The induction of CYP26A expression by $\mathrm{P}$ in the secretory phase most likely serves to inactivate excessive amounts of retinoids.

Databases can be explored with several different bioinformatics tools. We have employed the Ingenuity Pathways Analysis (IPA) program which has the added advantage that it is an evidence-based data mining tool. In contrast to most other bioinformatics tools which annotate certain functions to gene products, the IPA program includes any reported interaction between two genes, whether it involves regulation of gene or protein expression, protein-protein interactions or enzymatic conversion (for example, phosphorylation). It is therefore a continuously growing database and by the nature of its development not complete. It is not unusual that the most affected genes are not presented in the networks. The networks present groups 
of genes that have a proven biologically relationship. The nodes in these highly significant networks presumably represent genes that have important modulatory roles. When interpreting the data one has to realize that the IPA database is biased in that certain genes have received more attention than others and therefore have a higher likelihood to be included in a network. However, the continuously growing database will allow the re-analysis of the data in the future which may reveal novel unidentified relationships between genes or groups of genes.

The significant suppressive actions of $\mathrm{P}$ on nodes representing immunomodulators were immediately apparent. These included IL1 $\beta$, IL8, COX2, the chemokine CCL5, and members of the TGF $\beta$ superfamily (TGF $\beta 2$ and -3 , INHBA, and their signalling molecules SMAD2 and -3). At the end of the secretory phase a rapid influx in the endometrium can be observed of leukocytes mostly consisting of NK cells and macrophages, which is believed to be the result of the disappearance of $\mathrm{P}$ suppression on key inflammatory mediators [294, 295]. Apparently, these immunosuppressive actions of $\mathrm{P}$ can at least partly be mimicked in the explant model by short term incubation with $17 \beta-\mathrm{E}_{2}$ and $\mathrm{P}$.

One of the few nodes present in highly significant networks identified by the IPA program in both $17 \beta-\mathrm{E}_{2}$ and $\mathrm{P}$-treated menstrual and late proliferative phase endometrium, was FGF2 or basic fibroblast growth factor (bFGF). FGF2 expression is suppressed by $\mathrm{P}$. The significance of this finding is illustrated by the fact that FGF2 inhibits the decidualization process in human endometrial stromal cells [296], and should therefore be controlled by P during the secretory phase. FGF2 is an important mitogenic and angiogenic factor which is expressed as different isoforms synthesized through the alternative use of translation initiation codons [297]. In human endometrium, only the smallest isoform, an $18 \mathrm{kD}$ isoform, is present [298]. It is located predominantly in the cytoplasm, and is stored in the extracellular matrix [299]. FGF2 is released mostly during menstruation and early proliferative phase, and expressed in blood vessels throughout the menstrual cycle [298, 300]. The FGF receptors however, were not expressed in the blood vessels, with the exception of the mid-secretory (FGFR2) and late secretory phases (FGFR1 and FGFR2). Blood vessels may therefore not be the main target of FGF2. FGF2 receptors are predominantly found in the epithelial compartment [301], suggesting that FGF2 is involved in the control of regeneration and growth of epithelial cells in a paracrine fashion. FGF2 is known to regulate proliferation of various cell populations of the bone marrow [301], which were shown to be of eminent importance for the regeneration of the human endometrium [97].

In conclusion, explant culture of human endometrium is a biologically relevant in vitro model system which allows for the investigation of steroid regulation of gene expression in the tissue context. The regulation of the expression of several genes associated with embryo implantation can be mimicked in vitro. We showed that the expression of thrombomodulin, monoamine oxidase A and SPARClike-1 is regulated by progestins. Only a subset of implantation-associated genes was modulated in the short term explant cultures, however, we clearly showed that we 
can distinguish genes that require continuous presence of $17 \beta-\mathrm{E}_{2}$ from those that depend on $\mathrm{P}$ only. Therefore $17 \beta-\mathrm{E}_{2}$ selectively primes implantation-related genes for the effects of progesterone. 


\section{Chapter 7 \\ Haemoglobin expression in human endometrium}

H Dassen ${ }^{1,2}$, R Kamps $^{1,2}$, C Punyadeera ${ }^{1,2}$, F Dijcks $^{4}$, A de Goeij ${ }^{1,2}$, A Ederveen ${ }^{4}, \mathrm{G}$ Dunselman $^{1,3 *}$ and P Groothuis ${ }^{1,3}$,

${ }^{1}$ Research Institute GROW; Departments of ${ }^{2}$ Pathology and ${ }^{3}$ Obstetrics and Gynaecology, University Hospital Maastricht/University Maastricht; ${ }^{4}$ Department of Pharmacology, Organon N.V., Oss, The Netherlands

Published in: Hum reprod. 2008 Mar; 23 (3): 635-41. 


\section{Abstract}

BACKGROUND The general concept that haemoglobin is only a carrier protein for oxygen and carbon dioxide is challenged since recent studies have shown haemoglobin expression in non-erythroid cells and the protection of haemoglobin against oxidative and nitrosative stress. Using microarrays, we previously showed expression of haemoglobins $\alpha, \beta, \delta$, and $\gamma$ and the haeme metabolizing enzyme, haeme oxygenase (HO)-1 in human endometrium.

METHODS Using real-time quantitative PCR, haemoglobin $\alpha, \beta, \delta$, and $\gamma$, and HO-1 mRNA levels were assessed throughout the menstrual cycle $(n=30$ women). Haemoglobin and HO-1 protein levels in the human endometrium were assessed with immunohistochemistry. For steroid responsiveness menstrual and late proliferative phase endometrial explants were cultured for 24 hours in the presence of vehicle $\left(0.1 \%\right.$ ethanol), oestradiol $\left(17 \beta-\mathrm{E}_{2}, 1 \mathrm{nM}\right)$, progestin (Org 2058,1 nM) or $17 \beta-\mathrm{E}_{2}+\operatorname{Org} 2058$.

RESULTS All haemoglobins and the HO-1 were expressed in normal human endometrium. Haemoglobin mRNA and protein expression did not vary significantly during the menstrual cycle. Explant culture with Org 2058 or $17 \beta$ $\mathrm{E}_{2}+$ Org2058 increased haemoglobin $\gamma$ mRNA expression $(P<0.05)$. HO-1 mRNA levels, and not protein levels, were significantly higher during the menstrual phase (M) of the cycle $(P<0.05)$, and were down-regulated by Org 2058 in M explants and by $17 \beta-E_{2}+$ Org 2058 in late proliferative phase explants, versus control $(P<0.05)$.

CONCLUSION The haemoglobin-HO-1 system may be required to ensure adequate regulation of the bioavailability of haeme, iron and oxygen in human endometrium.

\section{Introduction}

The concept that haemoglobin is merely a protein that carries $\mathrm{O}_{2}$ and $\mathrm{CO}_{2}$ in erythroid cells is now being challenged. It has long been thought that haemoglobin is only produced by erythroid cells, however recently it was shown that haemoglobins are also produced by activated macrophages, cells of the lens of the eye and alveolar epithelial cells [302-304]. Evidence is accumulating that haemebinding proteins, including haemoglobin, protect cells against oxidative and nitrosative stress $[305,306]$.

We showed recently using global gene expression analysis that various members of the haemoglobin gene family (haemoglobins $\alpha, \beta, \delta$, and $\gamma$ ) are expressed at the mRNA levels in human endometrium [136]. In addition, 
haemoglobin $\beta$ expression was reported in the implantation window [82, 83]. The haemoglobin molecule is a tetramer composed of a combination of $2 \alpha$-globin chains and 2 non- $\alpha$-globin chains $\left(\alpha_{1}\right.$ and $\alpha_{2}, \beta, \gamma$ or $\delta$-globin). This tetramer is then associated with the iron containing haeme complex [307, 308].

The haemoglobin, iron and haeme are all oxidative stress-inducing agents and thus potentially toxic for human tissues [309, 310]. Once haemoglobin is released from the cell, it is oxidized rapidly in the extracellular environment to ferrihaemoglobin, which in turn will readily release the haeme [311]. Particularly the hydrophobic nature of haeme ensures that it can easily cross cell membranes [311]. Free haeme levels are controlled in cells by intracellular and extracellular scavenger molecules, such as haeme binding proteins (haemopexin and albumin) and haeme oxygenases (HOs) [312-314], and by anti-oxidative enzymes [315]. It is likely that the local production of haemoglobin also contributes to the regulation of intracellular haeme bioavailability.

The HOs are the enzymes that neutralize haeme by converting it into iron, carbon monoxide and biliverdin [314-321]. Thus, by clearing the haeme, these enzymes contribute to the release of free iron. The expression of HOs has been reported in the human endometrium [322, 323] and placenta [324]. The protective effect of the HO system was demonstrated in experimental models of various diseases, including acute inflammation, atherosclerosis, degenerative diseases, and cancer, in which the induction of HO-1 can prevent or mitigate the symptoms associated with these ailments [325]. The aberrant haemoglobin and HO levels in peritoneal fluid and lesions of women with endometriosis suggests their involvement in endometrial pathologies as well [326].

Iron was shown to be an important determinant in the control of proliferation, since various key enzymes involved in oxygen sensing, energy metabolism, respiration, folate metabolism and DNA synthesis require iron. Deprivation of iron was shown to prevent cells proceeding from the G1 to the $S$ phase of the cell cycle [327], suggesting that iron may be an essential element for endometrial growth during the menstrual cycle. This is supported by the observations of Defrère and coworkers [328] who showed that administration of an iron chelator i.p. to nude mice bearing endometriotic lesions inhibited the proliferative activity of the ectopic endometrial cells. This suggests that the production of haemoglobin in endometrial cells may be a mechanism to control intracellular iron levels and proliferation.

The emerging importance of the haemoglobin-HO system in the female genital tract warrants a closer evaluation of the various components in the human endometrium. In this study we evaluated the expression of various haemoglobin isoforms $(\alpha, \beta, \gamma$ and $\delta)$ and HO-1 at the mRNA and protein level in the human endometrium throughout the menstrual cycle. In addition, we employed our tissue explant culture system to investigate the steroid regulation of the expression of these proteins in the human endometrium. According to the microarray experiment [136] we predict that the haemoglobin and $\mathrm{HO}$ expression will be induced by progestins and oestradiol $\left(17 \beta-\mathrm{E}_{2}\right)$ combined with a progestin in the explant cultures. We 
hypothesize that haemoglobin plays an important role during the implantation window and accordingly we predict that the highest haemoglobin expression will occur during the mid secretory phase of the menstrual cycle.

\section{Materials and methods}

\section{Human endometrial tissue}

Endometrium was collected from hysterectomy specimens or by pipelle biopsies during laparoscopy (Pipelle catheter, Unimar Inc., Prodimed, NeuillyEnthelle, France) in 30 women of 20-45 years of age with regular menstrual cycles, who underwent surgery for benign indications. The women were documented as not being on any kind of steroid medication. All women signed an informed consent, according to a protocol approved by the Medical Ethical Committee of the Academic Hospital Maastricht.

After hysterectomy, the endometrium was inspected macroscopically by a pathologist for abnormalities. Endometrium was then gently scraped from the surface and the tissue was transported to the laboratory in Dulbecco's modified Eagle's medium (DMEM)/Ham's F12 medium on ice. A portion of each sample was fixed in $10 \%$ buffered formalin for histological evaluation. The endometrium was dated according to clinical information with respect to the start of the last menstrual period, which was reconfirmed by histological examination of the tissue [258]. Of the 30 biopsies that were collected, 10 were collected in the menstrual (M) phase (cycle day 1-5), 13 were collected in the proliferative phase: early proliferative phase (cycle day 6-11), $n=5$; late proliferative (LP) phase (cycle day 12-14), $n=8$, and 7 were collected in the secretory phase of the cycle: early secretory phase (cycle day 15-18), $n=5$; mid-secretory phase (cycle day 19-23), $n=2$. The collected biopsies were partly snap frozen in lysis buffer from the SV total RNA isolation kit (Promega, Madison, WI, USA) and stored at $-80{ }^{\circ} \mathrm{C}$ for RNA isolation and partly fixed in $10 \%$ buffered formalin and paraffin embedded for immunohistochemistry. These were the uncultured samples. Explant cultures were prepared from $\mathbf{M}$ and proliferative phase endometrium.

\section{Explant cultures}

Human endometrium explant cultures were prepared from $M(n=8)$ and proliferative phase $(n=8)$ endometrium as described by Punyadeera et al. [33]. In brief, human endometrium tissue was cut into pieces of $2-3 \mathrm{~mm}^{3}$. Twenty-four explants per well were placed in Millicell-CM culture inserts (pore size of $0.4 \mathrm{~m}$, $30 \mathrm{~mm}$ diameter, Millipore, Billerica, MA, USA) in 6-well plates containing $1.2 \mathrm{ml}$ phenol red-free DMEM/Ham's F12 medium (Life Technologies, Grand Island, NY, 
USA), supplemented with L-glutamine (1\%), penicillin and streptomycin (1\%). Cultures were performed for 24 hours. Previous experiments have shown that collagenase activity remains very low in proliferative endometria during the first 24 hours of culture [152], and that the tissue viability is not affected after 24 hours of culture [153]. Treatments included: vehicle only $\left(0.1 \%\right.$ ethanol), oestradiol $\left(17 \beta-\mathrm{E}_{2}\right.$, $1 \mathrm{nM}$ ), 17 $\beta$ - $\mathrm{E}_{2}+$ progestin (Org 2058, $1 \mathrm{nM}$ each) and Org 2058 alone (1 nM). The steroid hormones were provided by Organon N.V. (Oss, The Netherlands).

\section{Total RNA extraction and cDNA synthesis}

Total cellular RNA from explants and uncultured samples was extracted using the SV total RNA isolation kit (Promega, Madison, WI, USA) according to the manufacturer's protocol, with slight modifications. The concentration of DNase-1 for DNase treatment of the RNA samples was doubled and the incubation time was extended by 15 minutes in order to completely remove genomic DNA. Total RNA was eluted from the column in $50 \quad 1$ RNase-free water and stored at $-70{ }^{0} \mathrm{C}$ until further analysis. The quality of the RNA samples was determined by spectrophotometry (NanoDrop, Wilmington, Delaware, USA). All the samples analysed gave $28 \mathrm{~S}$ to $18 \mathrm{~S}$ ratios higher than 1.5 . A PCR for a housekeeping gene, glyceraldehyde-3-phosphate dehydrogenase, was performed to confirm that the RNA samples were free of genomic DNA.

Total RNA (1 $\mu \mathrm{g})$ was incubated with random hexamers (1 g/ 1, Promega, USA) at $70{ }^{0} \mathrm{C}$ for $10 \mathrm{~min}$. The samples were chilled on ice for $5 \mathrm{~min}$. To this mixture, a reverse transcriptase mix consisting of $5 \mathrm{x}$ reverse transcriptase-buffer (4 $\mu \mathrm{l}), 10 \mathrm{mM}$ dNTP mix (1 $\mu \mathrm{l})$ (Pharmacia, Uppsala, Sweden), 0.1 M dithiothreitol (2 $\mu l)$ (Invitrogen, Breda, The Netherlands) and superscript II reverse transcriptase $(200 \mathrm{U} / \mu \mathrm{l})$ (Invitrogen) was added and the samples were incubated at $42{ }^{\circ} \mathrm{C}$ for one hour, after which the reverse transcriptase was inactivated by heating the samples at $95{ }^{0} \mathrm{C}$ for $5 \mathrm{~min}$. The complementary DNA (cDNA) was stored at $-20{ }^{0} \mathrm{C}$ until further use.

\section{Real-time PCR}

In each real-time PCR reaction $50 \mathrm{ng}$ of cDNA template was used. Primers and probes for HO-1 (Hs00157965-m1), haemoglobin $\beta$ (Hs00747223-g1) and $\delta$ (Hs00426283-m1) and cyclophylin A (Hs99999904-m1) were purchased from Perkin-Elmer Applied Biosystems as pre-developed assays. For these PCRs FAMTAMRA was the fluorescent tag. The primers for haemoglobin $\alpha$ and $\gamma$ were designed and purchased from Sigma (Cambridgeshire, UK; sequences are described in table 7.1). For these PCRs SYBR green, (SYBR Green PCR Master Mix, Applied Biosystems, Warrington, UK) was the fluorescent tag. Human cyclophylin A was selected as an endogenous RNA control in all PCRs in order to normalize for the differences in the amount of total RNA added to each reaction. A pool of human endometrium tissues was included as positive control. All PCRs were performed on a Biorad thermal cycler (MIQ Single- Color - Real Time PCR System, BioRad Laboratories, Hercules, California, USA). The thermal cycling conditions comprised 
an initial uracil-DNA glycosylase decontamination step that prevents carryover of PCR products between wells at $50{ }^{\circ} \mathrm{C}$ for $2 \mathrm{~min}$, a denaturing step at $95{ }^{\circ} \mathrm{C}$ for 10 min and 40 cycles of $15 \mathrm{sec}$ at $95{ }^{\circ} \mathrm{C}$ followed by $1 \mathrm{~min}$ at $60{ }^{\circ} \mathrm{C}$. Experiments were performed for each sample in duplicate. Quantitative values were obtained from the threshold cycle number $(\mathrm{Ct})$ at which the increase in the signal associated with exponential growth of PCR products was first detected with the mIQ (mIQ SingleColor-Real Time PCR System, BioRad Laboratories) software. The fold-change in expression was calculated using the Ct method, with cyclophylin A mRNA as an internal control [156].

Table 7.1. Primer sequences designed and synthesized for the real-time PCRs with SYBR Green.

\begin{tabular}{|l|l|}
\hline Gene & Sequence \\
\hline Hemoglobin alpha1 & $\begin{array}{l}\text { Forward - 5'-CCTGCCGACAAGACCAACG-3' } \\
\text { Reverse - 5'-AGTGCGGGAAGTAGGTCTTGG-3' }\end{array}$ \\
\hline Hemoglobin gamma 1 & $\begin{array}{l}\text { Forward - 5'-CAAGGTGAATGTGGAAGATGCTG-3' } \\
\text { Reverse - 5'-TGGCAGAGGCAGAGGACAGG-3' }\end{array}$ \\
\hline Cyclophylin A & $\begin{array}{l}\text { Forward - 5'-CTCGAATAAGTTTGACTTGTGTT-3' } \\
\text { Reverse - 5'-CTAGGCATGGGAGGGAACA-3' }\end{array}$ \\
\hline
\end{tabular}

\section{Immunohistochemistry}

Paraffin sections of $5 \mathrm{~m}$ were cut from uncultured and cultured explants. After overnight incubation at $37{ }^{\circ} \mathrm{C}$ the sections were dewaxed in xylene and rehydrated. Endogenous peroxidases were blocked by incubating $30 \mathrm{~min}$ in $0.3 \%$ $\mathrm{H}_{2} \mathrm{O}_{2}$ in methanol. The antibodies, dilutions and antigen retrieval treatments are described in table 7.2. Antigen retrieval with citrate and Tris/EDTA-buffer was performed in a microwave at $650 \mathrm{Watts}$ for $20 \mathrm{~min}$. After washing in phosphatebuffered saline (PBS) the sections were incubated $1 \mathrm{hr}$ with diluted antibody. Both antibodies were diluted in PBS/ $0.1 \%$ Tween/ $0.1 \%$ bovine serum albumin. After 3 washes in PBS of $5 \mathrm{~min}$ each, the sections were incubated $30 \mathrm{~min}$ at room temperature with Chemate Envision ${ }^{\mathrm{TM}}$ (Dako, Glostrup, Denmark). To visualize the staining, the sections were incubated $10 \mathrm{~min}$ in 1:50 diluted diaminobenzidine solution (Dako). The reaction was stopped in water. The sections were briefly counter-stained in haematoxylin, dehydrated and sealed in entalan.

Table 7.2. Antibodies used for immunohistochemistry and incubation conditions used.

\begin{tabular}{l|l|l|l|l|}
\hline Antigen & Antibody & Source & Dilution & Antigen retrieval treatment \\
\hline $\mathrm{HO}-1$ & rabbit-anti-human haemeoxygenase-1 & Stressgen & $1: 2400$ & citrate buffer $\mathrm{pH} 6.0$ \\
\hline $\mathrm{Hb}$ & mouse-anti-human haemoglobin & Biodesign & $1: 2000$ & TE-buffer $\mathrm{pH} 8.0$ \\
\hline
\end{tabular}


To confirm that the observed haemoglobin $(\mathrm{Hb})$ staining was specific, increasing amounts of haemoglobin (undiluted and diluted 1:1 to 1:120 from a saturated solution) were added to the antibody mix, $30 \mathrm{~min}$ before application to the sections.

The sections were scored according to a previously published method [209]. Sections were scored for epithelial and stromal cells separately. A three-point scale was used for both the intensity and percentage for epithelial and stromal cells separately. Intensity: negative (score $=0)$, weak (score $=1)$, moderate $($ score $=2$ ), and strong (score $=3)$; Percentage: $0 \%($ score $=0),<10 \%($ score $=1)$, between 10 and $50 \%($ score $=2)$, more than $50 \%($ score $=3)$.

\section{Statistical analysis}

Statistical tests were carried out using the Statistical Package for the Social Sciences (SPSS 11) (SPSS Inc., Chicago, IL, USA) statistical analysis package. To evaluate whether mRNA and protein expression levels varied significantly throughout the menstrual cycle, the nonparametric unpaired Mann Whitney U test was used to test for differences versus the $\mathrm{M}$ phase. The nonparametric Wilcoxon signed rank test was used to test for differences between steroid treated explants and controls at a confidence level of $95 \%$.

\section{Results}

\section{Haemoglobin and HO-1 mRNA in human endometrium}

Transcripts for HO-1 and all haemoglobins were detectable in human endometrium in all the phases of the menstrual cycle investigated. HO-1 mRNA levels in human endometrium were significantly higher during the $\mathrm{M}$ phase of the cycle compared to the other phases of the menstrual cycle (figure 7.1).

Figure 7.1. The relative expression of haemoxygenase $(\mathrm{HO})-1$ in the different phases of the menstrual

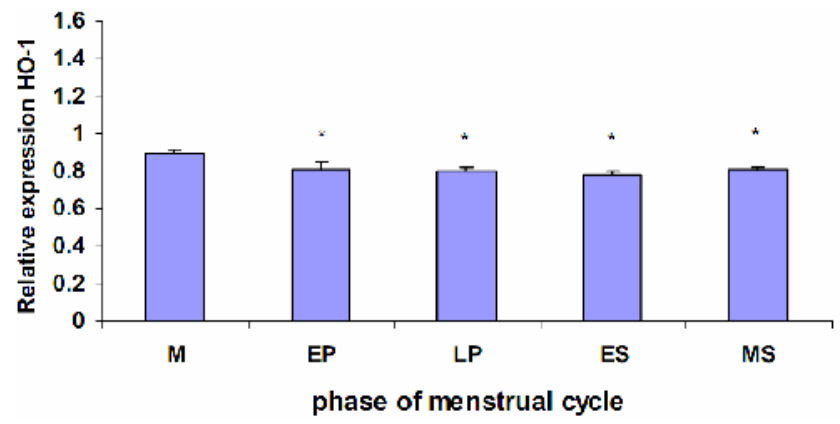
cycle presented as relative expression levels. * $\mathrm{p}<0.05$ versus menstrual (M) phase. $\mathrm{M}$ phase $(\mathrm{n}=6)$; early proliferative $(\mathrm{EP})$ phase $(\mathrm{n}=$ 5); late proliferative (LP) phase $(\mathrm{n}=7)$; early secretory (ES) phase $(n=6)$; and midsecretory (MS) phase $(n=3)$. 
The most prominently expressed haemoglobin was haemoglobin $\alpha$, followed by haemoglobin $\beta$ (figure 7.2). Haemoglobin $\delta$ was expressed at very low levels and was sometimes undetectable in the human endometrium. None of the haemoglobins showed a clear cyclic expression pattern during the phases of the menstrual cycle.

Figure 7.2. The relative expression of haemoglobin $\alpha, \beta, \gamma$ and $\delta$ mRNA in the different phases of the menstrual cycle. Data presented as relative expression levels. M phase $(n=10)$; EP phase $(n=5)$; LP phase $(n=7)$; ES phase $(n=6)$; and MS phase $(n=2)$.

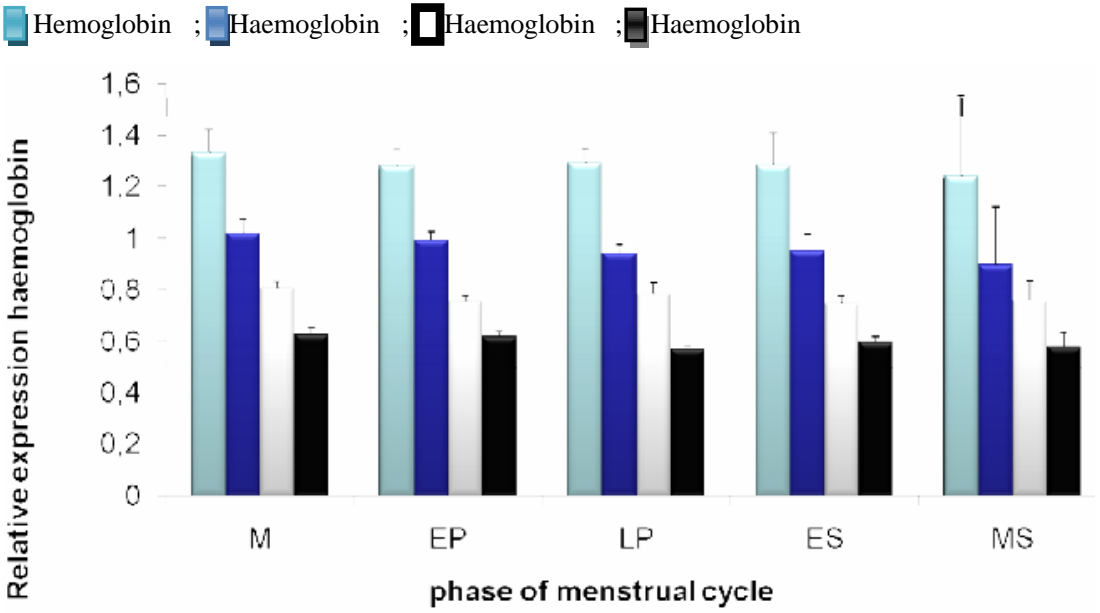

Levels of HO-1 mRNA were significantly reduced by Org $2058(\mathrm{P}<0.05)$ in M-phase explants when compared to controls. In LP phase explants, the expression of HO-1 was reduced by treatment with $17 \beta-\mathrm{E}_{2}+$ Org $2058(\mathrm{P}<0.05)$ compared to control (figure 7.3). When M and LP phase explants were analysed together, both Org $2058(\mathrm{P}<0.05)$ and $17 \beta-\mathrm{E}_{2}+$ Org $2058(\mathrm{P}<0.05)$ significantly reduced HO-1 mRNA levels.

Haemoglobin $\alpha, \beta$ and $\delta$ transcript levels were not significantly altered in the presence of $17 \beta-E_{2}$, Org 2058 or $17 \beta-E_{2}+$ Org 2058 when compared to the vehicle treated explants (data not shown). However, there was a tendency for Org 2058 to increase haemoglobin $\gamma$ mRNA expression in both M and LP phase explants (figure 7.4). Reanalysis of the data after pooling all experiments (in M and LP phase explants) revealed that haemoglobin $\gamma$ mRNA expression was significantly increased by Org 2058 and $17 \beta-\mathrm{E}_{2}+$ Org $2058(\mathrm{P}<0.05)$. 
Figure 7.3. The relative HO-1 mRNA expression in M-phase $(n=8)$ and LP-phase $(n=5)$ explants treated with $17 \beta$-oestradiol $\left(\mathrm{E}_{2}\right)(1 \mathrm{nM})$, Org $2058(\mathrm{P}, 1 \mathrm{nM})$, and 17 $\beta-\mathrm{E}_{2}+\mathrm{Org} 2058(1 \mathrm{nM}$ each) and compared to vehicle treated (control, $0.1 \%$ ethanol). ${ }^{*} \mathrm{p}<0.05$ versus control.

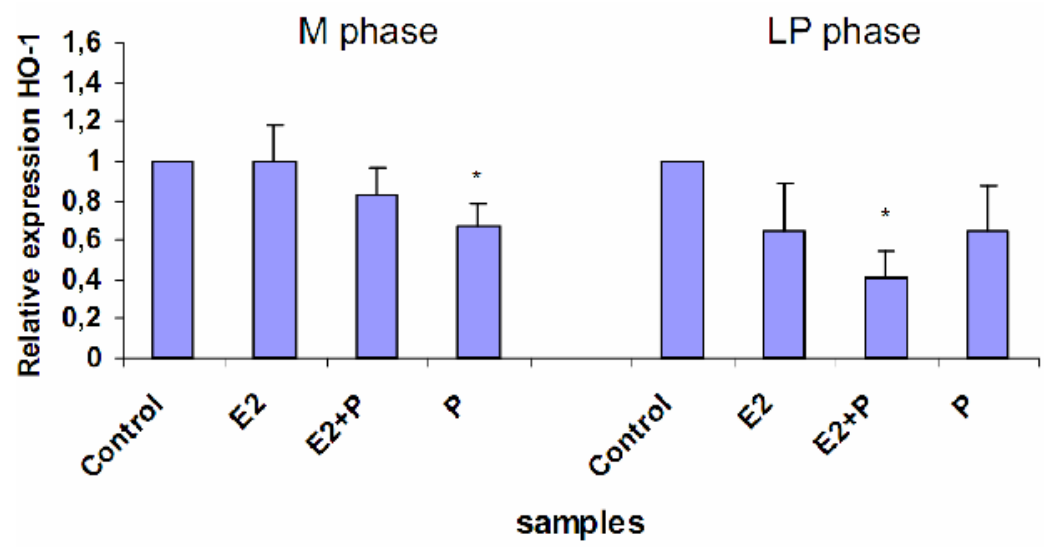

Figure 7.4. The relative haemoglobin $\gamma$ mRNA expression in $M+L P-p h a s e ~(n=16)$ explants treated with $17 \beta$ - oestradiol $\left(\mathrm{E}_{2}\right)(1 \mathrm{nM})$, Org $2058(\mathrm{P}, 1 \mathrm{nM})$, and 17 $\beta-\mathrm{E}_{2}+\operatorname{Org} 2058$ (1 nM each) compared to vehicle treated (control, $0.1 \%$ ethanol). ${ }^{*} \mathrm{p}<0.05$ versus control; \& $\mathrm{p}<0.05$ versus $17 \beta-\mathrm{E}_{2}+\mathrm{Org} 2058$

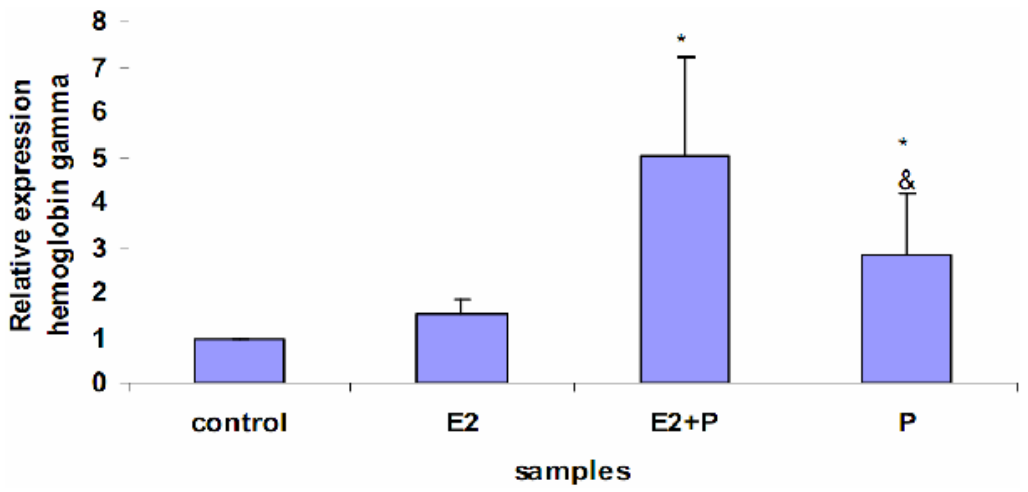

Haemoglobin and $\mathrm{HO}-1$ protein in human endometrium

Haemoglobin staining by the pan-haemoglobin antibody was specific, as evidenced by the disappearance of immunostaining after preincubation with the $1: 10$ dilution of the saturated haemoglobin solution (figure 7.5). Haemoglobin and HO-1 protein were stained in both epithelial and stromal cells of the human endometrium (figure 7.6). Expression was also observed in endothelium. Haemoglobin expression was higher in the epithelium than in stroma (table 7.3, figure 7.6). All the epithelial 
cells were positive for haemoglobin and approximately $75 \%$ of the stromal cells (figure 7.6). HO-1 was expressed mostly in epithelial cells (table 7.3, figure 7.6). In addition, staining was observed in the endothelium, and intensely positive individual cells were present throughout the stromal compartment (Figure 7.6).

Figure 7.5. Representative photographs of placenta tissue stained brown with the pan anti-human haemoglobin $(\mathrm{Hb})$ antibody. Sections stained with 1:1200 and 1:2400 dilutions. Pre-saturation of the

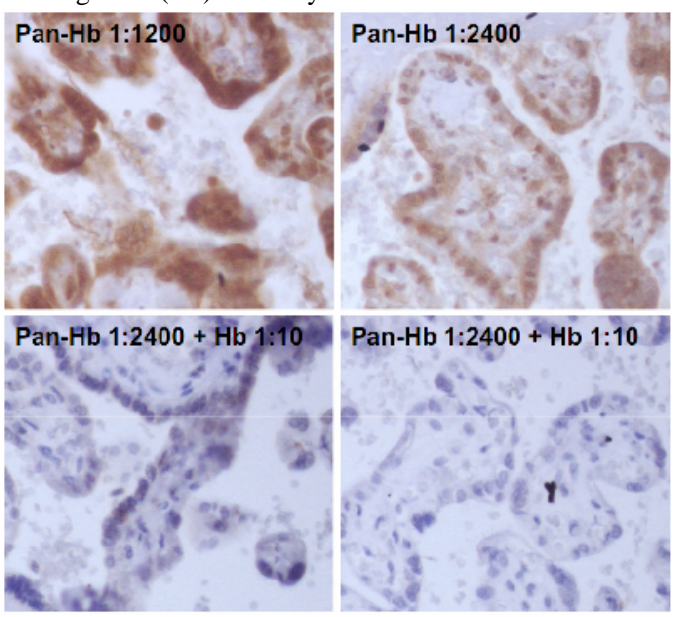
antibody with a 1:10 dilution of the saturated $\mathrm{Hb}$ solution prevents antibody binding, indicating that the antibody specifically binds $\mathrm{Hb}$.
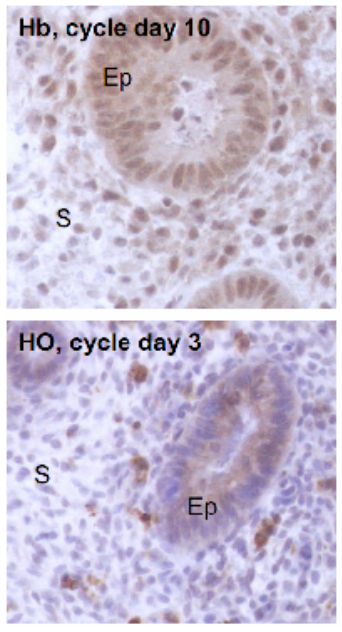
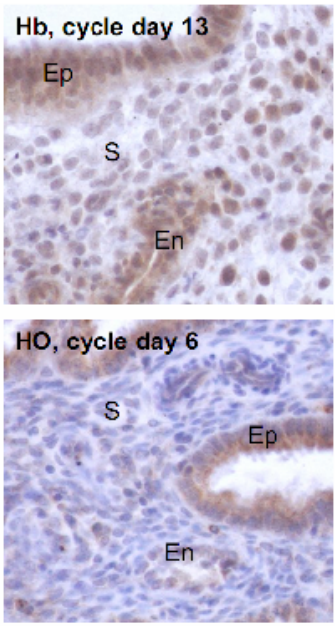

Figure 7.6. Representative photographs of two endometrial biopsies collected at different stages in the proliferative phase stained with the pan anti-human $\mathrm{Hb}$ antibody and the anti-HO-1 antibody. Immunostaining is present in all cell compartments, but is most prominent in the epithelium and endothelium. Intense HO-1 staining is also present in individual cells in the stroma. Ep = epithelial cells, En $=$ endothelial cells and $\mathrm{S}=$ stromal cells.

Treating the explants with $17 \beta-\mathrm{E}_{2}, 17 \beta-\mathrm{E}_{2}+$ Org 2058 or Org 2058 alone did not significantly alter the intensity of the staining in epithelial and stromal cells or the number of positive stromal cells for either HO-1 or haemoglobin (data not shown). There were also no significant differences in the intensity of the staining or the number of positive stromal cells for either HO-1 or haemoglobin between $\mathrm{M}$ and LP-phase endometrium explants. 
Table 7.3. The average immunoscores for haemoglobin and haemoxygenase-1 (HO-1) as assessed in all explant cultures $(n=19)$. M phase: menstrual phase of cycle. LP: late proliferative phase

\begin{tabular}{|c|c|c|c|c|}
\hline \multirow{2}{*}{$\begin{array}{l}\text { Haemoglobin } \\
\text { (Mean } \pm \text { SD) }\end{array}$} & \multicolumn{2}{|l|}{ M-phase } & \multicolumn{2}{|l|}{ LP-phase } \\
\hline & Intensity & Percentage & Intensity & Percentage \\
\hline Epithellum & $2.2 \pm 0.6$ & 3.0 & $1.8 \pm 0.7$ & \\
\hline Stroma & $2.1 \pm 0.6$ & $2.9 \pm 0.2$ & $1.6 \pm 0.8$ & $2.9 \pm 0.2$ \\
\hline \multirow{2}{*}{\multicolumn{5}{|c|}{$\begin{array}{l}\text { HO-1 } \\
(\text { Mean } \pm S D)\end{array}$}} \\
\hline & & & & \\
\hline Epithellum & $1.6 \pm 0.6$ & & $1.4 \pm 0.4$ & \\
\hline Stroma & $2.8 \pm 0.4$ & $1.3 \pm 0.6$ & $3.0^{\circ}$ & $1.1 \pm 0.3$ \\
\hline
\end{tabular}

\section{Discussion}

We show in this study for the first time that haemoglobin is present in the human endometrium. The fact that endometrial cells produce gene transcripts for the different haemoglobin isoforms $(\alpha, \beta, \delta$, and $\gamma)$ and that haeme is produced by the mitochondria of all nucleated cells [315], suggests that haemoglobin is actively produced by the endometrial cells.

Overall haemoglobin protein production did not vary throughout the menstrual cycle and was not affected by the presence of steroid hormones. The use of a pan-haemoglobin antibody did not allow the distinction between the different haemoglobin isoforms. Only haemoglobin $\gamma$ mRNA levels responded to steroid hormone treatment, however, the abundant expression of the haemoglobin $\alpha$ and $\beta$ mRNA isoforms, may have masked changes of the haemoglobin $\gamma$ at the protein level. Another relevant observation is the fact that the expression of the four studied haemoglobin genes in the M-phase endometrium, at which time hypoxia is most pronounced, is not higher than in the LP phase endometrium. This suggests that haemoglobin gene expression is not regulated by hypoxia.

Only recently it became clear that haemoglobin is also produced by nonerythroid cells. Why haemoglobin is produced in the human endometrium is not clear, however, it is likely that haemoglobin in the endometrium is involved in the regulation of local iron and haeme levels to prevent overexposure of the cells to these potentially detrimental molecules [307].

Iron overload results in cytotoxicity due to iron-induced formation of reactive oxygen species [329]. Yet iron is critical for the proliferation of endometrial cells, and iron levels must therefore be closely monitored. Deprivation of iron was shown to prevent cells to proceed from the G1 to the $S$ phase of the cell cycle [327], and Defrère and co-workers [328] showed in a mouse model of endometriosis that 
i.p. treatment with an iron chelator inhibited proliferative activity in the ectopic endometriotic lesions. Iron may thus be a limiting factor in $17 \beta-\mathrm{E}_{2}$-controlled endometrial growth during the menstrual cycle.

Haeme is synthesized in all human nucleated cells [315], and most mammalian cells probably maintain a pool of 'free' haeme serving both precursor and regulator functions [330]. The function of the haeme molecule is determined by the properties of the polypeptide bound to it. For instance, in haemoglobin haeme is used for oxygen transport, in cytochromes it is involved in electron transport, energy generation, and chemical transformation, whereas in peroxidases it functions in the inactivation of hydrogen peroxide radicals. In addition, haeme is indispensable for the activity of a wide array of enzymes including cyclooxygenase and nitric-oxide synthase, and was shown to influence gene expression at the levels of transcription, protein synthesis and post-translational modifications [315]. Haeme therefore can play a determining role in the regulation of endometrial cell function.

One of the enzymes that control intracellular haeme levels is HO. The HO system was shown to prevent or mitigate the symptoms associated with various diseases, including acute inflammation, atherosclerosis, degenerative diseases, and cancer [325]. HO-1 was expressed in the human endometrium and was predominantly present in the epithelium. HO-1 expression can be induced by oxidative stress [312, 331], hypoxia [318, 332] and haeme [333], which could explain why the HO-1 mRNA expression was higher in M-phase endometrium compared to the rest of the menstrual cycle. However, this difference was not reflected at the protein level. There are various reports suggesting that the expression of HO-1 is regulated by steroid hormones [313, 334-336]. In this study using our steroid-responsive explant cultures of human endometrium we clearly showed that even though HO-1 mRNA levels were suppressed by Org 2058, no effects were noted at the protein level, nor was there a difference between proliferative and secretory endometrium, which agrees with the findings of Yoshiki and coworkers [322] and Casanas-Roux and coworkers [323].

Despite rapid cyclical changes in leukocyte infiltration, angiogenic activity, hypoxia, proliferation, hormone concentrations and metabolic activity, expression levels of haemoglobin (and HO-1 particularly) in epithelial cells remained stable. This suggests that the haemoglobin-HO-1 system functions as a buffer in the supply of haeme and iron under these rapidly changing conditions, thereby contributing to the regulation of endometrial function.

Jauniaux et al. described that the earliest stages of embryo development take place under a low $\mathrm{O}_{2}$ concentration of approximately 1-9 \% [337]. They also found that first trimester placenta limits rather than facilitates $\mathrm{O}_{2}$ supply to the foetus, reducing the oxygen stress of the foetus and protecting it against free radicals [338]. A high or rapidly fluctuating $\mathrm{O}_{2}$ concentration damages the early villous tissue and causes miscarriage [338]. So haemoglobin and HO-1 could be involved in the regulation of the $\mathrm{O}_{2}$ and subsequent free radical concentration in the uterus during implantation. 
In summary, we have shown that haemoglobin is present in, and probably synthesised by, endometrial cells. The expression of the various haemoglobin isoforms suggests that haemoglobin is indeed produced by the endometrial cells. The $\alpha$-globin and $\beta$-globin, the globins needed for haemoglobin A, were the most abundantly expressed haemoglobins in the human endometrium. The $\delta$-globin, required for haemoglobin $\mathrm{A}_{2}$, and $\gamma$-globin, required for haemoglobin $\mathrm{F}$, were also expressed. Only $\gamma$-globin expression was significantly enhanced by Org 2058. Steroid regulation of the total haemoglobin pool could not be demonstrated. HO-1 mRNA levels, which degrades haeme, were slightly higher in M-phase endometrium and inhibited by Org 2058. However, no changes were observed at the protein level. The presence of the haemoglobin-HO-1 system may be required to ensure adequate regulation of the bioavailability of haeme, iron and oxygen in the different compartments of the endometrium. 


\section{Chapter 8}

\section{General discussion}

The general aim of the work presented in this thesis is to further improve our insights in the regulation of endometrium growth and maturation under the influences of oestradiol (E2) and progesterone (P4). To study human endometrium function in women poses an interesting challenge. For obvious ethical reasons it is not feasible to do intervention studies in women. Even though much information can be gathered from non-human primate studies, these also are confronted with ethical concerns and high costs. Alternatively, one can use rodent models to interrogate the effects of oestradiol and progesterone on the endometrium, however these are nonmenstruating species, and the relation between hormone levels and proliferative activity and apoptosis is different. In rodents proliferative activity in the epithelium is highest during metestrous and diestrous (peak P4), whereas apoptosis was observed around estrous (peak E2) [339], whereas proliferation and apoptosis in the endometrium are highest during the proliferative phase (peak E2) and late secretory/pre-menstrual phase. This is reflected by the limited accordance between the human and rat microarray data investigating the relation between E2 and proliferation (reviewed in Chapter 2).

Another approach by which hormonal effects on endometrial cells can be studied is through the use of in vitro culture systems. Evidently, most investigators have employed either endometrial cancer cell-lines and/or monolayer cultures of isolated luminal, glandular and stromal cells of human endometrium or immortalised cell-lines derived thereof. A major drawback of the use of primary and immortalized endometrial cells is the fact that nuclear receptor expression rapidly diminishes in time and consequently the cells fail to respond to hormonal treatments. Cell lines derived from tumours have been genetically challenged, and some characteristics of the original cells may have been preserved, but overall they phenotypically and biochemically do not represent a normal endometrial cell anymore.

Earlier studies [340] have demonstrated that endometrial cell function largely depends on the paracrine, juxtracrine and matricrine interactions between cells and extracellular matrix. Obviously, enzymatic digestion generally used to obtain isolated endometrial glands and stroma, destroys this tissue context. We have adopted tissue explant culture as an alternative method to study endometrium function [33]. The advantage of this culture method is, that the tissue context is preserved which increases the relevance and translational value of the studies performed with this system. A drawback of the system proved to be that only short term cultures can be performed. Upon the isolation from the uterus, matrix metalloproteinases are activated which degrade the tissue after 24 hours [341]. Therefore incubation times have to be limited to 24 hours, unless the regulation of MMP expression and/or activity is investigated [341]. 
Initial studies in our laboratory with explant cultures were focussed on evaluating the responsiveness of the endometrial tissue to E2 with respect to proliferation and the expression of a selection of oestrogen-responsive genes, the progesterone receptor and COX-2 [33]. The most striking observation was the fact that the responses of the explant cultures showed distinct differences depending on the phase of the menstrual cycle the tissue was isolated from. In menstrual phase explants (cycle days [CD] 1-5) only gene expression could be induced, but not proliferation. In contrast, in early/mid-proliferative (CD 6-11) endometrium the opposite was observed, only proliferative activity was enhanced by $17 \beta$-oestradiol.

\section{Oestrogen-modulated gene expression in the human endometrium}

Global gene expression profiling is a powerful tool to identify genes or pathways that are associated with hormonal responses. In Chapter 3 we present the data from our first microarray study in which we zoomed in on the effects of oestradiol on gene expression in endometrium from different phases of the cycle. This was done by comparing gene expression profiles prepared from late proliferative phase (LP) endometrium, which has been exposed to high E2 levels for several days, with menstrual phase (MP) endometrium which has not yet been exposed to follicular E2. In addition, gene expression profiles were generated from cultured MP and LP endometrium tissue exposed to E2 or vehicle.

Menstrual phase endometrium turned out to be much more sensitive to E2 treatment than LP endometrium, most likely due to the fact that the LP endometrium has been exposed to high E2 levels for several days. There are a few lessons we can learn from this study. The MP endometrium is a nice model to study E2 regulation of gene expression in the endometrium, however the MP response to E2 is not predictive for the state of LP endometrium. A total of 193 gene transcript were regulated significantly by E2 in MP endometrium, versus only 16 transcripts in the LP endometrium. When comparing the genes regulated by E2 in vitro to the genes that were differently expressed in LP endometrium versus MP endometrium (794 genes), only 20 genes changed in the same direction and 18 genes changed in the opposite direction. The study also shows that, besides regulating proliferation, E2 regulates the expression of genes implicated in the maturation and differentiation of the human endometrium. Lastly, the extreme sensitivity of MP endometrial cells to E2 was rather surprising, in particular since oestrogen receptor (ER) levels are similar in MP and LP endometrium. Biopsies obtained during menstruation will consist of a mixture of tissue which has been exposed to high levels of E2 and P4 for a prolonged period of time and which is in the process of being shed (functionalis layer), and the residing basal endometrium which known not respond to cyclical variations in peripheral sex steroid levels but which is responsible for the regeneration of a new functional layer. This is illustrated in our earlier study [33], 
where in the MP biopsies endometrium with both a secretory and basal layer phenotype were found. Since all biopsies obtained during menstruation, with varying ratios of menstrual and secretory endometrium, responded to E2 in tissue culture, the most likely explanation is that the tissue regains responsiveness because of the extremely low E2 levels during this period.

In this study we also found several gene transcripts not previously know to be expressed by the human endometrium (Mucin-9, dipeptidyl peptidase VI and olfactomedin 4), as well as genes that were not previously known to be oestrogen responsive (gelsolin, flotillin-1, TUWD12). One gene was particularly interesting, olfactomedin-4, as it was found to be highly expressed in the LP endometrium, and inducible by E2 in MP endometrium. Further studies showed that olfactomedin-4 is also induced by $\mathrm{P} 4$ in vitro (results not shown), however, its expression reduces during the luteal phase (Chapter 4). This would indicate that P4 down-regulates the olfactomedin-4 mRNA expression in properly primed endometrium, or that the gene does not respond to P4 anymore. The latter also explains why olfactomedin-4 expression in LP endometrium hardly responds to E2 and P4.

We have also provided evidence that the regulation of olfactomedin- 4 gene expression is governed by ER $\alpha$ in concert with HER1, the human epidermal growth factor (EGF) receptor type 1. Reports in literature do not agree well with regard to the expression levels of HER1 and its ligands EGF, heparin-binding EGF, TGF $\alpha$, betacellulin, epiregulin and amphiregulin in human endometrium throughout the menstrual cycle. According to Ejskjaer et al. [223] the expression of HER1 is high in proliferative endometrium. Since E2 levels are also rapidly increasing during this period this could explain the high expression of olfactomedin- 4 in the proliferative phase. In secretory endometrium olfactomedin-4 expression is strongly reduced, despite the presence of high E2 and P4 levels. Corresponding to the decrease in olfactomedin-4 expression, it was reported that the expression of HER1 and one of its ligands, TGF $\alpha$, are also much lower during the luteal phase when compared with the early proliferative phase endometrium [223, 342]. In addition, HER3 and HER4, postulated to be negative regulators of the proliferative stimulus exerted through HER1 and HER2 [343], are significantly upregulated in the secretory endometrium [223] and could be responsible for the reduced olfactomedin-4 expression. It remains to be explained however, why olfactomedin-4 expression can be dramatically induced by E2 in MP endometrium, at which time EGF receptor levels are low [225, 342]. 


\section{Progesterone regulation of implantation-related genes: new insights into the role of oestrogen}

Next to promoting growth, oestradiol is important for the preparation of the endometrium to be able to respond properly to the increasing concentrations of progesterone after ovulation. We have referred to this process as maturation. To study this process in more detail, we applied global gene expression analysis on menstrual phase and late proliferative phase endometrial explants after 24 hours exposure to progesterone (Chapter 6).

The expression of genes that have been implicated in the process of embryo implantation could be induced by exposing explant cultures to oestradiol and progesterone. In late proliferative phase explants the number of genes that was induced by progesterone was twice as high as compared to menstrual phase explants, indicating that oestrogen priming sensitizes the endometrium for progesterone regulation. This could be the result of oestrogenic induction of PR gene expression [33]. These findings also support the contention that variations in the duration of oestradiol priming can affect the response of the endometrium to progesterone and therefore the subsequent implantation process $[18,21]$.

For most of these genes prolonged in vivo exposure to oestradiol is required for adequate progesterone regulation. For in vitro fertilisation purposes this means that the endometrium has to be exposed long enough to oestrogens before being exposed to progesterone for the endometrium to be receptive for the transferred embryo. This has been previously confirmed by Younis and coworkers and Navot et al., who showed that oestrogen exposure for less than six days was not sufficient to support successful implantation $[9,18,177]$.

We were able to make a clear distinction between genes that are regulated by progesterone irrespective of the presence of oestradiol, and genes of which the expression clearly is influenced by the continuous presence of oestradiol, which would suggest that both oestradiol and progesterone are needed for successful embryo implantation. However, studies in the new world monkey Cebus paella treated with an ER antagonist, ICI 182780 on days 4-7 of the luteal phase [344], ovariectomized rhesus macaques receiving a surrogate embryo transfer [84] and women [345, 346], do not support an essential role for luteal phase ovarian oestrogen in implantation and maintenance of pregnancy. 


\section{Oestrogen metabolizing enzymes in endometrium and endometriosis}

An important aspect of proper endometrium function is the ability of the tissue to control oestrogen exposure. To this end multiple steroid synthesizing and metabolizing enzymes are present in the human endometrium. In normal human endometrium the expression of enzymes responsible for oestradiol production and metabolism is tuned towards oestradiol inactivation (chapter 5) and a dysbalance in oestrogen metabolism is known to be an etiological factor in various endometriumrelated disorders including endometriosis and endometrial cancer.

We described that only the oestrogen metabolizing enzymes $17 \beta$-HSD type 2 and EST showed a variable expression throughout the menstrual cycle, with increased expression during the secretory phase. Their role is most likely to neutralize the effects of the follicular oestradiol at the end of the proliferative phase and the increased levels of luteal oestradiol during the implantation window. Both enzymes are under the control of progesterone and require prolonged oestradiol exposure for full induction by progesterone.

Only very low levels of aromatase mRNA and no $17 \beta$-HSD type 1 mRNA were found in normal human endometrium. In line with our findings, earlier reports also indicated that the aromatase enzyme is not expressed by normal endometrium [260], or expressed at very low levels [239]. Aromatase mRNA levels were higher in eutopic and ectopic endometrium of endometriosis patients than in the endometrium of controls, which is in agreement with the findings of others [74, 239, 347]. In contrast, Colette et al. were unable to detect any aromatase expression at the protein level and barely detectable amounts of aromatase mRNA in endometriotic lesions [348]. In more recent studies we also found very low, and most likely not relevant, aromatase activity in eutopic en ectopic endometrium [206].

In deep-invasive endometriosis, the most pronounced difference with regard to the expression of the oestrogen metabolizing enzymes appears to be the dramatic down-regulation of the oestrogen metabolizing enzyme type 2 17 $\beta$-HSD. Next to the slightly elevated expression of aromatase and the continuous presence of $17 \beta$-HSD type 1 and STS, this may shift the balance towards significantly higher levels of oestradiol in the endometriotic lesions. The fact that this was not observed in the eutopic endometrium, and that expression of the other progesteroneresponsive enzyme EST was not down-regulated, suggests local and selective dysregulation of type $217 \beta$-HSD expression. Also Delvoux et al. found that the enzyme activity in endometiotic lesions was skewed in favour of oestradiol production [206]. This was nicely reflected by the fact that in the ectopic endometrium from endometriosis patients the expression of an oestrogen-responsive gene (trefoil factor-1 (TFF1)) was higher than in the eutopic endometrium, which is indicative of a net higher oestrogenic activity in the ectopic endometrium [206].

It has been postulated that the relevance of the increased net oestrogenic activity in endometriotic lesions is an essential element in the pathogenesis if the 
disease. Increased oestrogenic activity may lead to induction of cyclooxygenase type $2(\mathrm{COX}-2)$ gene expression resulting in increased prostaglandin $(\mathrm{PG}) \mathrm{E}_{2}$ production. Prostaglandin $\mathrm{E}_{2}$ in turn is a very potent inducer of the aromatase gene, and it is also known to suppress local immune function and confer apoptosis resistance [232, 348, 349].

\section{Haemoglobin expression in human endometrium}

An unexpected finding when studying the endometrium response to $\mathrm{P} 4$ was the expression of various members of the haemoglobin family in the human endometrium (Chapter 7). Only recently haemoglobin expression was described for the first in non-erythroid cells [315], including in human endometrium during the implantation window [82, 83]. Why haemoglobin is produced in the human endometrium is not clear, but it is tempting to suggest that haemoglobin in the endometrium is involved in the regulation of local iron and haeme levels to prevent overexposure of the cells to these potentially detrimental molecules. Iron overload results in cytotoxicity due to iron-induced formation of reactive oxygen species [329]. On the other hand, iron is critical for the proliferation of cells [350], and may thus be a limiting factor in oestradiol-controlled endometrial growth during the menstrual cycle. Moreover, insufficient iron stores early in pregnancy are known to increase the risk of preterm deliveries and lower-weight newborns [351].

Deng et al. [352] reported that haemoglobin is a precursor of antibacterial peptides, making erythrocytes from endometrium a source of the antimicrobial molecules that may play a role in the host defense against pathogens during menstruation. Another function of haemoglobin may be the temporal induction of epithelial-mesenchymal transitions [353] in epithelial cells of the basalis in order to accellerate the restoration of the luminal surface of the endometrium after shedding of the functional layer.

Haeme is a ubiquitous molecule with an active iron center and is released from haemoglobin after hemorrhage. Free haeme and iron are pro-inflammatory and stimulate local inflammatory reactions [354]. They generate intracellular reactive oxidative radicals and subsequently activate the transcription factors NF- $\mathrm{BB}, \mathrm{AP}-1$ and SP-1 [355]. One of the enzymes that controls intracellular haeme levels is haeme oxygenase. The HO system was shown to prevent or mitigate the symptoms associated with various diseases, including acute inflammation, atherosclerosis, degenerative diseases, and cancer [325]. HO-1 knockout mice are characterized by displaying severe inflammatory conditions, growth retardation, infertility and are prone to abortions [315, 320]. Haeme oxygenase-1 was expressed in the human endometrium and was predominantly present in the epithelium. Haeme oxygenase-1 expression can be induced by oxidative stress [312, 331], hypoxia [318, 332] and 
haeme itself [333], which could explain why the HO-1 mRNA expression was slightly higher in menstrual phase endometrium compared to the rest of the menstrual cycle because of the hypoxic conditions and the release and lysis of large numbers of erythrocytes.

The relevance of the haemoglobin/haeme/HO/iron system in the pathogenesis was illustrated by a series of studies from the Donnez laboratory. Iron and haemoglobin levels are elevated in the peritoneal fluid of endometriosis patients, HO-1 and HO-2 mRNA and protein levels are strongly expressed in the ectopic lesions [326, 356], iron storage [357] and expression of the transferring receptor CD71 [358] were significantly increased peritoneal fluid macrophages, which is indicative of local increases in free iron levels, and finally, intraperitoneal treatment of mouse endometrium xenografts with an iron chelator inhibited proliferative activity in the ectopic lesions [328]. In addition, several endometrios-related genes identified in global gene expression studies overlap with those known to be regulated by iron [355]. Some of these genes were also modulated by iron chelators in cells of different origin [359]. Genes that were modulated are known to be involved in regulating oxidative stress, lipid peroxidation, energy metabolism and fibrosis. Unfortunately, there is no information with regard to the expression of the transferrin receptor (CD71) which mediates the uptake of iron bound to transferrin, or the expression of the two mRNA-binding molecules known as iron-regulatory proteins-1 and -2 (also referred to as asconitase-1, ACO1) which regulate intracellular iron haemostasis, in endometrium or endometriosis. Neoplastic cells are known to have significantly higher levels of transferrin receptor-1, and treatment with iron chelators and anti-transferrin receptor antibodies halts cellular proliferation [355].

The human endometrium is an extremely plastic tissue, capable of achieving implantation and supporting pregnancy under extreme conditions. The regulation of endometrium growth and differentiation does not only depend on the presence and cyclical changes in E2 and P4 levels in the circulation and the expression of their receptors in the endometrial cells, but the processes in the endometrium are to a large extent also governed by other systems that safeguard the homeostasis in the cells of the endometrium and the developing embryo, and which are modulated directly or indirectly by E2 and P4 at the cell and tissue level. Severe disturbances in these systems can result in impaired fertility and other gynaecological pathologies including endometriosis, leiomyomas, or endometrial cancer.

Interrogating target tissues in biologically relevant model systems using global gene expression analysis is a powerful way to gain better insight into the physiological responses to E2 and $\mathrm{P} 4$, as well as mechanisms known to be aberrant in the condition of interest, in this case endometriosis. It is also clear however, that in order to fully understand the impact of certain genes or mechanisms, in depth studies are essential as each level of regulation or organization adds another level of complexity. 
We have used explant cultures of human endometrium in combination with global gene expression analysis and have shown that this is a promising approach to study oestrogenic and progestagenic influences on the human endometrium. The current limitation of this approach is that the subsequent in depth studies remain dependent on the use of cancer cell lines. There is an urgent need for model systems based on primary cultures of isolated human glandular epithelial and stromal cells in which the basic characteristics of the endometrium are preserved. The best example of this are the primary cultures of the stromal fibroblasts isolated from ovarian endometriotic cysts which have been used by several laboratories. These cells maintain the expression of the genes typical for the endometriotic cells, i.e elevated expression of ER $\beta$, aromatase, type 1 17 $\beta$-HSD and COX-2, for at least 4-5 passages. 


\section{Summary}

The human endometrium, the inner lining of the uterine cavity, is a dynamic tissue. Every month the endometrium undergoes changes; The functional layer is shed during menstruation, whereafter from the basal layer a new functional layer develops during the proliferative phase, that is prepared for the implanting embryo during the secretory phase. Oestradiol and progesterone play an important role in these processes. How the maturation process of the endometrium takes place is not completely understood. In this thesis we used gene-expression studies to investigate the effects of oestradiol and progesterone on the expression of genes involved in the proliferation and differentiation of the human endometrium. We used explant cultures for this purpose, because in this type of culture the original structure of the endometrial tissue is preserved. The use of explant cultures is important for the biological relevance.

The studies described in this thesis provided the following results. Explant cultures of menstrual endometrium responded more pronounced to oestradiol exposure than explant cultures of late-proliferative endometrium. Although this finding was as expected, since late-proliferative endometrium has been exposed to oestradiol in utero for a longer period of time than menstrual endometrium, this has not previously been demonstrated. Furthermore late-proliferative endometrium responded stronger to progesterone compared to menstrual endometrium. This was similarly according to our expectations, since the endometrium is prepared by oestradiol to responds properly to the luteal phase progesterone. The most remarkable finding, however, was that gene-regulation by progesterone can be divided into two categories, genes independent of oestradiol pre-incubation, and thus directly regulated by progesterone, and genes depending on oestrogenic preincubation. Only a small part of genes, expressed during the implantation window in the explant cultures was induced by oestradiol and progesterone. It is likely, that part of the genes need prolonged progesterone exposure to be expressed, as has been described for prolactin and IGFBP-1. An alternate explanation could be that the culture conditions of the model system were not optimal.

Studying the gene-lists, the extremely high sensitivity of Olfactomedin-4 to oestradiol and the expression of haemoglobin isoforms in the endometrium were outstanding.

Olfactomedin-4 (OLM-4) is a protein, produced by the cell and is a constituent of the extracellular matrix. In previous studies it has been linked to the development of gastro-intestinal tumours. OLM-4 is highly expressed in lateproliferative human endometrium and its expression could be induced by oestradiol in menstrual phase endometrium and by progesterone in late-proliferative endometrium. The results of our study indicate, that OLM-4 expression is regulated by oestradiol and $\mathrm{OH}$-Tamoxifen. However, the presence of epidermal growth factor receptor 1 (EGFR1) is necessary for this effect to take place. Also the opposite is the 
case, for a maximal induction of OLM-4 by EGF, ER- $\alpha$ expression is needed. These findings show, that endometrial growth and function is amongst others regulated by complex interactions between steroid hormones and growth factor signal transduction.

The finding of haemoglobin and the haeme-metabolising enzyme haeme oxygenase-1 (HO-1) in human endometrium came as a surprise. The exact function of the haemoglobin-HO-1 system is unknown, but it may probably play a role in regulating the intracellular bio-availability of and exposure to haeme, iron and oxygen. However, the fact, that hypoxia and steroid hormones only minimally influence the expression of these genes, may be a clue that this system is mainly involved in intracellular homeostasis.

Finally, we studied the expression of oestrogen metabolising enzymes, because the presence of these enzymes strongly regulated the bio-activity of oestradiol in the human endometrium. In oestrogen-dependent diseases, like breast cancer, endometrial cancer and endometriosis, an imbalance in the enzymes responsible for the production and inactivation of oestradiol is found. This imbalance causes an increase in the local production of oestradiol. The results of our study show, that in endometriosis the shift in this balance is mainly the effect of a decreased expression of type $217 \beta$-HSD. The increased expression of aromatase and type $117 \beta-\mathrm{HSD}$ are significant in ectopic endometrium. However, the expression levels are so low, that the biological impact may not be relevant.

The regulation of endometrial growth and differentiation is not only dependant on the presence of the steroid hormones oestradiol and progesterone in the circulation and the expression of their receptors in endometrial cells, but is also determined by systems that directly or indirectly influence the activity of oestradiol and progesterone on cellular and tissue levels. Moreover it is regulated by systems, which independently of the presence of steroid hormones guard the homeostasis of endometrial cells. Because of this, the endometrium is a dynamic tissue, capable of establishing a normal pregnancy. Disturbances in these systems conceivably lead to subfertility and gynaecological diseases, like endometriosis and endometrial cancer. 


\section{Samenvatting}

Het humane endometrium, de binnenste bekleding van het cavum uteri, is een dynamisch weefsel. Elke maand ondergaat het endometrium veranderingen; de functionele laag wordt afgestoten tijdens de menstruatie fase, waarna vanuit de basale laag een nieuwe functionele laag wordt opgebouwd tijdens de proliferatie fase, die tijdens de secretie fase wordt voorbereid op het implanterende embryo. Oestradiol en progesteron spelen een rol bij deze processen. Hoe het proces van rijping van het endometrium verloopt, is nog niet volledig bekend. In dit proefschrift hebben we genexpressie studies gebruikt om de effecten van oestradiol en progesteron op de expressie van genen te onderzoeken die betrokken zijn bij de groei en differentiatie van het endometrium. Als modelsysteem zijn weefselkweken gebruikt, omdat aangetoond is dat in dit type kweken de originele structuur van het endometrium weefsel behouden blijft, wat de biologische relevantie ten goede komt.

De studies beschreven in dit proefschrift lieten de volgende resultaten zien. In de eerste plaats bleek dat weefselkweken van menstrueel endometrium veel sterker reageren op blootstelling aan oestradiol, dan weefselkweken van laatproliferatief endometrium. Dit is volgens verwachting, omdat laat-proliferatief endometrium in utero al langdurig aan oestradiol blootgesteld is geweest in tegenstelling tot menstrueel endometrium. Dit was echter nog niet eerder

aangetoond. Vervolgens bleek dat laat-proliferatief endometrium veel sterker reageerde op progesteron dan menstrueel endometrium; dit is ook volgens verwachting, omdat altijd verondersteld is dat het endometrium door oestradiol wordt voorbereid om adequaat op het luteale progesteron te reageren. De meest opmerkelijke bevinding was echter dat de regulatie van genen door progesteron in twee categorieën verdeeld kon worden, genen die geen oestradiol pre-incubatie nodig hadden en dus direct gereguleerd worden door progesteron, en genen die wel oestrogeen pre-incubatie nodig hebben. Daarnaast werd in de weefselkweken slechts een klein deel van de genen die tot expressie komen tijdens het implantatie window geïnduceerd door oestradiol en progesteron. Het is waarschijnlijk dat een deel van de genen langdurigere blootstelling aan progesteron nodig hebben om tot expressie te komen, zoals is beschreven voor prolactine en IGFBP-1. Een andere verklaring zou kunnen zijn dat de kweekomstandigheden van het modelsysteem niet optimaal zijn.

Tijdens het bestuderen van de genlijsten vielen twee dingen direct op, de extreme mate van gevoeligheid van Olfactomedin-4 voor oestrogenen, en de expressie van hemoglobine isovormen in het endometrium.

Olfactomedin-4 (OLM-4) is een eiwit dat door de cel wordt geproduceerd en een onderdeel is van de extracellulaire matrix. In eerdere studies is het in verband gebracht met de ontwikkeling van gastro-intestinale maligniteiten. OLM-4 komt zeer hoog tot expressie in laat-proliferatief humaan endometrium, en de expressie was induceerbaar door oestradiol in menstrueel endometrium, en door progesteron in laat-proliferatief endometrium. Onze studies hebben laten zien dat de expressie van 
OLM-4 weliswaar wordt gereguleerd door oestradiol en OH-tamoxifen. Echter, epidermal growth factor receptor 1 (EGFR1) is noodzakelijk voor dit effect. Ook het omgekeerde is het geval; voor een maximale inductie van de OLM-4 promotor door EGF is ER- $\alpha$ expressie nodig. Deze bevindingen laten zien dat de groei en functie van het endometrium mede gereguleerd worden door complexe interacties tussen steroidhormoon- en groeifactor signaaltransductie.

De aanwezigheid van hemoglobine alsmede het haeme-metabolizerende enzym, haeme oxygenase-1 (HO-1) in het endometrium, was een verrassing. De exacte functie van het hemoglobine-HO-1 systeem is niet bekend, maar speelt waarschijnlijk een rol in de regulatie van de intracellulaire beschikbaarheid van en blootstelling aan haeme, ijzer en zuurstof. Het feit echter dat hypoxie en steroid hormonen de expressie van deze genen niet in sterke mate lijken te reguleren, is mogelijk een aanwijzing dat dit systeem met name bijdraagt aan de intracellulaire homeostase.

Tot slot hebben we nog een studie gedaan naar de expressie van enzymen die betrokken zijn bij het metabolisme van oestradiol, omdat de aanwezigheid van deze enzymen in sterke mate de bioactiviteit van oestradiol in het endometrium reguleren. Bij oestrogeen-afhankelijke ziektebeelden, zoals mammacarcinoom, endometrium carcinoom en endometriose, wordt vaak een dysbalans aangetroffen bij de enzymen verantwoordelijk voor de productie en inactivatie van oestradiol, resulterend in een verhoogde lokale productie van oestradiol. De resultaten van onze studie laten zien dat bij endometriose de verschuiving van die balans voornamelijk het gevolg is van een verlaagde expressie van de type $217 \beta$-HSD. Tegelijkertijd zijn de verhoogde expressie van aromatase en type $117 \beta-H S D$ in ectopisch endometrium weliswaar significant, echter de expressieniveaus zijn zo laag dat de biologische relevantie mogelijk niet groot is.

De regulatie van endometriumgroei en -differentiatie is niet alleen afhankelijk van de aanwezigheid van de steroïdhormonen oestradiol en progesteron in de circulatie en de expressie van hun receptoren in endometriumcellen, maar wordt mede bepaald door systemen die direct of indirect de activiteit van oestradiol en progesteron op cel- en weefselniveau reguleren, en door systemen die onafhankelijk van de aanwezigheid van de steroïdhormonen de homeostase van de endometriumcellen bewaken. Mede hierdoor is het endometrium een uiterst dynamisch weefsel, dat in staat is een normale zwangerschap tot stand te laten komen. Het is aannemelijk dat verstoringen in deze systemen leiden tot subfertiliteit en gynaecologische afwijkingen als endometriose en het endometriumcarcinoom. 


\section{References}

1. Punyadeera, C., et al., Oestrogen-modulated gene expression in the human endometrium. Cell Mol Life Sci, 2005. 62(2): p. 239-50.

2. Bulmer, J.N., D.P. Lunny, and S.V. Hagin, Immunohistochemical characterization of stromal leucocytes in nonpregnant human endometrium. Am J Reprod Immunol Microbiol, 1988. 17(3): p. 83-90.

3. Dietl, J., et al., The decidua of early human pregnancy: immunohistochemistry and function of immunocompetent cells. Gynecol Obstet Invest, 1992. 33(4): p. 197-204.

4. Moggs, J.G., et al., Phenotypic anchoring of gene expression changes during estrogen-induced uterine growth. Environ Health Perspect, 2004. 112(16): p. 1589-606.

5. Fertuck, K.C., et al., Identification of temporal patterns of gene expression in the uteri of immature, ovariectomized mice following exposure to ethynylestradiol. Physiol Genomics, 2003. 15(2): p. 127-41.

6. Mote, P.A., et al., Colocalization of progesterone receptors $A$ and $B$ by dual immunofluorescent histochemistry in human endometrium during the menstrual cycle. J Clin Endocrinol Metab, 1999. 84(8): p. 2963-71.

7. Riesewijk, A., et al., Gene expression profiling of human endometrial receptivity on days $\mathrm{LH}+2$ versus $\mathrm{LH}+7$ by microarray technology. Mol Hum Reprod, 2003. 9(5): p. 253-64.

8. Martin, J., et al., Human endometrial receptivity: gene regulation. J Reprod Immunol, 2002. 55(1-2): p. 131-9.

9. Navot, D., et al., Hormonal manipulation of endometrial maturation. J Clin Endocrinol Metab, 1989. 68(4): p. 801-7.

10. Ferenczy, A., Studies on the cytodynamics of human endometrial regeneration. I. Scanning electron microscopy. Am J Obstet Gynecol, 1976. 124(1): p. 64-74.

11. Ferenczy, A., G. Bertrand, and M.M. Gelfand, Proliferation kinetics of human endometrium during the normal menstrual cycle. Am J Obstet Gynecol, 1979. 133(8): p. 859-67.

12. Giudice, L.C., Genes associated with embryonic attachment and implantation and the role of progesterone. J Reprod Med, 1999. 44(2 Suppl): p. 165-71.

13. Giudice, L.C., et al., The molecular basis for implantation failure in endometriosis: on the road to discovery. Ann N Y Acad Sci, 2002. 955: p. 252-64; discussion 293-5, 396-406.

14. Lessey, B.A., Two pathways of progesterone action in the human endometrium: implications for implantation and contraception. Steroids, 2003. 68(10-13): p. 809-15.

15. Develioglu, O.H., et al., Endometrial estrogen and progesterone receptor and pinopode expression in stimulated cycles of oocyte donors. Fertil Steril, 1999. 71(6): p. 1040-7.

16. Sharkey, A.M. and S.K. Smith, The endometrium as a cause of implantation failure. Best Pract Res Clin Obstet Gynaecol, 2003. 17(2): p. 289-307. 
17. Jung, H. and H.K. Roh, The effects of E2 supplementation from the early proliferative phase to the late secretory phase of the endometrium in hMGstimulated IVF-ET. J Assist Reprod Genet, 2000. 17(1): p. 28-33.

18. Younis, J.S., et al., Artificial endometrial preparation for oocyte donation: the effect of estrogen stimulation on clinical outcome. J Assist Reprod Genet, 1992. 9(3): p. 222-7.

19. Ma, W.G., et al., Estrogen is a critical determinant that specifies the duration of the window of uterine receptivity for implantation. Proc Natl Acad Sci U S A, 2003. 100(5): p. 2963-8.

20. Michalas, S., et al., A flexible protocol for the induction of recipient endometrial cycles in an oocyte donation programme. Hum Reprod, 1996. 11(5): p. 1063-6.

21. Navot, D. and P. Bergh, Preparation of the human endometrium for implantation. Ann N Y Acad Sci, 1991. 622: p. 212-9.

22. Remohi, J., et al., Endometrial thickness and serum oestradiol concentrations as predictors of outcome in oocyte donation. Hum Reprod, 1997. 12(10): p. 2271-6.

23. Clark, J.H., et al., Nuclear binding of the estrogen receptor: heterogeneity of sites and uterotropic response. Adv Exp Med Biol, 1979. 117: p. 17-46.

24. Kuiper, G.G., et al., Cloning of a novel receptor expressed in rat prostate and ovary. Proc Natl Acad Sci U S A, 1996. 93(12): p. 5925-30.

25. Mosselman, S., J. Polman, and R. Dijkema, ER beta: identification and characterization of a novel human estrogen receptor. FEBS Lett, 1996. 392(1): p. 49-53.

26. Lubahn, D.B., et al., Alteration of reproductive function but not prenatal sexual development after insertional disruption of the mouse estrogen receptor gene. Proc Natl Acad Sci U S A, 1993. 90(23): p. 11162-6.

27. Krege, J.H., et al., Generation and reproductive phenotypes of mice lacking estrogen receptor beta. Proc Natl Acad Sci U S A, 1998. 95(26): p. 1567782.

28. Punyadeera, C., P. Verbost, and P. Groothuis, Oestrogen and progestin responses in human endometrium. J Steroid Biochem Mol Biol, 2003. 84(4): p. 393-410.

29. Tung, L., et al., Antagonist-occupied human progesterone B-receptors activate transcription without binding to progesterone response elements and are dominantly inhibited by A-receptors. Mol Endocrinol, 1993. 7(10): p. 1256-65.

30. Vegeto, E., et al., Human progesterone receptor $A$ form is a cell- and promoter-specific repressor of human progesterone receptor B function. Mol Endocrinol, 1993. 7(10): p. 1244-55.

31. Wen, D.X., et al., The A and B isoforms of the human progesterone receptor operate through distinct signaling pathways within target cells. Mol Cell Biol, 1994. 14(12): p. 8356-64.

32. Mulac-Jericevic, B., et al., Subgroup of reproductive functions of progesterone mediated by progesterone receptor-B isoform. Science, 2000. 289(5485): p. 1751-4. 
33. Punyadeera, C., et al., Triphasic pattern in the ex vivo response of human proliferative phase endometrium to oestrogens. J Steroid Biochem Mol Biol, 2004. 92(3): p. 175-85.

34. Garcia, E., et al., Use of immunocytochemistry of progesterone and estrogen receptors for endometrial dating. J Clin Endocrinol Metab, 1988. 67(1): p. 80-7.

35. Burton, K.A., et al., Local levonorgestrel regulation of androgen receptor and 17beta-hydroxysteroid dehydrogenase type 2 expression in human endometrium. Hum Reprod, 2003. 18(12): p. 2610-7.

36. Noe, M., et al., The cyclic pattern of the immunocytochemical expression of oestrogen and progesterone receptors in human myometrial and endometrial layers: characterization of the endometrial-subendometrial unit. Hum Reprod, 1999. 14(1): p. 190-7.

37. Matsuzaki, S., et al., Oestrogen receptor alpha and beta mRNA expression in human endometrium throughout the menstrual cycle. Mol Hum Reprod, 1999. 5(6): p. 559-64.

38. Strauss III, J.F. and E. Gurpide, The endometrium: regulation and dysfunction. Reproductive Endocrinology, ed. R.J. SSC Yen. 1991, Philadelphia: Saunders. 309-56.

39. Coppens, M.T., et al., The distribution of oestrogen and progesterone receptors in the human endometrial basal and functional layer during the normal menstrual cycle. An immunocytochemical study. Histochemistry, 1993. 99(2): p. 121-6.

40. Yang, S., et al., Stromal PRs mediate induction of 17beta-hydroxysteroid dehydrogenase type 2 expression in human endometrial epithelium: a paracrine mechanism for inactivation of E2. Mol Endocrinol, 2001. 15(12): p. 2093-105.

41. Cooke, P.S., et al., Stromal estrogen receptors mediate mitogenic effects of estradiol on uterine epithelium. Proc Natl Acad Sci U S A, 1997. 94(12): p. 6535-40.

42. Pierro, E., et al., Stromal-epithelial interactions modulate estrogen responsiveness in normal human endometrium. Biol Reprod, 2001. 64(3): p. 831-8.

43. Tseng, L. and H.H. Zhu, Regulation of progesterone receptor messenger ribonucleic acid by progestin in human endometrial stromal cells. Biol Reprod, 1997. 57(6): p. 1360-6.

44. Berry, M., D. Metzger, and P. Chambon, Role of the two activating domains of the oestrogen receptor in the cell-type and promoter-context dependent agonistic activity of the anti-oestrogen 4-hydroxytamoxifen. Embo J, 1990. 9(9): p. 2811-8.

45. Ali, S., et al., Modulation of transcriptional activation by ligand-dependent phosphorylation of the human oestrogen receptor A/B region. Embo J, 1993. 12(3): p. 1153-60.

46. Bunone, G., et al., Activation of the unliganded estrogen receptor by EGF involves the MAP kinase pathway and direct phosphorylation. Embo J, 1996. 15(9): p. 2174-83. 
47. Hovland, A.R., et al., An N-terminal inhibitory function, IF, suppresses transcription by the A-isoform but not the B-isoform of human progesterone receptors. J Biol Chem, 1998. 273(10): p. 5455-60.

48. Giangrande, P.H., et al., The opposing transcriptional activities of the two isoforms of the human progesterone receptor are due to differential cofactor binding. Mol Cell Biol, 2000. 20(9): p. 3102-15.

49. Qian, Y.M. and W.C. Song, Regulation of estrogen sulfotransferase expression in Leydig cells by cyclic adenosine 3',5'-monophosphate and androgen. Endocrinology, 1999. 140(3): p. 1048-53.

50. Tseng, L., Estrogen synthesis in human endometrial epithelial glands and stromal cells. J Steroid Biochem, 1984. 20(4A): p. 877-81.

51. Lepine, J., et al., Specificity and regioselectivity of the conjugation of estradiol, estrone, and their catecholestrogen and methoxyestrogen metabolites by human uridine diphospho-glucuronosyltransferases expressed in endometrium. J Clin Endocrinol Metab, 2004. 89(10): p. 522232.

52. Mensah-Nyagan, A.G., et al., Anatomical and biochemical evidence for the synthesis of unconjugated and sulfated neurosteroids in amphibians. Brain Res Brain Res Rev, 2001. 37(1-3): p. 13-24.

53. Luu-The, V., Analysis and characteristics of multiple types of human 17beta-hydroxysteroid dehydrogenase. J Steroid Biochem Mol Biol, 2001. 76(1-5): p. 143-51.

54. Husen, B., et al., Mechanisms of estradiol inactivation in primate endometrium. Mol Cell Endocrinol, 2001. 171(1-2): p. 179-85.

55. Miettinen, M.M., et al., Human 17 beta-hydroxysteroid dehydrogenase type 1 and type 2 isoenzymes have opposite activities in cultured cells and characteristic cell- and tissue-specific expression. Biochem J, 1996. 314 ( Pt 3): p. 839-45.

56. Reddy, V.V., P. Hanjani, and R. Rajan, Synthesis of catechol estrogens by human uterus and leiomyoma. Steroids, 1981. 37(2): p. 195-203.

57. Hukkanen, J., et al., Expression of cytochrome P450 genes encoding enzymes active in the metabolism of tamoxifen in human uterine endometrium. Pharmacol Toxicol, 1998. 82(2): p. 93-7.

58. Tsuchiya, Y., et al., Human CYP1B1 is regulated by estradiol via estrogen receptor. Cancer Res, 2004. 64(9): p. 3119-25.

59. Salih, S.M., et al., Expression and cyclic variations of catechol-O-methyl transferase in human endometrial stroma. Fertil Steril, 2008. 90(3): p. 78997.

60. Pollow, K., et al., Progesterone metabolism in normal human endometrium during the menstrual cycle and in endometrial carcinoma. J Clin Endocrinol Metab, 1975. 41(4): p. 729-37.

61. Payne, A.H. and D.B. Hales, Overview of steroidogenic enzymes in the pathway from cholesterol to active steroid hormones. Endocr Rev, 2004. 25(6): p. 947-70.

62. Tsai, S.J., et al., Regulation of steroidogenic acute regulatory protein expression and progesterone production in endometriotic stromal cells. $\mathrm{J}$ Clin Endocrinol Metab, 2001. 86(12): p. 5765-73. 
63. Hustin, J. and P. Kremers, Steroid 17alpha-hydroxylase activity in normal and cancerous endometria. J Clin Endocrinol Metab, 1975. 41(2): p. 41921.

64. Tseng, L., Effect of estradiol and progesterone on human endometrial aromatase activity in primary cell culture. Endocrinology, 1984. 115(2): p. 833-5.

65. Smuc, T., et al., Expression analysis of the genes involved in estradiol and progesterone action in human ovarian endometriosis. Gynecol Endocrinol, 2007. 23(2): p. 105-11.

66. Dassen, H., et al., Estrogen metabolizing enzymes in endometrium and endometriosis. Hum Reprod, 2007. 22(12): p. 3148-58.

67. Poutanen, M., et al., Role of 17 beta-hydroxysteroid dehydrogenase type 1 in endocrine and intracrine estradiol biosynthesis. J Steroid Biochem Mol Biol, 1995. 55(5-6): p. 525-32.

68. Luu-The, V., P. Tremblay, and F. Labrie, Characterization of type 12 17beta-hydroxysteroid dehydrogenase, an isoform of type 3 17betahydroxysteroid dehydrogenase responsible for estradiol formation in women. Mol Endocrinol, 2006. 20(2): p. 437-43.

69. Pasqualini, J.R., The selective estrogen enzyme modulators in breast cancer: a review. Biochim Biophys Acta, 2004. 1654(2): p. 123-43.

70. Chaminadas, G., et al., Oestrone sulphate metabolism in normal human endometrium grown in organ culture. Exp Clin Endocrinol, 1987. 90(2): p. 199-205.

71. Longcope, C., Dehydroepiandrosterone metabolism. J Endocrinol, 1996. 150 Suppl: p. S125-7.

72. Mindnich, R., G. Moller, and J. Adamski, The role of 17 betahydroxysteroid dehydrogenases. Mol Cell Endocrinol, 2004. 218(1-2): p. 720.

73. Liu, H.C. and L. Tseng, Estradiol metabolism in isolated human endometrial epithelial glands and stromal cells. Endocrinology, 1979. 104(6): p. 1674-81.

74. Noble, L.S., et al., Aromatase expression in endometriosis. J Clin Endocrinol Metab, 1996. 81(1): p. 174-9.

75. Bulun, S.E., et al., Endocrine disorders associated with inappropriately high aromatase expression. J Steroid Biochem Mol Biol, 1997. 61(3-6): p. 133-9.

76. Noble, L.S., et al., Prostaglandin E2 stimulates aromatase expression in endometriosis-derived stromal cells. J Clin Endocrinol Metab, 1997. 82(2): p. 600-6.

77. Kitawaki, J., et al., Detection of aromatase cytochrome P-450 in endometrial biopsy specimens as a diagnostic test for endometriosis. Fertil Steril, 1999. 72(6): p. 1100-6.

78. Purohit, A., et al., Inhibition of steroid sulphatase activity in endometriotic implants by 667 COUMATE: a potential new therapy. Hum Reprod, 2008. 23(2): p. 290-7.

79. Zeitoun, K., et al., Deficient 17beta-hydroxysteroid dehydrogenase type 2 expression in endometriosis: failure to metabolize 17beta-estradiol. J Clin Endocrinol Metab, 1998. 83(12): p. 4474-80. 
80. Carneiro, M.M., et al., Expression of 17beta-hydroxysteroid dehydrogenase type 2 in pelvic endometriosis. Gynecol Endocrinol, 2007. 23(4): p. 188-92.

81. Bulun, S.E., et al., Estrogen production and metabolism in endometriosis. Ann N Y Acad Sci, 2002. 955: p. 75-85; discussion 86-8, 396-406.

82. Ponnampalam, A.P., et al., Molecular classification of human endometrial cycle stages by transcriptional profiling. Mol Hum Reprod, 2004. 10(12): p. 879-93.

83. Borthwick, J.M., et al., Determination of the transcript profile of human endometrium. Mol Hum Reprod, 2003. 9(1): p. 19-33.

84. Ghosh, D., P. De, and J. Sengupta, Luteal phase ovarian oestrogen is not essential for implantation and maintenance of pregnancy from surrogate embryo transfer in the rhesus monkey. Hum Reprod, 1994. 9(4): p. 629-37.

85. Smitz, J., et al., A prospective randomized study on oestradiol valerate supplementation in addition to intravaginal micronized progesterone in buserelin and HMG induced superovulation. Hum Reprod, 1993. 8(1): p. 40-5.

86. Barton, H.A., M.E. Andersen, and B.C. Allen, Dose-response characteristics of uterine responses in rats exposed to estrogen agonists. Regul Toxicol Pharmacol, 1998. 28(2): p. 133-49.

87. Agarwal, A.K., S. Durani, and B.S. Setty, Dose dependent modulation of receptor dynamics and uterine growth in immature rat by estradiol: importance of an additional nuclear binding at $24 \mathrm{hr}$ for long-term (72 hr) uterine growth. Endokrinologie, 1982. 79(2): p. 235-41.

88. Loose-Mitchell, D.S., C. Chiappetta, and G.M. Stancel, Estrogen regulation of c-fos messenger ribonucleic acid. Mol Endocrinol, 1988. 2(10): p. 946-51.

89. Hyder, S.M., G.M. Stancel, and D.S. Loose-Mitchell, Steroid hormoneinduced expression of oncogene encoded nuclear proteins. Crit Rev Eukaryot Gene Expr, 1994. 4(1): p. 55-116.

90. Cheng, S.V., et al., Cell growth and cell proliferation may be dissociated in the mouse uterine luminal epithelium treated with female sex steroids. Exp Cell Res, 1985. 160(2): p. 459-70.

91. Katzenellenbogen, B.S., E.R. Ferguson, and N.C. Lan, Fundamental differences in the action of estrogens and antiestrogens on the uterus: comparison between compounds with similar duration of action. Endocrinology, 1977. 100(5): p. 1252-9.

92. Medlock, K.L., T.M. Forrester, and D.M. Sheehan, Short-term effects of physiological and pharmacological doses of estradiol on estrogen receptor and uterine growth. J Recept Res, 1991. 11(5): p. 743-56.

93. Stormshak, F., et al., Stimulatory and inhibitory effects of estrogen on uterine DNA synthesis. Endocrinology, 1976. 99(6): p. 1501-11.

94. Newbold, R.R., W.N. Jefferson, and E. Padilla-Banks, The mouse uterotrophic assay: other end points. Environ Health Perspect, 2001. 109(12): p. A569-70.

95. Milligan, S.R., P.E. Cohen, and C.A. Finn, The minimum requirements for oestradiol to induce uterine sensitivity for implantation and decidualization in mice. Hum Reprod, 1995. 10(6): p. 1502-6. 
96. Finn, C.A., M. Pope, and S.R. Milligan, Control of uterine stromal mitosis in relation to uterine sensitivity and decidualization in mice. $\mathrm{J}$ Reprod Fertil, 1995. 103(1): p. 153-8.

97. Taylor, H.S., Endometrial cells derived from donor stem cells in bone marrow transplant recipients. Jama, 2004. 292(1): p. 81-5.

98. Kurita, T., et al., The activation function-1 domain of estrogen receptor alpha in uterine stromal cells is required for mouse but not human uterine epithelial response to estrogen. Differentiation, 2005. 73(6): p. 313-22.

99. Noci, I., et al., Hormonal patterns, steroid receptors and morphological pictures of endometrium in hyperstimulated IVF cycles. Eur J Obstet Gynecol Reprod Biol, 1997. 75(2): p. 215-20.

100. Pellicer, A., et al., Lower implantation rates in high responders: evidence for an altered endocrine milieu during the preimplantation period. Fertil Steril, 1996. 65(6): p. 1190-5.

101. Simon, C., et al., Clinical evidence for a detrimental effect on uterine receptivity of high serum oestradiol concentrations in high and normal responder patients. Hum Reprod, 1995. 10(9): p. 2432-7.

102. Simon, C., et al., Increasing uterine receptivity by decreasing estradiol levels during the preimplantation period in high responders with the use of a follicle-stimulating hormone step-down regimen. Fertil Steril, 1998. 70(2): p. 234-9.

103. Serhal, P.F. and I.L. Craft, Ovum donation--a simplified approach. Fertil Steril, 1987. 48(2): p. 265-9.

104. Sauer, M.V., R.J. Paulson, and R.A. Lobo, A preliminary report on oocyte donation extending reproductive potential to women over 40 . N Engl J Med, 1990. 323(17): p. 1157-60.

105. de Ziegler, D., et al., Controlled preparation of the endometrium with exogenous estradiol and progesterone in women having functioning ovaries. Fertil Steril, 1991. 56(5): p. 851-5.

106. de Ziegler, D. and P. Bouchard, Understanding endometrial physiology and menstrual disorders in the 1990s. Curr Opin Obstet Gynecol, 1993. 5(3): p. 378-88.

107. Sharara, F.I. and H.D. McClamrock, Differences in in vitro fertilization $(I V F)$ outcome between white and black women in an inner-city, universitybased IVF program. Fertil Steril, 2000. 73(6): p. 1170-3.

108. Gelety, T.J. and R.P. Buyalos, The influence of supraphysiologic estradiol levels on human nidation. J Assist Reprod Genet, 1995. 12(7): p. 406-12.

109. Navot, D., et al., Asynchronous ovulation in human menopausal gonadotropin induction of ovulation for in vitro fertilization. Fertil Steril, 1984. 42(5): p. 806-7.

110. Yaron, Y., et al., Uterine preparation with estrogen for oocyte donation: assessing the effect of treatment duration on pregnancy rates. Fertil Steril, 1995. 63(6): p. 1284-6.

111. Borini, A., et al., Effect of duration of estradiol replacement on the outcome of oocyte donation. J Assist Reprod Genet, 2001. 18(4): p. 185-90.

112. Horcajadas, J.A., et al., Global gene expression profiling of human endometrial receptivity. J Reprod Immunol, 2004. 63(1): p. 41-9. 
113. Hong, S.H., et al., Analysis of estrogen-regulated genes in mouse uterus using cDNA microarray and laser capture microdissection. J Endocrinol, 2004. 181(1): p. 157-67.

114. Watanabe, H., et al., Analysis of temporal changes in the expression of estrogen-regulated genes in the uterus. J Mol Endocrinol, 2003. 30(3): p. 347-58.

115. Watanabe, S., et al., Marked developmental changes in heme oxygenase-1 (HO-1) expression in the mouse placenta: correlation between $\mathrm{HO}-1$ expression and placental development. Placenta, 2004. 25(5): p. 387-95.

116. Hewitt, S.C., et al., Estrogen receptor-dependent genomic responses in the uterus mirror the biphasic physiological response to estrogen. Mol Endocrinol, 2003. 17(10): p. 2070-83.

117. Yanaihara, A., et al., Differences in gene expression in the proliferative human endometrium. Fertil Steril, 2005. 83 Suppl 1: p. 1206-15.

118. Jones, R.L., et al., Identification of chemokines important for leukocyte recruitment to the human endometrium at the times of embryo implantation and menstruation. J Clin Endocrinol Metab, 2004. 89(12): p. 6155-67.

119. Tan, Y.F., et al., Global gene profiling analysis of mouse uterus during the oestrous cycle. Reproduction, 2003. 126(2): p. 171-82.

120. Watanabe, H., et al., Genome-wide analysis of changes in early gene expression induced by oestrogen. Genes Cells, 2002. 7(5): p. 497-507.

121. Hewitt, S.C., et al., Global uterine genomics in vivo: microarray evaluation of the estrogen receptor alpha-growth factor cross-talk mechanism. Mol Endocrinol, 2005. 19(3): p. 657-68.

122. Wu, X., et al., Gene expression profiling of the effects of castration and estrogen treatment in the rat uterus. Biol Reprod, 2003. 69(4): p. 1308-17.

123. Naciff, J.M., et al., Gene expression profile induced by 17 alpha-ethynyl estradiol in the prepubertal female reproductive system of the rat. Toxicol Sci, 2003. 72(2): p. 314-30.

124. Pole, J.C., et al., Gene expression changes induced by estrogen and selective estrogen receptor modulators in primary-cultured human endometrial cells: signals that distinguish the human carcinogen tamoxifen. Toxicology, 2005. 206(1): p. 91-109.

125. Kang, K.S., et al., Immature uterotrophic assay is more sensitive than ovariectomized uterotrophic assay for the detection of estrogenicity of pnonylphenol in Sprague-Dawley rats. Toxicol Lett, 2000. 118(1-2): p. 10915.

126. Klotz, D.M., et al., Requirement of estrogen receptor-alpha in insulin-like growth factor-1 (IGF-1)-induced uterine responses and in vivo evidence for IGF-1/estrogen receptor cross-talk. J Biol Chem, 2002. 277(10): p. 8531-7.

127. Nelson, K.G., et al., Epidermal growth factor replaces estrogen in the stimulation of female genital-tract growth and differentiation. Proc Natl Acad Sci U S A, 1991. 88(1): p. 21-5.

128. Klotz, D.M., et al., Activation of a uterine insulin-like growth factor I signaling pathway by clinical and environmental estrogens: requirement of estrogen receptor-alpha. Endocrinology, 2000. 141(9): p. 3430-9.

129. Paules, R., Phenotypic anchoring: linking cause and effect. Environ Health Perspect, 2003. 111(6): p. A338-9. 
130. Norbury, C. and P. Nurse, Animal cell cycles and their control. Annu Rev Biochem, 1992. 61: p. 441-70.

131. Quarmby, V.E. and K.S. Korach, The influence of 17 beta-estradiol on patterns of cell division in the uterus. Endocrinology, 1984. 114(3): p. 694702.

132. Hyder, S.M., C. Chiappetta, and G.M. Stancel, Synthetic estrogen 17alphaethinyl estradiol induces pattern of uterine gene expression similar to endogenous estrogen 17beta-estradiol. J Pharmacol Exp Ther, 1999. 290(2): p. 740-7.

133. Critchley, H.O., et al., Estrogen receptor beta, but not estrogen receptor alpha, is present in the vascular endothelium of the human and nonhuman primate endometrium. J Clin Endocrinol Metab, 2001. 86(3): p. 1370-8.

134. Dubowy, R.L., et al., Improved endometrial assessment using cyclin E and p27. Fertil Steril, 2003. 80(1): p. 146-56.

135. Punyadeera, C., et al., Expression and regulation of vascular endothelial growth factor ligands and receptors during menstruation and postmenstrual repair of human endometrium. Mol Hum Reprod, 2006. 12(6): p. 367-75.

136. Dassen, H., et al., Progesterone regulation of implantation-related genes: new insights into the role of oestrogen. Cell Mol Life Sci, 2007. 64(7-8): p. 1009-32.

137. Stossi, F., et al., Estrogen-occupied estrogen receptor represses cyclin G2 gene expression and recruits a repressor complex at the cyclin $G 2$ promoter. J Biol Chem, 2006. 281(24): p. 16272-8.

138. Fang, G., H. Yu, and M.W. Kirschner, Control of mitotic transitions by the anaphase-promoting complex. Philos Trans R Soc Lond B Biol Sci, 1999. 354(1389): p. 1583-90.

139. Talbi, S., et al., Molecular phenotyping of human endometrium distinguishes menstrual cycle phases and underlying biological processes in normo-ovulatory women. Endocrinology, 2006. 147(3): p. 1097-121.

140. Doisneau-Sixou, S.F., et al., Estrogen and antiestrogen regulation of cell cycle progression in breast cancer cells. Endocr Relat Cancer, 2003. 10(2): p. 179-86.

141. Curtis Hewitt, S., et al., Studies using the estrogen receptor alpha knockout uterus demonstrate that implantation but not decidualization-associated signaling is estrogen dependent. Biol Reprod, 2002. 67(4): p. 1268-77.

142. Sharkey, A.M., et al., Vascular endothelial growth factor expression in human endometrium is regulated by hypoxia. J Clin Endocrinol Metab, 2000. 85(1): p. 402-9.

143. Wright, M.W. and E.A. Bruford, Human and orthologous gene nomenclature. Gene, 2006. 369: p. 1-6.

144. Clemons, M. and P. Goss, Estrogen and the risk of breast cancer. N Engl J Med, 2001. 344(4): p. 276-85.

145. Rogers, P.A., Endometrial vasculature in Norplant users. Hum Reprod, 1996. 11 Suppl 2: p. 45-50.

146. Okada, H., et al., Microarray analysis of genes controlled by progesterone in human endometrial stromal cells in vitro. Gynecol Endocrinol, 2003. 17(4): p. 271-80. 
147. Carson, D.D., et al., Changes in gene expression during the early to midluteal (receptive phase) transition in human endometrium detected by highdensity microarray screening. Mol Hum Reprod, 2002. 8(9): p. 871-9.

148. Kao, L.C., et al., Global gene profiling in human endometrium during the window of implantation. Endocrinology, 2002. 143(6): p. 2119-38.

149. Paulson, R.J., M.V. Sauer, and R.A. Lobo, Embryo implantation after human in vitro fertilization: importance of endometrial receptivity. Fertil Steril, 1990. 53(5): p. 870-4.

150. de Ziegler, D., et al., The hormonal control of endometrial receptivity: estrogen (E2) and progesterone. J Reprod Immunol, 1998. 39(1-2): p. 14966.

151. Noyes, R., A. Hertig, and J. Rock, Dating the endometrial biopsy. fertility and sterility, 1950. 1(1): p. 3-25.

152. Cornet, P.B., et al., Regulation and function of LEFTY-A/EBAF in the human endometrium. mRNA expression during the menstrual cycle, control by progesterone, and effect on matrix metalloprotineases. J Biol Chem, 2002. 277(45): p. 42496-504.

153. Marbaix, E., et al., Progesterone regulates the activity of collagenase and related gelatinases $A$ and $B$ in human endometrial explants. Proc Natl Acad Sci U S A, 1992. 89(24): p. 11789-93.

154. Weng, L., Data Processing and Analysis Methods in the Rosetta Resolver. Technical report. 2003.

155. Liu, G., et al., NetAffx: Affymetrix probesets and annotations. Nucleic Acids Res, 2003. 31(1): p. 82-6.

156. Livak, K.J. and T.D. Schmittgen, Analysis of relative gene expression data using real-time quantitative PCR and the 2(-Delta Delta $C(T))$ Method. Methods, 2001. 25(4): p. 402-8.

157. Eckert, R.L. and B.S. Katzenellenbogen, Human endometrial cells in primary tissue culture: modulation of the progesterone receptor level by natural and synthetic estrogens in vitro. J Clin Endocrinol Metab, 1981. 52(4): p. 699-708.

158. Jakowlew, S.B., et al., Sequence of the pS2 mRNA induced by estrogen in the human breast cancer cell line MCF-7. Nucleic Acids Res, 1984. 12(6): p. 2861-78.

159. Fukuhara, K., et al., Secreted frizzled related protein 1 is overexpressed in uterine leiomyomas, associated with a high estrogenic environment and unrelated to proliferative activity. J Clin Endocrinol Metab, 2002. 87(4): p. 1729-36.

160. Li, Q.F. and A.G. Dai, Hypoxia-inducible factor-1 alpha regulates the role of vascular endothelial growth factor on pulmonary arteries of rats with hypoxia-induced pulmonary hypertension. Chin Med J (Engl), 2004. 117(7): p. 1023-8.

161. Nguyen, S.V. and W.C. Claycomb, Hypoxia regulates the expression of the adrenomedullin and HIF-1 genes in cultured HL-1 cardiomyocytes. Biochem Biophys Res Commun, 1999. 265(2): p. 382-6.

162. Nogradi, A., et al., Up-regulation of cerebral carbonic anhydrase by anoxic stress in piglets. J Neurochem, 2003. 85(4): p. 843-50. 
163. Denko, N., et al., Epigenetic regulation of gene expression in cervical cancer cells by the tumor microenvironment. Clin Cancer Res, 2000. 6(2): p. 480-7.

164. Salamonsen, L.A. and D.E. Woolley, Matrix metalloproteinases in normal menstruation. Hum Reprod, 1996. 11 Suppl 2: p. 124-33.

165. Pilka, R., et al., Epithelial expression of matrix metalloproteinase-26 is elevated at mid-cycle in the human endometrium. Mol Hum Reprod, 2003. 9(5): p. 271-7.

166. Li, Q., et al., Identification and specific expression of matrix metalloproteinase-26 in rhesus monkey endometrium during early pregnancy. Mol Hum Reprod, 2002. 8(10): p. 934-40.

167. Salamonsen, L.A., Tissue injury and repair in the female human reproductive tract. Reproduction, 2003. 125(3): p. 301-11.

168. Poulsom, R. and N.A. Wright, Trefoil peptides: a newly recognized family of epithelial mucin-associated molecules. Am J Physiol, 1993. 265(2 Pt 1): p. G205-13.

169. Wright, N.A., et al., Rolling in the clover: trefoil factor family (TFF)domain peptides, cell migration and cancer. FEBS Lett, 1997. 408(2): $\mathrm{p}$. 121-3.

170. Watson, M.A., et al., Structure and transcriptional regulation of the human mammaglobin gene, a breast cancer associated member of the uteroglobin gene family localized to chromosome 11q13. Oncogene, 1998. 16(6): p. 817-24.

171. Grunewald, K., et al., Mammaglobin expression in gynecologic malignancies and malignant effusions detected by nested reverse transcriptase-polymerase chain reaction. Lab Invest, 2002. 82(9): p. 114753.

172. Carter, D., et al., Purification and characterization of the mammaglobin/lipophilin B complex, a promising diagnostic marker for breast cancer. Biochemistry, 2002. 41(21): p. 6714-22.

173. Kundu, G.C., et al., Recombinant human uteroglobin suppresses cellular invasiveness via a novel class of high-affinity cell surface binding site. Proc Natl Acad Sci U S A, 1996. 93(7): p. 2915-9.

174. Shijubo, N., et al., Clinical aspects of Clara cell 10-kDa protein/ uteroglobin (secretoglobin 1A1). Curr Pharm Des, 2003. 9(14): p. 1139-49.

175. Epifanova, O.I., Mitotic cycles in estrogen-treated mice: a radioautographic study. Exp Cell Res, 1966. 42(3): p. 562-77.

176. Gorski, J., et al., Hormone regulation of growth: stimulatory and inhibitory influences of estrogens on DNA synthesis. J Toxicol Environ Health, 1977. 3(1-2): p. 271-9.

177. Younis, J.S., et al., The effect of a prolonged artificial follicular phase on endometrial development in an oocyte donation program. J In Vitro Fert Embryo Transf, 1991. 8(2): p. 84-8.

178. Kawano, Y. and R. Kypta, Secreted antagonists of the Wnt signalling pathway. J Cell Sci, 2003. 116(Pt 13): p. 2627-34.

179. Miller, C. and D.A. Sassoon, Wnt-7a maintains appropriate uterine patterning during the development of the mouse female reproductive tract. Development, 1998. 125(16): p. 3201-11. 
180. Mericskay, M., J. Kitajewski, and D. Sassoon, Wnt5a is required for proper epithelial-mesenchymal interactions in the uterus. Development, 2004. 131(9): p. 2061-72.

181. Tulac, S., et al., Identification, characterization, and regulation of the canonical Wnt signaling pathway in human endometrium. J Clin Endocrinol Metab, 2003. 88(8): p. 3860-6.

182. Carta, L. and D. Sassoon, Wnt7a is a suppressor of cell death in the female reproductive tract and is required for postnatal and estrogen-mediated growth. Biol Reprod, 2004. 71(2): p. 444-54.

183. Block, K., et al., In utero diethylstilbestrol (DES) exposure alters Hox gene expression in the developing mullerian system. Faseb J, 2000. 14(9): p. 1101-8.

184. Akbas, G.E., J. Song, and H.S. Taylor, A HOXA10 estrogen response element (ERE) is differentially regulated by 17 beta-estradiol and diethylstilbestrol (DES). J Mol Biol, 2004. 340(5): p. 1013-23.

185. Dennis, S., et al., A secreted frizzled related protein, FrzA, selectively associates with Wnt-1 protein and regulates wnt-1 signaling. J Cell Sci, 1999. 112 ( Pt 21): p. 3815-20.

186. Dufourcq, P., et al., FrzA, a secreted frizzled related protein, induced angiogenic response. Circulation, 2002. 106(24): p. 3097-103.

187. Abu-Jawdeh, G., et al., Differential expression of frpHE: a novel human stromal protein of the secreted frizzled gene family, during the endometrial cycle and malignancy. Lab Invest, 1999. 79(4): p. 439-47.

188. Care, A., et al., HOXB7: a key factor for tumor-associated angiogenic switch. Cancer Res, 2001. 61(17): p. 6532-9.

189. Reed, K.E., et al., Molecular cloning and functional expression of human connexin37, an endothelial cell gap junction protein. J Clin Invest, 1993. 91(3): p. 997-1004.

190. Simon, A.M. and A.R. McWhorter, Decreased intercellular dye-transfer and downregulation of non-ablated connexins in aortic endothelium deficient in connexin37 or connexin40. J Cell Sci, 2003. 116(Pt 11): p. 2223-36.

191. Simon, A.M. and A.R. McWhorter, Role of connexin37 and connexin40 in vascular development. Cell Commun Adhes, 2003. 10(4-6): p. 379-85.

192. Simon, A.M., et al., Female infertility in mice lacking connexin 37. Nature, 1997. 385(6616): p. 525-9.

193. Zhang, J., et al., Identification and characterization of a novel member of olfactomedin-related protein family, hGC-1, expressed during myeloid lineage development. Gene, 2002. 283(1-2): p. 83-93.

194. Liu, W., et al., The glycoprotein hGC-1 binds to cadherin and lectins. Exp Cell Res, 2006. 312(10): p. 1785-97.

195. Zhang, X., et al., GW112, a novel antiapoptotic protein that promotes tumor growth. Cancer Res, 2004. 64(7): p. 2474-81.

196. Oue, N., et al., Genes involved in invasion and metastasis of gastric cancer identified by array-based hybridization and serial analysis of gene expression. Oncology, 2005. 69 Suppl 1: p. 17-22.

197. Oue, N., et al., Gene expression profile of gastric carcinoma: identification of genes and tags potentially involved in invasion, metastasis, and 
carcinogenesis by serial analysis of gene expression. Cancer Res, 2004. 64(7): p. 2397-405.

198. Aung, P.P., et al., Systematic search for gastric cancer-specific genes based on SAGE data: melanoma inhibitory activity and matrix metalloproteinase10 are novel prognostic factors in patients with gastric cancer. Oncogene, 2006. 25(17): p. 2546-57.

199. Yasui, W., et al., Molecular-pathological prognostic factors of gastric cancer: a review. Gastric Cancer, 2005. 8(2): p. 86-94.

200. Liu, W., et al., Reduced hGC-1 protein expression is associated with malignant progression of colon carcinoma. Clin Cancer Res, 2008. 14(4): p. 1041-9.

201. Liu, W., et al., Expression of $h G C-1$ is correlated with differentiation of gastric carcinoma. Histopathology, 2007. 51(2): p. 157-65.

202. Shinozaki, S., et al., Upregulation of Reg lalpha and GW112 in the epithelium of inflamed colonic mucosa. Gut, 2001. 48(5): p. 623-9.

203. Mannick, E.E., et al., Gene expression in gastric biopsies from patients infected with Helicobacter pylori. Scand J Gastroenterol, 2004. 39(12): p. 1192-200.

204. Koshida, S., et al., Specific overexpression of OLFM4(GW112/HGC-1) $m R N A$ in colon, breast and lung cancer tissues detected using quantitative analysis. Cancer Sci, 2007. 98(3): p. 315-20.

205. Kobayashi, D., et al., Olfactomedin 4 promotes $S$-phase transition in proliferation of pancreatic cancer cells. Cancer Sci, 2007. 98(3): p. 334-40.

206. Delvoux, B., et al., Increased production of 17beta-estradiol in endometriosis lesions is the result of impaired metabolism. J Clin Endocrinol Metab, 2009. 94(3): p. 876-83.

207. Schenken, R.S. and D.S. Guzick, Revised endometriosis classification: 1996. Fertil Steril, 1997. 67(5): p. 815-6.

208. Pecorelli, S., Revised FIGO staging for carcinoma of the vulva, cervix, and endometrium. Int J Gynaecol Obstet, 2009. 105(2): p. 103-4.

209. Pijnenborg, J.M., et al., Aberrations in the progesterone receptor gene and the risk of recurrent endometrial carcinoma. J Pathol, 2005. 205(5): p. 597605.

210. Romano, A., et al., Identification of novel ER-alpha target genes in breast cancer cells: gene- and cell-selective co-regulator recruitment at target promoters determines the response to 17beta-estradiol and tamoxifen. Mol Cell Endocrinol, 2009. 314(1): p. 90-100.

211. Romano, A., et al., The PROGINS polymorphism of the human progesterone receptor diminishes the response to progesterone. $\mathrm{J}$ Mol Endocrinol, 2007. 38(1-2): p. 331-50.

212. Oehler, M.K., et al., Functional characterization of somatic point mutations of the human estrogen receptor alpha (hERalpha) in adenomyosis uteri. Mol Hum Reprod, 2004. 10(12): p. 853-60.

213. Reardon, D.B., et al., Dominant negative EGFR-CD533 and inhibition of MAPK modify JNK1 activation and enhance radiation toxicity of human mammary carcinoma cells. Oncogene, 1999. 18(33): p. 4756-66. 
214. Contessa, J.N., et al., ErbB receptor tyrosine kinase network inhibition radiosensitizes carcinoma cells. Int J Radiat Oncol Biol Phys, 2006. 65(3): p. 851-8.

215. Chin, K.L., et al., The regulation of OLFM4 expression in myeloid precursor cells relies on NF-kappaB transcription factor. Br J Haematol, 2008. 143(3): p. 421-32.

216. Schutte, B., et al., Keratin $8 / 18$ breakdown and reorganization during apoptosis. Exp Cell Res, 2004. 297(1): p. 11-26.

217. Ivaska, J., et al., Novel functions of vimentin in cell adhesion, migration, and signaling. Exp Cell Res, 2007. 313(10): p. 2050-62.

218. Bargagna-Mohan, $\mathrm{P}$., et al., The tumor inhibitor and antiangiogenic agent withaferin A targets the intermediate filament protein vimentin. Chem Biol, 2007. 14(6): p. 623-34.

219. Arpino, G., et al., Crosstalk between the estrogen receptor and the HER tyrosine kinase receptor family: molecular mechanism and clinical implications for endocrine therapy resistance. Endocr Rev, 2008. 29(2): p. 217-33.

220. von Schalburg, K.R., et al., Expression of morphogenic genes in mature ovarian and testicular tissues: potential stem-cell niche markers and patterning factors. Mol Reprod Dev, 2006. 73(2): p. 142-52.

221. Demir, A.Y., et al., Menstrual effluent induces epithelial-mesenchymal transitions in mesothelial cells. Hum Reprod, 2004. 19(1): p. 21-9.

222. Gentilini, D., et al., PI3K/Akt and ERK1/2 signalling pathways are involved in endometrial cell migration induced by 17 beta-estradiol and growth factors. Mol Hum Reprod, 2007. 13(5): p. 317-22.

223. Ejskjaer, K., et al., Expression of the epidermal growth factor system in human endometrium during the menstrual cycle. Mol Hum Reprod, 2005. 11(8): p. 543-51.

224. Bonaccorsi, G., et al., Modification of number and of affinity of endometrial EGF receptors during the menstrual cycle. Eur J Obstet Gynecol Reprod Biol, 1989. 33(2): p. 177-82.

225. Imai, T., et al., Changes in epidermal growth factor receptor and the levels of its ligands during menstrual cycle in human endometrium. Biol Reprod, 1995. 52(4): p. 928-38.

226. Bilotas, M., et al., Effect of GnRH analogues on apoptosis and expression of Bcl-2, Bax, Fas and FasL proteins in endometrial epithelial cell cultures from patients with endometriosis and controls. Hum Reprod, 2007. 22(3): p. 644-53.

227. Meresman, G.F., et al., Apoptosis and expression of Bcl-2 and Bax in eutopic endometrium from women with endometriosis. Fertil Steril, 2000. 74(4): p. 760-6.

228. Velarde, M.C., et al., Increased mitogen-activated protein kinase kinase/extracellularly regulated kinase activity in human endometrial stromal fibroblasts of women with endometriosis reduces 3',5'-cyclic adenosine 5'-monophosphate inhibition of cyclin D1. Endocrinology, 2009. 150(10): p. 4701-12.

229. Kjerulff, K.H., B.A. Erickson, and P.W. Langenberg, Chronic gynecological conditions reported by US women: findings from the 
National Health Interview Survey, 1984 to 1992. Am J Public Health, 1996. 86(2): p. 195-9.

230. Olive, D.L. and L.B. Schwartz, Endometriosis. N Engl J Med, 1993. 328(24): p. 1759-69.

231. Vessey, M.P., L. Villard-Mackintosh, and R. Painter, Epidemiology of endometriosis in women attending family planning clinics. Bmj, 1993. 306(6871): p. 182-4.

232. Bulun, S.E., et al., Mechanisms of excessive estrogen formation in endometriosis. J Reprod Immunol, 2002. 55(1-2): p. 21-33.

233. Zeitoun, K., et al., Stimulation of aromatase $P 450$ promoter (II) activity in endometriosis and its inhibition in endometrium are regulated by competitive binding of steroidogenic factor-1 and chicken ovalbumin upstream promoter transcription factor to the same cis-acting element. Mol Endocrinol, 1999. 13(2): p. 239-53.

234. Bulun, S.E., et al., Aromatase as a therapeutic target in endometriosis. Trends Endocrinol Metab, 2000. 11(1): p. 22-7.

235. Dizerega, G.S., D.L. Barber, and G.D. Hodgen, Endometriosis: role of ovarian steroids in initiation, maintenance, and suppression. Fertil Steril, 1980. 33(6): p. 649-53.

236. Tseng, L., et al., Estrogen synthesis in normal and malignant human endometrium. J Clin Endocrinol Metab, 1982. 55(5): p. 1029-31.

237. Yamaki, J., T. Yamamoto, and H. Okada, Aromatization of androstenedione by normal and neoplastic endometrium of the uterus. $\mathbf{J}$ Steroid Biochem, 1985. 22(1): p. 63-6.

238. Yamamoto, T., et al., Evidence for estrogen synthesis in adenomyotic tissues. Am J Obstet Gynecol, 1993. 169(3): p. 734-8.

239. Matsuzaki, S., et al., Analysis of aromatase and 17beta-hydroxysteroid dehydrogenase type 2 messenger ribonucleic acid expression in deep endometriosis and eutopic endometrium using laser capture microdissection. Fertil Steril, 2006. 85(2): p. 308-13.

240. Kitawaki, J., et al., Expression of aromatase cytochrome $P 450$ protein and messenger ribonucleic acid in human endometriotic and adenomyotic tissues but not in normal endometrium. Biol Reprod, 1997. 57(3): p. 514-9.

241. Velasco, I., J. Rueda, and P. Acien, Aromatase expression in endometriotic tissues and cell cultures of patients with endometriosis. Mol Hum Reprod, 2006. 12(6): p. 377-81.

242. Murakami, K., et al., Danazol inhibits aromatase activity of endometriosisderived stromal cells by a competitive mechanism. Fertil Steril, 2006. 86(2): p. 291-7.

243. Takayama, K., et al., Treatment of severe postmenopausal endometriosis with an aromatase inhibitor. Fertil Steril, 1998. 69(4): p. 709-13.

244. Ailawadi, R.K., et al., Treatment of endometriosis and chronic pelvic pain with letrozole and norethindrone acetate: a pilot study. Fertil Steril, 2004. 81(2): p. 290-6.

245. Matsuoka, R., et al., Regulation of estrogen activity in human endometrium: effect of IL-1beta on steroid sulfatase activity in human endometrial stromal cells. Steroids, 2002. 67(7): p. 655-9. 
246. Moeller, G. and J. Adamski, Multifunctionality of human 17betahydroxysteroid dehydrogenases. Mol Cell Endocrinol, 2006. 248(1-2): p. 47-55.

247. Fusi, L., et al., Therapeutic targeting of steroid sulfatase activity in endometriosis. Abstract presented at the 9th World Congress on Endometriosis (WCE) in Maastricht, The Netherlands, 2005.

248. Tsai, S.J., et al., Regulation of steroidogenic acute regulatory protein expression and progesterone production in endometriotic stromal cells. $\mathrm{J}$ Clin Endocrinol Metab, 2001. 86(12): p. 5765-73.

249. Utsunomiya, H., et al., Steroid sulfatase and estrogen sulfotransferase in human endometrial carcinoma. Clin Cancer Res, 2004. 10(17): p. 5850-6.

250. Tseng, L. and E. Gurpide, Estradiol and 20alpha-dihydroprogesterone dehydrogenase activities in human endometrium during the menstrual cycle. Endocrinology, 1974. 94(2): p. 419-23.

251. Tseng, L. and E. Gurpide, Induction of human endometrial estradiol dehydrogenase by progestins. Endocrinology, 1975. 97(4): p. 825-33.

252. Kauppila, A., Progestin therapy of endometrial, breast and ovarian carcinoma. A review of clinical observations. Acta Obstet Gynecol Scand, 1984. 63(5): p. 441-50.

253. Casey, M.L., P.C. MacDonald, and S. Andersson, 17 beta-Hydroxysteroid dehydrogenase type 2: chromosomal assignment and progestin regulation of gene expression in human endometrium. J Clin Invest, 1994. 94(5): p. 2135-41.

254. Mustonen, M.V., et al., Human 17beta-hydroxysteroid dehydrogenase type 2 messenger ribonucleic acid expression and localization in term placenta and in endometrium during the menstrual cycle. J Clin Endocrinol Metab, 1998. 83(4): p. 1319-24.

255. Zhang, W., et al., Progestagenic effects of tibolone are target gene-specific in human endometrial cells. J Soc Gynecol Investig, 2006. 13(6): p. 45965.

256. Kitawaki, J., et al., Progesterone induction of 17beta-hydroxysteroid dehydrogenase type 2 during the secretory phase occurs in the endometrium of estrogen-dependent benign diseases but not in normal endometrium. J Clin Endocrinol Metab, 2000. 85(9): p. 3292-6.

257. Vierikko, P., et al., Steroidal regulation of endometriosis tissue: lack of induction of 17 beta-hydroxysteroid dehydrogenase activity by progesterone, medroxyprogesterone acetate, or danazol. Fertil Steril, 1985. 43(2): p. 218-24.

258. Noyes, R.W., A.T. Hertig, and J. Rock, Dating the endometrial biopsy. Am J Obstet Gynecol, 1975. 122(2): p. 262-3.

259. Husen, B., et al., Human hydroxysteroid (17-beta) dehydrogenase 1 expression enhances estrogen sensitivity of MCF-7 breast cancer cell xenografts. Endocrinology, 2006. 147(11): p. 5333-9.

260. Bulun, S.E., M.S. Mahendroo, and E.R. Simpson, Polymerase chain reaction amplification fails to detect aromatase cytochrome $P 450$ transcripts in normal human endometrium or decidua. J Clin Endocrinol Metab, 1993. 76(6): p. 1458-63. 
261. Utsunomiya, H., et al., The analyses of 17beta-hydroxysteroid dehydrogenase isozymes in human endometrial hyperplasia and carcinoma. J Clin Endocrinol Metab, 2001. 86(7): p. 3436-43.

262. Delvoux, B., et al., A sensitive HPLC method for the assessment of metabolic conversion of estrogens. J Steroid Biochem Mol Biol, 2007.

263. Simpson, E.R., et al., Aromatase cytochrome P450, the enzyme responsible for estrogen biosynthesis. Endocr Rev, 1994. 15(3): p. 342-55.

264. Benedetto, M.T., S. Tabanelli, and E. Gurpide, Estrone sulfate sulfatase activity is increased during in vitro decidualization of stromal cells from human endometrium. J Clin Endocrinol Metab, 1990. 70(2): p. 342-5.

265. Maentausta, O., et al., Immunohistochemical localization of 17 betahydroxysteroid dehydrogenase in the human endometrium during the menstrual cycle. Lab Invest, 1991. 65(5): p. 582-7.

266. Pack, B.A., et al., The cyclic relationship of estrogen sulfurylation to the nuclear receptor level in human endometrial curettings. J Clin Endocrinol Metab, 1979. 48(3): p. 420-4.

267. Cheng, Y.H., et al., Stromal cells of endometriosis fail to produce paracrine factors that induce epithelial 17beta-hydroxysteroid dehydrogenase type 2 gene and its transcriptional regulator Sp1: a mechanism for defective estradiol metabolism. Am J Obstet Gynecol, 2007. 196(4): p. 391 e1-7; discussion 391 e7-8.

268. Groothuis, P.G., et al., Tibolone and metabolites induce prolactin production in human endometrial stromal cells in vitro: evidence for cellspecific metabolism. J Steroid Biochem Mol Biol, 2006. 100(4-5): p. 15260.

269. Sherbet, D.P., et al., Cofactors, redox state, and directional preferences of hydroxysteroid dehydrogenases. Mol Cell Endocrinol, 2007. 265-266: p. 83-8.

270. Krebs, H.A., Pyridine nucleotides and rate control. Symp Soc Exp Biol, 1973. 27: p. 299-318.

271. Reich, J. and E. Sel'kov, Energy metabolism of the cell: a theoretical treatise. 1981, New York: Academic Press.

272. Steckelbroeck, S., et al., Human cytosolic 3alpha-hydroxysteroid dehydrogenases of the aldo-keto reductase superfamily display significant 3beta-hydroxysteroid dehydrogenase activity: implications for steroid hormone metabolism and action. J Biol Chem, 2004. 279(11): p. 10784-95.

273. Miller, W.L., Minireview: regulation of steroidogenesis by electron transfer. Endocrinology, 2005. 146(6): p. 2544-50.

274. Salih, S.M., et al., Expression and cyclic variations of catechol-O-methyl transferase in human endometrial stroma. Fertil Steril, 2007.

275. Ghosh, D. and J. Sengupta, Another look at the issue of peri-implantation oestrogen. Hum Reprod, 1995. 10(1): p. 1-2.

276. Brosens, J.J., N. Hayashi, and J.O. White, Progesterone receptor regulates decidual prolactin expression in differentiating human endometrial stromal cells. Endocrinology, 1999. 140(10): p. 4809-20.

277. Satyaswaroop, P.G. and S. Tabibzadeh, Progestin regulation of human endometrial function. Hum Reprod, 2000. 15 Suppl 1: p. 74-80. 
278. Markiewicz, L. and E. Gurpide, In vitro evaluation of estrogenic, estrogen antagonistic and progestagenic effects of a steroidal drug (Org OD-14) and its metabolites on human endometrium. J Steroid Biochem, 1990. 35(5): p. 535-41.

279. Weng, L., Data Processing and Analysis Methods in the Rosetta Resolver. 38. Technical report, 2003.

280. Tseng, L., et al., Effect of progestin, antiprogestin, and relaxin on the accumulation of prolactin and insulin-like growth factor-binding protein-1 messenger ribonucleic acid in human endometrial stromal cells. Biol Reprod, 1992. 47(3): p. 441-50.

281. Chuaqui, R.F., et al., Post-analysis follow-up and validation of microarray experiments. Nat Genet, 2002. 32 Suppl: p. 509-14.

282. Rockett, J.C. and G.M. Hellmann, Confirming microarray data--is it really necessary? Genomics, 2004. 83(4): p. 541-9.

283. Goodman, N., Microarrays: hazardous to your science. Genome Technol, 2003. 32: p. 42-5.

284. Zheng, X.Y., G.A. Chen, and H.Y. Wang, Expression of cystic fibrosis transmembrane conductance regulator in human endometrium. Hum Reprod, 2004. 19(12): p. 2933-41.

285. Wilson, J.G., C.B. Roth, and J. Warkany, An analysis of the syndrome of malformations induced by maternal vitamin A deficiency. Effects of restoration of vitamin A at various times during gestation. Am J Anat, 1953. 92(2): p. 189-217.

286. Simsek, M., et al., Blood plasma levels of lipoperoxides, glutathione peroxidase, beta carotene, vitamin $A$ and $E$ in women with habitual abortion. Cell Biochem Funct, 1998. 16(4): p. 227-31.

287. O'Toole, B.A., et al., Vitamin A deficiency and reproduction in rhesus monkeys. J Nutr, 1974. 104(11): p. 1513-24.

288. Huang, F.J., et al., Retinoic acid decreases the viability of mouse blastocysts in vitro. Hum Reprod, 2003. 18(1): p. 130-6.

289. Brar, A.K., et al., Retinoic acid suppresses in-vitro decidualization of human endometrial stromal cells. Mol Hum Reprod, 1996. 2(3): p. 185-93.

290. Vahlquist, A., A. Johnsson, and K.G. Nygren, Vitamin A transporting plasma proteins and female sex hormones. Am J Clin Nutr, 1979. 32(7): p. 1433-8.

291. Yeung, D.L. and P.L. Chan, Effects of a progestogen and a sequential type oral contraceptive on plasma vitamin A, vitamin $E$, cholesterol and triglycerides. Am J Clin Nutr, 1975. 28(7): p. 686-91.

292. Deng, L., et al., Coordinate regulation of the production and signaling of retinoic acid by estrogen in the human endometrium. J Clin Endocrinol Metab, 2003. 88(5): p. 2157-63.

293. Underwood, B.A., Vitamin A in animal and human nutrition, in The retinoids, M.B.R. Sporn, A.B.; Goodman, D.S., Editor. 1984, Academic Press: London. p. 281-392.

294. Critchley, H.O., et al., Antiprogestins as a model for progesterone withdrawal. Steroids, 2003. 68(10-13): p. 1061-8. 
295. Flynn, L., et al., Menstrual cycle dependent fluctuations in NK and Tlymphocyte subsets from non-pregnant human endometrium. Am J Reprod Immunol, 2000. 43(4): p. 209-17.

296. Irwin, J.C., W.H. Utian, and R.L. Eckert, Sex steroids and growth factors differentially regulate the growth and differentiation of cultured human endometrial stromal cells. Endocrinology, 1991. 129(5): p. 2385-92.

297. Florkiewicz, R.Z. and A. Sommer, Human basic fibroblast growth factor gene encodes four polypeptides: three initiate translation from non-AUG codons. Proc Natl Acad Sci U S A, 1989. 86(11): p. 3978-81.

298. Moller, B., et al., Expression of the angiogenic growth factors VEGF, FGF2, EGF and their receptors in normal human endometrium during the menstrual cycle. Mol Hum Reprod, 2001. 7(1): p. 65-72.

299. Florkiewicz, R.Z., J. Anchin, and A. Baird, The inhibition of fibroblast growth factor-2 export by cardenolides implies a novel function for the catalytic subunit of $\mathrm{Na}+\mathrm{K}+-$ ATPase. J Biol Chem, 1998. 273(1): p. 54451.

300. Sangha, R.K., et al., Fibroblast growth factor receptor-1 is a critical component for endometrial remodeling: localization and expression of basic fibroblast growth factor and FGF-R1 in human endometrium during the menstrual cycle and decreased FGF-RI expression in menorrhagia. Lab Invest, 1997. 77(4): p. 389-402.

301. Allouche, M. and A. Bikfalvi, The role of fibroblast growth factor-2 (FGF2) in hematopoiesis. Prog Growth Factor Res, 1995. 6(1): p. 35-48.

302. Newton, D.A., et al., Hemoglobin is expressed by alveolar epithelial cells. J Biol Chem, 2006. 281(9): p. 5668-76.

303. Liu, L., M. Zeng, and J.S. Stamler, Hemoglobin induction in mouse macrophages. Proc Natl Acad Sci U S A, 1999. 96(12): p. 6643-7.

304. Wride, M.A., et al., Expression profiling and gene discovery in the mouse lens. Mol Vis, 2003. 9: p. 360-96.

305. Crawford, M.J. and D.E. Goldberg, Regulation of the Salmonella typhimurium flavohemoglobin gene. A new pathway for bacterial gene expression in response to nitric oxide. J Biol Chem, 1998. 273(51): p. 34028-32.

306. Gross, S.S. and P. Lane, Physiological reactions of nitric oxide and hemoglobin: a radical rethink. Proc Natl Acad Sci U S A, 1999. 96(18): p. 9967-9.

307. Poole, J.H., Thalassemia and pregnancy. J Perinat Neonatal Nurs, 2003. 17(3): p. 196-208.

308. Feng, D.X., et al., The expression of human alpha-like globin genes in transgenic mice mediated by bacterial artificial chromosome. Proc Natl Acad Sci U S A, 2001. 98(26): p. 15073-7.

309. Abraham, N.G., et al., Transfection of the human heme oxygenase gene into rabbit coronary microvessel endothelial cells: protective effect against heme and hemoglobin toxicity. Proc Natl Acad Sci U S A, 1995. 92(15): p. 6798-802.

310. Balla, J., et al., Endothelial-cell heme uptake from heme proteins: induction of sensitization and desensitization to oxidant damage. Proc Natl Acad Sci U S A, 1993. 90(20): p. 9285-9. 
311. Balla, J., et al., Heme, heme oxygenase and ferritin in vascular endothelial cell injury. Mol Nutr Food Res, 2005. 49(11): p. 1030-43.

312. Bauer, I., et al., Expression pattern and regulation of heme oxygenase1/heat shock protein 32 in human liver cells. Shock, 2003. 20(2): p. 116-22.

313. Szalay, L., et al., Mechanism of salutary effects of estradiol on organ function after trauma-hemorrhage: upregulation of heme oxygenase. Am J Physiol Heart Circ Physiol, 2005. 289(1): p. H92-8.

314. Otterbein, L.E. and A.M. Choi, Heme oxygenase: colors of defense against cellular stress. Am J Physiol Lung Cell Mol Physiol, 2000. 279(6): p. L1029-37.

315. Wagener, F.A., et al., Different faces of the heme-heme oxygenase system in inflammation. Pharmacol Rev, 2003. 55(3): p. 551-71.

316. Yachie, A., et al., Oxidative stress causes enhanced endothelial cell injury in human heme oxygenase-1 deficiency. J Clin Invest, 1999. 103(1): p. 12935 .

317. Dennery, P.A., et al., Oxygen toxicity and iron accumulation in the lungs of mice lacking heme oxygenase-2. J Clin Invest, 1998. 101(5): p. 1001-11.

318. Lee, P.J., et al., Hypoxia-inducible factor-1 mediates transcriptional activation of the heme oxygenase-1 gene in response to hypoxia. $\mathrm{J} \mathrm{Biol}$ Chem, 1997. 272(9): p. 5375-81.

319. Poss, K.D. and S. Tonegawa, Reduced stress defense in heme oxygenase 1deficient cells. Proc Natl Acad Sci U S A, 1997. 94(20): p. 10925-30.

320. Shibahara, S., The heme oxygenase dilemma in cellular homeostasis: new insights for the feedback regulation of heme catabolism. Tohoku J Exp Med, 2003. 200(4): p. 167-86.

321. Appleton, S.D., et al., Effects of hypoxia on heme oxygenase expression in human chorionic villi explants and immortalized trophoblast cells. Am J Physiol Heart Circ Physiol, 2003. 284(3): p. H853-8.

322. Yoshiki, N., T. Kubota, and T. Aso, Identification of heme oxygenase in human endometrium. J Clin Endocrinol Metab, 2001. 86(10): p. 5033-8.

323. Casanas-Roux, F., et al., Expression of inducible heme oxygenase in human endometrium. Fertil Steril, 2002. 78(6): p. 1327-8.

324. McLaughlin, B.E., et al., Heme oxygenase activity in term human placenta. Placenta, 2000. 21(8): p. 870-3.

325. Prawan, A., J.K. Kundu, and Y.J. Surh, Molecular basis of heme oxygenase-1 induction: implications for chemoprevention and chemoprotection. Antioxid Redox Signal, 2005. 7(11-12): p. 1688-703.

326. Van Langendonckt, A., et al., Potential involvement of hemoglobin and heme in the pathogenesis of peritoneal endometriosis. Fertil Steril, 2002. 77(3): p. 561-70.

327. Le, N.T. and D.R. Richardson, The role of iron in cell cycle progression and the proliferation of neoplastic cells. Biochim Biophys Acta, 2002. 1603(1): p. 31-46.

328. Defrere, S., et al., Iron overload enhances epithelial cell proliferation in endometriotic lesions induced in a murine model. Hum Reprod, 2006. 21(11): p. 2810-6.

329. Aisen, P., G. Cohen, and J.O. Kang, Iron toxicosis. Int Rev Exp Pathol, 1990. 31: p. 1-46. 
330. Ponka, P., Cell biology of heme. Am J Med Sci, 1999. 318(4): p. 241-56.

331. Keyse, S.M. and R.M. Tyrrell, Heme oxygenase is the major 32-kDa stress protein induced in human skin fibroblasts by UVA radiation, hydrogen peroxide, and sodium arsenite. Proc Natl Acad Sci U S A, 1989. 86(1): p. 99-103.

332. Panchenko, M.V., H.W. Farber, and J.H. Korn, Induction of heme oxygenase-1 by hypoxia and free radicals in human dermal fibroblasts. Am J Physiol Cell Physiol, 2000. 278(1): p. C92-C101.

333. Alam, J., S. Shibahara, and A. Smith, Transcriptional activation of the heme oxygenase gene by heme and cadmium in mouse hepatoma cells. J Biol Chem, 1989. 264(11): p. 6371-5.

334. Toth, B., et al., Sex differences in hepatic heme oxygenase expression and activity following trauma and hemorrhagic shock. Arch Surg, 2003. 138(12): p. 1375-82.

335. Acevedo, C.H. and A. Ahmed, Hemeoxygenase-1 inhibits human myometrial contractility via carbon monoxide and is upregulated by progesterone during pregnancy. J Clin Invest, 1998. 101(5): p. 949-55.

336. Cella, M., et al., Heme oxygenase-carbon monoxide (HO-CO) system in rat uterus: effect of sexual steroids and prostaglandins. J Steroid Biochem Mol Biol, 2006. 99(1): p. 59-66.

337. Jauniaux, E., et al., Distribution and transfer pathways of antioxidant molecules inside the first trimester human sestational sac. J Clin Endocrinol Metab, 2004. 89(3): p. 1452-8.

338. Jauniaux, E., L. Poston, and G.J. Burton, Placental-related diseases of pregnancy: Involvement of oxidative stress and implications in human evolution. Hum Reprod Update, 2006. 12(6): p. 747-55.

339. Burroughs, K.D., et al., Altered hormonal responsiveness of proliferation and apoptosis during myometrial maturation and the development of uterine leiomyomas in the rat. Biol Reprod, 2000. 63(5): p. 1322-30.

340. Cunha, G.R., P.S. Cooke, and T. Kurita, Role of stromal-epithelial interactions in hormonal responses. Arch Histol Cytol, 2004. 67(5): p. 41734.

341. Cornet, P.B., et al., Regulation of matrix metalloproteinase-9/gelatinase B expression and activation by ovarian steroids and LEFTY-A/endometrial bleeding-associated factor in the human endometrium. J Clin Endocrinol Metab, 2005. 90(2): p. 1001-11.

342. Hansard, L.J., et al., Human endometrial transforming growth factoralpha: a transmembrane, surface epithelial protein that transiently disappears during the midsecretory phase of the menstrual cycle. J Soc Gynecol Investig, 1997. 4(3): p. 160-6.

343. Falls, D.L., Neuregulins: functions, forms, and signaling strategies. Exp Cell Res, 2003. 284(1): p. 14-30.

344. Ortiz, M.E., et al., Progesterone, but not luteal estrogen, is required for the establishment of pregnancy in the new world monkey Cebus apella. Am J Primatol, 2007. 69(10): p. 1131-40.

345. Zegers-Hochschild, F. and E. Altieri, Luteal estrogen is not required for the establishment of pregnancy in the human. J Assist Reprod Genet, 1995. 12(3): p. 224-8. 
346. Younis, J.S., et al., The effect of estradiol depletion during the luteal phase on endometrial development. Fertil Steril, 1994. 62(1): p. 103-7.

347. Aghajanova, L., et al., Steroidogenic enzyme and key decidualization marker dysregulation in endometrial stromal cells from women with versus without endometriosis. Biol Reprod, 2009. 80(1): p. 105-14.

348. Colette, S., et al., Absence of aromatase protein and $m R N A$ expression in endometriosis. Hum Reprod, 2009. 24(9): p. 2133-41.

349. Attar, E., et al., Prostaglandin E2 via steroidogenic factor-1 coordinately regulates transcription of steroidogenic genes necessary for estrogen synthesis in endometriosis. J Clin Endocrinol Metab, 2009. 94(2): p. 62331.

350. Lederman, H.M., et al., Deferoxamine: a reversible S-phase inhibitor of human lymphocyte proliferation. Blood, 1984. 64(3): p. 748-53.

351. Newman, B., Iron depletion by whole-blood donation harms menstruating females: the current whole-blood-collection paradigm needs to be changed. Transfusion, 2006. 46(10): p. 1667-81.

352. Deng, L., et al., Hemoglobin and its derived peptides may play a role in the antibacterial mechanism of the vagina. Hum Reprod, 2009. 24(1): p. 211-8.

353. Demir, A.Y., et al., Molecular characterization of soluble factors from human menstrual effluent that induce epithelial to mesenchymal transitions in mesothelial cells. Cell Tissue Res, 2005. 322(2): p. 299-311.

354. Kumar, S. and U. Bandyopadhyay, Free heme toxicity and its detoxification systems in human. Toxicol Lett, 2005. 157(3): p. 175-88.

355. Kobayashi, H., et al., The role of iron in the pathogenesis of endometriosis. Gynecol Endocrinol, 2009. 25(1): p. 39-52.

356. Van Langendonckt, A., F. Casanas-Roux, and J. Donnez, Oxidative stress and peritoneal endometriosis. Fertil Steril, 2002. 77(5): p. 861-70.

357. Lousse, J.C., et al., Iron storage is significantly increased in peritoneal macrophages of endometriosis patients and correlates with iron overload in peritoneal fluid. Fertil Steril, 2009. 91(5): p. 1668-75.

358. Martinez-Roman, S., et al., Transferrin receptor (CD71) expression in peritoneal macrophages from fertile and infertile women with and without endometriosis. Am J Reprod Immunol, 1997. 38(6): p. 413-7.

359. Templeton, D.M. and Y. Liu, Genetic regulation of cell function in response to iron overload or chelation. Biochim Biophys Acta, 2003. 1619(2): p. 113-24. 


\section{Curriculum vitae}

Helen Dassen is geboren op 30 augustus 1976 in Sittard. In 1994 behaalde ze haar eindexamen VWO aan het Sancta Maria College (thans College Rolduc) te Kerkrade. Aansluitend studeerde ze gezondheidswetenschappen aan de Universiteit Maastricht, waarvoor ze in 1999 haar doctoraalexamen behaalde in de afstudeerrichting biologische gezondheidskunde. In 1999 kon ze, na 5 keer te zijn uitgeloot, aan de studie geneeskunde beginnen aan de Universiteit Maastricht. Haar artsenexamen behaalde ze in maart 2006. De eerste stappen als arts-assistent gynaecologie zette ze in het Catharina-ziekenhuis te Eindhoven, waar ze in augustus 2006 begon als AGNIO. Voor de opleiding tot gynaecologe week ze echter uit naar België, waar ze in januari 2008 begon in het UZGent te Gent onder leiding van Prof. Dr. M. Dhont en vanaf september 2008 bij Prof. Dr. M. Temmerman. Tijdens deze opleiding heeft Helen naast Gent ook in Antwerpen en Sittard gewerkt. Momenteel is ze in opleiding in Genk.

Tijdens de geneeskunde opleiding heeft ze gelijktijdig onderzoek gedaan bij de onderzoeksgroep Groei \& Ontwikkeling (GROW) op de afdeling Pathologie van 1999 tot juni 2006 onder leiding van Dr. P. Groothuis en Dr. G. Dunselman. Dit onderzoek heeft geleid tot dit proefschrift. 


\section{Dankwoord}

Vele mensen zijn betrokken geweest bij het tot stand komen van dit proefschrift. Ik wil hierbij iedereen bedanken die een bijdrage heeft geleverd aan dit proefschrift voor de hulp. In het bijzonder wil ik een aantal mensen noemen:

Pap en mam, ik wil jullie bedanken voor het geduld dat jullie met me gehad hebben. Mam bedankt voor al de keren, dat ik niet hoefde te helpen en voor het geduld, dat je met me hebt gehad. Pap, je dramde soms wel eens door, maar dat was dan ook nodig. Bedankt voor jullie steun.

Rob en Yvonne, bedankt voor jullie hulp en geduld. Rob bedankt voor al je hulp met de computer. Ook voor de hulp bij het goed zetten van de tekst en de figuren in dit proefschrift. Ik vind het super dat je vandaag een van mijn Paranymfen bent. Yvonne ook bedankt voor al je hulp en voor de keren, dat ik Rob moest lenen. Heel hartelijk bedankt voor jullie steun.

Irene, bedankt dat je hier vandaag als mijn beste vriendin en een van mijn Paranymfen staat. Bedankt voor al je adviezen en je hulp. De kaft is prachtig geworden. Guido bedankt voor al je steun.

Dr. P.G. Groothuis, beste Patrick, zonder je steun en vertrouwen was dit proefschrift niet tot stand gekomen. Ik kan me nog de eerste keer herinneren dat ik in je kantoor kwam, eigenlijk op zoek naar Dr. A. De Goeij en hoe je vertelde over de onderzoeken met betrekking tot het endometrium. Een paar dagen later had ik al de beslissing genomen om me te gaan weiden aan het immortaliseren van het endometrium. Helaas liep dit onderzoek niet zoals gewenst. Gelukkig had je alle vertrouwen in me en is het gelukt om alsnog een proefschrift te schrijven.

Dr. G. Dunselman, bedankt voor uw structurerende correcties in de teksten en voor uw vertrouwen. Ik heb heel veel gehad aan uw opbouwende kritiek tijdens mijn onderzoek en bij het schrijven van de artikelen.

Prof. J. Evers, bedankt voor uw ondersteuning bij dit onderzoek en uw vertrouwen als mijn promotor.

Christa en Natasja, bedankt voor jullie hulp bij de eerste stappen, die ik zette op de afdeling Pathologie. De werksfeer op de afdeling was heel prettig. Ik heb heel graag met jullie samengewerkt.

Edith, Mat en Peter, bedankt voor jullie uitleg over bacteriekweken en maken van vectors. Bedankt voor jullie tijd en hulp bij het eigen maken van de technieken, zoals bacteriekweken, electroporatie en kloneren.

Rick, hartelijk dank voor al het werk, dat je hebt gedaan, wanneer ik eens niet aan een immunokleuring of PCR toekwam en voor de hulp bij het tot stand komen van de artikelen. 
Chamindie, thanks for all your advice and help in realising this thesis.

Andrea and Bert, thanks for all your help in realising the article on Olfactomedin- 4 .

Guido Roumen, bedankt voor de fijne en gezellige tijd in het lab. Met jou in de buurt, was het altijd wel lachen.

Jacqueline, Annemiek en Kim, bedankt voor het leren luikjes zagen in kippeneieren en voor het kweken van endometrium op CAM. De samenwerking vond ik zeer prettig.

Ayşe, bedankt voor je hulp bij enkele moeilijke experimenten en je hulp bij het leren van $2 \mathrm{D}$-electroforese. Ik vond het een gemis, toen je wegging. Ik hoop dat je nu als klinisch chemicus je droombaan hebt gevonden.

De gynaecologen en arts-assistenten in Maastricht, Heerlen en Sittard, die hebben gezorgd voor het endometrium.

De leden van de beoordelingscommissie (Prof. Dr. Ramaekers, Prof. Dr. Dhont, Prof. Dr. Zur Hausen, Prof. Dr. Kruitwagen en Prof. Dr. Tjan-Heijnen) voor het kritisch beoordelen van dit proefschrift.

En ook bedankt aan iedereen, die ik niet bij naam heb genoemd, maar waardoor ik terugdenk aan een heel fijne tijd op het pathologie laboratorium. 